\title{
ESTUDO COMPARATIVO DA CRONOLOGIA DE ERUPÇÃO DOS DENTES PERMANENTES E DA CALCIFICAÇÃO DOS SEGUNDOS MOLARES NAS MÁS OCLUSÕES DE CLASSE I E CLASSE II DE ANGLE
}

RODRIGO HERMONT CANÇADO

\begin{abstract}
Dissertação apresentada à
Faculdade de Odontologia de Bauru Universidade de São Paulo, como parte dos requisitos para a obtenção do título de Mestre em Odontologia, área de Ortodontia.
\end{abstract}

(Edição Revisada) 


\title{
ESTUDO COMPARATIVO DA CRONOLOGIA DE ERUPÇÃO DOS DENTES PERMANENTES E DA CALCIFICAÇÃO DOS SEGUNDOS MOLARES NAS MÁS OCLUSÕES DE CLASSE I E CLASSE II DE ANGLE
}

RODRIGO HERMONT CANÇADO

\begin{abstract}
Dissertação apresentada à
Faculdade de Odontologia de Bauru Universidade de São Paulo, como parte dos requisitos para a obtenção do título de Mestre em Odontologia, área de Ortodontia.
\end{abstract}

(Edição Revisada)

Orientador: Prof. Dr. Arnaldo Pinzan 


\begin{tabular}{|c|c|}
\hline C16e & $\begin{array}{l}\text { Cançado, Rodrigo Hermont } \\
\text { Estudo comparativo da cronologia de erupção dos dentes } \\
\text { permanentes e da calcificação dos segundos molares nas más oclusōes } \\
\text { de Classe I e Classe II de Angle / Rodrigo Hermont Cançado, - Bauru, } \\
2003 \text {. } \\
\quad \text { xviii, } 142 \text { p. ; il. ; } 30 \mathrm{~cm} \text {. }\end{array}$ \\
\hline & $\begin{array}{l}\text { Dissertaçăo (Mestrado) - Faculdade de Odontologia de Bauru. } \\
\text { Universidade de Săo Paulo. }\end{array}$ \\
\hline & Orientador: Prof. Dr. Arnaldo Pinzan \\
\hline
\end{tabular}

Autorizo, exclusivamente para fins académicos e cientificos, a reprodução total ou parcial desta dissertaçăo, por processos fotocopiadores e outros meios eletrônicos.

Bauru, 27 de novembro de 2002.

Assinatura:

Projeto de Pesquisa aprovado pelo Comitẽ de Ética em Pesquisa da Faculdade de Odontologia de Bauru, Universidade de São Paulo. Of. $n^{\circ}$ CEP/06 2002/FOB 


\section{RODRIGO HERMONT CANCADO}

02 de julho de 1975

Belo Horizonte - MG

1994-1997

$1998-2001$

$2001-2003$

Associação
Nascimento

Curso de Graduação em Odontologia pela Faculdade de Odontologia de Bauru Universidade de São Paulo.

Curso de Aperfeiçoamento em Ortodontia na ACOPEN - Bauru - SP.

Curso de Pós-Graduação em Ortodontia, ao nível de Mestrado, pela Faculdade de Odontologia de Bauru - Universidade de São Paulo.

Associação Paulista de CirurgiõesDentistas 
"Os momentos mais esplêndidos da vida não são os chamados de êxito, mas sim, aqueles dias em que, saindo do desânimo e do desespero sentimos erguer-se dentro de nós um desafio: a vida e a promessa de futuras realizações.”

(Gustave Flaubert) 


\section{DEDICO ESTE TRABALHO}

A Deus, pela minha saúde e que sempre esteve ao meu lado me dando forças e ajudando a superar os obstáculos encontrados para que eu alcançasse os meus sonhos, e me presenteando com pessoas e momentos tão especiais.

À minha querida mãe, Sheila, por ter sacrificado os seus sonhos em favor dos meus. Obrigado mãe, por todo amor, pelos seus ensinamentos e dedicação com que se empenhou para que eu alcançasse meus objetivos. Até nos momentos em que a vida nos exigiu um esforço extremo para superarmos obstáculos que pareciam intransponíveis, você não somente estava ao meu lado me apoiando e me dando forças, como também me mostrou a mulher admirável, de muita garra e vencedora que é. A você que compartilhou comigo inúmeros momentos felizes e também momentos difíceis, não poderia deixar de dividir e dedicar esta importante vitória da minha vida. Não há outras palavras a não ser: OBRIGADO, EU AMO VOCÊ!

Ao meu pai, José Eustáquio, pelo esforço dedicado na minha criação e enriquecimento profissional e que tantas vezes compartilhou e sentiu o meu cansaço e preocupação.

Ao meu irmão, Otávio, pelo companheirismo, amizade, apoio em todos os momentos de minha vida e pela compreensão nos momentos em que estive ausente. 


\section{Com muito amor e carinho, agradeço}

A tia Pazinha, pelo incentivo e apoio para o meu crescimento profissional e pessoal, pela presença importante e agradável ao longo de minha vida e pela disponibilidade e atenção sempre dispensadas a mim e minha família.

Aos meus primos, Mateus e Tássia, pela convivência alegre e descontraída nos momentos em que estamos juntos.

A Leniana, pelos momentos agradáveis proporcionados pela sua presença, pelo companheirismo, generosidade e apoio incessante em todos os momentos. 


\section{Agradecimentos especiais}

Ao meu orientador, Prof. Dr. Arnaldo Pinzan, pela confiança em mim depositada e pelos ensinamentos e orientações ao longo do curso de mestrado.

Ao Prof. Dr. Guilherme Janson, coordenador do curso de mestrado, pela dedicação e seriedade com que conduziu o curso, fazendo com que os nossos objetivos fossem alcançados de forma primorosa.

Aos demais professores da disciplina de Ortodontia, Prof. Dr. Décio Rodrigues Martins, Prof. Dr. José Fernando Castanha Henriques, Prof Dr. Marcos Roberto de Freitas e Prof. Dr. Renato Rodrigues de Almeida, pelos valiosos ensinamentos que muito contribuíram para a minha formação profissional. A todos vocês, a sinceridade de minha gratidão. 


\section{Agradeço}

A Prof. Dra. Maria Fidela de Lima Navarro, Diretora da Faculdade de Odontologia de Bauru da Universidade de São Paulo.

Ao Prof. Dr. José Carlos Pereira, Presidente da Comissão de PósGraduação da Faculdade de Odontologia de Bauru da Universidade de São Paulo.

Ao professor José Roberto Lauris pelos ensinamentos transmitidos e orientação em relação a análise estatística deste trabalho.

Aos colegas e amigos do curso de mestrado, Analu, Angela, Celso, Yuka, Daniele, Karina Lima e Leniana pela convivência e momentos agradáveis que passamos juntos.

Aos amigos do mestrado "antigo", Adriana, Cláudia, Celinha, Daniele, Denise, Fábio, Fabrício, Fernanda, José Eduardo, José Norberto, Karina Freitas, Maria Fernanda, Rejane e Sandra, pelo companheirismo e amizade ao longo do curso.

Aos alunos do Doutorado, Adriano, Ana Carla, Ana Cláudia, Daniela Garib, Danilo, Fausto, Karina Cruz, Karyna Valle, Paulo e Renata, pelo auxílio prestado e conhecimentos transmitidos.

Aos Professores do curso de graduação desta faculdade, em especial a Prof. Dra. Lucimar, por todos os valiosos conhecimentos transmitidos que contribuíram sobremaneira para o meu aprimoramento científico e crescimento pessoal. 


\section{$\underline{\text { Agradeço }}$}

Ao meu grande amigo, Flávio Monteiro Amado, pela amizade sincera e companheirismo durante toda a nossa trajetória em Bauru.

A minha amiga Janeysa, pela companhia alegre e bem humorada e por torcer pelo meu sucesso.

Aos meus amigos do curso de Graduação, em especial o Chicão, o Fabrício e o Maguila pela amizade e bons momentos compartilhados.

Aos colegas e amigos do curso de Pós-Graduação, Alexandre, Marcelo, Rogério, Diego e Leonardo pelos momentos descontraídos que passamos juntos.

Aos meus colegas de profissão, Adriana, Cláudia e Thaís pela solicitude e por acompanharem o meu crescimento profissional.

Ao Juliano e Pedro Luís, amigos inseparáveis, pelo apoio incessante e pela amizade e confiança em todas as etapas da minha vida.

Aos meus pacientes, pela confiança em mim depositada e por contribuírem para o meu enriquecimento profissional.

Aos funcionários da Disciplina de Ortodontia, Cris, Verinha, Sérgio, Boné, “Tia" Maria e Fernando pela atenção e carinho com que sempre me atenderam. 


\section{Agradeço}

Aos funcionários da ACOPEN, em especial ao Walter, pela convivência harmoniosa que tivemos juntos.

Aos funcionários da Biblioteca e da Pós-Graduação pela atenção e disponibilidade com que sempre me atenderam.

A CAPES (Coordenação de Aperfeiçoamento de Pessoal de Nível Superior) pela concessão da bolsa de estudo.

A todas as pessoas que contribuíram, direta ou indiretamente, para a realização desse trabalho. 


\section{SUMÁRIO}

LISTA DE FIGURAS

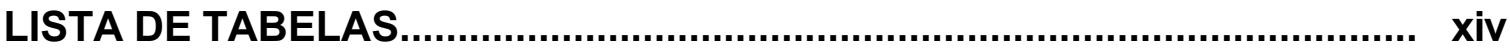

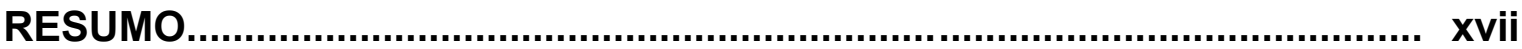

1. INTRODUÇÃO

2. REVISÃO DA LITERATURA

2.1. Desenvolvimento da dentição permanente.................................... 5

2.1.1. Erupção dentária......................................................... 5

2.1.1.1. Seqüência e cronologia de erupção............................. 7

2.1.2. Fatores gerais e locais que influenciam a erupção dentária.. 28

2.1.2.1. Fatores de ordem geral............................................ 28

2.1.2.2. Fatores de ordem local.............................................. 36

2.1.3. Processos bioquímicos envolvidos no mecanismo da erupção dentária............................................................ 43

2.2. Calcificação dos dentes permanentes........................................ 44

2.2.1. Seqüência e cronologia de calcificação............................... 44

2.2.2. Relação entre calcificação dos dentes permanentes e desenvolvimento somático.............................................. 62

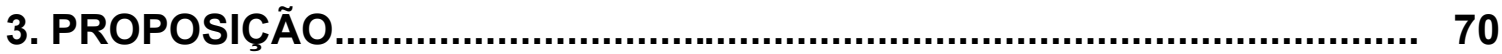

4. MATERIAL E MÉTODOS................................................................ 72

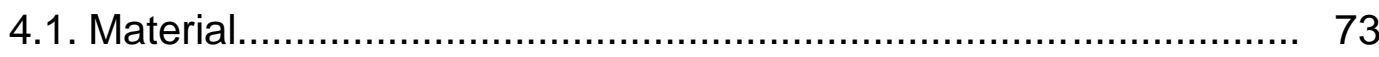

4.1.1. Obtenção da amostra.................................................... 73

4.1.2. Material para elaboração do traçado.................................... 74

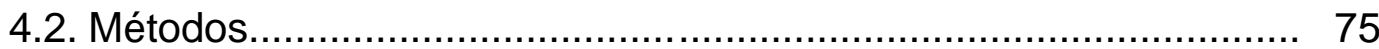

4.2.1. Telerradiografia em norma lateral....................................... 75

4.2.1.1. Traçado anatômico................................................... 75

4.2.1.2. Pontos de referência............................................. 75

4.2.1.3. Grandezas cefalométricas esqueléticas...................... 76

4.2.1.3.1. Maxilares........................................................ 76

4.2.1.3.2. Mandibulares..................................................... 76

4.2.1.3.3. Maxilomandibular...................................... 
4.2.1.4. Análise estatística...................................................... 77

4.2.1.4.1 . Erro do método.................................................. 77

4.2.1.4.2. Testes estatísticos.............................................. 77

4.2.2. Radiografias panorâmicas................................................ 79

4.2.2.1. Análise estatística...................................................... 81

4.2.2.1.1. Erro do método................................................. 81

4.2.2.1.2. Teste estatístico................................................ 81

4.2.3. Análise de Correlação entre as grandezas cefalométricas estudadas e os estágios de calcificação dos segundos molares

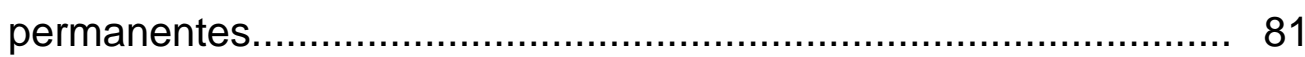

4.2.4. Modelos de Gesso............................................................ 82

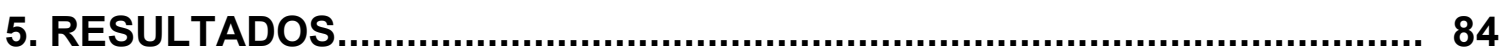

6. DISCUSSÃO

6.1. Seleção da Amostra ................................................................. 96

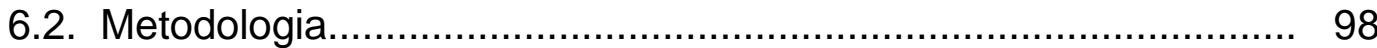

6.2.1. Magnificação das imagens radiográficas.............................. 100

6.2.2. Precisão da Metodologia................................................... 100

6.2.3. O método de Karber........................................................... 101

6.3. Discussão dos resultados........................................................ 103

6.3.1. Telerradiografias em norma lateral..................................... 103

6.3.2. Radiografias Panorâmicas.................................................. 105

6.3.3. Análise de correlação....................................................... 106

6.3.4. Modelos de gesso.......................................................... 107

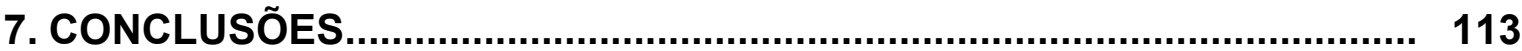

REFERÊNCIAS BIBLIOGRÁFICAS....................................................... 115

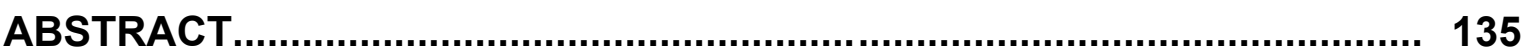

APÊNDICES 


\section{LISTA DE FIGURAS}

FIGURA 1 Cefalograma com os pontos de referência e linhas utilizadas. 78

FIGURA 2 Esquema dos estágios de desenvolvimento de Nolla para comparações radiográficas. Reproduzido de FERREIRA ${ }^{37} \ldots 80$ 


\section{LISTA DE TABELAS}

TABELA 1 Cronologia de erupção dos dentes permanentes de crianças da cidade de São Paulo......................................................... 20

TABELA 2 Condições gerais, doenças e síndromes associadas ao retardo ou ausência eruptiva.

TABELA 3 Fatores locais associados ao retardo eruptivo do dente permanente.

TABELA 4 Cronologia de erupção (em anos) dos dentes permanentes, segundo diversos autores.

TABELA 5 Média, desvio padrão, mediana e valores mínimo e máximo das idades dos jovens dos grupos Classe I e Classe II

TABELA 6 Número de pares de modelos avaliados em cada idade na faixa etária dos 5 aos 13 anos de idade, distribuídos de acordo com a relação molar.

TABELA 7 Resultados do teste $t$ independente entre as variáveis do grupo Classe I e do grupo Classe II.

TABELA 8 Resultados do teste $t$ independente entre as variáveis do grupo Classe I dividido quanto ao gênero para avaliar a presença de dimorfismo entre os gêneros.

TABELA 9 Resultados do teste $t$ independente entre as variáveis do grupo Classe II dividido quanto ao gênero para avaliar a presença de dimorfismo entre os gêneros.

TABELA 10 Análise do erro intra-examinador. Apresentação dos erros casuais, das médias, dos desvios padrão e nível de significância estatística dos erros sistemáticos, entre os traçados repetidos. 
TABELA 11 Resultado do teste não paramétrico de Mann-Whitney entre os estágios de calcificação dos segundos molares dos grupos Classe I e Classe II.

TABELA 12 Resultado do teste não paramétrico de Mann-Whitney entre os estágios de calcificação dos segundos molares dos gêneros masculino e feminino nos grupos Classe I e Classe II para avaliar a presença de dimorfismo entre os gêneros

TABELA 13 Resultados do teste de correlação de Pearson entre os estágios de calcificação dos segundos molares superiores $e$ as grandezas cefalométricas do Grupo Classe I.

TABELA 14 Resultados do teste de correlação de Pearson entre os estágios de calcificação dos segundos molares inferiores e as grandezas cefalométricas do Grupo Classe I.

TABELA 15 Resultados do teste de correlação de Pearson entre os estágios de calcificação dos segundos molares superiores e as grandezas cefalométricas do Grupo Classe II............................. 88

TABELA 16 Resultados do teste de correlação de Pearson entre os estágios de calcificação dos segundos molares inferiores e as grandezas cefalométricas do Grupo Classe II.

TABELA 17 Idade média de erupção, desvio padrão e erro padrão de cada dente permanente nos grupos Classe I e Classe II e o nível de significância estatística quando aplicado o teste t independente.. 90

TABELA 18 Idade média de erupção, desvio padrão e erro padrão de cada dente permanente nos gêneros masculino e feminino no grupo Classe I e o nível de significância estatística quando aplicado o teste $t$ independente entre os gêneros.

TABELA 19 Idade média de erupção, desvio padrão e erro padrão de cada dente permanente nos gêneros masculino e feminino no grupo Classe II e o nível de significância estatística quando aplicado o teste $t$ independente entre os gêneros. 
TABELA 20 Nível de significância estatística (p) quando aplicado o teste $t$ independente entre as idades médias de erupção dos dentes permanentes dos lados direito e esquerdo no grupo Classe I...... 93

TABELA 21 Nível de significância estatística (p) quando aplicado o teste $t$ independente entre as idades médias de erupção dos dentes permanentes dos lados direito e esquerdo no grupo Classe II..... 93

TABELA 22 Nível de significância estatística ( $p$ ) quando aplicado o teste $\mathrm{t}$ independente entre as idades médias de erupção dos dentes permanentes dos arcos superior e inferior no grupo Classe I....... 94

TABELA 23 Nível de significância estatística ( $p$ ) quando aplicado o teste $t$ independente entre as idades médias de erupção dos dentes permanentes dos arcos superior e inferior no grupo Classe II..... 94

TABELA 24 Seqüência de erupção dos dentes permanentes mais comumente encontrada nos grupos Classe I e Classe II............. 112 
Resumo 


\section{RESUMO}

O objetivo deste estudo foi comparar a cronologia de erupção dos dentes permanentes e os estágios de calcificação dos segundos molares nas másoclusões de Classe I e Classe II de Angle e avaliar a existência de correlação entre esses estágios de calcificação e as grandezas cefalométricas SNA, SNB, ANB, Co-A e Co-Gn. Para avaliar a cronologia de erupção dos dentes permanentes (com exceção dos terceiros molares), foram utilizados 527 pares de modelos de gesso de jovens na faixa etária dos 5 aos 13 anos de idade que foram divididos em dois grupos. O grupo 1 ficou constituído por modelos de gesso que apresentassem uma relação molar de Classe I de Angle, e o grupo 2, por aqueles que apresentassem uma relação molar de Classe II de Angle. A idade média de erupção dos dentes permanentes foi determinada pelo método de Karber. A comparação entre os grupos foi realizada por meio do teste $t$ independente. Para avaliar os estágios de calcificação dos segundos molares e a existência de correlação com as grandezas cefalométricas SNA, SNB, ANB, Co-A e Co-Gn, foram utilizadas 60 radiografias panorâmicas e 60 telerradiografias em norma lateral dos mesmos jovens, obtidas aos 8 anos de idade. Estas radiografias também foram divididas em dois grupos. $O$ grupo 1 ficou constituído por radiografias de jovens com relação molar de Classe I de Angle e o grupo 2 por radiografias de jovens com relação molar de Classe II de Angle. Os estágios de calcificação dos segundos molares foram determinados pelo método de NOLLA. A comparação entre os grupos foi realizada por meio do teste não paramétrico de Mann-Whitney. Os resultados mostraram que, de uma maneira geral, os indivíduos com relação molar de Classe I de Angle apresentam idades de erupção dos dentes permanentes mais precoces que os indivíduos com relação molar de Classe II de Angle, e esta diferença foi estatisticamente significante para todos os segundos molares, além dos dentes $15,23,34$ e 45 . Não houve diferença estatisticamente significante entre os estágios de calcificação dos segundos molares nos grupos considerados e não houve correlação entre as variáveis cefalométricas estudadas e os estágios de calcificação em nenhum dos grupos. 
1. Introdução 


\section{INTRODUÇÃO}

O processo fisiológico de erupção dentária representa a razão da existência da Odontologia. A ciência, há mais de dois séculos e meio, vem ampliando o acesso para desvendar os fenômenos individuais do organismo para compor o entendimento dele como um todo. A influência dos fatores genéticos no processo de erupção dentária é indiscutível, pois pela própria determinação dos padrões hereditários, cada indivíduo é um modelo original e específico denominado genótipo, o qual, pode sofrer influências ambientais, constituindo o fenótipo.

A idade dentária tem alcançado significante respaldo como excelente indicador do desenvolvimento somático, podendo ser baseada nos estágios de calcificação dentária2, 26, 130, 135 ou ainda pelo número de dentes decíduos ou número de dentes permanentes irrompidos $50,51,74$. Os estudos a respeito do assunto demonstram que os genes possuem um grau de penetrância bastante elevado, incluindo as dimensões das diversas partes do corpo, a velocidade de crescimento e a época do início dos eventos de crescimento como, por exemplo, a menarca, a calcificação dentária e óssea, a erupção dos dentes e o começo do surto de crescimento puberal135. Os efeitos dos fatores genéticos interagem de tal forma com uma variedade de fatores ambientais, que tentar separá-los é um dos mais antigos, mais difíceis e controvertidos temas da genética humana.

Muitos esforços têm sido empreendidos no sentido de ampliar os conhecimentos sobre $\mathrm{o}$ assunto, não somente sobre a cronologia $\mathrm{e}$ seqüência de erupção ou épocas de mineralização, mas para utilizar a idade dentária como auxiliar no diagnóstico dos distúrbios de crescimento e desenvolvimento físicos 11-13, 30, 50, 127, 160. Particularmente em Odontopediatria e Ortodontia, a fase de transição dentária reveste-se de maior importância por coincidir com um período de importantes eventos para o desenvolvimento físico geral e por constituir-se numa fase de grande 
susceptibilidade da erupção dentária aos fatores interferentes. Desta forma, torna-se indiscutível o fato da importância dos estudos que busquem maiores esclarecimentos sobre a erupção dentária.

Na literatura consultada, há inúmeros estudos que relatam a grande variabilidade de seqüência e cronologia de erupção dos dentes permanentes e os fatores, sejam de natureza ambiental ou genética, que interagem com o desenvolvimento dentário.

Atualmente, observa-se que a literatura é escassa em trabalhos sobre a cronologia e seqüência de erupção dos dentes permanentes enfocando a classificação das más-oclusões. Em particular, nas más-oclusões de Classe II, a correção da relação molar é um dos aspectos mais importantes e desafiadores no tratamento ortodôntico e a obtenção da mesma pode ser conseguida por meio da aplicação de forças que são mais efetivas quando aplicadas antes da erupção do segundo molar permanente.

Baseando-se nos aspectos acima mencionados, decidiu-se realizar um estudo comparativo da cronologia de erupção dos dentes permanentes e da calcificação dos segundos molares nas más-oclusões de Classe I e Classe II de Angle. 


\section{Revisão da Literatura}




\section{2- REVISÃO DA LITERATURA}

Objetivando uma melhor compreensão, a revisão da literatura foi desenvolvida de maneira a oferecer informações quanto ao desenvolvimento da dentição permanente, enfocando separadamente a calcificação e a erupção dos dentes permanentes, apesar de haver uma íntima relação entre esses dois processos. Com relação à calcificação dentária, foram revisadas sua seqüência e cronologia, a relação entre a calcificação dos dentes permanentes e o desenvolvimento somático, os fatores que influenciam o desenvolvimento e calcificação dos dentes permanentes, além de relatarmos, da forma mais abrangente possível, os principais métodos para avaliar os estágios de calcificação dentária que são mais confiáveis e portanto mais utilizados atualmente. Ao revisar a erupção dentária, foram abordadas a seqüência e cronologia da mesma, além dos fatores gerais e locais que influenciam a erupção dos dentes permanentes.

\section{1- Desenvolvimento da dentição permanente}

O desenvolvimento da dentição permanente é um processo complexo, que se inicia com a formação do folículo dentário, atinge a completa formação dos dentes permanentes e o desempenho de suas funções, e se estende ao longo de toda a vida do ser humano.

\subsection{1- Erupção dentária}

Segundo VAN DER LINDEN154 em 1986, entende-se por erupção dentária o movimento de um dente em direção oclusal; e por irrupção, a perfuração do tecido gengival e o aparecimento do dente na cavidade oral.

Embora muitos cirurgiões-dentistas utilizem a expressão erupção dentária para se referirem ao momento no qual o dente irrompe na cavidade bucal, esse marco significante do processo de erupção é uma das etapas de 
todo o fenômeno, que se inicia com a formação do órgão dentário (odontogênese) e o acompanha por toda sua vida.

Segundo FERREIRA 37 em 1998, o mecanismo da erupção pode ser estudado considerando-se três períodos que se sucedem e que são interdependentes:

-Período inicial ou pré-eruptivo

-Período de erupção propriamente dita

-Período pós-eruptivo.

O período inicial ou pré-eruptivo tem seu início com a diferenciação dos germes dentários ainda na vida intra-uterina e vai até o contato da borda incisal ou triturante com o cório ou derma da mucosa buca|36. No entanto, GUEDES-PINTO49 em 1997 considera que este período termina com a completa formação da coroa, sem que o dente movimente em direção ao plano oclusal e alcance a mucosa bucal.

O período de erupção propriamente dita (fase eruptiva) está compreendido desde o momento em que se dá o rompimento do epitélio bucal e o conseqüente aparecimento do dente na cavidade bucal, até o estabelecimento de contato dos dentes de um arco com os do arco antagonista 36 . Paralelamente, GUEDES-PINTO49 considera que este período inicia-se quando a coroa está formada e termina quando o dente atinge o plano oclusal. Portanto, durante esse período o dente continua adaptando a sua posição dentro do osso basal em crescimento e move-se em direção ao plano oclusal. Esta fase eruptiva é intra e extra-óssea.

O período pós-eruptivo inicia-se quando o dente entra em oclusão e segue por toda a vida ou termina com a perda ou remoção do mesmo. Este período corresponde à fase passiva da erupção dentária. São movimentos dentários pós-eruptivos aqueles que mantêm a posição do dente irrompido, 
enquanto a base óssea continua a crescer, e aqueles que compensam os desgastes oclusais e proximais.

KARDOS70 em 1996 afirmou que forças pulsáteis oriundas dos vasos sanguíneos da região apical são responsáveis pela origem da força eruptiva dos dentes. Como a erupção dentária consiste em um processo que pode ser explicado pela ação de forças que atuam em um relacionamento dinâmico com a remodelação óssea, existem vários fatores (por exemplo: idade, nutricional, hormonal, celular, molecular e físico-químico) que podem modificar a velocidade e direção desse processo. Os componentes-chave do processo são a presença de uma força pulsátil contínua, a calcificação dentária e uma matriz extracelular por meio da qual o dente pode se mover.

Para NOGUEIRA et al. ${ }^{107}$, no ano de1997 um dente incluso é aquele dente isolado que não irrompeu graças à ausência de força eruptiva e um dente impactado é aquele impedido de irromper por alguma barreira física.

\subsubsection{1 - Seqüência e cronologia de erupção}

A seqüência de erupção dentária é a ordem na qual os dentes irrompem na cavidade bucal e para muitos, é mais importante uma seqüência de erupção favorável do que a cronologia.

Há uma grande variação na seqüência de erupção dos dentes permanentes. Os trabalhos de maior relevância sobre o assunto serão descritos a seguir por ordem cronológica.

TOMES151 em 1859 acreditava que os dentes do lado esquerdo irrompiam em idades mais precoces do que seus correspondentes do lado direito. 
No ano de 1914, BEAN6 concluiu que há uma diferença tênue entre a época de erupção dos dentes permanentes do lado direito e do lado esquerdo, e que, em alguns casos, os dentes do lado direito irrompem primeiro e, em outros, os dentes do lado esquerdo antecedem os dentes homólogos do lado direito.

Com o objetivo de estimar a idade dentária ou a idade biológica segundo a cronologia de erupção, CATTELL21, em 1928, avaliou 7689 pacientes, tendo como base o irrompimento dos dentes permanentes na cavidade bucal. Não foi encontrada nenhuma diferença estatisticamente significante entre a época de erupção dos dentes permanentes do lado esquerdo e direito, com exceção do primeiro pré-molar superior direito que irrompeu, em média, 2 meses mais cedo do que seu correspondente do lado esquerdo. Quando os gêneros foram avaliados separadamente, o feminino mostrou um maior número de dentes irrompidos ou uma maior maturidade eruptiva em todas as faixas etárias. O resultado mais impressionante foi a grande variação encontrada ao longo do desenvolvimento dentário. 0 desenvolvimento de alguns dentes cessa em dois meses, enquanto outros não atingem a sua maturidade eruptiva depois de dezoito meses. Parece haver uma tendência de alguns dentes se desenvolverem mais rapidamente que outros, mas mesmo se considerando dentes iguais, há uma grande variação entre os indivíduos.

Com o objetivo de determinar a idade média e a variabilidade na erupção de todos os dentes permanentes, com exceção dos terceiros molares, COHEN24, também em 1928, avaliou 2848 jovens em idade escolar, com idades variando entre 5 e 15 anos. Quando os indivíduos da amostra foram divididos segundo o gênero, houve uma tendência dos dentes das jovens irromperem, em média, 5 meses mais cedo do que os dos jovens. Além disso, o autor concluiu que havia a presença, em média, de um dente permanente a mais no arco inferior do que no arco superior em qualquer idade dos indivíduos da amostra. 
Sabendo da grande variabilidade do número de dentes permanentes presentes na cavidade bucal em determinada faixa etária e com a finalidade de representar graficamente estas variações, KLEIN; CODY74, em 1939, conduziram um estudo e observaram que os indivíduos do gênero feminino apresentaram uma maior variabilidade do que os do masculino quanto ao número de dentes permanentes presentes na cavidade bucal e que o gênero feminino apresentava, em média, um maior número de dentes permanentes presentes na cavidade bucal na faixa etária entre 6 e 15 anos.

Em 1941, SCHOUR; MASSLER ${ }^{133}$, em 1941, fizeram uma breve revisão da literatura no que tange ao desenvolvimento da dentição humana e à cronologia de erupção, desde a fase pré-natal até a completa formação da dentadura permanente. Ressaltaram, no entanto, que a idade de erupção de qualquer dente permanente na cavidade bucal é extremamente variável e está na dependência da interação existente entre diversos fatores tais como a raça, o gênero, nutrição, condição sistêmica e condições locais. A seqüência de erupção mais comumente encontrada, em ambos os arcos, foi a seguinte: primeiro molar, incisivo central, incisivo lateral, primeiro prémolar, segundo pré-molar, segundo molar e canino. Concluíram que os dentes permanentes, geralmente, irrompem na cavidade bucal mais cedo em jovens do gênero feminino e que os dentes inferiores, como via de regra, antecedem os dentes superiores.

No ano seguinte, com o objetivo de estudar a influência da raça na idade média de erupção dentária e realizar uma comparação entre os gêneros e entre os arcos, STEGGERDA; HILL ${ }^{143}$, no ano de 1942, conduziram um estudo longitudinal por um período de 10 anos em três raças, a saber, branca, negra e indígena, sendo que na raça indígena duas etnias foram avaliadas, os Navajos e os Mayas. Concluíram que há uma tendência dos dentes irromperem aos pares, no entanto houve uma grande variabilidade de época de erupção entre dentes homólogos e os indivíduos do gênero feminino apresentaram uma precocidade eruptiva nos quatro 
grupos estudados. A maior diferença entre os gêneros aconteceu nos caninos, ao passo que nos primeiros molares superiores não houve diferença estatisticamente significante. Em poucos casos os dentes superiores irromperam antes dos seus correspondentes inferiores. A seqüência de erupção dentária parece ser a mesma em todas as raças estudadas, mas difere entre a maxila e a mandíbula e entre os gêneros.

Com o objetivo de investigar se durante o período de desenvolvimento radicular, o movimento axial é causado por processos e estruturas presentes nos dentes, SICHER ${ }^{134}$, em 1942, utilizou como grupo experimental secções seriadas de mandíbulas e maxilas humanas em diferentes idades, e como grupo controle utilizou maxilares de cães e porcos. Da análise dos resultados obtidos, o autor concluiu que a força de erupção se dá pela combinação do crescimento da polpa em uma zona de proliferação restrita na região apical do dente e pela proliferação de tecido osteogênico que antecede a aposição óssea. Após o completo desenvolvimento radicular, a "força" de erupção é resultado da aposição óssea que ocorre no fundo do alvéolo dentário.

Devido à grande discordância entre as tabelas existentes até o momento e à falta de informação a respeito do grau de variação que pode ser esperado ao examinar a erupção dentária de jovens do gênero feminino e masculino, HURME56, em 1949, realizou uma revisão da literatura a respeito da cronologia de erupção dentária. Os dados analisados revelaram que não há diferenças entre os gêneros quando se considera a cronologia de erupção dentária. $\mathrm{O}$ autor afirma ainda que, o fato dos jovens do gênero feminino apresentarem uma precocidade eruptiva de 5 meses, em média, não é estatisticamente significante.

Para obter informações a respeito da cronologia de erupção dos dentes permanentes e esfoliação dos dentes decíduos, STONES et al. ${ }^{145}$, em 1951, examinaram 320 crianças inglesas, sendo180 do gênero 
masculino e 140 do feminino. Os autores concluíram que a cronologia de erupção do dente permanente depende, em grande parte, da época de esfoliação do seu dente decíduo predecessor. De um modo geral, os caninos e incisivos decíduos superiores esfoliam mais tarde em relação aos seus correspondentes no arco inferior. Estas diferenças são significantes para jovens do gênero feminino, enquanto que para os do gênero masculino, apenas a diferença dos caninos apresenta-se significante. Coerentemente, os incisivos e caninos permanentes superiores irrompem mais tarde em relação aos seus correspondentes mandibulares. Esta diferença foi significante nos três dentes. Os pré-molares inferiores irrompem mais tarde que os seus correspondentes superiores para ambos os gêneros e esta diferença foi estatisticamente significante. Não houve uma diferença estatisticamente significante quando foi avaliada a cronologia de erupção dos dentes permanentes comparando-se os hemi-arcos direito e esquerdo. $O$ dimorfismo entre os gêneros foi particularmente marcante quando a cronologia de erupção dos caninos permanentes foi avaliada. Essa diferença é de aproximadamente 10 a 11 meses.

No ano de 1953, LO; MOYERS ${ }^{84}$, em 1953, realizaram um estudo para determinar se a seqüência de erupção dos dentes permanentes afetava a oclusão final, qual a seqüência de erupção que ocorre mais freqüentemente e que tipo de oclusão era resultado das diferentes seqüências de erupção. Ao final do estudo com 236 jovens sendo 116 do gênero feminino e 120 do gênero masculino, verificaram 18 seqüências de erupção diferentes no arco superior e 17 seqüências de erupção diferentes no arco inferior. Considerando o gênero, não houve diferença estatisticamente significante na seqüência de erupção quando todos os dentes do arco foram considerados. No entanto, quando avaliando a ordem de erupção em indivíduos com oclusão normal, o sétimo dente a irromper na cavidade bucal em jovens do gênero masculino era o primeiro pré-molar superior e o oitavo o canino inferior. Em jovens do gênero feminino, a seqüência de erupção destes dois dentes era inversa. Neste mesmo estudo 
a ordem de erupção foi simétrica bilateralmente, com exceção de casos que apresentavam patologias localizadas. Os autores afirmam que a presença de uma área patológica extensa ao nível das raízes dos dentes decíduos e com conseqüente perda óssea significante é, em alguns casos, suficiente para que o sucessor permanente irrompa mais rápido do que o seu correspondente no lado oposto do arco dentário. Os resultados deste estudo permitiram as seguintes conclusões:

- A seqüência de erupção mais freqüente na maxila foi: primeiro molar, incisivo central, incisivo lateral, primeiro pré-molar, segundo prémolar, canino e segundo molar.

- A seqüência de erupção mais freqüente na mandíbula foi: primeiro molar, incisivo central, incisivo lateral, canino, primeiro pré-molar, segundo pré-molar e segundo molar.

- A combinação das seqüências de erupção descritas acima ocasionou a maior prevalência de uma relação molar normal.

- A seqüência de erupção mais desfavorável na maxila foi aquela em que o segundo molar irrompeu antes que os caninos ou pré-molares.

- A seqüência de erupção mais desfavorável na mandíbula foi aquela em que os caninos irromperam mais tarde que os pré-molares ou quando o segundo molar irrompeu antes dos caninos ou pré-molares.

- Nos casos com relação molar de Classe II há uma forte tendência dos molares superiores irromperam antes que os seus correspondentes inferiores.

- Jovens do gênero feminino apresentaram uma maior prevalência da seqüência de erupção mais comumente encontrada, resultando em uma relação molar normal.

- O estudo da seqüência de erupção por meio de radiografias, em casos em que não há perdas prematuras de dentes decíduos, tem um certo valor prognóstico.

Com o propósito de estudar a cronologia de esfoliação dos dentes decíduos e de erupção dos seus sucessores permanentes, a seqüência de 
erupção dos dentes permanentes, o intervalo de tempo entre a perda dos dentes decíduos e a erupção dos seus sucessores, a incidência de perda prematura e de retenção prolongada dos dentes decíduos, os efeitos aparentes de algum desses fatores e do uso dos mantenedores de espaço na incidência de más-oclusões, KRONFELD77, em 1953, examinou 400 crianças durante um período de 14 anos $\mathrm{O}$ exame consistia de séries radiográficas de toda a boca realizadas pelo menos a cada 6 meses, e modelos de estudo confeccionados pelo menos a cada ano. Da análise dos resultados $o$ autor concluiu que quanto maior o intervalo de tempo entre a esfoliação normal do dente decíduo e a erupção do seu sucessor, maior a probabilidade de ocorrer um mau posicionamento deste último. Além disso, constatou que a seqüência de erupção dos caninos permanentes e dos prémolares exerce pouca ou nenhuma influência no desenvolvimento da máoclusão; que a perda prematura de um dente decíduo no período de 1 ano a 1 ano e meio da época normal de esfoliação do mesmo normalmente resulta em uma aceleração da erupção do seu dente sucessor, e que todos os caninos e molares decíduos perdidos prematuramente, sempre que possível, precisam ser substituídos imediatamente por mantenedores de espaço, uma vez que a perda muito prematura de um dente decíduo resulta em um atraso na erupção do dente sucessor e provavelmente em um mau posicionamento do mesmo, a menos que se utilize um mantenedor de espaço adequado.

Com a intenção de determinar um padrão de erupção dos dentes humanos baseando-se em registros longitudinais de crianças que foram acompanhadas durante todo o período de suas vidas, NANDA104, no ano de 1960, avaliou questionários periódicos de saúde, exames dentários e médicos, modelos de estudo, radiografias da cabeça e esporadicamente história nutricional. Os dados foram estudados separadamente para a mandíbula e maxila e para os gêneros. Não houve diferença entre os gêneros considerando-se 0 número de dentes presentes em uma determinada faixa etária e as idades médias de erupção nas crianças examinadas. $\mathrm{Na}$ dentição permanente, as diferenças entre os gêneros variaram de um mínimo de 0,01 ano para os primeiros molares superiores a 
0,8 ano para os caninos inferiores. A diferença entre a maxila e a mandíbula foi, entretanto, vista com bastante freqüência tanto para os valores individuais como dos grupos. A existência de correlação entre a idade em que a dentadura permanente se completou, a idade da velocidade máxima do surto de crescimento pubescente para os dois gêneros e a idade da menarca para as jovens foi negativa. A correlação negativa pode ser devido ao pequeno tamanho da amostra. Foi sugerido, entretanto, que a fraca correlação entre os atributos físicos estudados podem, de fato, ser devido a um relacionamento não específico entre maturação dentária e puberdade. Desde que os padrões de crescimento da face humana e da estatura corpórea apresentem uma estreita relação, pode-se deduzir que a correlação entre o crescimento da face e 0 desenvolvimento da dentição também se apresenta baixo. Este fato é de considerável importância, se confirmado por estudos futuros, no diagnóstico e plano de tratamento ortodôntico.

Com o propósito de avaliar a existência de uma relação entre a cronologia de erupção e calcificação dos caninos permanentes e prémolares inferiores com o apinhamento dos dentes inferiores, BRADLEY14, em 1961, utilizou radiografias do lado direito da mandíbula e modelos de 89 jovens do gênero masculino com idades variando entre 3 e 18 anos. Da análise dos resultados obtidos concluíram que o aumento do apinhamento nos dentes permanentes inferiores apresentou uma baixa, porém significante, correlação com o retardo das fases iniciais de erupção do canino, e com o retardo da calcificação do segundo pré-molar, seguido por uma aceleração das fases iniciais de sua erupção. A variação individual foi tão grande que se torna impraticável predizer a existência de apinhamento a partir da calcificação ou época de erupção ou a influência que apinhamentos moderados exercem sobre a cronologia de erupção.

Com o objetivo de avaliar a seqüência e cronologia de erupção dentária e examinar a possibilidade de predizer a época de erupção de 
caninos e pré-molares a partir da idade de irrupção dos incisivos e primeiros molares, STURDIVANT; KNOTT; MEREDITH ${ }^{146}$, no ano de 1962, examinaram modelos de estudo de 57 jovens do gênero masculino, leucodermas, em diversas idades. A idade média de erupção para os incisivos e caninos no arco inferior foi mais precoce do que a encontrada para os dentes correspondentes no arco superior. A variabilidade na idade de erupção apresenta-se menor para os primeiros molares, intermediária para os incisivos laterais, e maior para os caninos e segundos pré-molares. As seqüências de erupção dentária que ocorreram com freqüência superior a 15 por cento são: primeiro molar, incisivo central, incisivo lateral, primeiro pré-molar, canino, segundo pré-molar e segundo molar; primeiro molar, incisivo central, incisivo lateral, primeiro pré-molar, segundo pré-molar, canino e segundo molar no arco superior, e no arco inferior: incisivo central, primeiro molar, incisivo lateral, primeiro pré-molar, canino, segundo prémolar e segundo molar; incisivo central, primeiro molar, incisivo lateral, canino, primeiro pré-molar, segundo pré-molar e segundo molar. Nenhuma das quatro seqüências de erupção foram encontradas em mais de 30 por cento dos jovens. Os autores finalmente concluíram que se pode estimar a idade de erupção do canino inferior com uma razoável confiabilidade a partir da época de erupção do incisivo lateral inferior.

Para estabelecer um padrão de época de erupção dos dentes permanentes de crianças de Canberra na Austrália e determinar a diferença, se existente, entre as idades médias e medianas de erupção dentária, CARR ${ }^{18}$, em 1962, utilizou dois métodos de pesquisa, o método transversal e o longitudinal. Foram observadas poucas diferenças entre os resultados obtidos por esses métodos. As idades médias de erupção foram de um a dois meses maiores que as idades medianas. Os dentes das jovens do gênero feminino irromperam em média cinco meses mais cedo que os dos jovens do gênero masculino. O canino inferior nos jovens do gênero masculino irrompe de 6 a 12 meses mais tarde do que as idades publicadas em estudos anteriores. 
Com o objetivo de estudar a erupção dos dentes permanentes em crianças judias do grupo Ashkenazim, ABRAMOWICZ1', em 1964, avaliou 1538 alunos, sendo 794 do gênero masculino e 744 do feminino, de escolas particulares da cidade de São Paulo, de níveis sócio-econômicos elevados na faixa etária de 5 a 13 anos. Da análise dos dados obtidos, o autor concluiu que não há diferenças maiores de 1 ano entre os gêneros, salvo algumas exceções (8 casos $=0,52 \%$ ); somente os incisivos e o primeiro molar completam sua erupção até os 13 anos de idade no gênero masculino; considerando-se o gênero feminino separadamente, todos os dentes, do incisivo central ao primeiro molar, completam sua erupção até os 13 anos de idade, com exceção do segundo e do terceiro molar; não houve diferenças maiores que 1 ano entre a cronologia de erupção dos dentes superiores e os inferiores; não houve diferenças entre a cronologia de erupção dos dentes do lado direito e esquerdo de ambos os arcos, com algumas exceções (27 casos $=1,70 \%$ ); apesar da influência de determinados fatores na cronologia de erupção dentária, esta apresenta-se relativamente constante, advindo daí seu interesse prático nas perícias odonto-legais de determinação da idade.

GATES45, em 1964, procurou determinar padrões de erupção dentária para crianças da cidade australiana de New South Wales. Selecionou-se para o estudo 5.660 crianças leucodermas (2.753 do gênero feminino e 2.907 do gênero masculino), com idades entre 6 e 15 anos. O autor concluiu que não houve diferenças significantes entre as idades medianas de erupção para os dentes correspondentes do lado esquerdo e direito dos arcos dentários; as jovens do gênero feminino irromperam seus dentes em idade mais precoce que os do masculino, sendo que a diferença média entre as idades medianas de erupção foi de 5 meses. A menor diferença, 0,16 ano, foi observada nos molares superiores enquanto que a maior diferença, 1,10 ano foi encontrada nos caninos inferiores.

MILLER; HOBSON; GASKELL100, no ano de 1965, realizaram um estudo longitudinal em 694 crianças para avaliar a esfoliação dos dentes 
decíduos e um estudo transversal em 2000 crianças para avaliar a seqüência e cronologia de erupção dos dentes permanentes. Observaram que o padrão de esfoliação dos dentes decíduos apresentourse semelhante ao encontrado por STONES et al. ${ }^{145}$ em 1951, tanto em relação à seqüência de esfoliação dos dentes decíduos quanto em relação às idades médias. Os dentes decíduos esfoliaram mais cedo no gênero feminino do que no masculino. A seqüência de erupção foi a mesma para os jovens de ambos os gêneros até a erupção do incisivo lateral superior. A partir daí, a seqüência diferiu entre os gêneros. No gênero masculino, o primeiro prémolar superior precedeu o canino inferior, ao contrário do que ocorreu no gênero feminino.

Considerando a relação existente entre o tipo de má-oclusão e a seqüência de erupção dentária, GRABER 46 ressalta, em 1965, que em uma grande quantidade de casos de má-oclusão de Classe II, Divisão 1 , 0 segundo molar superior tende a irromper antes que seu correspondente do arco inferior.

KNOTT; MEREDITH75, em 1996, conduziram um estudo longitudinal com 107 jovens americanos, leucodermas e nível sócio-econômico elevado para caracterizar a seqüência e cronologia de erupção dos dentes permanentes. Os autores concluíram que: incisivos e caninos irrompem em idades mais precoces na mandíbula do que na maxila; os caninos inferiores apresentaram o maior dimorfismo de gênero em relação à idade de emergência na cavidade bucal; as variações para a época de erupção são menores para os incisivos e primeiros molares do que para caninos e prémolares; há uma correlação moderadamente forte entre a época de erupção dos dentes permanentes homólogos nos dois lados de um mesmo arco dentário. Além disso, concluíram que se pode predizer satisfatoriamente a idade de erupção do canino inferior a partir da idade de erupção do incisivo lateral inferior. 
GARN; BURDH1 acreditam que a seqüência de erupção dos dentes permanentes sofreu e continua sofrendo uma mudança progressiva. A provável seqüência de erupção nos primatas era a seguinte: primeiro molar, segundo molar, terceiro molar, incisivo central, incisivo lateral, primeiro prémolar, segundo pré-molar e canino. Segundo os autores, há uma grande variabilidade na seqüência de erupção dos dentes permanentes, variando entre os arcos, entre os gêneros e também de acordo com as características individuais.

Sabendo da grande variabilidade de erupção dos dentes permanentes e que os fatores genéticos, destes em particular os étnicos e também os fatores ambientais, exercem uma influência bastante significativa neste processo e também dos cuidados que devemos ter na aceitação de parâmetros de uma região para a outra, SOUZA-FREITAS; ALVARES; LOPES ${ }^{139}$, em 1970, conduziram um estudo com 3688 crianças brasileiras brancas de terceira geração, (descendentes de avós portugueses, italianos e espanhóis) de ambos os gêneros com idade cronológica compreendida entre 51 a 168 meses da cidade de Marília. Neste estudo a classificação œmo brancos foi inteiramente subjetiva, baseada na cor da pele e tipo de cabelo, conforme descrições clássicas. Qualquer processo patológico, mesmo indeterminado, julgado capaz de interferir no processo de erupção, determinou a exclusão da criança do trabalho. Da análise dos dados colhidos, concluíram que houve uma diferença estatisticamente significante na erupção dos dentes permanentes, com precocidade para o gênero feminino e que exceto para os primeiros e segundos pré-molares no gênero masculino e primeiro pré-molar no feminino, os dentes inferiores irrompiam mais cedo que seus homólogos do arco superior.

No ano de 1972 com o intuito de avaliar a existência de correlação positiva entre a erupção dentária e a idade cronológica, BROOK; BARKER ${ }^{15}$ estudaram 4873 indivíduos de 3 grupos étnicos diferentes e confirmaram a existência de uma forte correlação positiva entre a erupção de dentes 
permanentes e a idade cronológica do indivíduo em todos os grupos étnicos estudados. No entanto, ressaltaram a limitação deste método de predição da idade cronológica e também da existência de fatores locais e gerais que acarretam uma grande variabilidade na seqüência e cronologia de erupção dos dentes permanentes.

SAVARA; STEEN132, em 1978, avaliaram a cronologia e seqüência de erupção dos dentes permanentes de 287 jovens da cidade de Oregon (124 do gênero masculino e 163 do feminino). No presente estudo, a erupção dentária foi definida como emergência gengival. A diferença nas idades de erupção dos dentes homólogos em cada arco (direito e esquerdo) ou foram pequenas ou inexistentes. As jovens apresentaram uma maior variabilidade na idade de erupção do que os jovens e a erupção ocorreu em geral mais cedo nas do gênero feminino. A seqüência de erupção mais freqüente na maxila do gênero feminino foi: primeiro molar, incisivo central, incisivo lateral, primeiro pré-molar, canino, segundo pré-molar e segundo molar e ocorreu em $11,4 \%$ dos casos, e na mandíbula foi: incisivo central, primeiro molar, incisivo lateral, canino, primeiro pré-molar, segundo prémolar e segundo molar. Para os do gênero masculino, a seqüência de erupção mais freqüente foi: primeiro molar, incisivo central, incisivo lateral, primeiro pré-molar, segundo pré-molar, canino e segundo molar e ocorreu em $13,4 \%$ dos casos. Realizourse uma comparação entre os gêneros, dos 3 dentes permanentes que irrompem em uma primeira fase (incisivo central, incisivo lateral e primeiro molar), e dos 4 dentes permanentes que irrompem mais tarde, em uma segunda etapa (canino, primeiro pré-molar, segundo pré-molar e segundo molar). Houve grandes semelhanças para os dentes que irrompem primeiramente, com exceção do primeiro molar inferior. As diferenças apresentaram-se grandes para os dentes que irrompem posteriormente, com exceção dos caninos inferiores e dos primeiros prémolares superiores e inferiores. 
No ano de 1978, MARQUES; GUEDES-PINTO; ABRAMOWICZ93 realizaram um estudo com 1741 crianças nascidas na cidade de São Paulo com idade variando entre 4 e 14 anos. Pode-se observar que os dentes permanentes das crianças do gênero feminino irromperam antes dos dentes permanentes das crianças do gênero masculino. Além disso, os dentes da mandíbula irromperam antes que os correspondentes da maxila, exceção observada para os pré-molares onde acontece o inverso. A cronologia de erupção dos dentes permanentes, considerando-se o valor mediano, está descrita na tabela 1. Nos achados deste estudo, observam-se evidentes diferenças dos dados com os apresentados por autores estrangeiros, demonstrando, mais uma vez, a importância desses estudos na nossa população.

TABELA 1 - Cronologia de erupção dos dentes permanentes de crianças da cidade de São Paulo.

\begin{tabular}{|c|c|c|c|}
\hline Arco & Dente & Masculino & Feminino \\
\hline \multirow{7}{*}{ Superior } & 1 & 7 a 7,5 & 6,5 a 7 \\
\hline & 2 & 8 a 8,5 & 7,5 a 8,5 \\
\hline & 3 & 11,5 a 12 & 10,5 a 11 \\
\hline & 4 & 9,5 a 10 & 9 a 9,5 \\
\hline & 5 & 10,5 a 11 & 10 a 10,5 \\
\hline & 6 & 6 a 6,5 & 6 a 6,5 \\
\hline & 7 & 12 a 12,5 & 12 a 12,5 \\
\hline \multirow{7}{*}{ Inferior } & 1 & 6 a 6,5 & 5,5 a 6 \\
\hline & 2 & 7 a 7,5 & 6,5 a 7,5 \\
\hline & 3 & 10 a 10,5 & 9 a 9,5 \\
\hline & 4 & 9,5 a 10,5 & 9,5 a 10,5 \\
\hline & 5 & 11 a 12 & 10,5 a 11 \\
\hline & 6 & 6 a 6,5 & 5,5 a 6,5 \\
\hline & 7 & 11,5 a 12 & 11 a 11,5 \\
\hline
\end{tabular}


Para investigar a seqüência de erupção dos dentes permanentes em 448 crianças do gênero masculino com idades compreendidas entre 7 e 10 anos, PARREIRA et al.116, em 1982, realizaram tomadas radiográficas periapicais de todos os dentes decíduos e permanentes dessas crianças. Os autores concluíram que a seqüência provável de erupção para os dentes do arco superior é em $85 \%$ dos casos: primeiro molar, incisivo central, incisivo lateral, primeiro pré-molar, segundo pré-molar e canino; enquanto que para o arco inferior é em $84 \%$ dos casos: primeiro molar, incisivo central, incisivo lateral, canino, primeiro pré-molar e segundo pré-molar. Estes resultados sugerem que a ordem de aparecimento dos dentes na cavidade bucal se mantém relativamente constante, e que as discrepâncias geralmente observadas poderiam estar relacionadas a fatores locais e sistêmicos que afetam o desenvolvimento de cada dente individualmente. Comparando os resultados da erupção dos dentes permanentes nas crianças do gênero masculino com os resultados de uma pesquisa anterior, realizada em 1979 também na mesma cidade por VIANNA et al. ${ }^{155}$, que estudaram a seqüência de erupção em crianças do gênero feminino, pode-se verificar uma similaridade na seqüência de erupção em ambos os gêneros.

Com a finalidade de obter um padrão de época de erupção e dos estágios de calcificação na população japonesa, HÖFFDING et al.54, em 1984, conduziram um estudo com 1819 jovens com idade entre 6 e 15 anos. Os resultados mostraram seqüências específicas de erupção em ambos os arcos dentários e a existência de dimorfismo entre os gêneros na época de irrompimento do dente na cavidade bucal, sendo que no gênero feminino a erupção do dente ocorre mais precocemente. Além disso, da comparação com uma amostra do ano de 1934, houve, em geral, uma tendência de erupção mais precoce dos dentes na população japonesa contemporânea.

Com o objetivo de avaliar a diversidade de épocas de erupção dos dentes permanentes de crianças de uma população indígena da região noroeste de Ontário, TITLEY149, no ano de 1984, examinou 1191 crianças 
com idades entre 5 e 17 anos. A época da erupção dentária foi definida como o momento em que qualquer parte da coroa dentária perfurasse a gengiva. A partir dessa definição, todos os dentes permanentes foram registrados como irrompidos, não irrompidos ou ausentes devido a extrações ou ausência congênita. Os resultados mostraram que, em geral, as crianças do gênero feminino apresentaram um período de erupção dentária em idades mais precoces do que as do gênero masculino e este resultado foi estatisticamente significante, e a seqüência de erupção dentária em ambos os gêneros foi semelhante.

No ano de 1985, HÄGG;TARANGER51 realizaram um estudo longitudinal do nascimento aos 18 anos de idade em 212 indivíduos suecos com atenção especial à época de irrupção dos dentes na cavidade bucal. Concluíram que a diferença média entre a idade dentária estimada e a idade cronológica era de aproximadamente um mês em ambos os gêneros e que no gênero feminino o irrompimento dos dentes na cavidade bucal ocorria mais precocemente, exceção feita ao terceiro molar que irrompia mais precocemente em indivíduos do gênero masculino.

No ano de 1987, SMITH; GARN136 forneceram novas informações a respeito da freqüência das diferentes seqüências de erupção dos dentes permanentes em um estudo transversal com 6000 crianças americanas leucodermas e melanodermas. Da análise dos resultados, concluiurse que há uma maior variação das seqüências de erupção na mandíbula do que na maxila. Os autores acreditam que a época e a seqüência de erupção dentária podem estar relacionadas de uma maneira geral à expectativa de vida, ao crescimento craniofacial, ao estabelecimento da oclusão, à maturação dos músculos da mastigação, à maturação sexual, e à demanda de uso.

Com o propósito de estudar a cronologia e a seqüência de erupção dos dentes permanentes (caninos e pré-molares) em escolares na faixa 
etária de 11 a 15 anos, GALVÃO39, em 1991, examinou clinicamente 401 crianças das zonas urbana e rural da cidade de Araçatuba-SP. A erupção foi considerada nos arcos dentários e não por hemi-arcos, por não haver diferenças significativas entre os lados esquerdo e direito. $O$ autor concluiu que a seqüência de erupção de caninos e pré-molares mais freqüente foi no arco inferior: canino, primeiro pré-molar e segundo pré-molar; e no arco superior: primeiro pré-molar, segundo pré-molar e canino. Para muitos ortodontistas, estas seqüências são consideradas ideais por proporcionarem melhores condições para estabelecimento de uma oclusão clinicamente aceitável. No arco dentário superior, não houve alteração na seqüência eruptiva cosiderando-se os gêneros separadamente. No arco inferior, para o gênero masculino, os primeiros pré-molares irromperam antes dos caninos, enquanto que, para o gênero feminino, a seqüência foi aquela considerada a ideal.

No ano de 1993, PINHEIRO; CASADO; ASSUNÇÃO119 apresentaram o tema erupção dentária, com a finalidade de observar e analisar o conceito discriminativo deste assunto (fisiológico ou patológico) que é transmitido à comunidade (pais e responsáveis), bem como analisar a clientela estudada e se o tempo de profissão interfere nesta concepção conceitual. $\mathrm{Na}$ avaliação das respostas de 50 médicos pediatras de Brasília a um questionário fechado e constituído de cinco questões, $88 \%$ responderam que a erupção dentária é um processo fisiológico e em algumas ocasiões pode acontecer ligeiro desconforto.

Com a intenção de obter um padrão de erupção dentária da população finlandesa, VIRTANEN; BLOIGU; LARMAS156, no ano de 1994, analisaram os dados de 911 crianças, sendo 456 do gênero masculino e 455 do feminino, com idades variando entre 3 e 21 anos. Da análise dos dados, os autores concluíram que as diferenças na época de erupção entre dentes homólogos de um mesmo arco dentário foram pequenas ou inexistentes, entretanto, os dentes inferiores irromperam em idades mais precoces do que 
seus correspondentes superiores; todos os dentes irromperam mais cedo no gênero feminino, com diferença variando entre 0,1 a 1,0 ano dependendo do dente.

No ano de 1996, SALEEMI et al. ${ }^{129}$ realizaram um estudo longitudinal em uma amostra de 443 crianças paquistanesas e não observou a presença de dimorfismo entre os gêneros no processo de erupção dos dentes decíduos. No entanto, houve uma diferença estatisticamente significante no processo de irrupção do dente na cavidade bucal quando foi feita uma comparação entre indivíduos de classes econômicas distintas, com um maior número de dentes irrompidos para indivíduos de classes menos favorecidas.

Com o propósito de examinar o movimento para a mesial dos primeiros molares permanentes no arco inferior e sua relação com a magnitude e direção de crescimento facial e a erupção dentária, RICHARDSON125, em 1996, utilizou cefalogramas obtidos com uma angulação de $60^{\circ}$ de 22 pacientes do gênero masculino e 29 do feminino com idades cronológicas compreendidas entre 13 e 18 anos. Análise de correlação foi feita para examinar a relação entre o movimento para a mesial do primeiro molar permanente e erupção dentária e alterações no comprimento mandibular e a altura facial anterior e a direção de crescimento. Os resultados indicaram, em média, um movimento para anterior dos primeiros molares em torno de 2,0-3,0 mm e uma quantidade de erupção que variou entre $2,0-4,0 \mathrm{~mm}$. Não foi observada nenhuma relação entre o movimento para a anterior dos primeiros molares e sua quantidade de erupção ou a magnitude e direção do crescimento facial.

No ano de 1996, CHATTOPADHYAY; SRINIVAS23 verificaram a existência de uma forte relação entre os pacientes que apresentavam transposição dentária e os seus familiares. Os autores concluíram que 
diversos fatores, analisados conjuntamente, apontam para a etiologia de caráter genético da transposição dentária.

SYMONS; TAVERNE147, em 1996, relataram casos clínicos relacionados a distúrbios na formação e erupção dentária do segundo prémolar. Os autores acreditam que estas anormalidades podem surgir durante os vários estágios de desenvolvimento dos dentes.

Com o objetivo de investigar a prevalência de diferentes características oclusais, anormalidades na dentição e anomalias de espaços em crianças da Islândia, com 6 anos de idade, JOHANNSDOTTIR; WISTH; MAGNUSSON68, em 1997, examinaram radiografias panorâmicas e modelos de gesso de 396 crianças islandesas (204 do gênero masculino e 192 do feminino). Verificaram que as crianças do gênero feminino estavam à frente das crianças do gênero masculino em relação ao estágio de desenvolvimento dentário e que em 11 crianças analisadas o primeiro molar superior permanente encontrava-se em posição ectópica.

Para GUEDES-PINTO49, a seqüência de erupção dos dentes permanentes mais favorável é: primeiro molar inferior, primeiro molar superior, incisivo central inferior, incisivo lateral inferior, incisivo central superior, incisivo lateral superior, canino inferior, primeiro pré-molar inferior, primeiro pré-molar superior, segundo pré-molar inferior, segundo pré-molar superior, canino superior, segundo molar inferior, segundo molar superior, apesar de isso não significar o padrão normal de erupção. Além disso, o autor relata que crianças que nascem e vivem em países cuja temperatura média anual é baixa, parece haver um discreto retardo na época de erupção dos dentes permanentes quando comparadas com aquelas nascidas em países tropicais e no mesmo país aquelas nascidas e criadas em cidades litorâneas parecem ter erupção mais precoce. 
WISE159, em 1998, afirma que o estudo da biologia da erupção dentária é um campo de pesquisa fascinante e que além das aves e répteis que se libertam dos tecidos duros em que estão confinados, a erupção dentária é o único processo de desenvolvimento em que um tecido duro, o dente, deve libertar-se de sua cápsula, o osso alveolar, em que está inserido.

Com o objetivo de investigar a idade média, o intervalo de idade e a seqüência de erupção dos dentes permanentes levando em consideração o efeito da perda prematura dos dentes antecessores decíduos, KOCHHAR; RICHARDSON76, no ano de 1998, realizaram um estudo longitudinal com indivíduos leucodermas da região da Irlanda do Norte. O material consistiu de modelos de gesso de 276 indivíduos (146 do gênero masculino e 130 do feminino) com idades variando entre 5 e 15 anos. Foram realizadas comparações entre as idades médias de erupção em casos com e sem a perda prematura de dentes decíduos, entre o arco superior e o inferior, entre os lados esquerdo e direito e entre indivíduos do gênero feminino e masculino. A seqüência de erupção também foi investigada. Os resultados mostraram que a perda prematura dos dentes decíduos retarda a erupção dos sucessores permanentes, com exceção feita aos pré-molares superiores em que a erupção foi mais acelerada. Cada dente permanente do arco inferior irrompeu mais cedo do que o seu correspondente no arco superior com exceção dos pré-molares. Não houve diferença estatisticamente significante quando foram considerados os lados direito e esquerdo. Indivíduos do gênero feminino apresentam uma tendência de erupção em idades mais precoces do que indivíduos do gênero masculino, com exceção dos segundos molares tanto do arco superior como do inferior. No entanto, os únicos dentes que apresentaram uma diferença estatisticamente significante foram os caninos superiores e inferiores e os incisivos laterais superiores. A seqüência clássica de erupção: primeiro molar, incisivo central, incisivo lateral, primeiro pré-molar, canino, segundo pré-molar e segundo molar no arco superior (sic) e incisivo central, primeiro molar, incisivo lateral, 
canino, primeiro pré-molar, segundo pré-molar e segundo molar no arco inferior (sic) ocorreu em 16\% dos casos no arco superior e 13\% dos casos no arco inferior. Os autores ressaltam a precisão deste estudo por ser longitudinal, os indivíduos da amostra serem todos leucodermas e o fato do estudo ter levado em consideração o efeito da perda prematura dos dentes decíduos.

Com o objetivo de contribuir para melhor entender o desequilíbrio na formação radicular, ARRUDA et al. ${ }^{4}$, no ano de 2000, realizaram uma revisão da literatura sobre a fisiologia de erupção normal, bem como sobre a possível causa do desequilíbrio no tempo de formação da raiz e da alteração fisiológica que acontece no processo de erupção. Tem sido observado clinicamente que o atraso na formação dos dentes permanentes é um fenômeno que ocorre mais freqüentemente em pré-molares. $O$ desequilíbrio na formação é provavelmente causado pelo retardo da mineralização. A mineralização atrasada dos primeiros e segundos pré-molares aparece com igual freqüência em jovens do gênero feminino e masculino. $A$ incidência na maxila é maior do que na mandíbula. A impacção do dente não impede a rizogênese, tendo em vista as observações radiográficas da formação de raízes de dentes impactados. No âmbito do diagnóstico e do planejamento terapêutico ortodôntico, o atraso na rizogênese de pré-molares superiores e inferiores, muitas vezes não identificado clinicamente, apresenta um papel importante. $O$ atraso no desenvolvimento, com conseqüente atraso na troca de dentes, não raramente prolonga o tratamento, bem como pode ser fator etiológico de uma má-oclusão.

Em um estudo de 55 radiografias panorâmicas de pacientes que apresentavam os caninos superiores deslocados para a região palatina e de 57 que apresentavam os caninos posicionados adequadamente, BECKER; CHAUSHU7, em 2000, confirmaram a desconfiança clínica de que os pacientes que apresentam caninos deslocados para a região palatina apresentam um atraso no desenvolvimento dentário. Aproximadamente a 
metade dos pacientes com deslocamento palatino dos caninos superiores apresentou um desenvolvimento dentário significantemente atrasado, enquanto que o desenvolvimento dentário dos demais pacientes pareceu estar normal.

\subsection{2- Fatores gerais e locais que influenciam a erupção dentária}

Existem inúmeros fatores capazes de alterar a seqüência e/ou a cronologia de erupção dos dentes permanentes. Esses fatores podem ser de ordem geral ou local, e serão enfocados separadamente neste trabalho por razões didáticas.

\subsubsection{1 - Fatores de ordem geral}

Tanto a seqüência quanto a época de erupção parecem ser, em grande parte, determinadas pelos genes. Alem disso, há seqüências e épocas de erupção que são típicas para certos grupos raciais. Não se sabe bem como os genes interferem nos processos básicos de calcificação e erupção. As influências nutricionais sobre a calcificação e a erupção são pouco significantes, sendo observadas somente nos extremos da variação nutricional. Tanto a calcificação quanto a erupção respondem menos aos distúrbios endócrinos do que o desenvolvimento esquelético.

Com o intuito de avaliar clinicamente e experimentalmente as teorias de erupção, MASSLER; SCHOUR ${ }^{95}$, em 1941, mostraram a relação existente entre fatores sistêmicos (sic) e a quantidade de erupção. Por meio dos estudos das diferentes teorias de erupção, relataram que o gênero feminino apresentava uma maior velocidade eruptiva do que o gênero masculino e que os dentes dos indivíduos do gênero feminino irrompiam em uma idade mais precoce do que os do gênero masculino. Afirmavam que este aspecto estava diretamente relacionado com o crescimento e desenvolvimento físico mais precoce em indivíduos do gênero feminino no 
período da infância. Este aspecto se torna mais evidente entre gêmeos, uma vez que a herança genética e a influência do meio ambiente são semelhantes e apenas o gênero é diferente.

Para verificar a influência dos fatores hereditários e ambientais no desenvolvimento da dentição, NISWANDER ${ }^{106}$, em 1963, analisou os efeitos da procriação consangüínea na erupção dos dentes permanentes e comparou as diferenças dessa erupção dentária entre os filhos de casais japoneses que apresentavam algum grau de parentesco e os que não apresentavam grau de parentesco. Foram examinados aproximadamente 3.500 filhos de casais de primos e um número equivalente de jovens como controle. $\mathrm{Na}$ análise da erupção dentária, considerava-se o número total de dentes permanentes já irrompidos no momento do exame. Se qualquer porção da coroa dentária tivesse perfurado a gengiva, o dente era considerado irrompido. O autor não observou nenhum efeito da procriação consangüínea na erupção dentária, assim, o número de dentes irrompidos em uma determinada faixa etária não depende de fatores genéticos recessivos, enquanto que uma positiva correlação foi encontrada entre 0 custo da alimentação por mês por família e a erupção dentária, evidenciando um envolvimento dos fatores ambientais. Observourse também uma tendência de irmãos apresentarem uma maior semelhança nos padrões da erupção dentária do que jovens não irmãos em idades similares.

Com objetivo de avaliar a seqüência e a cronologia de erupção dos dentes permanentes em escolares primários de ambos os gêneros, brasileiros, brancos, da cidade de Araçatuba; avaliar os efeitos prováveis da urbanização, como um fator de variação do tempo de erupção e verificar a seqüência média de erupção dos dentes permanentes da maxila e da mandíbula nas crianças das áreas examinadas, TOLEDO150, em 1963, examinou um total de 1356 jovens distribuídos entre as idades de 5 a 13 anos, sendo 745 pertencentes à área urbana, e 611 à área rural. Foi observado o fato de os dentes permanentes irromperem mais cedo nos 
jovens do gênero feminino que nos do gênero oposto, em concordância com a informação unânime dos autores consultados. Adicionalmente, a variação apresentada entre a cronologia eruptiva das áreas urbana e rural não indicam a precocidade ou o atraso de uma área em relação à outra.

Analisando a influência da condição sócio-econômica sobre a cronologia e seqüência de erupção dos dentes permanentes, ARBENZ; ABRAMOWICZ3 $^{3}$, no ano de 1964, avaliaram 2030 crianças de escola pública da cidade de São Paulo e 1538 crianças de nível sócio-econômico elevado de uma escola particular. Os autores observaram que a seqüência e a cronologia de erupção apresentaram-se diferentes nas duas amostras. $O$ número de dentes permanentes irrompidos foi um indicador mais confiável do que a seqüência ou cronologia de erupção para as estimativas da idade cronológica do indivíduo.

GRABER ${ }^{46}$, em 1965, afirma em seu livro que a disponibilidade de espaço não é o único fator que atua sobre a erupção dos dentes permanentes e a reabsorção dos decíduos. Distúrbios endócrinos podem alterar esta erupção. Por exemplo, glândulas tireóides que apresentem algum distúrbio são relativamente freqüentes e seus efeitos podem ser observados no desenvolvimento da oclusão. As enfermidades febris podem desordenar a cronologia e seqüência de erupção dentária, assim como provocar distúrbios locais.

KRUMHOLT; ROED-PETERSEN; PINDBORG78, em 1971, analisaram a cronologia de erupção (tanto a idade média como a idade mediana) dos dentes permanentes de 622 jovens de Uganda. Os dentes permanentes dos jovens examinados apresentaram uma precocidade de erupção em relação a jovens leucodermas. Nem a fluoretação da água de abastecimento, nem a prevalência de cáries, e nem as extrações de dentes decíduos nas regiões geográficas estudadas puderam ser responsabilizadas por tal precocidade. Relatos prévios de que a erupção dos dentes 
permanentes em melanodermas apresenta-se acelerada em comparação com populações leucodermas foram confirmadas pelo presente estudo. Os melanodermas irromperam seus dentes em média 1 a 1,5 ano à frente dos jovens leucodermas. Os dentes permanentes irromperam discretamente mais cedo nas jovens do gênero feminino, entretanto, os jovens do gênero masculino irromperam os primeiros 3 pares de dentes em idades mais precoces. A diferença média para a época de erupção de todos os dentes permanentes entre os gêneros foi de 0,5 ano.

Para investigar a influência de distúrbios mentais na cronologia de erupção dentária, MOLINA; VIÑAS; GARCÍA-GODOY101, no ano de 1982, examinaram 182 crianças dominicanas (63 do gênero feminino e 119 do masculino) na faixa etária compreendida entre 2 a 14 anos. Os indivíduos do gênero masculino foram os primeiros a apresentar erupção de um dente permanente, iniciando o processo aos 6,06 (DP $\pm 1,09$ ) anos com o incisivo central inferior. Os indivíduos do gênero feminino iniciaram seu processo eruptivo aos 7,3 ( $D P \pm 1,76$ ) anos com o primeiro molar inferior. Em ambos os gêneros, a irrupção dentária iniciou no arco inferior. Aparentemente, o grau de comprometimento mental das crianças parece influenciar a idade de irrupção dentária, já que nessa pesquisa foi constatado que as crianças com Síndrome de Down iniciaram o processo eruptivo em idades mais avançadas que as crianças com paralisia cerebral. Os autores sugerem que se realizem mais estudos a esse respeito, enfocando os distintos graus de comprometimento mental.

No ano de 1995, VALLADARES-NETO; SILVA; KAADI153 realizaram uma revisão da literatura a respeito dos principais agentes etiológicos gerais responsáveis pelo retardo eruptivo (TABELA 2). Os autores concluíram que, geralmente, os fatores gerais afetam vários dentes e apresentam outros sinais e sintomas que auxiliam a formular o diagnóstico. 
TABELA 2 - Condições gerais, doenças e síndromes associadas ao retardo ou ausência eruptiva.

\begin{tabular}{ll}
\hline Hereditariedade \\
\hline Distúrbios endócrinos \\
$-\quad$ Hipopituitarismo \\
$-\quad \quad$ Hipoparatireoidismo \\
$-\quad$ Hipotireoidismo \\
\hline Deficiência nutricional \\
$-\quad$ Hipovitaminose A \\
$-\quad$ Hipovitaminose D \\
\hline Síndrome de Maroteaux-Lamy \\
\hline Síndrome de Down \\
\hline Elefantíase \\
\hline Osteopetrose \\
\hline Radiação 11 \\
\hline Displasia ectodérmica \\
\hline Sífilis congênita \\
\hline Acondroplastia \\
\hline Amelogênese imperfeita \\
\hline Alguns tipos de sinostose craniofacial como a síndrome de \\
\hline Crouzon \\
\hline Fissura lábio-palatina \\
\hline Atrofia hemi-facial \\
\hline Puberdade tardia \\
\hline Síndrome de Rothmund-Thompson \\
\hline Uso sistêmico de flúor \\
\hline Síndrome de Gardner \\
\hline Fibromatose gengival \\
\hline Síndrome de Ellis-Van-Creveld \\
\hline Consistência alimentar \\
\hline Doenças febris \\
\hline Síndrome da pequena estatura e erupção retardada \\
\hline Síndrome otodental \\
\hline Fator idiopático \\
\hline
\end{tabular}

No ano de 1996, PACKOTA; PHAROAH; PETRIKOWSKM11 descreveram os principais achados radiográficos em doze indivíduos portadores de displasia odontomaxilar. As características mais comuns foram a presença de um trabeculado ósseo mais delgado e esclerótico, a ausência dos pré-molares, seio maxilar com dimensões reduzidas e uma erupção tardia dos dentes posteriores permanentes. As características menos comumente observadas foram o alargamento das coroas, raízes e 
polpa dos molares decíduos e a reabsorção irregular das raízes dos molares decíduos que pode interferir no processo de erupção do sucessor permanente.

Com a intenção de avaliar os fatores responsáveis pelo atraso na erupção dentária de 14 casos ( 9 do gênero masculino e 5 do feminino) de 10 famílias norueguesas, RASMUSSEN; KOTSAKI22, no ano de 1997, realizaram um estudo longitudinal e que no máximo a cada 2 anos eram obtidas radiografias panorâmicas, fotografias clínicas e modelos de gesso dos pacientes. A estimativa da idade dentária (desenvolvimento dentário) foi realizada de acordo com o método proposto por DEMIRJIAN; GOLDSTEIN; TANNER ${ }^{31}$. Os principais achados clínicos e radiográficos foram: 1) todos os dentes da dentadura permanente foram afetados, às vezes também alguns dos segundos molares decíduos; 2) a cronologia da formação dentária estava dentro de limites normais; 3) a extração dos dentes decíduos, a fim de estimular a erupção dos sucessores, não obteve sucesso na maioria dos casos; 4) os dentes com retardo atingiram, muito freqüentemente, sem intervenção o nível do plano oclusal. As posições aberrantes e raízes em forma de gancho parecem não impedir a erupção; 5) secundariamente à falha primária de erupção, outros distúrbios podem aparecer, causados por migração dentária, falta de espaço, fibrose gengival, reabsorção radicular, reabsorção patológica. Estes distúrbios podem impedir a erupção especialmente entre os grupos de dentes em fases tardias; 6) os dentes reagem às forças ortodônticas. Portanto, a anquilose não pareceu ser o mecanismo responsável pelo retardo eruptivo nos pacientes avaliados.

FRANKLIN; ROBERTS ${ }^{38}$, em 1998, relataram um caso clínico de uma criança do gênero masculino, de 6 anos de idade, portadora de hipertricose lanuginosa onde se observou um atraso na erupção dentária. Esta patologia pode ocasionar anomalias dentárias, como dentes neonatais, hipodontia, presença de dentes supranumerários e defeitos no esmalte. 
No ano de 1998, ROSENBLUM ${ }^{127}$ relatou um caso clínico de um paciente com 14 anos e 9 meses de idade com o desenvolvimento dentário atrasado e que era portador de uma patologia não muito comum denominada síndrome de Gorlin-Goltz. Esta síndrome apresenta como sinal principal a existência de múltiplos cistos na região dos maxilares e até então nenhum estudo tinha dado ênfase a seqüência e cronologia de erupção dos dentes permanentes em pacientes portadores desta patologia. $O$ autor considera a hipótese, do caso clínico apresentado, ser apenas uma mera coincidência entre uma doença sistêmica e uma manifestação de desenvolvimento dentário atrasado. Sugere que novos estudos sejam realizados em pacientes portadores desta enfermidade para confirmar a influência desta síndrome no desenvolvimento dentário.

No ano de 1999, McNAMARA et al. ${ }^{96}$ descreveram um caso clínico de erupção dentária precoce de um primeiro pré-molar superior de um paciente portador de fissura do palato e afirmaram que esta precocidade no processo de erupção dentária, tanto na dentição decídua como na permanente, pode ocorrer devido a manifestações de natureza sistêmica como por exemplo hipofosfatasia, hipertireoidismo, leucemia linfóide aguda, neutropenia, histiocitose $X$, síndrome de Papillon-Lefèvre e querubismo. Os autores salientam a importância de um controle adequado do processo eruptivo dentário de pacientes com as referidas condições sistêmicas sob pena de comprometer a permanência de elementos dentários na cavidade bucal.

A displasia cleidocraniana apresenta como principais manifestações bucais a falha na erupção dos dentes permanentes e a presença de múltiplos dentes supranumerários. Assim sendo, a radiografia panorâmica constitui um valioso coadjuvante na confirmação do diagnóstico desta patologia97.

Com o objetivo de avaliar a incidência de anomalias craniofaciais e dentárias em crianças portadoras da forma mais severa de osteogênese 
imperfeita, O'CONNELL; MARINI109, em 1999, avaliaram 40 crianças com idades entre 1 e 17 anos. Verificaram o atraso no desenvolvimento dentário em $21 \%$ dos pacientes portadores de osteogênese imperfeita, ao passo que em $23 \%$ dos pacientes ocorreu uma precocidade deste desenvolvimento. Além disso, a erupção ectópica ocorreu em 13 pacientes. A má-oclusão de Classe III ocorreu em 70 a $80 \%$ da população estudada com uma alta incidência de mordida cruzada anterior e posterior e de mordida aberta.

Em um outro estudo no ano seguinte, O'CONNELL et al.110 avaliaram 34 indivíduos (com idades variando entre 2 e 40 anos) portadores da síndrome de hiperimunoglobulinemia $E$ para verificar a incidência de erupção dentária anormal. A relação entre a idade cronológica, a idade dentária e a idade na época de erupção dos dentes foi determinada. A idade dentária nos pacientes com idade inferior a 17 anos foi determinada por 2 métodos: (1) a avaliação clínica da erupção dentária e (2) o método radiográfico. Os resultados mostraram que $75 \%$ dos pacientes, com idade maior que 7 anos, relataram problemas na erupção dos dentes permanentes como pode ser evidenciado pela retenção prolongada de dentes decíduos ou pela necessidade de extrações de tais dentes para permitir a erupção do sucessor permanente. Nenhum dos pacientes relatou problemas na erupção dos dentes decíduos. A erupção dos primeiros e segundos molares permanentes ocorreu também em época adequada. A maturidade dentária foi determinada em 14 pacientes com 17 anos de idade ou menos. Em cada caso, a diferença entre a idade cronológica e a idade dentária foi menor que 12 meses; no entanto, uma diferença estatisticamente significante entre a idade cronológica e a idade média de erupção dos dentes em $80 \%$ dos casos foi verificada quando valores padrões foram considerados. Além disso, a persistência da bainha epitelial de Hertwig nas raízes dos dentes decíduos foi observada em exames histológicos e, clinicamente, grande parte dos pacientes apresentou lesões compatíveis com candidíase crônica. As alterações no processo de erupção dentária ocorreram principalmente 
pelo atraso na esfoliação dos dentes decíduos ao invés de um atraso no desenvolvimento e formação dos dentes permanentes.

\subsubsection{2- Fatores de ordem local}

Os distúrbios mecânicos, bem como os processos patológicos localizados, podem alterar o plano genético de erupção. As lesões periapicais, as pulpites e a pulpotomia de um molar decíduo aceleram a erupção do pré-molar sucessor. Se o dente decíduo for extraído depois que o sucessor permanente tenha iniciado os movimentos ativos de erupção, o dente irromperá precocemente. Se o dente decíduo for extraído antes do início dos movimentos eruptivos do permanente (antes da formação da raiz), é bem provável que a época de irrupção do dente permanente seja retardada, pois o processo alveolar pode voltar a se formar sobre o dente sucessor, tornando a erupção mais difícil e lenta. Assim, os possíveis efeitos da extração do dente decíduo sobre a erupção do seu sucessor relacionamse com o estágio de desenvolvimento dos dentes permanentes. Também pode ser observado que o apinhamento dos dentes permanentes afeta, ligeiramente, sua velocidade de calcificação e erupção. Também o trauma nos dentes decíduos, especialmente nos dentes anteriores, pode prejudicar o irrompimento normal do sucessor permanente.

Com o objetivo de relacionar os efeitos da perda prematura dos molares decíduos e a erupção dos pré-molares correspondentes, POSEN120, no ano de 1965, avaliou 62 pacientes do Centro de Pesquisa Ortodôntica de Burlington, que foram submetidos à extração de molares decíduos, sendo 34 do gênero feminino e 28 do masculino. $O$ autor concluiu que a erupção dos pré-molares é fortemente afetada pela perda prematura dos molares decíduos. Houve um atraso na erupção dos pré-molares em crianças que apresentam perda prematura dos molares decíduos nas idades de 4 e 5 anos; após a idade de 5 anos, há uma gradual redução no atraso da erupção do pré-molar e um gradual aumento na velocidade de erupção até a 
idade de 8 anos ser alcançada; nas idades de 8, 9 e 10 anos, há uma acentuada aceleração na velocidade de erupção do pré-molar, em decorrência da perda prematura de molares decíduos.

Em um estudo com o objetivo de verificar a possível influência da fluoretação na cronologia de erupção dos dentes permanentes, SOUZAFREITAS et al.141, em 1971, utilizaram os mesmos indivíduos da amostra do estudo realizado no ano anterior ${ }^{139}$ e uma outra amostra com 3345 jovens com idade cronológica compreendida entre 48 e 180 meses da cidade de Ribeirão Preto de uma região aonde a água de abastecimento público não continha fluoretos. Da comparação entre as amostras, foi observado que houve um atraso na erupção dentária na população da cidade de Marília (água fluoretada) em relação à de Ribeirão Preto (água não fluoretada).

Com o objetivo de avaliar o efeito da extração de molares decíduos, em pacientes de diferentes idades, no desenvolvimento dos pré-molares sucessores, utilizando o dente do lado oposto (sem extração) como controle, LOEVY86, em 1989, avaliou radiografias de 33 casos de pacientes da Universidade de Illinois. A avaliação desses dados demonstrou que condições locais, como a extração e a terapia endodôntica, podem influenciar a erupção dentária. A erupção do dente sucessor pode ocorrer precocemente quando o dente decíduo tiver sido extraído ou submetido a pulpotomia, independentemente da maturação desse dente (sic). Apesar dos fatores locais exercerem uma certa influência na irrupção dentária, eles parecem exercer pouca influência na maturação dentária. Em casos isolados, nos quais os pacientes são controlados periodicamente, a erupção dentária após a extração do dente decíduo pode ser acelerada. Entretanto, cada caso precisa ser analisado individualmente para determinar a conduta mais adequada em relação ao espaço deixado pelo dente extraído.

Com a intenção de investigar a provável relação entre mortificação pulpar de dentes decíduos e o desvio na erupção dos seus sucessores 
permanentes, BENGTSON; BENGTSON ${ }^{10}$, no ano de 1990, utilizaram em sua amostra radiografias periapicais pela técnica do "cone longo" de 54 primeiros molares decíduos inferiores e 49 segundos molares decíduos inferiores, juntamente com os seus sucessores. Os dentes deveriam apresentar cáries profundas com ou sem exposição pulpar quer na forma de pulpite aguda ou crônica. Em alguns casos eram evidentes os abscessos e/ou fístulas. Os autores concluíram que somente a mortificação pulpar de molares decíduos não altera o trajeto de erupção dos seus sucessores; que existe uma relação direta no desvio do trajeto de erupção do germe do dente permanente quando o antecessor decíduo é portador de abscesso (com rarefação óssea). Dos 65 germes que sofreram desvio no trajeto de erupção, 61 eram de sucessores decíduos portadores de abscessos, o que corresponde a $94,15 \%$ dos dentes que apresentaram o seu trajeto eruptivo alterado.

Com o objetivo de comparar a cronologia de erupção dos pré-molares superiores e inferiores após a pulpotomia dos dentes antecessores, utilizando o lado oposto como controle (desta maneira as variações individuais puderam ser desconsideradas), LOEVY; CRAWFORD 87 , em 1991, utilizaram radiografias seriadas de molares decíduos de 14 crianças do gênero masculino e 13 do feminino, com idades na época do tratamento pulpar variando entre 3,23 e 9,00 anos, sendo a idade média de 6,42 anos. Todas as pulpotomias foram realizadas pelo mesmo profissional. A erupção dos dentes sucessores ocorreu mais cedo (em 15 casos), aproximadamente ao mesmo tempo (em 9 casos), ou mais tarde (em 3 casos) do que os dentes controle, dependendo das características individuais do paciente. As diferenças entre os grupos foram estatisticamente significantes.

Com o propósito de estudar comparativamente populações de duas cidades, sendo que uma possui água de abastecimento público fluoretada artificialmente e a outra não, e investigar nas regiões anatômicas de caninos e molares decíduos, se há diferença quanto aos seguintes fatores: 
desequilíbrio entre rizólise e rizogênese e retenção prolongada de dentes decíduos, GARDUCCI; LINO40, em 1992, realizaram tomadas radiográficas periapicais pela técnica do paralelismo de alunos de escolas públicas na faixa etária de nove a quatorze anos de idade, de ambos os gêneros, leucodermas, com níveis sócio-econômicos semelhantes. Um grupo foi formado por jovens que residem em cidade com águas de abastecimento público fluoretada artificialmente (Marília - SP). O outro por indivíduos que residem em cidade sem fluoretação (Brodósqui - SP). Cada grupo era constituído de 60 jovens, 30 de cada gênero. Houve uma criteriosa seleção da amostra, excluindo da mesma os jovens que residissem na zona rural, que tivessem extraído algum dente, que apresentassem cáries extensas nas regiões anatômicas analisadas, bem como agenesias, dentes supranumerários, odontomas, cistos, anquiloses e que tivessem ingerido flúor por outros meios que não fosse o de fluoretação das águas, entre outros critérios. Considerou-se retenção prolongada, quando 3/4 ou mais da raiz do dente permanente estava formada e o correspondente decíduo não havia esfoliado. Foram investigados ambos os lados, pois os aspectos a serem observados são alterações que podem ocorrer unilateralmente. Os autores concluíram, em relação às populações estudadas com e sem fluoretação das águas de abastecimento público, que não há diferença estatisticamente significante quanto ao fator desequilíbrio rizólise-rizogênese e quanto ao fator retenção prolongada de dentes decíduos.

Para avaliar a prevalência de anquilose de molares decíduos em 3775 pacientes de 4 a 12 anos, de ambos os gêneros e relacioná-la com o gênero, número de dentes afetados por paciente, arco e hemi-arco, grau de infra-oclusão, anodontia, alterações no grau de formação radicular e padrão de erupção do sucessor, COUTINHO; SOUZA 28 , em 1994, realizaram exames radiográficos como complementação do exame clínico. A partir da análise dos resultados, os autores não observaram correlação entre a anquilose e a ocorrência de anodontia, alterações no grau de formação radicular e no padrão de erupção do sucessor permanente. 
No ano de 1995, VALLADARES-NETO; SILVA; KAADI153 realizaram uma revisão de literatura a respeito dos principais agentes etiológicos locais responsáveis pelo retardo eruptivo (TABELA 3). Os autores afirmam que a precocidade ou retardo extremos, bem como uma seqüência de erupção atípica, podem influenciar o futuro desenvolvimento da dentição, constituindo motivo de atenção especial por parte dos odontopediatras e ortodontistas.

TABELA 3 - Fatores locais associados ao retardo eruptivo do dente permanente.

\begin{tabular}{l}
\hline Discrepância óssea-dentária negativa \\
\hline Erupcão ectópica \\
\hline Trauma \\
\hline Raiz residual persistente \\
\hline Infra-oclusão ou anquilose \\
\hline Perda prematura \\
\hline Espessamento do folículo dentário \\
\hline Cisto \\
\hline Dente supranumerário \\
\hline Dilaceração radicular \\
\hline Odontoma \\
\hline Neoplasia/tumores \\
\hline Má-formação de dentes permanentes ou decíduos incluindo \\
a odontodisplasia \\
\hline Fibrose gengival \\
\hline Raiz supranumerária \\
\hline Macrodontia \\
\hline Seqüência alterada de erupção \\
\hline Fenda alveolar \\
\hline Cárie ou restauração defeituosa \\
\hline Agenesia de incisivo lateral \\
\hline Fator iatrogênico \\
\hline Fator idiopático \\
\hline
\end{tabular}

Com o objetivo de verificar se há uma associação entre a pulpectomia de dentes decíduos e a alteração na trajetória de erupção do sucessor permanente, COLL; SADRIAN ${ }^{25}$, em 1996, avaliaram 65 pacientes (33 do gênero masculino e 32 do feminino). Todos os pacientes foram submetidos a procedimentos de pulpectomia e tiveram seus canais obturados com cimento a base de óxido de zinco e eugenol, sem formocresol. Foram incluídos neste 
estudo apenas os pacientes submetidos a pulpectomia de dente decíduo que apresentassem sinais clínicos e/ou radiográficos pré-operatórios de pulpite irreversível (por exemplo, radiolucidez na bifurcação, reabsorção radicular patológica, polpa necrótica seca, ou fístula). Os autores concluíram que em $21,6 \%$ dos casos, os molares pulpectomizados necessitaram ser extraídos devido à dificuldade de esfoliação do dente decíduo ou à erupção ectópica do pré-molar.

Em uma revisão de literatura a respeito da prevalência, etiologia, características clínicas e tratamento dos molares decíduos em infra-oclusão, JOHAL 67 , no ano de 1997, descreve os possíveis efeitos da infra-oclusão dos molares decíduos no desenvolvimento da oclusão: atraso na esfoliação do molar decíduo, atraso na erupção do permanente sucessor ou impacção do mesmo, padrão de erupção anormal dos permanentes sucessores, rotação do dente sucessor, formação de cistos na região dos permanentes sucessores, perda de comprimento do arco dentário, sobre-erupção do dente antagonista, inclinação dos dentes adjacentes, mordida aberta localizada e função anormal da língua, inibição do desenvolvimento ósseo vertical e crescimento do processo alveolar, deterioração da função mastigatória, e o local apresenta-se com forte potencial para o desenvolvimento de uma má-oclusão.

TAKAGI; KOYAMA ${ }^{148}$, afirmaram no ano de 1998 que o cisto dentígero está sempre associado com a coroa de um dente impactado ou não irrompido. A maioria dos pacientes acometidos por esta lesão são jovens com idades inferiores a 20 anos. Os autores ilustram o artigo com a descrição de um caso clínico de cisto dentígero que ocasiona a impactação do segundo pré-molar superior esquerdo no teto do seio maxilar em uma jovem de 6 anos de idade. $O$ tratamento realizado consistiu na marsupialização da lesão cística, o que fez com que o referido dente irrompesse gradualmente e depois fosse tratado ortodonticamente. Após 5 
anos de controle do caso, o segundo pré-molar superior esquerdo encontrava-se em uma posição aceitável.

KALK; BATENBURG; VISSINK ${ }^{69}$, em 1998, apresentaram 5 casos clínicos com atraso nos padrões de erupção dentária e este atraso foi atribuído à displasia dentinária do tipo I. Esta desordem é caracterizada radiograficamente, tanto na dentadura decídua como na permanente, pela obliteração parcial ou total da câmara pulpar, formação radicular defeituosa, e uma tendência à radiolucidez periapical sem uma causa aparente. $O$ tratamento ortodôntico em crianças portadoras deste distúrbio local é desaconselhado, devido à morfologia radicular destes indivíduos que predispõe reabsorções radiculares extensas, comprometendo sobremaneira a permanência dos dentes na cavidade bucal.

YONEMOCHI; NODA; SAKU161 acreditam que a presença de hamartomas pericoronários, apresentando dois tipos de variações histológicas - hiperplasia mixofibrosa pericoronária (PMH) e fibromatose ameloblástica infantil (IAF) - bem como a fibrose gengival induzida por essas lesões, podem ser os principais fatores locais responsáveis pelo atraso da erupção dentária.

PEREIRA; RODRIGUES117, em 1999, ressaltam a importância de um exame clínico cuidadoso para o acompanhamento e o tratamento correto da anquilose dentoalveolar, visto que esta pode causar vários problemas no desenvolvimento da dentição e da oclusão, como atraso na esfoliação do molar decíduo afetado, trajetória anormal de erupção do dente permanente sucessor, impacção ou rotação do permanente sucessor bem como distúrbios no desenvolvimento radicular, inclinação dos dentes adjacentes aos molares decíduos afetados e extrusão dos dentes antagonistas, entre outros. 
BEKISZ; DARIMONT; ROMPEN9 , no ano de 2000, descreveram um caso clínico de hipertrofia gengival unilateral difusa associada com a neurofibromatose de von Recklinghausen. $O$ exame clínico desta paciente revelou um atraso na erupção de alguns dentes permanentes.

CARRARA $^{19}$, em 2000, verificou em seus estudos que os indivíduos portadores de fissura labial apresentam idade média de erupção maior em relação aos indivíduos não fissurados para a maioria dos dentes permanentes, em todos os hemi-arcos e em ambos os gêneros.

\subsection{3- Processos bioquímicos envolvidos no mecanismo da erupção dentária}

Estudando os processos bioquímicos envolvidos na erupção dentária, IV et al.60, em 1998, estudaram a influência de uma molécula presente nas células do folículo dentário de ratos denominada CSF-1 e que é capaz de acelerar o processo de erupção dentária. O mecanismo de ação desta molécula é que no início do processo de erupção dentária ocorre um fluxo de células mononucleares para o folículo dentário e estas células, posteriormente, agregam-se umas as outras e formam os osteoclastos que iniciam o processo de reabsorção do osso alveolar. Os autores estudam ainda a ação de um nucleotídeo capaz de reduzir os níveis da molécula CSF-1 nas células do folículo dentário e que conseqüentemente retardaria o processo de erupção dentária.

Continuando ainda com o estudo dos processos bioquímicos envolvidos na erupção dos dentes, PHILBRICK et al.118, no ano de 1998 , conduziram um estudo em ratos e verificaram a necessidade da presença de uma proteína do hormônio da paratireóide para que a trajetória da erupção dentária seja a mais fisiológica possível e que os defeitos no processo de reabsorção óssea sejam reparados e restabeleçam o programa normal da erupção dentária. 
PAIVA; CIAMPONI113, no ano de1998, apresentam e descrevem detalhadamente as principais moléculas conhecidas como iniciadoras e reguladoras da erupção, que são: a imunoleucina 1 (IL-1), o fator 1 de estimulação de colônia (CSF-1), o fator transformador de crescimento tipo $\beta$ (TGF- $\beta$ ) e o fator de crescimento epidermal (EGF), as quais estão presentes em células do reticulo estrelado e/ou do folículo dentário. A IL-1 está presente em células do retículo estrelado e estimula a produção do CSF-1. O CSF-1 encontra-se no folículo dentário e acelera a erupção. O TGF - $\beta$ está localizado no retículo, atrai monócitos e estimula a atuação da IL-1. O EGF está também presente no retículo estrelado e aumenta a síntese de IL -1.

QUE; WISE121, em 1998, afirmam que a erupção dentária é um evento do desenvolvimento localizado que requer a presença do folículo dentário, um tecido conjuntivo frouxo que circunda cada dente. Por meio de estudo em ratos, os autores evidenciaram, logo após o nascimento, um fluxo de células mononucleares (monócitos) para dentro do folículo, que por sua vez, se fundem para formar os osteoclastos que reabsorvem o osso para formar um caminho eruptivo. O agente quimiotático que pode atrair as células mononucleares ao folículo para iniciar os eventos celulares da erupção dentária é a MCP-1 (monocyte chemotactic protein-one).

\section{2- Calcificação dos dentes permanentes}

\subsection{1- Seqüência e cronologia de calcificação}

Os dentes humanos, elementos mineralizados, derivados do ectoderma e mesoderma embrionários, são os órgãos mais duros do organismo, sendo muitas vezes o único vestígio de uma espécie animal. Devido a importância do tecido mineral presente nas estruturas dentárias, inúmeros trabalhos foram desenvolvidos no sentido de se estabelecer parâmetros cada vez mais precisos a respeito da calcificação dos dentes permanentes. 
Com o objetivo de estudar o dimorfismo entre os gêneros na calcificação dentária, GARN et al.43, em 1958, realizaram um estudo longitudinal com 255 pacientes por um período de 18 anos, utilizando radiografias oblíquas de mandíbula de jovens leucodermas da região sudoeste de Ohio. Os autores utilizaram a seguinte classificação para os diferentes estágios de calcificação: Estágio I - presença da cripta; Estágio II - coroa completa e início da formação radicular; Estágio III - rompimento da margem óssea alveolar (início da erupção); Estágio IV - chegada ao nível oclusal; Estágio V - fechamento do ápice radicular. Em geral, jovens do gênero feminino apresentaram uma maturação dentária mais avançada do que jovens do gênero masculino. O menor dimorfismo entre os gêneros foi obtido em idades mais precoces e com uma absoluta divergência entre os gêneros (maior dimorfismo entre os gêneros) com o passar dos anos. Considerando que o percentual de dimorfismo entre os gêneros existente na cronologia de calcificação dentária foi em torno de $3 \%$ de precocidade para o gênero feminino e que este percentual está em torno de $5 \%$ quando consideramos a erupção dentária, estes indicadores são consideravelmente menores que o desenvolvimento ósseo encontrado entre os gêneros (10 a $25 \%$ ). Considerando que o gênero feminino esteve em um estágio bem mais desenvolvido que o gênero masculino, em termos de calcificação dentária, até o décimo ano de vida, estas diferenças não podem ser atribuídas somente a fatores de ordem hormonal. Os achados mostram claramente a necessidade de maiores estudos no que concerne ao dimorfismo entre os gêneros e estabelecimento de normas quantitativas diferentes para os gêneros quando da avaliação do desenvolvimento dentário.

Até o ano de 1960, o único método disponível para avaliar a idade dentária baseava-se na cronologia de erupção dos dentes. Entretanto, considerar apenas a irrupção faz referência a apenas uma fase do desenvolvimento dentário e NOLLA ${ }^{108}$ acreditava que a avaliação da calcificação dentária em diferentes idades forneceria um índice mais preciso e confiável para a determinação da idade dentária e contribuiria para a 
compreensão do desenvolvimento humano como um todo. Este estudo longitudinal teve o objetivo de desenvolver um método preciso para a avaliação detalhada do desenvolvimento da dentição permanente por meio de radiografias. O material utilizado para este estudo consistiu de radiografias bucais seriadas de 25 jovens do gênero masculino e 25 do gênero feminino. Cada série de radiografias incluía: extrabucal lateral dos maxilares do lado direito e do lado esquerdo; intrabucal oclusal da maxila e da mandíbula; intrabucais periapicais dos lados direito e esquerdo dos dentes posteriores. Cada série de radiografias era obtida anualmente, próxima à época do aniversário do indivíduo. O desenvolvimento dentário foi avaliado em estudos radiográficos e foi graduado em uma escala de 0 a 10. Esta escala é representada por uma série de desenhos ilustrando os 10 estágios de desenvolvimento dos dentes permanentes observados radiograficamente. A autora considerou que os lados direito e esquerdo e os gêneros apresentam uma similaridade nos estágios de desenvolvimento, apesar de reconhecer que as jovens iniciam e cessam o desenvolvimento dentário em idades mais precoces do que os jovens. Com raras exceções, não houve diferenças aparentes entre os gêneros na seqüência geral do desenvolvimento de cada dente. A fim de se obter uma avaliação do desenvolvimento de um dente em particular, a radiografia foi comparada o mais próximo possível com a figura correspondente. Quando a leitura da radiografia indicava um desenvolvimento intermediário, entre dois estágios, a avaliação era indicada com o valor 0,5 . Por exemplo, se a leitura da radiografia indicava um estágio entre um terço e dois terços de raiz completa, registrava-se o valor de 7,5. Quando a radiografia indicava um estágio que era ligeiramente maior do que o estágio ilustrado, mas não chegava à metade entre esse estágio e o próximo, adicionava-se o valor 0,2. Por exemplo, se um pouco mais que dois terços da coroa estava completa, registrava-se o valor 4,2. Se o desenvolvimento fosse ligeiramente menor que um determinado estágio, indicava-se o valor adicionando-se 0,7 ao estágio anterior. Por exemplo, se quase dois terços da coroa estivessem completos, deveria se atribuir o escore 3,7 . O primeiro sinal radiográfico do 
desenvolvimento dentário consiste na visualização de uma estrutura radiolúcida circular no osso denominada cripta. O germe dentário encontrase incluído dentro desta cripta. A próxima alteração observada era a visualização de pequenos pontos triangulares radiopacos próximos ao limite interno da borda coronária da cripta. Nas radiografias anuais sucessivas, $\mathrm{O}$ aumento quantitativo da calcificação torna-se facilmente visualizado. A completa formação do ápice radicular constitui o último estágio a ser observado radiograficamente no processo de maturação. A diferença entre 0 desenvolvimento real e a média revela a quantidade de variação, que é conhecida como individualidade no desenvolvimento dentário. Por essa razão, deve-se evitar o pensamento de que a cronologia média de erupção dentária é uma norma rígida ou um padrão a ser seguido. A informação sobre o desenvolvimento dentário é importante, não apenas por razões de diagnóstico e tratamento, mas também por motivos de pesquisas. Assim, a calcificação dentária pode ser utilizada como um critério para a determinação da idade dentária e idade fisiológica do paciente. Ela fornece um índice de maturidade fisiológica dos dentes permanentes. O conhecimento sobre a aceleração ou o retardo da calcificação dos dentes permanentes de um indivíduo é importante para o ortodontista que deseja determinar o tempo de tratamento com base na idade fisiológica do paciente.

No ano de 1968, WEYMAN 158 fez uma revisão dos efeitos da irradiação no desenvolvimento dentário em pacientes portadores de tumor na região da face e relatou um caso clínico de um paciente que recebeu uma baixa taxa de irradiação aos 5 meses de idade e os efeitos desta irradiação no desenvolvimento dentário por um período de 15 anos. Dentre os principais efeitos da irradiação no desenvolvimento dentário, cita a anodontia total e/ou parcial, anomalias de tamanho e forma, atraso no desenvolvimento e calcificação dentária e comprometimento da estrutura radicular, tanto em seu aspecto morfológico, como funcional. Em alguns casos pode ocorrer também uma erupção precoce do dente, no entanto com menor freqüência do que os efeitos acima relatados. Em suma, conclui que o grau de prejuízo 
no desenvolvimento dentário causado pela irradiação está na dependência de inúmeros fatores, dentre eles o estágio da histogênese dos dentes em desenvolvimento e a dose de irradiação merecem um destaque especial.

SOUZA-FREITAS138, em 1969, realizou um trabalho com o propósito de estudar a correlação entre a idade cronológica e a idade dentária, determinada através de quatro principais tabelas para crianças, a saber: a de LOGAN e KRONFELD89 (modificada por McCALL e SCHOUR), a de GARN et al. ${ }^{42}$, a de NOLLA 108 e a de MOORREES et al. ${ }^{102}$. O estudo foi realizado em 420 leucodermas brasileiros de terceira geração (descendentes de avós portugueses, italianos e espanhóis), de ambos os gêneros, com idade cronológica compreendida entre 48 a 215 meses, dos perímetros urbano e suburbano da cidade de Bauru. O autor concluiu que a amostra estudada apresenta desenvolvimento dentário precoce nas menores idades, o inverso ocorrendo em idades mais avançadas, em relação às amostras utilizadas na confecção das tabelas empregadas. Além disso, para o cálculo da idade cronológica na população da amostra, as idades dentárias devem ser corrigidas através de equações de regressão calculadas no trabalho.

No ano de 1973, DEMIRJIAN; GOLDSTEIN; TANNER ${ }^{31}$ propuseram um novo método para a estimativa da maturidade ou idade dentária por meio de radiografias panorâmicas e utilizando a imagem dos setes dentes permanentes inferiores do lado esquerdo. De acordo com este método proposto, atribui-se aos dentes oito estágios de desenvolvimento, $A$ até $H$, que vão desde a aparência dos primeiros pontos de calcificação até o completo fechamento do ápice radicular. Com a utilização deste método, nos casos de agenesias dentárias, o uso de combinações de diferentes dentes pode ser utilizado com algumas restrições. Apesar deste método de estimativa da idade dentária ser considerado universal, os autores enfatizam a necessidade de individualização dos dados obtidos de acordo com a população a ser estudada. 
TROTTER; HIXON; MACDONALD152, em 1977, avaliaram os estágios de desenvolvimento e o tamanho dos dentes em Macaca mulatta. Os estágios de desenvolvimento de cada dente foram classificados de acordo com os estágios propostos para dentes humanos por GARN et al. ${ }^{44}$, como descritos abaixo:

- Primeira aparição do folículo

- Desenvolvimento completo do folículo, sem calcificação da cúspide

- Início de calcificação da cúspide

- Calcificação da superfície coronária

- Extensão da raiz abaixo da coroa

- Maior desenvolvimento radicular

- Raiz completa exceto o ápice

- Fechamento do ápice

Os autores acreditam que o macaco Rhesus (Macaca mulatta), mais do que qualquer outro primata, pode ser utilizado em investigações científicas no que concerne ao processo de desenvolvimento e calcificação dos dentes.

No ano de 1980, DEMIRJIAN; LEVESQUE32 realizaram um estudo clássico sobre a existência de dimorfismo entre os gêneros no desenvolvimento dentário e na erupção dos dentes na cavidade bucal. Em uma amostra bastante homogênea (franco-canadenses) de crianças com idades entre dois anos e meio e 19 anos, os autores avaliaram 5437 radiografias panorâmicas e classificaram o desenvolvimento dentário pelo método de DEMIRJIAN; GOLDSTEIN; TANNER31. Um padrão comum foi encontrado para cada dente, principalmente a similaridade cronológica entre indivíduos do gênero feminino e masculino nos estágios mais precoces do desenvolvimento e com o evolver da idade há um avanço do gênero feminino frente ao masculino nos estágios mais tardios do desenvolvimento dentário. Até a faixa etária de seis anos não houve diferença estatisticamente significante entre os gêneros quando o desenvolvimento 
dentário foi avaliado, ao contrário do que aconteceu em idades mais avançadas, em que os indivíduos do gênero feminino estavam sempre em um estágio de desenvolvimento dentário mais avançado. Quando foi avaliada a existência de correlação entre o desenvolvimento dentário e a erupção dos dentes permanentes, houve uma forte correlação positiva entre a emergência dos dentes permanentes na cavidade bucal e os estágios de calcificação de todos os dentes.

No ano seguinte, LEVESQUE; DEMIRJIAN; TANGUAY82 realizaram um estudo para avaliar a existência de dimorfismo entre os gêneros no desenvolvimento, erupção e agenesia dos terceiro molares inferiores. Verificaram que a existência de agenesia bilateral dos terceiros molares inferiores foi da ordem de $9 \%$ sem diferenças estatisticamente significantes entre os gêneros. Os terceiros molares dos dois lados apresentaram o mesmo padrão de desenvolvimento coronário e radicular. Indivíduos do gênero feminino apresentaram-se em um estágio de desenvolvimento mais avançado até a segunda metade da formação coronária e esta diferença desapareceu no primeiro estágio de formação radicular. $O$ desenvolvimento radicular foi mais rápido no gênero masculino do que no gênero feminino. Quando se considerou a erupção destes dentes na cavidade bucal, os indivíduos do gênero masculino apresentaram, em média, seis meses de antecedência em relação aos indivíduos do gênero feminino.

No ano de 1983, LOEVY85 investigou a relação existente entre a idade cronológica e o desenvolvimento dos dentes permanentes em três grupos étnicos diferentes (leucodermas, negros e latinos) de acordo com o método descrito por DEMIRJIAN; GOLDSTEIN; TANNER ${ }^{31}$ em 1973. Radiografias panorâmicas de 1085 jovens com idades entre dois e quinze anos foram avaliadas. Apenas jovens em bom estado de saúde foram incluídos na amostra. $\mathrm{O}$ grau de maturação de cada dente permanente do lado esquerdo da mandíbula foi determinado. A análise dos dados demonstrou que todos os grupos deste estudo apresentaram um índice de 
maturidade para a idade cronológica mais avançado que os grupos de franco-canadenses apresentados por DEMIRJIAN; GOLDSTEIN; TANNER31 em 1973. Além disso, indivíduos latinos de ambos os gêneros apresentaram um escore de maturidade mais avançado do que indivíduos leucodermas de ambos os gêneros. Este estudo mostra claramente a influência da etnia na variabilidade de seqüência e cronologia de erupção dos dentes permanentes, assim como no desenvolvimento dentário.

Neste mesmo ano (1983), ALTINL2 afirmou que o tecido dentário é um dos mais importantes e confiáveis meios para a determinação da idade cronológica da espécie humana. Desde a fase intra-uterina até aproximadamente os 20 anos de idade, o estágio de desenvolvimento ou o estágio de mineralização é o meio mais confiável (sic). Após o término da mineralização, a idade cronológica pode ser determinada precisamente por meio das alterações estruturais na dentina e no esmalte (sic). O autor afirma que as alterações anatômicas e químicas nos maxilares, com o decorrer da idade, são de pequeno valor na determinação da idade cronológica e que inúmeras lacunas neste campo de pesquisa ainda permanecem.

Com 0 intuito de verificar a influência dos fluoretos no desenvolvimento dentário, ELBADRAWY34, em 1984, realizou um estudo com 167 jovens com idades compreendidas entre 6 e 12 anos de idade de comunidades que apresentavam níveis distintos de flúor na água de abastecimento. Os resultados mostraram que não houve influência dos níveis de fluoretos no desenvolvimento dentário nos dois grupos considerados, que foram comunidades com nível ótimo e sub-ótimo de flúor na água de abastecimento.

SOUZA-FREITAS et al. ${ }^{140}$, em 1990, realizaram um estudo em 2130 escolares de ambos os gêneros da região de Bauru, com idades variando de 3 a 11 anos e obtiveram, os conteúdos das tabelas da evolução dentária para cada dente, considerando a maxila, mandíbula e gênero. Os resultados 
foram comparados com outros estudos nacionais e internacionais, permitindo determinar o grau de variabilidade e confiabilidade destas tabelas. As diferenças nas idades médias de ocorrência de várias fases de formação dos dentes encontradas entre os gêneros colocam em evidência fato já conhecido de que o gênero feminino tende a ser precoce tanto na cronologia da mineralização como da erupção, confirmando a necessidade de normas quantitativas específicas para cada gênero. Observa-se que as diferenças são menores para as fases iniciais de formação dentária e que vão aumentando gradativamente, chegando a uma precocidade de $10 \%$ com relação ao gênero masculino nas faixas etárias de 11 a 14 anos, correspondentes à puberdade.

No ano de 1990, CARVALHO; CARVALHO; SANTOS PINTO20 por meio da utilização de radiografias panorâmicas avaliaram os estágios de desenvolvimento dos dentes permanentes de 156 crianças dos gêneros masculino e feminino cuja idade cronológica variava entre 84 e 131 meses, da cidade de Araçatuba e região circunvizinha, além de anotar suas massas corporais e alturas. Para avaliação do desenvolvimento dentário, utilizaram o esquema de estágios de formação de dentes baseado em DEMIRJIAN; GOLDSTEIN; TANNER ${ }^{31}$ e em SOUZA-FREITAS et al. ${ }^{140}$. Assim, puderam estimar suas idades dentárias e confrontá-las com suas idades cronológicas. Pelos resultados obtidos observaram que, de acordo com a metodologia empregada, as crianças do gênero feminino mostraram: precocidade na cronologia de formação dos dentes permanentes, valores médios de idade dentária maiores do que as crianças do gênero masculino da mesma idade cronológica e valores médios de idade dentária superiores aos de suas idades cronológicas.

BURDI; MOYERS ${ }^{16}$, em 1991, afirmam que o gênero feminino está mais adiantado na calcificação dos dentes permanentes que o gênero masculino em cada estágio. As diferenças entre os gêneros para a calcificação dos dentes são menores que para o desenvolvimento ósseo. 
Como o gênero feminino é bem mais desenvolvido que o gênero masculino aos 10 anos de idade, os autores afirmam que estas diferenças não são devidas à regulação de secreção de hormônios. A velocidade na qual os incisivos irrompem é muito mais rápida que aquela dos molares à época do aparecimento imediato na boca. Se observarmos uma criança com intervalos de 6 meses, por exemplo, pode parecer que o incisivo irrompeu primeiro, quando, na verdade, o molar o precedeu, mas ele se move tão lentamente que o incisivo o ultrapassa. Além disso, parece que não há diferença clínica se a seqüência de erupção for primeiro molar e incisivo central ou viceversa. Por outro lado, o aparecimento do segundo molar antes dos caninos ou dos pré-molares tem grande tendência a encurtar o perímetro do arco e pode criar dificuldades de espaço. Felizmente, a seqüência mais comum em cada arco (superior: primeiro molar, incisivo central, incisivo lateral, primeiro pré-molar, segundo pré-molar, canino e segundo molar; e inferior: primeiro molar, incisivo central, incisivo lateral, canino, primeiro pré-molar, segundo pré-molar e segundo molar) é favorável para manter o seu comprimento durante a dentadura mista.

Conscientes da grande variação regional existente no processo de desenvolvimento dentário, SOUZA-FREITAS; LOPES; DAMANTE ${ }^{142}$, em 1991, propuseram-se a construir tabelas, quanto ao desenvolvimento dentário, para estabelecer um padrão para os indivíduos da região de Bauru. Para isto, foram examinados 2.130 escolares leucodermas brasileiros, 1.065 de cada gênero, com idades variando de 3 a 18 anos, matriculados nas escolas públicas dos perímetros urbano e suburbano de Bauru-SP. O critério adotado na seleção da amostra foi a ascendência, cor, saúde e procedência. Foram obtidas radiografias panorâmicas e periapicais pela técnica da bissetriz para classificar os diversos estágios de desenvolvimento dentário segundo a metodologia descrita a seguir: 


\begin{tabular}{|c|c|}
\hline ase 0 & - ausência do folículo \\
\hline ase 0,25 & $\begin{array}{l}\text { - fase do folículo com as primeiras evidências de mineralização das } \\
\text { cúspides }\end{array}$ \\
\hline ase 0,50 & - metade da coroa dentária formada e mineralizada \\
\hline ase 1,00 & $\begin{array}{l}\text { - coroa totalmente formada e mineralizada, com ou sem iniciação da } \\
\text { formação radicular }\end{array}$ \\
\hline ase 2,00 & - raiz em formação, mas de tamanho inferior ao da coroa dentária \\
\hline Fase 3,00 & - raiz em formação e com tamanho equivalente ao da coroa dentária \\
\hline Fase 4,00 & $\begin{array}{l}\text { - raiz em formação e de tamanho superior ao da coroa dentária e } \\
\text { com ápice aberto e divergente }\end{array}$ \\
\hline Fase 5,00 & - raiz em formação e com ápice arredondado e convergente \\
\hline 00 & - raiz e ápice rad \\
\hline
\end{tabular}

Os autores concluíram com base nos resultados que nenhuma das tabelas propostas sobre a cronologia de mineralização e erupção dos dentes permanentes pode ter aplicação indiscriminada a qualquer população. Logo, torna-se necessário estabelecer tabelas com valores aplicáveis a grupos populacionais definidos. $\mathrm{Na}$ tabulação dos dados para a determinação do desenvolvimento dentário, os lados direito e esquerdo foram trabalhados em conjunto, partindo-se da premissa de que os dentes homólogos do mesmo arco não apresentam diferenças significantes quanto às suas fases de desenvolvimento 108 .

Para investigar o desenvolvimento dentário em pacientes com oligodontia, WEIDE; PRAHL-ANDERSEN; BOSMAN157, em 1993, analisaram os dados de 216 pacientes com oligodontia (121 do gênero feminino e 95 do masculino), com idade média de11,3 anos (variando de 5 a 14 anos). Neste estudo, oligodontia foi definida com a ausência congênita de seis ou mais dentes, com exceção dos terceiros molares. A amostra continha 6 pacientes com displasia ectodérmica. $O$ número médio de dentes 
ausentes foi de 10,7 para o gênero feminino e 11,7 para o masculino. 0 grupo controle consistiu de 443 jovens (233 do gênero feminino e 210 masculino) com idades entre 4 e 14 anos, e apresentavam a dentadura permanente completa. A metodologia utilizada foi a proposta por DEMIRJIAN; GOLDSTEIN; TANNER 31 que avalia os estágios de calcificação dos dentes inferiores do lado esquerdo em radiografias panorâmicas. Os resultados desse estudo mostraram uma grande variação individual no desenvolvimento dentário em pacientes com oligodontia. Alguns desses pacientes apresentaram um forte atraso na formação dentária, enquanto outros mostraram uma formação dentária normal. Portanto, a formação dentária de cada paciente com oligodontia deve ser examinada individualmente antes do início do tratamento. Há um atraso na formação dentária nos pacientes com oligodontia quando comparados ao grupo controle. Este atraso é melhor evidenciado no gênero masculino do que no feminino. Houve diferença estatisticamente significante na formação dentária entre os pacientes do gênero masculino com oligodontia e os pacientes do grupo controle em diversos estágios dessa formação. No gênero feminino, apenas o estágio $E$ (início da formação da bifurcação radicular) do segundo molar inferior apresentou diferença estatisticamente significante.

No ano de 1996, KIESER; GROENEVELD; SILVA73 estudaram a influência da exposição ao tabaco no atraso da formação dentária. A amostra foi composta de 203 radiografias panorâmicas de crianças leucodermas com idades cronológicas entre 7 e 10 anos. As radiografias foram divididas em quatro grupos: um grupo controle em que nenhum dos pais tinha o vício de fumar, um grupo em que apenas a mãe fumava, um outro grupo em que apenas o pai fumava, e finalmente, um em que ambos os progenitores fumavam. Em cada grupo, a idade cronológica foi comparada com a idade dentária (segundo o método de MOORREES et al. ${ }^{102}$ ) de cada indivíduo. Os resultados mostraram que não houve diferenças nas idades dentárias quando o gênero foi considerado. A maior 
discrepância entre a idade cronológica e a idade dentária foi observada no grupo em que ambos os progenitores tinham o vício de fumar. Neste grupo uma redução em torno de $35 \%$ na maturidade dentária foi observada. Os dentes mais afetados foram os segundos pré-molares superiores, ao passo que os dentes menos afetados foram os incisivos centrais sem distinção entre $o$ arco em que se encontravam.

RAVELI et al. ${ }^{123}$, em 1997, ressaltam a importância do conhecimento profundo das fases do desenvolvimento dentário na clínica, em particular, naqueles casos em que um programa de extração seriada está indicado. A desarmonia entre o tamanho dos dentes e do osso basal geralmente expressa um mau alinhamento dentário. No sentido de impedir a continuação da má-oclusão e a instalação de problemas mais sérios na dentadura permanente, a extração seriada vem sendo utilizada como um dos procedimentos mais eficazes, devendo ser feito um diagnóstico muito cuidadoso no início da dentadura mista. A remoção seriada dos dentes, tanto decíduos como permanentes, se baseiam na seqüência de erupção dos dentes permanentes; por exemplo, a época mais favorável para a remoção dos primeiros molares decíduos do arco inferior depende do estágio de calcificação atingido pelos primeiros pré-molares do mesmo arco.

Em um trabalho no ano de 1997, SALIBA et al. ${ }^{130}$ procuraram estimar a idade cronológica do indivíduo, através do desenvolvimento e mineralização dos dentes, utilizando-se de 274 indivíduos brasileiros, leucodermas, ambos os gêneros, nas faixas etárias de 6 a 14 anos, através de radiografias panorâmicas. Para a classificação dos diversos estágios de calcificação dentária, foi utilizado o método proposto por NOLLA ${ }^{108}$. Pela análise dos resultados obtidos, no presente trabalho, os autores concluíram que os dentes, tanto superiores quanto inferiores, em ambos os gêneros, não apresentaram grandes diferenças de mineralização, entre os lados direito e esquerdo. Incisivo central, incisivo lateral, canino do arco inferior e segundos molares do arco superior, em ambos os gêneros, apresentaram 
maior precocidade de mineralização nos estágios analisados. Os dentes do gênero feminino apresentaram um grau de mineralização mais precoce do que os do gênero masculino, em quase todos os dentes analisados. A análise de correlação, permitiu aos autores calcular uma fórmula para a estimativa da idade cronológica do indivíduo baseando-se nos dentes e no gênero.

Ainda no ano de 1997, HARUKI; KANOMI; SHIMONO52 observaram clinicamente que a erupção do segundo molar inferior em pacientes com máoclusão de Classe III ocorria mais precocemente do que em pacientes portadores de má-oclusão de Classe II. Sabendo que, tanto em pacientes portadores de má-oclusão de Classe II e Classe III, a correção da relação molar é um dos aspectos mais importantes e desafiadores no tratamento ortodôntico e que a obtenção da relação molar pode ser conseguida por meio de forças ortopédicas e que estas forças são mais efetivas quando aplicadas antes da erupção do segundo molar permanente, os autores realizaram um estudo levando em consideração as diferenças nos processos de calcificação e erupção dos segundos molares permanentes nos pacientes portadores destes dois tipos de má-oclusão e as possíveis implicações clínicas desta diferença. A amostra consistiu de 53 pacientes com idades entre 7 e 10 anos de idade e que nunca haviam se submetido a tratamento ortodôntico. Do total da amostra, 26 crianças eram portadoras de máoclusão de Classe III, com um valor de ANB negativo e um perfil côncavo e 27 eram portadoras de má-oclusão de Classe II com um valor de ANB maior que 5 o e um perfil convexo. Os resultados mostraram diferenças nos valores médios de calcificação dos segundos molares superiores entre os 2 grupos da amostra (usando a classificação proposta por NOLLA ${ }^{108}$ ). Entretanto, não houve diferença estatisticamente significante nos valores médios de calcificação entre os dois grupos quando os segundos molares inferiores foram avaliados. Não houve também diferença estatisticamente significante nos valores médios de calcificação dentária, usando a classificação proposta por NOLLA 108 , entre os gêneros masculino e feminino nos dois grupos 
considerados. Quando a quantidade de erupção dos segundos molares foi considerada, houve diferenças significantes. Para os segundos molares superiores, o estágio eruptivo se encontrava mais avançado em indivíduos com má-oclusão de Classe II do que em indivíduos com má-oclusão de Classe III. Ao contrário, no arco inferior os segundos molares apresentavamse em um estágio eruptivo mais avançado em indivíduos com má-oclusão de Classe III. Houve também uma correlação positiva entre o estágio de calcificação e a cronologia de erupção do segundo molar superior e o valor do ANB, ou seja, o segundo molar superior do paciente que apresentava 0 maior valor de ANB apresentou também um estágio de calcificação mais evoluído e a irrupção na cavidade bucal mais precoce. O resultado clínico deste estudo é que devemos considerar a época de tratamento e os tipos de aparelho quando o paciente apresentar uma má-oclusão esquelética, porque o desenvolvimento do segundo molar é diferente em pacientes com Classe II e com Classe III de Angle.

FERREIRA36, em 1998, afirma que o conhecimento dos estágios de desenvolvimento de NOLLA ${ }^{108}$ é de grande valia clínica, pois podemos acelerar ou retardar o processo de erupção dos dentes permanentes mediante a extração de seus antecessores decíduos, na época adequada. Além disso, o estágio médio de calcificação dos dentes em diferentes idades pode determinar um índice mais preciso de idade dentária do que a erupção dos mesmos. O autor, sabendo da grande variabilidade de cronologia de erupção, cita os principais autores e a cronologia de erupção segundo cada um deles como mostra a tabela a seguir. 
TABELA 4 - Cronologia de erupção (em anos) dos dentes permanentes, segundo diversos autores.

\begin{tabular}{l|c|c|c}
\hline \multicolumn{1}{c|}{ Dente } & SAPPEY & BOUCHUT & MAGITOT \\
\hline Incisivo central inferior & 6 a 8 & 6 a 8 & 7 \\
\hline Incisivo central superior & 7 a 8 & 7 a 9 & 7 \\
\hline Incisivos laterais & 8 a 9 & 7 a 9 & 8 \\
\hline Primeiros pré-molares & 9 a 10 & 9 a 10 & 9 a 12 \\
\hline Segundos pré-molares & 12 a 13 & 10 a 11 & 11 \\
\hline Caninos & 10 a 11 & 11 a 12 & 11 a 12 \\
\hline
\end{tabular}

Com o objetivo de determinar se havia diferenças na maturidade da idade dentária entre adolescentes tratados na década de 70 e na década de 90, NADLER ${ }^{103}$, em 1998, estudou uma amostra de 300 pacientes leucodermas, com idade entre 8 e 14 anos, sendo que 150 destes pacientes foram tratados na década de 70 e o restante na década de 90. A porcentagem de calcificação dos caninos inferiores foi calculada de acordo com o método proposto por DEMIRJIAN; GOLDSTEIN; TANNER 31 que classificou o desenvolvimento dentário em oito estágios distintos, de $\mathrm{A}$ até $\mathrm{H}$. A comparação foi feita utilizando-se o estágio $G$ do método acima citado entre os pacientes da amostra. Foi observada uma redução na idade dentária de 1,21 ano para o gênero masculino e 1,52 ano para o gênero feminino e quando a amostra foi avaliada sem distinção entre os gêneros, a redução foi de 1,4 ano.

Com o objetivo de investigar se havia diferença na maturidade dentária entre indivíduos com a mesma idade cronológica e portadores de mordida aberta esquelética e sobremordida profunda esquelética, JANSON et al.64, em 1998, utilizaram um material de 40 telerradiografias em norma lateral e 40 radiografias panorâmicas de 40 indivíduos leucodermas (20 do gênero feminino e 20 do gênero masculino) com idade cronológica média de 9 anos e 2 meses. A amostra foi dividida em dois grupos de 20 indivíduos cada (10 do gênero masculino e 10 do gênero feminino), onde os grupos 
caracterizaram-se por possuir indivíduos com uma mordida aberta associada com uma altura facial anterior inferior aumentada ou uma sobremordida profunda com uma altura facial anterior inferior diminuída. Para determinar a maturidade dentária de cada indivíduo da amostra, um estudo duplo cego foi realizado nas radiografias panorâmicas utilizando o método proposto por DEMIRJIAN; GOLDSTEIN; TANNER ${ }^{31}$ no ano de 1973. As idades dentárias médias, para os grupos com mordida aberta esquelética e sobremordida profunda esquelética, foram respectivamente 120,48 e 114,00 meses. O tratamento estatístico dos dados demonstrou que esta diferença foi estatisticamente significante para $\mathrm{P}<0,05$. Adicionalmente, os resultados sugerem que indivíduos portadores de mordida aberta esquelética possuem uma ligeira tendência de apresentar uma maturidade dentária mais avançada quando comparados com indivíduos portadores de sobremordida profunda esquelética.

Com o objetivo de investigar o impacto da raça no processo de formação dentária, MAKI et al.91, no ano de 1999, ealizaram um estudo com 650 indivíduos sendo 245 americanos leucodermas, 202 chineses e 203 japoneses com idades variando entre 5 e 12 anos. $O$ método utilizado foi a análise do desenvolvimento dos primeiro molares permanentes inferiores em radiografias panorâmicas. Os resultados estatísticos mostraram que os indivíduos do gênero feminino apresentaram uma erupção mais precoce em todos os grupos raciais considerados, e o desenvolvimento dentário, em indivíduos americanos leucodermas, mostrou estar significantemente mais avançado do que em qualquer outra raça. Adicionalmente, o coeficiente de correlação entre a formação do primeiro molar inferior e a idade cronológica foi: $0,802(p<0,05)$ para americanos leucodermas; $0,748(p<0,05)$ para chineses e 0,703 $(p<0,05)$ para os indivíduos japoneses. Os autores concluíram que a formação dentária do primeiro molar inferior mostrou ser um excelente indicativo na determinação da idade cronológica o que se justifica por valores de coeficientes de correlação elevados nos três grupos raciais estudados. 
Com o objetivo de comparar a idade dentária com a idade cronológica em um grupo de crianças nascidas 200 anos atrás e um outro grupo de crianças britânicas de época moderna, LIVERSIDGE83, em 1999, estudou a maturação dentária em 15 esqueletos intactos de indivíduos dos séculos passado e 30 crianças nascidas em idade contemporânea. O método proposto por DEMIRJIAN; GOLDSTEIN; TANNER ${ }^{31}$, no ano de 1973, foi utilizado para determinar a maturidade dentária. A diferença entre a idade dentária e a idade cronológica, para ambos os grupos, não foi estatisticamente significante, sugerindo um padrão de maturidade dentária similar que permanece por mais de 200 anos nos jovens britânicos.

No ano de 1999, NGAN; ALKIRE; FIELDS JUNIOR ${ }^{105}$ salientaram em seu artigo a importância da compreensão do desenvolvimento das dentaduras decídua e mista no que se refere ao manejo adequado dos espaços presentes no arco e na decisão de como e quando interceptar uma má-oclusão, se o apinhamento for detectado em idades mais precoces. Os autores afirmam que o programa de extração seriada está reservado para aqueles casos em que há uma grande discrepância entre o tamanho dentário e o tamanho do osso basal e quando da execução desta terapêutica, é essencial que o clínico conheça profundamente os diversos estágios de calcificação dos dentes para que um tratamento satisfatório seja alcançado.

Com o propósito de observar os estágios de calcificação de primeiros e segundos pré-molares e molares permanentes, bem como verificar a situação de erupção clínica em que esses dentes se encontram em uma comunidade rural da cidade de Araraquara, CORDEIRO et al.27, em 2000, utilizaram os critérios estabelecidos por PAHKALA; PAHKALA; LAINE112 para avaliação clínica dos estágios de erupção e os critérios estabelecidos por NOLLA108 para avaliação radiográfica dos estágios de calcificação. Os estágios de erupção estabelecidos por PAHKALA; PAHKALA; LAINE 112 são os seguintes: $0=$ não visível na cavidade bucal; $1=$ pelo menos uma cúspide 
visível; 2 = distância mesiodistal totalmente visível; $3=$ em oclusão ou no nível de oclusão se o dente antagonista não estiver totalmente irrompido. Os dados foram submetidos à análise estatística descritiva. Frente aos resultados obtidos, os autores concluíram que tanto a calcificação como a erupção dos dentes das crianças da zona rural ocorreram de maneira harmoniosa e uniforme, não apresentando nenhuma alteração significativa.

Com o propósito de comparar a maturidade dentária entre crianças portadoras de artrite reumatóide juvenil e crianças saudáveis, LEHTINEN et al.81, em 2000, avaliaram 95 crianças finlandesas do gênero feminino e 73 do gênero masculino com artrite reumatóide juvenil, e 102 crianças finlandesas do gênero feminino e 66 do masculino representando o grupo controle saudável. Todas as crianças apresentavam a idade cronológica variando de 6,3 a 14,4 anos. O desenvolvimento dentário foi avaliado na radiografia panorâmica, utilizando o método proposto por DEMIRJIAN; GOLDSTEIN; TANNER ${ }^{31}$. A maturidade dentária apresentourse significantemente avançada nas crianças portadoras de artrite reumatóide juvenil com 0,26 ano no gênero feminino e 0,28 ano no gênero masculino. Pode ser cautelosamente sugerido que o avanço no desenvolvimento dentário nas crianças com artrite reumatóide juvenil em comparação com as crianças saudáveis, seja, em parte, um efeito do tratamento dessa desordem com cortisona, enquanto que a influência da desordem por si só ainda necessita ser elucidada.

\subsection{2- Relação entre calcificação dos dentes permanentes e desenvolvimento somático}

A calcificação do dente permanente se correlaciona de um modo geral com altura, peso, tipo de corpo, e ossificação dos ossos do pulso, mas tais correlações raramente são significantes; além do mais, sua utilidade clínica é limitada. 
Com o objetivo de determinar a época de erupção dos 28 dentes permanentes na cavidade bucal e sua relação com os outros indicadores do crescimento e desenvolvimento puberal e esquelético bem como a correlação existente entre a maturidade somática e a presença dos dentes na cavidade bucal em uma amostra de 212 jovens suecos, HÄGG; TARANGER 50 , conduziram um estudo longitudinal no ano de 1984 . Os resultados mostraram uma baixa correlação entre o desenvolvimento somático e dentário em ambos os gêneros. No entanto, houve uma diferença marcante entre os gêneros, sendo que no feminino houve uma consistente e estatisticamente significante correlação entre o desenvolvimento de toda a dentadura permanente e o desenvolvimento somático puberal, ao passo que, no gênero masculino, o desenvolvimento dentário ocorreu quase sempre independente do desenvolvimento somático na puberdade. Além disso, não houve uma correlação positiva entre os diversos indicadores de desenvolvimento somático e o desenvolvimento dentário quando se considerou a época e a magnitude.

No ano seguinte (1985), com o intuito de avaliar a relação existente entre cinco eventos indicativos de maturidade fisiológica em uma amostra de 50 indivíduos do gênero feminino, a saber: a menarca, o pico de crescimento puberal, $75 \%$ da maturidade esquelética, a visualização do osso sesamóide e $90 \%$ do desenvolvimento dentário, DEMIRJIAN et al. ${ }^{30}$ concluíram que a idade média de ocorrência dos eventos acima citados diferiu significantemente $(P<0,01)$. A idade cronológica exata em que ocorriam $75 \%$ da maturidade esquelética e $90 \%$ do desenvolvimento dentário foi estimada considerando-se 0 desenvolvimento somático longitudinal completo de todo o indivíduo. A menarca e $90 \%$ do desenvolvimento dentário apresentaram a menor variabilidade. O pico de crescimento puberal, a menarca, e 75\% da maturidade esquelética apresentaram uma correlação estatisticamente significante $(P<0,05)$. A idade da menarca estava correlacionada positivamente com o pico de crescimento puberal. A visualização do osso sesamóide estava correlacionada positivamente com o 
alcance de $75 \%$ da maturidade esquelética. A idade em que as jovens atingiam $90 \%$ do desenvolvimento dentário não apresentou nenhuma relação significante com os outros indicadores de maturidade. Os resultados sugerem que os mecanismos que controlam o desenvolvimento dentário são independentes da maturidade somática ou sexual.

Com o objetivo de estudar a relação entre crescimento e desenvolvimento físico e erupção dentária, SATAKE; SILVA131, em 1990, examinaram 254 jovens com idades entre 4 anos completos a 8 anos incompletos de uma escola particular e de uma escola municipal periférica do mesmo bairro, tomando medidas antropométricas de estatura e peso e verificando a época de erupção dos primeiros molares permanentes. Verificaram que as crianças da escola particular apresentaram medidas médias de estatura e peso mais elevadas que as das escolas municipais periféricas, assim como maiores percentagens de primeiros molares permanentes irrompidos, em ambos os gêneros e em todas as idades e que houve uma correlação positiva entre crescimento e desenvolvimento físico e erupção dentária.

Com o objetivo de avaliar a relação entre crescimento e erupção dentária, BOSCO; SILVA ${ }^{11}$, no ano de 1991, examinaram 475 meninos e 525 meninas, de 5 anos completos a 8 anos incompletos, alunos de uma escola particular de Florianópolis/SC. Na primeira parte deste estudo, mediram o perímetro cefálico, com a intenção de estudar o processo de crescimento físico. Observaram que, embora houvesse um aumento gradativo do perímetro cefálico com o aumento da idade, em ambos os gêneros, esse aumento foi bastante discreto. Na segunda parte deste estudo,verificaram as percentagens de primeiros molares, incisivos centrais e laterais permanentes superiores e inferiores irrompidos, com o objetivo de verificar o comportamento da erupção dos dentes citados, em relação às variáveis idade e gênero, lados direito e esquerdo e arcos superior e inferior. Observaram que as percentagens de dentes irrompidos foram maiores no 
gênero feminino e no arco inferior, em todas as idades, não tendo sido observadas diferenças significativas entre os lados direito e esquerdo. $\mathrm{Na}$ terceira parte deste estudo, foram consideradas as medidas antropométricas de peso e estatura e a erupção de primeiros molares, incisivos centrais e laterais permanentes superiores e inferiores, com o objetivo de verificar as possíveis relações entre crescimento e desenvolvimento físicos e a erupção dentária. Foi observada uma relação positiva entre peso-erupção e estaturaerupção, sendo mais ajustada a correlação entre estatura-erupção.

MAPPES; HARRIS; BEHRENTS 92 , em 1992, realizaram uma comparação entre o desenvolvimento dentário e o esquelético. Neste estudo, os autores utilizaram radiografias panorâmicas e carpais, uma vez que fazem parte de uma documentação diagnóstica de rotina. Os critérios de seleção da amostra foram: (1) os pacientes deveriam ser leucodermas; (2) a idade cronológica deveria estar entre 12 e 13 1/2 anos; (3) a história médica desses pacientes deveria ser irrelevante. Da análise dos resultados, concluiurse que há uma independência entre o desenvolvimento ósseo e o desenvolvimento dentário.

Sabendo que o número de dentes permanentes irrompendo ou irrompidos, tem sido considerado como um excelente indicador do desenvolvimento biológico, principalmente quando é associado com outros avaliadores somáticos, YARED160, em 1994, procurou estudar a relação entre os parâmetros morfológicos de peso e altura e a erupção dos dentes permanentes, à partir da emergência dentária, em função do nível sócioeconômico, da faixa etária e do gênero. Esta pesquisa foi realizada em 2.262 escolares, leucodermas de ambos os gêneros, da cidade de Araraquara, na faixa etária de 72 meses a 155 meses, divididos em dois grupos de níveis sócio-econômicos. As crianças foram examinadas quanto ao número de dentes permanentes presentes, em seguida, foram tomadas suas medidas de peso e altura. As análises estatísticas de correlação e regressão, entre os indicadores somáticos peso e altura e número de dentes permanentes 
presentes, apresentaram resultados positivos e significantes com a fase $3 \mathrm{da}$ erupção clínica (erupção completa e coroa clínica em contato com o dente antagonista), sendo, portanto, mais expressiva com a idade cronológica. Entretanto a correlação dos valores de peso foi não significante para os escolares de nível sócio-econômico médio.

Com o objetivo de avaliar a existência de correlação entre maturidade sexual e estatura e peso corporal e maturidade dentária em uma população de chineses, SO137, no ano de 1995, conduziu um estudo com 102 indivíduos chineses do gênero feminino com idade cronológica de 12 anos. Para estimar a maturidade sexual, foram consideradas as características sexuais secundárias: idade de ocorrência da menarca, idade em que os primeiros pelos pubianos apareceram, idade que em os pelos axilares apareceram e o desenvolvimento dos seios. Os resultados mostraram que as jovens que apresentavam um desenvolvimento dentário mais avançado têm uma tendência de ter a menarca em idades mais precoce.

Com o objetivo de observar o relacionamento da idade óssea com os estágios de calcificação de molares e pré-molares, CORDEIRO et al. ${ }^{26}$, em 1997, interpretaram radiografias carpais de 120 crianças de ambos os gêneros, na faixa etária compreendida entre 6 anos e 11 anos e 11 meses e compararam com o Atlas de GREULICH; PYLE48. Os estágios de calcificação foram determinados através de comparação com a escala de NOLLA 108 em radiografias panorâmicas dos mesmos pacientes. Já que tanto dentes como ossos traduzem fenômenos semelhantes durante 0 crescimento, os autores esperavam que houvesse um sincronismo entre o desenvolvimento esquelético e o da dentição (sic). Caso exista uma íntima relação entre os 2 eventos, os estágios de calcificação dos dentes permanentes poderiam ser usados mais efetivamente para estimar 0 desenvolvimento esquelético dos pacientes. Os autores são unânimes em afirmar que as variações encontradas podem não só determinar 0 diagnóstico como influenciar no planejamento do tratamento. Frente aos 
resultados obtidos, os autores observaram uma certa concordância entre a idade cronológica e a idade óssea e uma tendência linear crescente para as idades de desenvolvimento estudadas, em ambos os gêneros.

Em 1999, SILVA; BOLOGNESE135 realizaram um estudo com a finalidade de avaliar se por meio do grau de calcificação do segundo prémolar inferior pode-se determinar a idade esquelética (surto de crescimento), a idade cronológica e a idade dentária geral da criança. Foram utilizadas 33 radiografias panorâmicas e 33 radiografias de punho e mão, de 18 meninos e 15 meninas. A avaliação dos estágios de calcificação do segundo prémolar inferior e determinação da idade dentária geral do indivíduo, por meio da radiografia panorâmica, foi feita de acordo com os estágios de calcificação propostos por NOLLA 108 e pelo método descrito por DEMIRJIAN; GOLDSTEIN; TANNER ${ }^{31}$. As radiografias de punho e mão foram utilizadas para avaliar a idade esquelética do indivíduo por meio do método de inspeção, utilizando-se o Atlas radiográfico de GREULICH; PYLE48. A análise dos resultados encontrados mostrou que o grau de calcificação do segundo pré-molar inferior não pode ser usado como indicador clínico da ocorrência do surto de crescimento puberal, em meninos e meninas; a correlação entre o grau de calcificação do segundo pré-molar inferior e a idade cronológica, nos meninos, não foi significativa e não ocorreu nas meninas. As correlações entre o grau de calcificação do segundo pré-molar inferior e as idades dentárias gerais determinadas pelos métodos de NOLLA 108 e de DEMIRJIAN et al.31, nos meninos, demonstraram ter uma forte significância e, nas meninas, demonstraram uma fraca correlação.

Com o objetivo de avaliar a existência de correlação entre os estágios de mineralização radicular dos segundos molares inferiores e a calcificação da região da articulação metacarpofalangeana do dedo, principalmente 0 osso sesamóide e a epífise da falange proximal, ROSSI; AMORIM; PACHECO ${ }^{128}$, em 1999, realizaram um estudo com o propósito de facilitar a 
estimativa da época de ocorrência do surto de crescimento puberal e do potencial de crescimento remanescente do paciente ortodôntico. Foram feitas radiografias intra-bucais e do dedo polegar do lado esquerdo de 72 crianças do gênero feminino, na faixa etária entre 8 e 13 anos de idade, além de ficha clínica com dados pessoais como altura, peso, idade cronológica e época de ocorrência da menarca. Os dados obtidos foram comparados e analisados estatisticamente aplicando-se o coeficiente de concordância Kappa (K) e intervalo de confiança de $95 \%$. Os resultados mostram que a maioria das crianças que estão nos estágios 6 e 7 de Nolla ainda não apresenta osso sesamóide, apresentam estágio epifisário $B$ e estão no início do surto de crescimento. Crianças no estágio 8 de Nolla apresentam início de formação do sesamóide, estão próximas ao pico de velocidade de crescimento puberal, apresentam estágio epifisário $C$ e ainda não tiveram a menarca. Crianças nos estágios 9 e 10 de Nolla já apresentam osso sesamóide formado, estão além do pico de crescimento puberal apresentam estágios epifisários $\mathrm{D}$ e $\mathrm{E}$ e, em geral, não tiveram a menarca. Com relação à curva do surto de crescimento puberal, crianças até o estágio 8 de Nolla se encontram na curva ascendente. Foi verificada a existência de correlação entre os estágios iniciais de calcificação radicular e o início do surto de crescimento puberal; entre o estágio intermediário de formação radicular e o pico de velocidade máxima e entre os estágios finais de calcificação radicular e o final do surto.

Com o propósito de avaliar a previsibilidade dos padrões de maturação dentária em jovens do gênero masculino utilizando as curvas de maturação desenvolvidas por DEMIRJIAN; GOLDSTEIN; TANNER ${ }^{31}$, LOEVY; GOLDBERG88, no ano de 1999, encontraram que $75,9 \%$ dos jovens avaliados, iniciaram a maturação dentária abaixo da média da curva de DEMIRJIAN; GOLDSTEIN; TANNER ${ }^{31}$ em uma idade precoce e ao final do estudo, estes mesmos jovens completaram a maturação dentária acima do valor médio. Os autores concluíram que a mudança dos valores abaixo da média para aqueles acima da média foi considerada um fator importante no plano de tratamento. Os dados indicaram que há um risco considerável 
para o plano de tratamento realizado anteriormente à idade de 8 anos. $O$ risco é maior quando a criança apresenta menos de 6 anos de idade, devido a incertezas na previsão do crescimento. 
3. Proposição 


\section{PROPOSIÇÃO}

O propósito deste trabalho consiste em:

- Comparar a cronologia de erupção dos dentes permanentes em indivíduos com Classe I e Classe II de Angle

- Comparar os estágios de calcificação dos segundos molares nas más-oclusões de Classe I e Classe II de Angle

- Verificar a existência de correlação entre a maturidade dentária dos segundos molares e as grandezas cefalométricas SNA, SNB, ANB, Co-A e Co-Gn. 


\section{Materiale Métodos}




\section{MATERIAL E MÉTODOS}

\subsection{Material}

\subsection{1 - Obtenção da amostra}

Procedeu-se à seleção da amostra, de caráter retrospectivo, a partir do arquivo da Disciplina de Ortodontia da Faculdade de Odontologia de Bauru - Universidade de São Paulo, FOB-USP.

A amostra constituiu-se de 60 telerradiografias em norma lateral e 60 radiografias panorâmicas dos mesmos indivíduos. Todas as radiografias, perfazendo um total de 120, foram obtidas aos 8 anos de idade e divididas em dois grupos (TABELA 5). O grupo Classe I ficou constituído por 60 radiografias (30 telerradiografias em norma lateral e 30 radiografias panorâmicas) de jovens que apresentavam uma relação molar de Classe I de Angle. O grupo Classe II ficou constituído por 60 radiografias (30 telerradiografias e 30 radiografias panorâmicas) de jovens que apresentavam uma relação molar de Classe II de Angle. A análise da relação molar dos jovens selecionados foi previamente avaliada em modelos de gesso.

Os critérios utilizados para a seleção da amostra dos grupos Classe I e Classe II foram: a presença de todos os dentes permanentes até os segundos molares nas radiografias panorâmicas, exclusão de radiografias que apresentassem agenesias ou dentes supranumerários e seleção das radiografias dos jovens que apresentassem uma relação molar de Classe I ou II de Angle.

Posteriormente, foram avaliados 527 pares de modelo de gesso de jovens na faixa etária dos 5 aos 13 anos de idade. Os modelos de gesso também foram divididos em dois grupos. O grupo Classe I ficou constituído 
por modelos de gesso que apresentavam uma relação molar de Classe I de Angle e o grupo Classe II por modelos de gesso que apresentavam uma relação molar de Classe II de Angle (TABELA 6).

TABELA 5 - Média, desvio padrão, mediana e valores mínimo e máximo das idades dos jovens dos grupos Classe I e Classe II.

\begin{tabular}{c|c|c|c|c|c}
\hline GRUPO & MÉDIA & d.p. & MEDIANA & MÁXIMO & MÍNIMO \\
\hline CLASSE I & 8,5166 & 0,2648 & 8,5000 & 8,9166 & 8,0000 \\
\hline CLASSE II & 8,5500 & 0,3235 & 8,5833 & 8,9166 & 8,0000 \\
\hline
\end{tabular}

TABELA 6 - Número de pares de modelos avaliados em cada idade na faixa etária dos 5 aos 13 anos de idade, distribuídos de acordo com a relação molar.

\begin{tabular}{l|c|c|c|c|c|c|c|c|c}
\hline & $\mathbf{5}$ & $\mathbf{6}$ & $\mathbf{7}$ & $\mathbf{8}$ & $\mathbf{9}$ & $\mathbf{1 0}$ & $\mathbf{1 1}$ & $\mathbf{1 2}$ & $\mathbf{1 3}$ \\
\hline CLASSE I & 30 & 30 & 30 & 30 & 30 & 30 & 29 & 25 & 28 \\
\hline CLASSE II & 30 & 30 & 30 & 30 & 30 & 30 & 30 & 30 & 25 \\
\hline
\end{tabular}

\subsection{2 - Material para elaboração do traçado}

Os traçados cefalométricos foram realizados em folhas de papel ultraphan de $0,07 \mathrm{~mm}$ de espessura e $17,5 \mathrm{~cm}$ de largura e comprimento, adaptadas nas telerradiografias. $O$ traçado anatômico e demarcação dos pontos de referência foram efetuados manualmente pelo autor com lapiseira de $0,5 \mathrm{~mm}$, sobre um negatoscópio, em uma sala escurecida. Foram traçadas nas radiografias as estruturas anátomo-radiográficas de interesse para a elaboração do cefalograma (FIGURA 1). 


\section{2 - Métodos}

\subsection{1 - Telerradiografia em norma lateral}

Utilizou-se 60 telerradiografias em norma lateral obtidas aos 8 anos de idade e de acordo com as normas preconizadas pela Disciplina de Radiologia da FOB-USP. O fator de magnificação das telerradiografias foi de $6 \%$.

\subsubsection{1 - Traçado Anatômico}

Foram delimitadas as seguintes estruturas dentoesqueléticas:

- perfil do osso frontal e dos ossos nasais

- sela túrcica

- meato acústico externo

- órbita

- maxila

- contorno da mandíbula e côndilo

- incisivos centrais e primeiros molares permanentes superiores e inferiores

- perfil mole

Para todas as estruturas bilaterais efetuourse o traçado médio.

\subsubsection{2 - Pontos de Referência}

Os pontos de referência anatômicos foram demarcados seguindo as especificações do Atlas de Crescimento Craniofacial94:

1. S (sela túrcica): centro da concavidade óssea da sela túrcica;

2. N (násio): interseção da sutura internasal com a sutura frontonasal; 
3. A (subespinhal): ponto mais profundo da concavidade anterior da maxila;

4. B (supramental): ponto mais profundo da concavidade anterior da mandíbula;

5. Co (condílio): ponto mais póstero-superior do contorno dos côndilos mandibulares;

6. Gn (gnátio): ponto mais ântero-inferior do contorno do mento ósseo.

\subsubsection{3 - Grandezas Cefalométricas Esqueléticas}

\subsubsection{1 - Maxilares}

1- SNA: ângulo formado pelas linhas SN e NA. Indica a relação sagital da maxila em relação à base do crânio. O seu aumento indica protrusão maxilar e a sua diminuição retrusão maxilar.

2- Co-A: distância entre os pontos condílio (Co) e subespinhal (A). Representa o comprimento efetivo da face média (maxila).

\subsubsection{2 - Mandibulares}

3- SNB: ângulo formado pelas linhas SN e NB. Indica a relação sagital da mandíbula em relação à base do crânio. O seu aumento indica protrusão mandibular e a sua diminuição retrusão mandibular.

4- Co-Gn: distância entre os pontos condílio (Co) e gnátio (Gn). Define o comprimento efetivo mandibular.

\subsubsection{3 - Maxilomandibular}

5- ANB: ângulo entre as linhas NA e NB. Representa o grau de discrepância sagital entre a maxila e a mandíbula. 


\subsubsection{4 - Análise estatística}

\subsubsection{1 - Erro do método}

Para a avaliação do erro intra-examinador foram traçadas e medidas novamente 20 telerradiografias escolhidas ao acaso dentre as 60 existentes na amostra. A aplicação da fórmula proposta por DAHLBERG ${ }^{29}\left(\mathrm{Se}^{2}=\right.$ $\left.\Sigma d^{2} / 2 n\right)$ permitiu estimar a ordem de grandeza dos erros casuais. A obtenção dos erros sistemáticos procedeu-se pela aplicação do teste t pareado de acordo com BAUMRIND; FRANTZ5, GRAVELY; BENZIES 47 , HOUSTON55 e RICHARDSON 124.

\subsubsection{2 - Testes Estatísticos}

As características cefalométricas dos jovens dos grupos Classe I e Classe II foram verificadas por estatística descritiva. A comparação entre os grupos foi realizada por meio do teste $t$ independente. Os resultados foram considerados estatisticamente significantes quando $p<0,05$. 


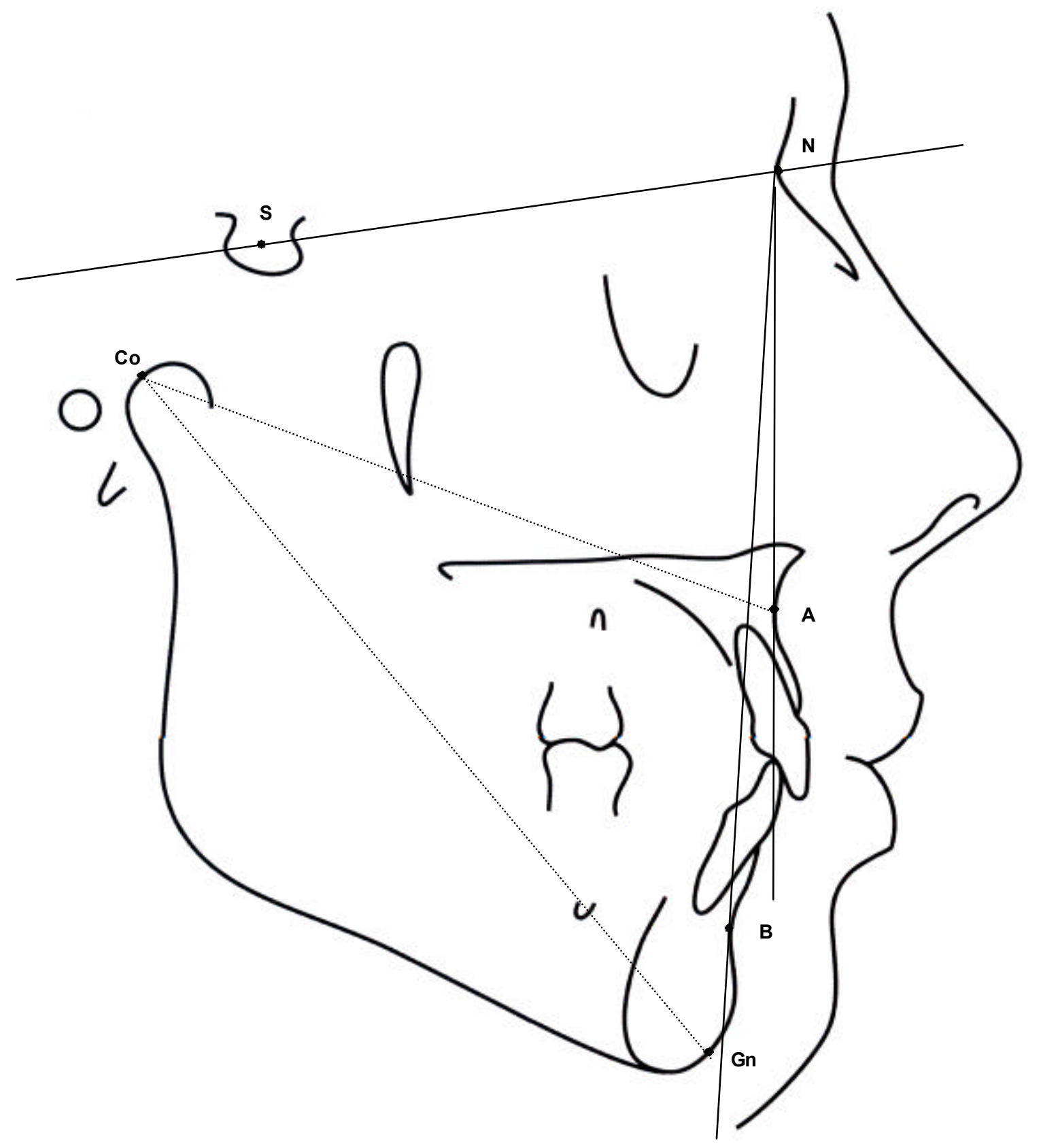

FIGURA 1 - Cefalograma com os pontos de referência e linhas utilizadas . 


\title{
4.2.2 - Radiografias Panorâmicas
}

Utilizou-se 60 radiografias panorâmicas obtidas aos 8 anos de idade dos mesmos jovens que tiveram suas telerradiografias selecionadas. Por meio destas radiografias, avaliou-se visualmente os estágios de calcificação dos segundos molares superiores e inferiores de acordo com o método proposto por NOLLA ${ }^{108}$ que se encontra descrito abaixo e ilustrado na figura 2.

\author{
Estágio 0 - ausência de cripta \\ Estágio 1 - presença de cripta \\ Estágio 2 - calcificação inicial da coroa \\ Estágio $3-1 / 3$ da coroa completa \\ Estágio $4-2 / 3$ da coroa completa \\ Estágio 5 - coroa praticamente completa \\ Estágio 6 - coroa completa \\ Estágio $7-1 / 3$ da raiz completa \\ Estágio $8-2 / 3$ da raiz completa \\ Estágio 9 - raiz praticamente completa, mas com ápice aberto \\ Estágio 10 - raiz completa e ápice fechado.
}

Quando a leitura da radiografia indicava um desenvolvimento intermediário, entre dois estágios, a avaliação era indicada com o valor 0,5. Por exemplo, se a leitura da radiografia indicava um estágio entre um terço e dois terços de raiz completa, registrava-se o valor de 7,5. 


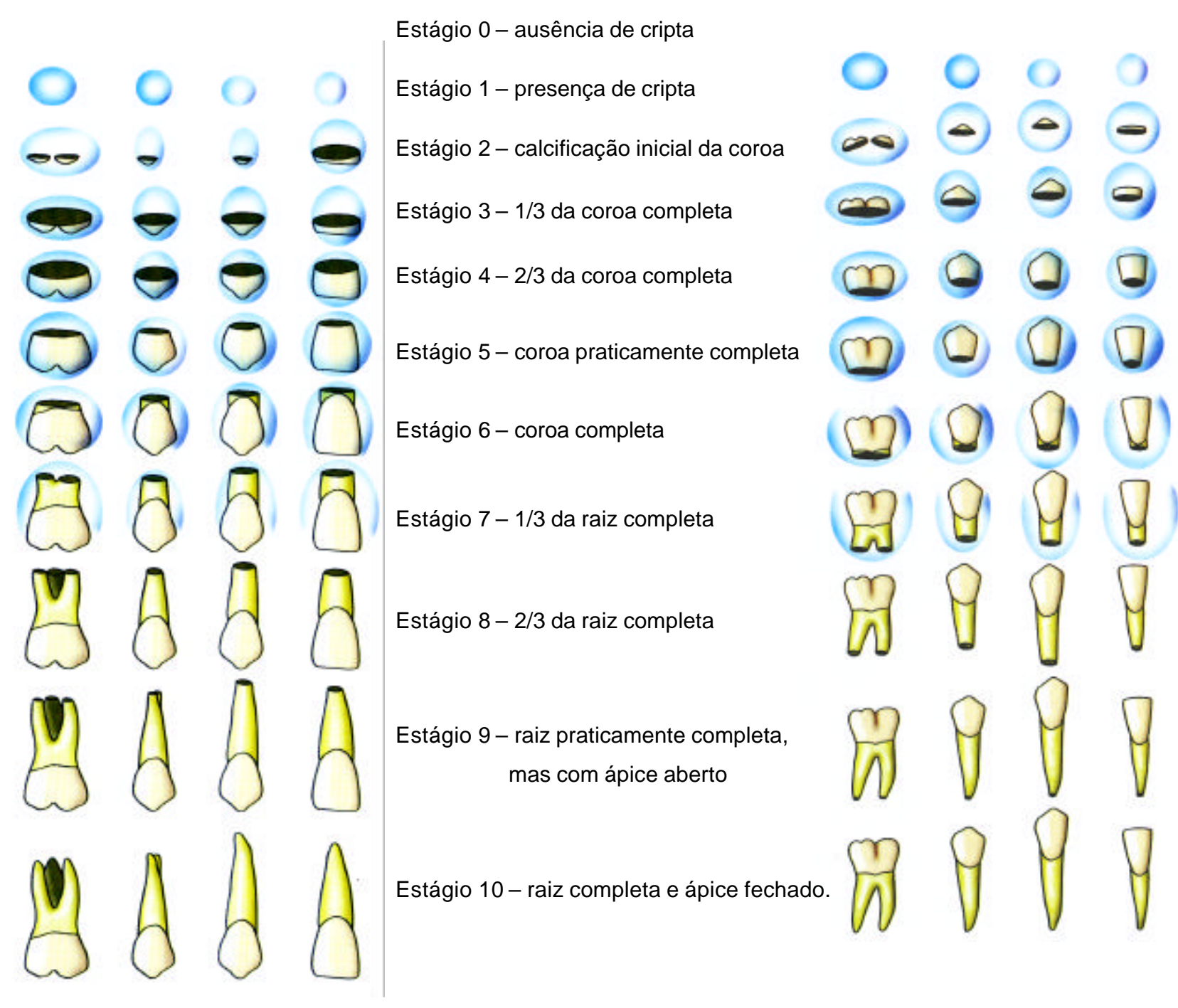

FIGURA 2 - Esquema dos estágios de desenvolvimento de Nolla para comparações radiográficas. Reproduzido de FERREIRA ${ }^{37}$. 


\subsubsection{1 - Análise estatística}

\subsubsection{1 - Erro do método}

A confiabilidade e precisão deste método foram verificadas pelo coeficiente Kappa em 20 radiografias selecionadas aleatoriamente nas quais os estágios de calcificação dos segundos molares foram reavaliados. Houve $65 \%$ de concordância entre as categorias o que corresponde a um valor de coeficiente Kappa de 0,55. De acordo com LANDIS; KOCH80 este valor é considerado satisfatório em uma avaliação de concordância entre dados categóricos. Nas duas avaliações, os valores dos estágios de calcificação de Nolla nunca excederam a um estágio.

\subsubsection{2 - Teste estatístico}

Para verificar a existência de diferença estatisticamente significante entre os grupos, foi realizado o teste não paramétrico de Mann-Whitney. Os resultados foram considerados estatisticamente significantes quando $p<0,05$.

\subsection{3 - Análise de Correlação entre as grandezas cefalométricas estudadas e os estágios de calcificação dos segundos molares permanentes}

Após a mensuração das grandezas cefalométricas SNA, SNB, ANB, Co-A e Co-Gn em todas as telerradiografias e a obtenção dos estágios de calcificação dos segundos molares permanentes nas radiografias panorâmicas, verificoutse a existência de correlação entre estas duas variáveis nos grupos com relação molar de Classe I e II de Angle por meio do teste de correlação de Pearson. 


\subsection{4 - Modelos de Gesso}

Foram avaliados 527 pares de modelos de gesso para avaliar a seqüência e cronologia de erupção dos dentes permanentes nos dois grupos considerados. A seleção dos modelos foi realizada pelo método transversal. Por este método, as idades médias de erupção de cada dente são obtidas por meio da análise de vários modelos em uma mesma faixa etária, fornecendo assim uma proporção de dentes irrompidos para cada idade. Desde que se utilize uma análise estatística adequada, este método pode ser utilizado com a mesma segurança do método longitudinal ${ }^{17}$.

Todos os exames foram realizados por um mesmo examinador, a fim de que fossem excluídas as possibilidades de variação no critério da análise segundo as interpretações pessoais.

Os dentes foram considerados irrompidos, quando qualquer porção da coroa estivesse visível112, 142, 150.

A idade de erupção dos dentes permanentes foi determinada pelo método de Karber, modificado por HAYES; MANTEL 53 que recomendam a utilização deste método pela sua maior simplicidade e pelas boas estimativas conseguidas por meio dele. A aplicação do método de Karber exige que as idades testadas cubram praticamente todo o intervalo de erupção dos dentes permanentes ${ }^{19}$. Por isso, estabeleceu-se que a idade mínima dos jovens da amostra deveria ser de 5 anos e a idade máxima de 13 anos.

O número de modelos de gesso examinados pode variar entre uma idade e outra, desde que essa variação não seja acentuada ${ }^{17}$.

As fórmulas estatísticas utilizadas para cálculo da idade média de erupção de cada dente, desvio padrão da idade média e erro padrão foram 
elaboradas a partir da fórmula original do método de Karber, com as devidas adaptações devido ao fato de se ter trabalhado com intervalos anuais e não mensais. As planilhas foram todas montadas no programa Excel.

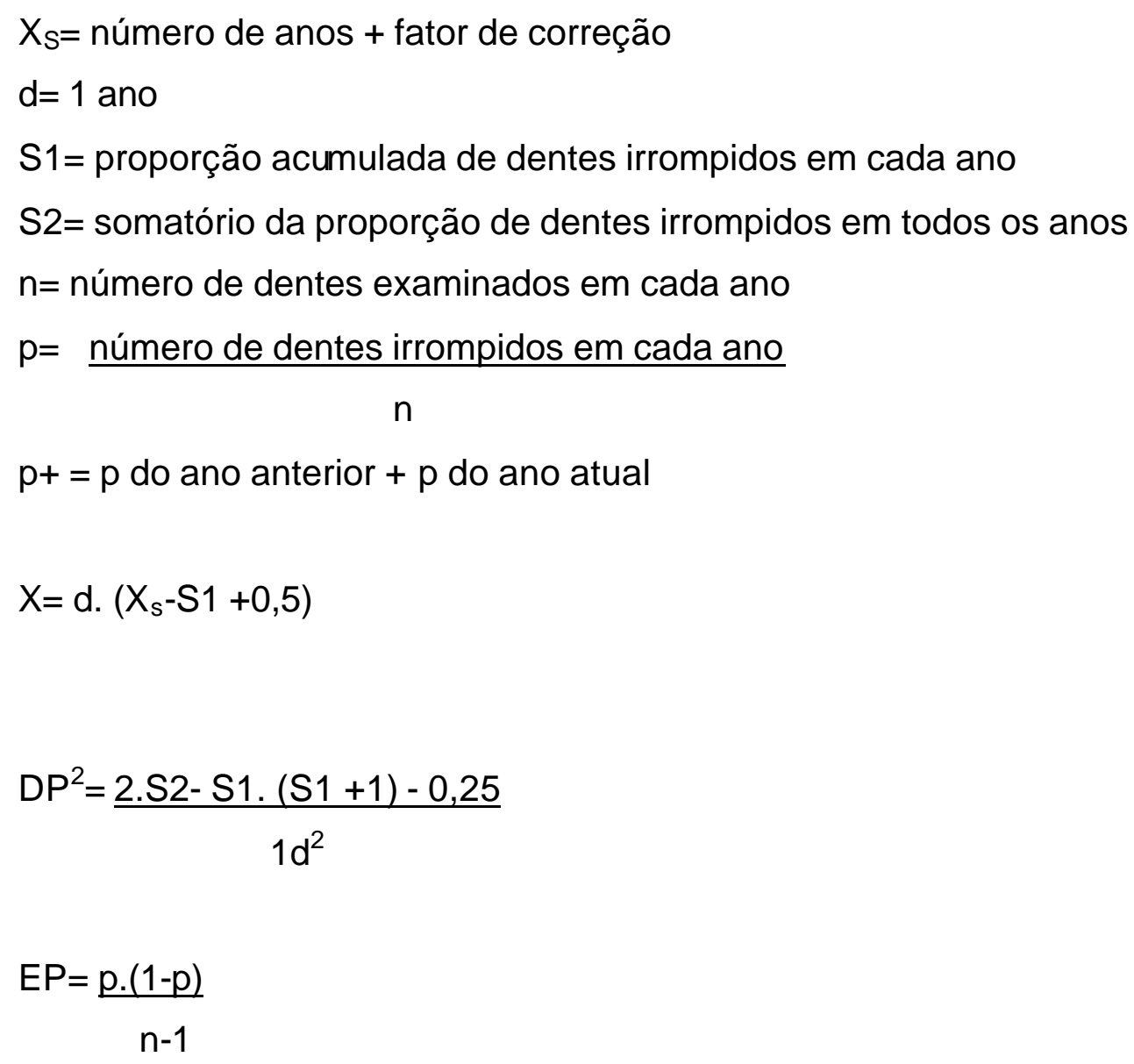

A análise estatística por meio do teste $\mathrm{t}$ independente foi realizada para comparar a idade média de erupção de cada dente permanente entre os indivíduos com Classe I e Classe II de Angle, bem como as possíveis diferenças entre os gêneros, entre os arcos e hemi-arcos dentários. Os resultados foram considerados estatisticamente significantes quando $p<0,05$. 
5. Resultados 


\section{RESULTADOS}

Os resultados estão apresentados nas tabelas seguintes. Na tabela 7 estão dispostos os resultados da comparação entre os grupos Classe I e Classe II nas variáveis cefalométricas estudadas. As tabelas 8 e 9 apresentam os resultados das comparações entre os gêneros nas mesmas grandezas cefalométricas. Na tabela 10 estão demonstrados os resultados do erro intra-examinador. As tabelas 11 e 12 apresentam os resultados do teste não paramétrico de Mann-Whitney realizado para a comparação dos estágios de calcificação dos segundos molares, respectivamente, entre a Classe I e a Classe II e entre os gêneros. As tabelas 13, 14, 15 e 16 evidenciam os resultados dos testes de correlação de Pearson entre os estágios de calcificação dos segundos molares $e$ as grandezas cefalométricas. A tabela 17 evidencia os resultados do teste $t$ independente entre as idades médias de erupção de todos os dentes permanentes nos grupos Classe I e Classe II. As tabelas 18 e 19 apresentam os resultados da comparação entre os gêneros, das idades de erupção de cada dente permanente, respectivamente na Classe I e Classe II. Nas tabelas 20 e 21 são apresentados os resultados da comparação entre os hemi-arcos dentários, respectivamente no grupo Classe I e no grupo Classe II. Finalmente, nas tabelas 22 e 23 encontram-se os resultados da comparação entre os arcos dentários, no grupo Classe I e no grupo Classe II.

Os valores em negrito foram estatisticamente significantes para $p<0,05$. 
TABELA 7 - Resultados do teste t independente entre as variáveis do grupo Classe I e do grupo Classe II.

\begin{tabular}{c|c|c|c|c|c|c}
\hline \multirow{2}{*}{ VARIÁVEIS } & \multicolumn{2}{|c|}{ CLASSE I } & \multicolumn{2}{c|}{ CLASSE II } & \multirow{2}{*}{ Dif. } & \multirow{2}{*}{$p$} \\
\cline { 2 - 5 } & MÉDIA & D.P. & MÉDIA & D.P. & & \\
\hline SNA & 80,6500 & 3,5963 & 79,5667 & 2,8549 & 1,0833 & 0,2013 \\
\hline SNB & $\mathbf{7 7 , 0 6 6 7}$ & $\mathbf{3 , 6 0 9 7}$ & $\mathbf{7 4 , 9 5 0 0}$ & $\mathbf{3 , 5 7 5 2}$ & $\mathbf{2 , 1 1 6 7}$ & $\mathbf{0 , 0 2 6 1}$ \\
\hline ANB & $\mathbf{3 , 5 8 3 3}$ & $\mathbf{2 , 0 0 4 7}$ & $\mathbf{4 , 6 1 6 7}$ & $\mathbf{1 , 9 6 3 8}$ & $\mathbf{- 1 , 0 3 3 3}$ & $\mathbf{0 , 0 4 8 3}$ \\
\hline Co-A & $\mathbf{8 1 , 6 8 3 3}$ & $\mathbf{4 , 6 7 2 9}$ & $\mathbf{8 4 , 8 5 0 0}$ & $\mathbf{4 , 2 3 8 9}$ & $\mathbf{- 3 , 1 6 6 7}$ & $\mathbf{0 , 0 0 7 9}$ \\
\hline Co-Gn & 103,8667 & 4,6143 & 104,6000 & 4,4361 & $-0,7333$ & 0,5327
\end{tabular}

TABELA 8 - Resultados do teste $t$ independente entre as variáveis do grupo Classe I dividido quanto ao gênero para avaliar a presença de dimorfismo entre os gêneros.

\begin{tabular}{c|c|c|c|c|c|c}
\hline \multirow{2}{*}{ VARIÁVEIS } & \multicolumn{2}{|c|}{ MASCULINO } & \multicolumn{2}{c|}{ FEMININO } & \multirow{2}{*}{ Dif. } & \multirow{2}{*}{$p$} \\
\cline { 2 - 5 } & MÉDIA & D.P. & MÉDIA & D.P. & & \\
\hline SNA & 81,5000 & 3,9731 & 79,8000 & 3,0752 & 1,7000 & 0,2006 \\
\hline SNB & 77,9333 & 3,9949 & 76,2000 & 3,0694 & 1,7333 & 0,1934 \\
\hline ANB & 3,5667 & 1,5221 & 3,6000 & 2,4509 & $-0,0333$ & 0,9646 \\
\hline Co-A & 82,2667 & 5,1474 & 81,1000 & 4,2435 & 1,1667 & 0,5037 \\
\hline Co-Gn & 105,0000 & 5,0000 & 102,7333 & 4,0438 & 2,2667 & 0,1830 \\
\hline
\end{tabular}

TABELA 9 - Resultados do teste $t$ independente entre as variáveis do grupo Classe II dividido quanto ao gênero para avaliar a presença de dimorfismo entre os gêneros.

\begin{tabular}{c|c|c|c|c|c|c}
\hline \multirow{2}{*}{ VARIÁVEIS } & \multicolumn{2}{|c|}{ MASCULINO } & \multicolumn{2}{c|}{ FEMININO } & \multirow{2}{*}{ Dif. } & \multirow{2}{*}{$p$} \\
\cline { 2 - 5 } & MÉDIA & D.P. & MÉDIA & D.P. & & \\
\hline SNA & 79,8000 & 2,4480 & 79,3333 & 3,2823 & 0,4667 & 0,6623 \\
\hline SNB & 74,6667 & 3,2440 & 75,2333 & 3,9725 & $-0,5667$ & 0,6719 \\
\hline ANB & 5,1333 & 2,1168 & 4,1000 & 1,7134 & 1,0333 & 0,1528 \\
\hline Co-A & 86,2667 & 4,5625 & 83,4333 & 3,4788 & 2,8333 & 0,0660 \\
\hline Co-Gn & $\mathbf{1 0 6 , 2 3 3 3}$ & $\mathbf{4 , 0 6 5 8}$ & $\mathbf{1 0 2 , 9 6 6 7}$ & $\mathbf{4 , 3 0 3 1}$ & $\mathbf{3 , 2 6 6 7}$ & $\mathbf{0 , 0 4 1 4}$ \\
\hline
\end{tabular}


TABELA 10 - Análise do erro intra-examinador. Apresentação dos erros casuais, das médias, dos desvios padrão e nível de significância estatística dos erros sistemáticos, entre os traçados repetidos.

\begin{tabular}{c|c|c|c|c|c|c|c}
\hline \multirow{2}{*}{ VARIÁVEIS } & \multicolumn{2}{|c|}{$1^{\underline{a}}$ MEDIÇÃO } & \multicolumn{2}{c|}{$2^{\underline{a}}$ MEDIČÃO } & \multirow{2}{*}{ Dif. } & Dahlberg & \multirow{2}{*}{$p$} \\
\cline { 2 - 5 } & MÉDIA & D.P. & MÉDIA & D.P. & & & \\
\hline SNA & 79,0750 & 2,6521 & 79,3000 & 2,6278 & $-0,2250$ & 0,7458 & 0,0828 \\
\hline SNB & $\mathbf{7 4 , 1 2 5 0}$ & $\mathbf{3 , 3 2 8 0}$ & $\mathbf{7 4 , 6 5 0 0}$ & $\mathbf{3 , 0 4 4 0}$ & $\mathbf{- 0 , 5 2 5 0}$ & $\mathbf{0 , 7 2 0 2}$ & $\mathbf{0 , 0 1 6 7}$ \\
\hline ANB & 4,7000 & 1,6173 & 4,6500 & 1,6392 & 0,0500 & 0,3708 & 0,6809 \\
\hline Co-A & 83,8500 & 4,3350 & 84,1750 & 3,7567 & $-0,3250$ & 0,8838 & 0,2550 \\
\hline Co-Gn & 103,5250 & 3,8439 & 104,1000 & 3,5229 & $-0,5750$ & 1,2723 & 0,1579 \\
\hline
\end{tabular}

TABELA 11 - Resultado do teste não paramétrico de Mann-Whitney entre os estágios de calcificação dos segundos molares dos grupos Classe I e Classe II.

\begin{tabular}{c|c|c|c}
\hline DENTE & $\begin{array}{c}\text { CLASSE I } \\
\text { POSTO MÉDIO }\end{array}$ & $\begin{array}{c}\text { CLASSE II } \\
\text { POSTO MÉDIO }\end{array}$ & $\mathbf{p}$ \\
\hline $\mathbf{1 7}$ & 30,2000 & 30,8000 & 0,8903 \\
\hline $\mathbf{2 7}$ & 30,2000 & 30,8000 & 0,8903 \\
\hline $\mathbf{3 7}$ & 33,4167 & 27,5833 & 0,1877 \\
\hline $\mathbf{4 7}$ & 33,4167 & 27,5833 & 0,1877 \\
\hline
\end{tabular}

TABELA 12 - Resultado do teste não paramétrico de Mann-Whitney entre os estágios de calcificação dos segundos molares dos gêneros masculino e feminino nos grupos Classe I e Classe II para avaliar a presença de dimorfismo entre os gêneros.

\begin{tabular}{c|c|c|c}
\hline GRUPO & $\begin{array}{c}\text { MASCULINO } \\
\text { POSTO MÉDIO }\end{array}$ & $\begin{array}{c}\text { FEMININO } \\
\text { POSTO MÉDIO }\end{array}$ & $\mathbf{p}$ \\
\hline CLASSE I & $\mathbf{4 8 , 8 0 0 0}$ & $\mathbf{7 2 , 2 0 0 0}$ & $\mathbf{0 , 0 0 0 1}$ \\
\hline CLASSE II & 58,9333 & 62,0667 & 0,6124 \\
\hline
\end{tabular}


TABELA 13 - Resultados do teste de correlação de Pearson entre os estágios de calcificação dos segundos molares superiores e as grandezas cefalométricas do Grupo Classe I.

\begin{tabular}{c|c|c}
\hline VARIÁVEIS & $\mathbf{r}$ & $\mathbf{p}$ \\
\hline SNA & $-0,0879$ & 0,6439 \\
\hline SNB & 0,0153 & 0,9359 \\
\hline ANB & $-0,1853$ & 0,3267 \\
\hline Co-A & 0,2023 & 0,2836 \\
\hline Co-Gn & 0,3535 & 0,0552
\end{tabular}

TABELA 14 - Resultados do teste de correlação de Pearson entre os estágios de calcificação dos segundos molares inferiores e as grandezas cefalométricas do Grupo Classe I.

\begin{tabular}{c|c|c}
\hline VARIÁVEIS & $\mathbf{r}$ & $\mathbf{p}$ \\
\hline SNA & $-0,2428$ & 0,1960 \\
\hline SNB & $-0,1560$ & 0,4101 \\
\hline ANB & $-0,1546$ & 0,4145 \\
\hline Co-A & 0,1013 & 0,5942 \\
\hline Co-Gn & 0,1067 & 0,5745
\end{tabular}

TABELA 15 - Resultados do teste de correlação de Pearson entre os estágios de calcificação dos segundos molares superiores e as grandezas cefalométricas do Grupo Classe II.

\begin{tabular}{c|c|c}
\hline VARIÁVEIS & $\mathbf{r}$ & $\mathbf{p}$ \\
\hline SNA & $-0,1031$ & 0,5874 \\
\hline SNB & $-0,1493$ & 0,4308 \\
\hline ANB & 0,1219 & 0,5209 \\
\hline Co-A & 0,0994 & 0,6009 \\
\hline Co-Gn & 0,2049 & 0,2773
\end{tabular}


TABELA 16 - Resultados do teste de correlação de Pearson entre os estágios de calcificação dos segundos molares inferiores e as grandezas cefalométricas do Grupo Classe II.

\begin{tabular}{c|c|c}
\hline VARIÁVEIS & $\mathbf{r}$ & $\mathbf{p}$ \\
\hline SNA & $-0,2066$ & 0,2731 \\
\hline SNB & $-0,1247$ & 0,5112 \\
\hline ANB & $-0,0733$ & 0,7001 \\
\hline Co-A & $-0,1019$ & 0,5920 \\
\hline Co-Gn & 0,0444 & 0,8156
\end{tabular}


TABELA 17 - Idade média de erupção, desvio padrão e erro padrão de cada dente permanente nos grupos Classe I e Classe II e 0 nível de significância estatística quando aplicado o teste $\mathrm{t}$ independente.

\begin{tabular}{c|c|c|c|c|c|c|c}
\hline \multirow{2}{*}{ DENTE } & \multicolumn{3}{|c|}{ CLASSE I } & \multicolumn{3}{c|}{ CLASSE II } & p \\
\cline { 2 - 8 } & MÉDIA & D.P. & E. P. & MÉDIA & D. P. & E. P & \\
\hline $\mathbf{1 7}$ & $\mathbf{1 1 , 4 0 1 6}$ & $\mathbf{1 , 3 7 1 2}$ & $\mathbf{0 , 1 3 5 3}$ & $\mathbf{1 2 , 0 4 6 6}$ & $\mathbf{1 , 5 0 7 0}$ & $\mathbf{0 , 1 4 8 6}$ & $\mathbf{0 , 0 0 1 5}$ \\
\hline $\mathbf{1 6}$ & 6,2666 & 1,1234 & 0,0913 & 6,2333 & 1,2297 & 0,1143 & 0,8212 \\
\hline $\mathbf{1 5}$ & $\mathbf{1 0 , 3 4 6 8}$ & $\mathbf{1 , 6 9 3 2}$ & $\mathbf{0 , 1 6 0 4}$ & $\mathbf{1 1 , 0 3 3 3}$ & $\mathbf{1 , 4 9 4 0}$ & $\mathbf{0 , 1 4 2 6}$ & $\mathbf{0 , 0 0 1 5}$ \\
\hline $\mathbf{1 4}$ & 9,9022 & 1,5157 & 0,1444 & 10,2333 & 1,3585 & 0,1270 & 0,0861 \\
\hline $\mathbf{1 3}$ & 11,0193 & 1,4487 & 0,1426 & 11,2133 & 1,5982 & 0,1531 & 0,3538 \\
\hline $\mathbf{1 2}$ & 7,9333 & 1,2892 & 0,1228 & 8,1000 & 1,3747 & 0,1293 & 0,3479 \\
\hline $\mathbf{1 1}$ & 6,8000 & 1,3266 & 0,1277 & 7,0000 & 1,2909 & 0,1200 & 0,2536 \\
\hline $\mathbf{2 1}$ & 6,8666 & 1,2578 & 0,1190 & 6,9666 & 1,2775 & 0,1169 & 0,5479 \\
\hline $\mathbf{2 2}$ & 7,9666 & 1,3287 & 0,1273 & 8,0333 & 1,3780 & 0,1290 & 0,7117 \\
\hline $\mathbf{2 3}$ & $\mathbf{1 0 , 7 7 8 2}$ & $\mathbf{1 , 5 0 7 2}$ & $\mathbf{0 , 1 4 4 5}$ & $\mathbf{1 1 , 2 0 6 6}$ & $\mathbf{1 , 5 8 8 6}$ & $\mathbf{0 , 1 5 4 2}$ & $\mathbf{0 , 0 4 3 6}$ \\
\hline $\mathbf{2 4}$ & 9,7011 & 1,5321 & 0,1471 & 10,0666 & 1,7688 & 0,1647 & 0,0989 \\
\hline $\mathbf{2 5}$ & 10,5758 & 1,5042 & 0,1479 & 10,9333 & 1,6316 & 0,1561 & 0,0964 \\
\hline $\mathbf{2 6}$ & 6,3333 & 1,1642 & 0,0913 & 6,1666 & 1,2405 & 0,1162 & 0,2583 \\
\hline $\mathbf{2 7}$ & $\mathbf{1 1 , 3 2 0 5}$ & $\mathbf{1 , 2 8 0 8}$ & $\mathbf{0 , 1 1 8 5}$ & $\mathbf{1 2 , 0 1 3 3}$ & $\mathbf{1 , 5 1 8 7}$ & $\mathbf{0 , 1 4 9 3}$ & $\mathbf{0 , 0 0 0 3}$ \\
\hline $\mathbf{3 7}$ & $\mathbf{1 1 , 0 1 5 8}$ & $\mathbf{1 , 3 5 2 3}$ & $\mathbf{0 , 1 3 0 5}$ & $\mathbf{1 1 , 6 6 6 6}$ & $\mathbf{1 , 4 2 2 0}$ & $\mathbf{0 , 1 3 6 4}$ & $\mathbf{0 , 0 0 0 7}$ \\
\hline $\mathbf{3 6}$ & 6,1666 & 1,2133 & 0,1088 & 6,2000 & 1,1661 & 0,1017 & 0,8183 \\
\hline $\mathbf{3 5}$ & 10,6904 & 1,6219 & 0,1580 & 11,1000 & 1,3988 & 0,1360 & 0,0505 \\
\hline $\mathbf{3 4}$ & $\mathbf{9 , 7 0 2 2}$ & $\mathbf{1 , 4 2 0 6}$ & $\mathbf{0 , 1 3 6 5}$ & $\mathbf{1 0 , 3 6 6 6}$ & $\mathbf{1 , 4 4 8 7}$ & $\mathbf{0 , 1 3 9 3}$ & $\mathbf{0 , 0 0 0 8}$ \\
\hline $\mathbf{3 3}$ & 9,8034 & 1,5827 & 0,1543 & 10,0666 & 1,5902 & 0,1533 & 0,2271 \\
\hline $\mathbf{3 2}$ & 7,1333 & 1,2840 & 0,1222 & 7,1333 & 1,3840 & 0,1286 & 1,0000 \\
\hline $\mathbf{3 1}$ & 6,2000 & 1,1075 & 0,0853 & 6,2666 & 1,2092 & 0,1089 & 0,6314 \\
\hline $\mathbf{4 1}$ & 6,1666 & 1,1279 & 0,0911 & 6,1000 & 1,2476 & 0,1156 & 0,6530 \\
\hline $\mathbf{4 2}$ & 7,0666 & 1,3399 & 0,1295 & 7,1333 & 1,3097 & 0,1216 & 0,7052 \\
\hline $\mathbf{4 3}$ & 9,8689 & 1,5021 & 0,1467 & 9,9333 & 1,4360 & 0,1397 & 0,7474 \\
\hline $\mathbf{4 4}$ & 9,8022 & 1,4948 & 0,1456 & 10,2000 & 1,5790 & 0,1490 & 0,0569 \\
\hline $\mathbf{4 5}$ & $\mathbf{1 0 , 5 8 4 9}$ & $\mathbf{1 , 6 2 3 4}$ & $\mathbf{0 , 1 5 7 3}$ & $\mathbf{1 1 , 1 6 6 6}$ & $\mathbf{1 , 4 3 9 5}$ & $\mathbf{0 , 1 3 9 6}$ & $\mathbf{0 , 0 0 6 0}$ \\
\hline $\mathbf{4 6}$ & 6,2000 & 1,1661 & 0,1017 & 6,2666 & 1,1527 & 0,0990 & 0,6411 \\
\hline $\mathbf{4 7}$ & $\mathbf{1 0 , 8 8 2 5}$ & $\mathbf{1 , 4 4 2 9}$ & $\mathbf{0 , 1 4 1 2}$ & $\mathbf{1 1 , 7 0 0 0}$ & $\mathbf{1 , 5 5 2 4}$ & $\mathbf{0 , 1 4 8 9}$ & $\mathbf{0 , 0 0 0 1}$ \\
& & & & & & & \\
\hline
\end{tabular}


TABELA 18 - Idade média de erupção, desvio padrão e erro padrão de cada dente permanente nos gêneros masculino e feminino no grupo Classe I e o nível de significância estatística quando aplicado o teste t independente entre os gêneros.

\begin{tabular}{c|c|c|c|c|c|c|c}
\hline \multirow{2}{*}{ DENTE } & \multicolumn{3}{|c|}{ MASCULINO } & \multicolumn{3}{c|}{ FEMININO } & p \\
\cline { 2 - 8 } & MÉDIA & D.P. & E. P. & MÉDIA & D. P. & E. P & \\
\hline $\mathbf{1 7}$ & 11,6315 & 1,4553 & 0,2196 & 11,2363 & 1,2647 & 0,1678 & 0,1547 \\
\hline $\mathbf{1 6}$ & 6,2941 & 1,0989 & 0,1139 & 6,2410 & 1,1472 & 0,1489 & 0,7763 \\
\hline $\mathbf{1 5}$ & 10,4658 & 1,3931 & 0,1875 & 10,1510 & 1,9462 & 0,2633 & 0,3327 \\
\hline $\mathbf{1 4}$ & 10,0068 & 1,2753 & 0,1613 & 9,7546 & 1,7153 & 0,2434 & 0,3892 \\
\hline $\mathbf{1 3}$ & $\mathbf{1 1 , 3 5 4 6}$ & $\mathbf{1 , 3 0 9 2}$ & $\mathbf{0 , 1 7 7 3}$ & $\mathbf{1 0 , 6 6 2 8}$ & $\mathbf{1 , 5 1 5 8}$ & $\mathbf{0 , 2 1 6 8}$ & $\mathbf{0 , 0 1 4 9}$ \\
\hline $\mathbf{1 2}$ & 8,1458 & 1,2245 & 0,1613 & 7,6945 & 1,3289 & 0,1902 & 0,0730 \\
\hline $\mathbf{1 1}$ & $\mathbf{7 , 0 7 3 5}$ & $\mathbf{1 , 1 9 2 0}$ & $\mathbf{0 , 1 4 6 9}$ & $\mathbf{6 , 3 9 4 1}$ & $\mathbf{1 , 3 3 8 3}$ & $\mathbf{0 , 1 9 3 3}$ & $\mathbf{0 , 0 0 5 9}$ \\
\hline $\mathbf{2 1}$ & $\mathbf{7 , 0 7 3 5}$ & $\mathbf{1 , 1 9 2 0}$ & $\mathbf{0 , 1 4 6 9}$ & $\mathbf{6 , 5 9 8 9}$ & $\mathbf{1 , 2 9 1 8}$ & $\mathbf{0 , 1 8 0 7}$ & $\mathbf{0 , 0 4 2 7}$ \\
\hline $\mathbf{2 2}$ & 8,2046 & 1,2866 & 0,1717 & 7,7611 & 1,3671 & 0,1967 & 0,0916 \\
\hline $\mathbf{2 3}$ & 11,0091 & 1,4643 & 0,2003 & 10,4622 & 1,3896 & 0,1996 & 0,0553 \\
\hline $\mathbf{2 4}$ & 9,7090 & 1,4455 & 0,1897 & 9,6819 & 1,6095 & 0,2316 & 0,9254 \\
\hline $\mathbf{2 5}$ & 10,6167 & 1,4320 & 0,2007 & 10,5817 & 1,5263 & 0,2198 & 0,9063 \\
\hline $\mathbf{2 6}$ & 6,4784 & 1,2313 & 0,1399 & 6,1538 & 1,0630 & 0,1041 & 0,0628 \\
\hline $\mathbf{2 7}$ & 11,5990 & 1,3286 & 0,2058 & 11,1071 & 1,1753 & 0,1480 & 0,0544 \\
\hline $\mathbf{3 7}$ & $\mathbf{1 1 , 3 0 0 7}$ & $\mathbf{1 , 3 7 6 8}$ & $\mathbf{0 , 2 0 1 1}$ & $\mathbf{1 0 , 7 5 3 4}$ & $\mathbf{1 , 3 0 9 4}$ & $\mathbf{0 , 1 8 3 6}$ & $\mathbf{0 , 0 4 7 0}$ \\
\hline $\mathbf{3 6}$ & 6,3450 & 1,1659 & 0,1399 & 5,9483 & 1,2200 & 0,1498 & 0,0535 \\
\hline $\mathbf{3 5}$ & 10,8006 & 1,3625 & 0,1886 & 10,6381 & 1,8040 & 0,2482 & 0,6038 \\
\hline $\mathbf{3 4}$ & $\mathbf{9 , 9 8 4 2}$ & $\mathbf{1 , 5 0 4 7}$ & $\mathbf{0 , 2 0 5 0}$ & $\mathbf{9 , 3 9 9 6}$ & $\mathbf{1 , 2 8 4 3}$ & $\mathbf{0 , 1 8 4 5}$ & $\mathbf{0 , 0 3 6 2}$ \\
\hline $\mathbf{3 3}$ & $\mathbf{1 0 , 4 2 8 8}$ & $\mathbf{1 , 5 6 3 2}$ & $\mathbf{0 , 2 1 7 1}$ & $\mathbf{9 , 1 1 2 4}$ & $\mathbf{1 , 3 3 2 6}$ & $\mathbf{0 , 1 9 1 8}$ & $\mathbf{0 , 0 0 0 0}$ \\
\hline $\mathbf{3 2}$ & $\mathbf{7 , 3 9 0 1}$ & $\mathbf{1 , 3 1 3 0}$ & $\mathbf{0 , 1 7 3 7}$ & $\mathbf{6 , 7 5 8 2}$ & $\mathbf{1 , 2 1 2 0}$ & $\mathbf{0 , 1 7 0 7}$ & $\mathbf{0 , 0 1 0 5}$ \\
\hline $\mathbf{3 1}$ & 6,2941 & 1,0989 & 0,1139 & 6,0871 & 1,1013 & 0,1236 & 0,2169 \\
\hline $\mathbf{4 1}$ & 6,2941 & 1,0989 & 0,1139 & 6,0205 & 1,1343 & 0,1382 & 0,1265 \\
\hline $\mathbf{4 2}$ & $\mathbf{7 , 3 3 1 3}$ & $\mathbf{1 , 3 5 1 1}$ & $\mathbf{0 , 1 7 9 8}$ & $\mathbf{6 , 7 5 2 7}$ & $\mathbf{1 , 2 7 0 7}$ & $\mathbf{0 , 1 8 3 4}$ & $\mathbf{0 , 0 2 5 8}$ \\
\hline $\mathbf{4 3}$ & $\mathbf{1 0 , 3 5 1 8}$ & $\mathbf{1 , 5 0 7 6}$ & $\mathbf{0 , 2 0 7 8}$ & $\mathbf{9 , 3 1 7 2}$ & $\mathbf{1 , 3 3 0 0}$ & $\mathbf{0 , 1 8 8 2}$ & $\mathbf{0 , 0 0 0 4}$ \\
\hline $\mathbf{4 4}$ & $\mathbf{1 0 , 2 2 6 3}$ & $\mathbf{1 , 6 1 3 8}$ & $\mathbf{0 , 2 2 0 7}$ & $\mathbf{9 , 3 1 2 4}$ & $\mathbf{1 , 2 2 1 0}$ & $\mathbf{0 , 1 6 5 2}$ & $\mathbf{0 , 0 0 1 2}$ \\
\hline $\mathbf{4 5}$ & $\mathbf{1 0 , 9 5 0 7}$ & $\mathbf{1 , 3 9 0 5}$ & $\mathbf{0 , 1 9 7 0}$ & $\mathbf{1 0 , 1 4 0 8}$ & $\mathbf{1 , 7 4 9 4}$ & $\mathbf{0 , 2 3 4 3}$ & $\mathbf{0 , 0 0 9 4}$ \\
\hline $\mathbf{4 6}$ & $\mathbf{6 , 4 1 1 7}$ & $\mathbf{1 , 1 1 4 5}$ & $\mathbf{0 , 1 2 3 0}$ & $\mathbf{5 , 9 5 3 8}$ & $\mathbf{1 , 1 6 2 6}$ & $\mathbf{0 , 1 4 9 2}$ & $\mathbf{0 , 0 1 9 1}$ \\
\hline $\mathbf{4 7}$ & 11,1025 & 1,4620 & 0,2107 & 10,6675 & 1,4246 & 0,2053 & 0,1416
\end{tabular}


TABELA 19 - Idade média de erupção, desvio padrão e erro padrão de cada dente permanente nos gêneros masculino e feminino no grupo Classe II e o nível de significância estatística quando aplicado o teste t independente entre os gêneros.

\begin{tabular}{c|c|c|c|c|c|c|c}
\hline \multirow{2}{*}{ DENTE } & \multicolumn{3}{|c|}{ MASCULINO } & \multicolumn{3}{c|}{ FEMININO } & p \\
\cline { 2 - 8 } & MÉDIA & D.P. & E. P. & MÉDIA & D. P. & E. P & \\
\hline $\mathbf{1 7}$ & 12,1459 & 1,4269 & 0,1991 & 12,0037 & 1,6127 & 0,2324 & 0,6433 \\
\hline $\mathbf{1 6}$ & 6,0630 & 1,2834 & 0,1750 & 6,4375 & 1,1162 & 0,1280 & 0,0870 \\
\hline $\mathbf{1 5}$ & 10,7924 & 1,4775 & 0,1932 & 11,3025 & 1,4396 & 0,2051 & 0,0729 \\
\hline $\mathbf{1 4}$ & 10,2352 & 1,2380 & 0,1556 & 10,2157 & 1,4705 & 0,2063 & 0,9383 \\
\hline $\mathbf{1 3}$ & 11,3106 & 1,5723 & 0,2126 & 11,0396 & 1,5612 & 0,2183 & 0,3749 \\
\hline $\mathbf{1 2}$ & 8,0588 & 1,2934 & 0,1687 & 8,1538 & 1,4707 & 0,2079 & 0,7223 \\
\hline $\mathbf{1 1}$ & 7,0446 & 1,1525 & 0,1399 & 6,9821 & 1,4204 & 0,1949 & 0,7955 \\
\hline $\mathbf{2 1}$ & 6,9821 & 1,1258 & 0,1292 & 6,9821 & 1,4204 & 0,1949 & 1,0000 \\
\hline $\mathbf{2 2}$ & 7,9963 & 1,2704 & 0,1616 & 8,0824 & 1,5004 & 0,2125 & 0,7473 \\
\hline $\mathbf{2 3}$ & 11,0549 & 1,5418 & 0,2087 & 11,3832 & 1,6172 & 0,2336 & 0,2947 \\
\hline $\mathbf{2 4}$ & 9,8245 & 1,8075 & 0,2299 & 10,3490 & 1,6656 & 0,2369 & 0,1132 \\
\hline $\mathbf{2 5}$ & $\mathbf{1 0 , 4 9 8 2}$ & $\mathbf{1 , 6 2 3 9}$ & $\mathbf{0 , 2 1 5 8}$ & $\mathbf{1 1 , 4 4 6 1}$ & $\mathbf{1 , 4 5 2 1}$ & $\mathbf{0 , 2 0 1 0}$ & $\mathbf{0 , 0 0 1 7}$ \\
\hline $\mathbf{2 6}$ & 5,9915 & 1,2568 & 0,1693 & 6,3605 & 1,7660 & 0,1494 & 0,1042 \\
\hline $\mathbf{2 7}$ & 12,1537 & 1,4640 & 0,2004 & 11,8703 & 1,5655 & 0,2283 & 0,3531 \\
\hline $\mathbf{3 7}$ & 11,8156 & 1,3852 & 0,1906 & 11,5025 & 1,4601 & 0,2053 & 0,2654 \\
\hline $\mathbf{3 6}$ & 6,0378 & 1,1786 & 0,1484 & 6,3750 & 1,1110 & 0,1250 & 0,0832 \\
\hline $\mathbf{3 5}$ & 11,1725 & 1,4078 & 0,1905 & 11,0153 & 1,3848 & 0,2001 & 0,5705 \\
\hline $\mathbf{3 4}$ & 10,3843 & 1,5407 & 0,2034 & 10,3641 & 1,3438 & 0,1970 & 0,9438 \\
\hline $\mathbf{3 3}$ & 10,2629 & 1,6427 & 0,2168 & 9,8468 & 1,1515 & 0,2265 & 0,1870 \\
\hline $\mathbf{3 2}$ & 7,0945 & 1,3691 & 0,1745 & 7,1071 & 1,3716 & 0,1867 & 0,9594 \\
\hline $\mathbf{3 1}$ & 6,1680 & 1,1726 & 0,1489 & 6,3695 & 1,2368 & 0,1632 & 0,3631 \\
\hline $\mathbf{4 1}$ & $\mathbf{5 , 8 4 8 7}$ & $\mathbf{1 , 1 8 9 1}$ & $\mathbf{0 , 1 4 9 6}$ & $\mathbf{6 , 3 6 9 5}$ & $\mathbf{1 , 2 3 6 8}$ & $\mathbf{0 , 1 6 3 2}$ & $\mathbf{0 , 0 1 9 9}$ \\
\hline $\mathbf{4 2}$ & 7,1696 & 1,2456 & 0,1607 & 7,1071 & 1,3716 & 0,1867 & 0,8010 \\
\hline $\mathbf{4 3}$ & 10,1843 & 1,3681 & 0,1804 & 9,6263 & 1,4612 & 0,2188 & 0,0512 \\
\hline $\mathbf{4 4}$ & 10,0786 & 1,5979 & 0,2063 & 10,3435 & 1,5341 & 0,2200 & 0,3812 \\
\hline $\mathbf{4 5}$ & 11,0470 & 1,3668 & 0,1832 & 11,2256 & 1,4868 & 0,2147 & 0,5287 \\
\hline $\mathbf{4 6}$ & $\mathbf{6 , 0 2 5 2}$ & $\mathbf{1 , 1 2 2 4}$ & $\mathbf{0 , 1 2 6 1}$ & $\mathbf{6 , 5 0 0 0}$ & $\mathbf{1 , 1 1 8 0}$ & $\mathbf{0 , 1 2 9 0}$ & $\mathbf{0 , 0 0 9 3}$ \\
\hline $\mathbf{4 7}$ & 11,7568 & 1,4791 & 0,1994 & 11,7025 & 1,5287 & 0,2186 & 0,8552
\end{tabular}


TABELA 20 - Nível de significância estatística (p) quando aplicado o teste $\mathrm{t}$ independente entre as idades médias de erupção dos dentes permanentes dos lados direito e esquerdo no grupo Classe I.

\begin{tabular}{c|c|c|c|c|c|c}
\hline DENTE & MÉDIA & D. P. & DENTE & MÉDIA & D. P. & p \\
\hline $\mathbf{1 7}$ & 11,4016 & 1,3712 & $\mathbf{2 7}$ & 11,3205 & 1,2808 & 0,6519 \\
\hline $\mathbf{1 6}$ & 6,2666 & 1,1234 & $\mathbf{2 6}$ & 6,3333 & 1,1642 & 0,6030 \\
\hline $\mathbf{1 5}$ & 10,3468 & 1,6932 & $\mathbf{2 5}$ & 10,5758 & 1,5042 & 0,2931 \\
\hline $\mathbf{1 4}$ & 9,9022 & 1,5157 & $\mathbf{2 4}$ & 9,7011 & 1,5321 & 0,3298 \\
\hline $\mathbf{1 3}$ & 11,0193 & 1,4487 & $\mathbf{2 3}$ & 10,7782 & 1,5072 & 0,2347 \\
\hline $\mathbf{1 2}$ & 7,9333 & 1,2892 & $\mathbf{2 2}$ & 7,9666 & 1,3287 & 0,8515 \\
\hline $\mathbf{1 1}$ & 6,8000 & 1,3266 & $\mathbf{2 1}$ & 6,8666 & 1,2578 & 0,7049 \\
\hline $\mathbf{4 1}$ & 6,1666 & 1,1279 & $\mathbf{3 1}$ & 6,2000 & 1,1075 & 0,7850 \\
\hline $\mathbf{4 2}$ & 7,0666 & 1,3399 & $\mathbf{3 2}$ & 7,1333 & 1,2840 & 0,7063 \\
\hline $\mathbf{4 3}$ & 9,8689 & 1,5021 & $\mathbf{3 3}$ & 9,8034 & 1,5827 & 0,7597 \\
\hline $\mathbf{4 4}$ & 9,8022 & 1,4948 & $\mathbf{3 4}$ & 9,7022 & 1,4206 & 0,6155 \\
\hline $\mathbf{4 5}$ & 10,5849 & 1,6234 & $\mathbf{3 5}$ & 10,6904 & 1,6219 & 0,6346 \\
\hline $\mathbf{4 6}$ & 6,2000 & 1,1661 & $\mathbf{3 6}$ & 6,1666 & 1,2133 & 0,8183 \\
\hline $\mathbf{4 7}$ & 10,8825 & 1,4429 & $\mathbf{3 7}$ & 11,0158 & 1,3523 & 0,4888
\end{tabular}

TABELA 21 - Nível de significância estatística (p) quando aplicado o teste $\mathrm{t}$ independente entre as idades médias de erupção dos dentes permanentes dos lados direito e esquerdo no grupo Classe II.

\begin{tabular}{c|c|c|c|c|c|c}
\hline DENTE & MÉDIA & D. P. & DENTE & MÉDIA & D. P. & p \\
\hline $\mathbf{1 7}$ & 12,0466 & 1,5070 & $\mathbf{2 7}$ & 12,0133 & 1,5187 & 0,8753 \\
\hline $\mathbf{1 6}$ & 6,2333 & 1,2297 & $\mathbf{2 6}$ & 6,1666 & 1,2405 & 0,6808 \\
\hline $\mathbf{1 5}$ & 11,0333 & 1,4940 & $\mathbf{2 5}$ & 10,9333 & 1,6316 & 0,6359 \\
\hline $\mathbf{1 4}$ & 10,2333 & 1,3585 & $\mathbf{2 4}$ & 10,0666 & 1,7688 & 0,4216 \\
\hline $\mathbf{1 3}$ & 11,2133 & 1,5982 & $\mathbf{2 3}$ & 11,2066 & 1,5886 & 0,9743 \\
\hline $\mathbf{1 2}$ & 8,1000 & 1,3747 & $\mathbf{2 2}$ & 8,0333 & 1,3780 & 0,7138 \\
\hline $\mathbf{1 1}$ & 7,0000 & 1,2909 & $\mathbf{2 1}$ & 6,9666 & 1,2775 & 0,8388 \\
\hline $\mathbf{4 1}$ & 6,1000 & 1,2476 & $\mathbf{3 1}$ & 6,2666 & 1,2092 & 0,2938 \\
\hline $\mathbf{4 2}$ & 7,1333 & 1,3097 & $\mathbf{3 2}$ & 7,1333 & 1,3840 & 1,0000 \\
\hline $\mathbf{4 3}$ & 9,9333 & 1,4360 & $\mathbf{3 3}$ & 10,0666 & 1,5902 & 0,5207 \\
\hline $\mathbf{4 4}$ & 10,2000 & 1,5790 & $\mathbf{3 4}$ & 10,3666 & 1,4487 & 0,4162 \\
\hline $\mathbf{4 5}$ & 11,1666 & 1,4395 & $\mathbf{3 5}$ & 11,1000 & 1,3988 & 0,7347 \\
\hline $\mathbf{4 6}$ & 6,2666 & 1,1527 & $\mathbf{3 6}$ & 6,2000 & 1,1661 & 0,6411 \\
\hline $\mathbf{4 7}$ & 11,7000 & 1,5524 & $\mathbf{3 7}$ & 11,6666 & 1,4220 & 0,9998 \\
\hline
\end{tabular}


TABELA 22 - Nível de significância estatística (p) quando aplicado o teste t independente entre as idades médias de erupção dos dentes permanentes dos arcos superior e inferior no grupo Classe I.

\begin{tabular}{c|c|c|c|c|c|c}
\hline DENTE & MÉDIA & D. P. & DENTE & MÉDIA & D. P. & $\mathbf{p}$ \\
\hline $\mathbf{1 7}$ & $\mathbf{1 1 , 4 0 1 6}$ & $\mathbf{1 , 3 7 1 2}$ & $\mathbf{4 7}$ & $\mathbf{1 0 , 8 8 2 5}$ & $\mathbf{1 , 4 4 2 9}$ & $\mathbf{0 , 0 0 8 5}$ \\
\hline $\mathbf{1 6}$ & 6,2666 & 1,1234 & $\mathbf{4 6}$ & 6,2000 & 1,1661 & 0,6247 \\
\hline $\mathbf{1 5}$ & 10,3468 & 1,6932 & $\mathbf{4 5}$ & 10,5849 & 1,6234 & 0,2895 \\
\hline $\mathbf{1 4}$ & 9,9022 & 1,5157 & $\mathbf{4 4}$ & 9,8022 & 1,4948 & 0,6251 \\
\hline $\mathbf{1 3}$ & $\mathbf{1 1 , 0 1 9 3}$ & $\mathbf{1 , 4 4 8 7}$ & $\mathbf{4 3}$ & $\mathbf{9 , 8 6 8 9}$ & $\mathbf{1 , 5 0 2 1}$ & $\mathbf{0 , 0 0 0 0}$ \\
\hline $\mathbf{1 2}$ & $\mathbf{7 , 9 3 3 3}$ & $\mathbf{1 , 2 8 9 2}$ & $\mathbf{4 2}$ & $\mathbf{7 , 0 6 6 6}$ & $\mathbf{1 , 3 3 9 9}$ & $\mathbf{0 , 0 0 0 0}$ \\
\hline $\mathbf{1 1}$ & $\mathbf{6 , 8 0 0 0}$ & $\mathbf{1 , 3 2 6 6}$ & $\mathbf{4 1}$ & $\mathbf{6 , 1 6 6 6}$ & $\mathbf{1 , 1 2 7 9}$ & $\mathbf{0 , 0 0 0 1}$ \\
\hline $\mathbf{2 1}$ & $\mathbf{6 , 8 6 6 6}$ & $\mathbf{1 , 2 5 7 8}$ & $\mathbf{3 1}$ & $\mathbf{6 , 2 0 0 0}$ & $\mathbf{1 , 1 0 7 5}$ & $\mathbf{0 , 0 0 0 0}$ \\
\hline $\mathbf{2 2}$ & $\mathbf{7 , 9 6 6 6}$ & $\mathbf{1 , 3 2 8 7}$ & $\mathbf{3 2}$ & $\mathbf{7 , 1 3 3 3}$ & $\mathbf{1 , 2 8 4 0}$ & $\mathbf{0 , 0 0 0 0}$ \\
\hline $\mathbf{2 3}$ & $\mathbf{1 0 , 7 7 8 2}$ & $\mathbf{1 , 5 0 7 2}$ & $\mathbf{3 3}$ & $\mathbf{9 , 8 0 3 4}$ & $\mathbf{1 , 5 8 2 7}$ & $\mathbf{0 , 0 0 0 0}$ \\
\hline $\mathbf{2 4}$ & 9,7011 & 1,5321 & $\mathbf{3 4}$ & 9,7022 & 1,4206 & 0,9960 \\
\hline $\mathbf{2 5}$ & 10,5758 & 1,5042 & $\mathbf{3 5}$ & 10,6904 & 1,6219 & 0,5947 \\
\hline $\mathbf{2 6}$ & 6,3333 & 1,1642 & $\mathbf{3 6}$ & 6,1666 & 1,2133 & 0,2380 \\
\hline $\mathbf{2 7}$ & 11,3205 & 1,2808 & $\mathbf{3 7}$ & 11,0158 & 1,3523 & 0,0837
\end{tabular}

TABELA 23 - Nível de significância estatística (p) quando aplicado o teste t independente entre as idades médias de erupção dos dentes permanentes dos arcos superior e inferior no grupo Classe II.

\begin{tabular}{c|c|c|c|c|c|c}
\hline DENTE & MÉDIA & $\mathbf{D . P .}$ & DENTE & MÉDIA & D. P. & $\mathbf{p}$ \\
\hline $\mathbf{1 7}$ & 12,0466 & 1,5070 & $\mathbf{4 7}$ & 11,7000 & 1,5524 & 0,0998 \\
\hline $\mathbf{1 6}$ & 6,2333 & 1,2297 & $\mathbf{4 6}$ & 6,2666 & 1,1527 & 0,8272 \\
\hline $\mathbf{1 5}$ & 11,0333 & 1,4940 & $\mathbf{4 5}$ & 11,1666 & 1,4395 & 0,5040 \\
\hline $\mathbf{1 4}$ & 10,2333 & 1,3585 & $\mathbf{4 4}$ & 10,2000 & 1,5790 & 0,8663 \\
\hline $\mathbf{1 3}$ & $\mathbf{1 1 , 2 1 3 3}$ & $\mathbf{1 , 5 9 8 2}$ & $\mathbf{4 3}$ & $\mathbf{9 , 9 3 3 3}$ & $\mathbf{1 , 4 3 6 0}$ & $\mathbf{0 , 0 0 0 0}$ \\
\hline $\mathbf{1 2}$ & $\mathbf{8 , 1 0 0 0}$ & $\mathbf{1 , 3 7 4 7}$ & $\mathbf{4 2}$ & $\mathbf{7 , 1 3 3 3}$ & $\mathbf{1 , 3 0 9 7}$ & $\mathbf{0 , 0 0 0 0}$ \\
\hline $\mathbf{1 1}$ & $\mathbf{7 , 0 0 0 0}$ & $\mathbf{1 , 2 9 0 9}$ & $\mathbf{4 1}$ & $\mathbf{6 , 1 0 0 0}$ & $\mathbf{1 , 2 4 7 6}$ & $\mathbf{0 , 0 0 0 0}$ \\
\hline $\mathbf{2 1}$ & $\mathbf{6 , 9 6 6 6}$ & $\mathbf{1 , 2 7 7 5}$ & $\mathbf{3 1}$ & $\mathbf{6 , 2 6 6 6}$ & $\mathbf{1 , 2 0 9 2}$ & $\mathbf{0 , 0 0 0 0}$ \\
\hline $\mathbf{2 2}$ & $\mathbf{8 , 0 3 3 3}$ & $\mathbf{1 , 3 7 8 0}$ & $\mathbf{3 2}$ & $\mathbf{7 , 1 3 3 3}$ & $\mathbf{1 , 3 8 4 0}$ & $\mathbf{0 , 0 0 0 0}$ \\
\hline $\mathbf{2 3}$ & $\mathbf{1 1 , 2 0 6 6}$ & $\mathbf{1 , 5 8 8 6}$ & $\mathbf{3 3}$ & $\mathbf{1 0 , 0 6 6 6}$ & $\mathbf{1 , 5 9 0 2}$ & $\mathbf{0 , 0 0 0 0}$ \\
\hline $\mathbf{2 4}$ & 10,0666 & 1,7688 & $\mathbf{3 4}$ & 10,3666 & 1,4487 & 0,1643 \\
\hline $\mathbf{2 5}$ & 10,9333 & 1,6316 & $\mathbf{3 5}$ & 11,1000 & 1,3988 & 0,4206 \\
\hline $\mathbf{2 6}$ & 6,1666 & 1,2405 & $\mathbf{3 6}$ & 6,2000 & 1,1661 & 0,8252 \\
\hline $\mathbf{2 7}$ & 12,0133 & 1,5187 & $\mathbf{3 7}$ & 11,6666 & 1,4220 & 0,0869 \\
\hline
\end{tabular}


6. Discussão 


\section{DISCUSSÃO}

Com o objetivo de facilitar a interpretação dos resultados obtidos neste trabalho, serão discutidos inicialmente os aspectos referentes à seleção da amostra. Logo após, serão tecidos comentários pertinentes à metodologia empregada, efetuando considerações sobre o erro intraexaminador e o método de Karber utilizado para cálculo da idade média de erupção dos dentes permanentes. Posteriormente, será realizada a interpretação dos resultados obtidos na análise das telerradiografias em norma lateral, nas radiografias panorâmicas e nos modelos de gesso.

\subsection{Seleção da Amostra}

Considerando que o propósito principal do estudo foi realizar uma comparação da cronologia de erupção dos dentes permanentes e da calcificação dos segundos molares nas más-oclusões de Classe I e Classe II de Angle, objetivou-se primeiramente a obtenção de grupos com a maior homogeneidade possível no que se refere à idade e distribuição quanto ao gênero, visando assim, a obtenção de resultados mais confiáveis. Este objetivo foi alcançado satisfatoriamente, uma vez que todas as radiografias foram obtidas aos 8 anos de idade e a distribuição quanto ao gênero foi feita da maneira mais uniforme possível, obtendo assim o mesmo número de radiografias de indivíduos do gênero feminino e do gênero masculino nos dois grupos considerados.

Há trabalhos na literatura consultada que relatam modificações na cronologia eruptiva dos dentes permanentes devido à presença de dentes supranumerários e agenesias ${ }^{153}$, devido a perda prematura dos dentes decíduos $86,120,153$, anquilose destes dentes $28,67,117,153$ e também devido a terapias endodônticas realizadas nos dentes decíduos ${ }^{10,25,87}$. Baseandose nessas informações, tornourse imprescindível a exclusão daquelas radiografias que apresentassem dentes supranumerários ou agenesias 
dentárias a fim de que os resultados obtidos apresentassem a menor influência destes fatores de origem local e por isso todas as radiografias da amostra apresentavam todos os dentes permanentes até os segundos molares. Em relação aos modelos de gesso, não foi possível a exclusão daqueles que apresentassem perdas prematuras ou retenção prolongada de dentes decíduos, uma vez que a identificação destes fatores de origem local por meio de modelos de gesso se torna extremamente dificultada a não ser naqueles casos extremos em que o paciente se encontrava no primeiro período transitório da dentadura mista e havia perdas de caninos ou molares decíduos ou naqueles casos em que o paciente se encontrava no final do segundo período transitório da dentadura mista ou início da dentadura permanente e havia a presença de um dente decíduo isolado no modelo de gesso. No entanto, este fato não invalida os resultados do trabalho, uma vez que os requisitos essenciais para a aplicação do método de Karber (que serão discutidos posteriormente) foram rigorosamente observados e devido ao número substancial de modelos de gesso analisados (527), a possibilidade de interferência no cálculo da idade média de erupção de um respectivo dente foi certamente mínima e não influenciou o resultado final da pesquisa. Além disso, como o objetivo principal do estudo foi realizar uma comparação entre os grupos e a existência de perdas prematuras ou anquilose de dentes decíduos não são influenciados pelo relacionamento ântero-posterior das bases apicais, uma vez que a prevalência destes fatores interferentes de origem local é semelhante para indivíduos com Classe I ou Classe II de Angle 8 , 59, 79, 90.

As radiografias panorâmicas e telerradiografias em norma lateral foram obtidas aos 8 anos de idade e esta idade foi escolhida devido a presença na literatura de um estudo conduzido por HARUKI; KANOMI; SHIMONO52 com metodologia semelhante em que realiza a comparação em indivíduos com más-oclusões de Classe II e Classe III de Angle e a idade média obtida foi de 8 anos fornecendo assim, parâmetros para uma comparação; a idade cronológica de 8 anos representa uma idade média ao 
longo de todo o desenvolvimento dos segundos molares, pois os primeiros pontos de calcificação aparecem aos 3 anos de idade e a erupção na cavidade bucal por volta dos 12 anos de idade 36, 56, 133, 145; por representar o estágio intermediário de desenvolvimento dos segundos molares, a idade de 8 anos engloba o maior número de estágios de calcificação propostos na classificação de NOLLA ${ }^{108}$ e isto de fato ocorreu, uma vez que os estágios de calcificação variaram, em uma escala de 0 a 10, de 3,5 a 7,0; e porque a fase de transição dentária reveste-se de grande importância por coincidir com um período de importantes modificações do desenvolvimento somático e por ser uma fase de grande susceptibilidade da erupção dentária aos fatores interferentes ${ }^{160}$.

Na seleção dos modelos de gesso de jovens na faixa etária dos 5 aos 13 anos de idade que apresentassem uma relação molar de Classe I ou Classe II de Angle, houve casos em que esta classificação apresentou uma maior dificuldade, devido à presença de um plano terminal reto e para que não houvesse dúvidas quanto à classificação em Classe I ou II, modelos de gesso dos mesmos jovens em idades em que todos os dentes permanentes estivessem presentes foram avaliados e assim adequadamente classificados.

\subsection{Metodologia}

O material de estudo consistiu de telerradiografias em norma lateral, radiografias panorâmicas e modelos de gesso. Todas as radiografias, 60 radiografias panorâmicas e 60 telerradiografias em norma lateral dos mesmos jovens, foram obtidas aos oito anos de idade. A análise do posicionamento das bases ósseas em relação a base do crânio por meio das grandezas cefalométricas SNA, SNB e ANB é amplamente utilizada na literatura $22,52,63,66,144$ e o estudo dos comprimentos efetivos da maxila e mandíbula, por meio das grandezas cefalométricas Co-A e Co-Gn, possui 
um valor diagnóstico fundamental na interpretação das discrepâncias esqueléticas ${ }^{98}$.

O método preconizado por NOLLA 108 para avaliação dos estágios de calcificação dos dentes permanentes fornece um índice de maturidade fisiológica dos dentes permanentes e foi utilizado em inúmeros trabalhos sobre calcificação dentária26, 27, 36, 52, 128, 130, 138. Para obter a avaliação do desenvolvimento de um dente em particular, a radiografia era comparada o mais próximo possível com a figura do dente correspondente (FIGURA 2). Quando a leitura da radiografia indicava um desenvolvimento intermediário, entre dois estágios, a avaliação era indicada com o valor 0,5.

Após a mensuração das grandezas cefalométricas nas 60 telerradiografias em norma lateral e a obtenção dos estágios de calcificação dos segundos molares nas radiografias panorâmicas, foi verificada a existência de correlação entre estas variáveis por meio do teste de correlação de Pearson, conforme preconizado por HARUKI; KANOMI; SHIMONO52(TABELAS 13, 14, 15 e 16).

O estudo da cronologia de erupção dos dentes permanentes em modelos de gesso é raramente utilizado, uma vez que muitos fatores externos podem influenciar os resultados 1, 3, 19, 39, 51, 100, 129, 132, 136, 142, 149, 156. Verificou-se a existência de somente dois trabalhos na literatura que avaliaram a cronologia de erupção dos dentes permanentes por meio de modelos de gesso 75, 146. Entretanto, o estudo da cronologia eruptiva dos dentes permanentes em indivíduos também pode apresentar erros e conseqüentes resultados equivocados. Por esse motivo, tentourse minimizar todas as variáveis que pudessem influir nos resultados obtidos nos modelos de gesso, tais como: modelos de gesso fraturados ou com imperfeições, recortes dos modelos na região posterior que dificultassem a avaliação da presença ou ausência dos últimos dentes do arco e dúvidas relacionadas quanto a anatomia dentária. 


\subsubsection{Magnificação das imagens radiográficas}

Todas as radiografias panorâmicas e telerradiografias foram realizadas no Departamento de Radiologia da Faculdade de Odontologia de Bauru da Universidade de São Paulo. Por esse motivo, o valor de magnificação de cada imagem radiográfica não interferiu na comparação entre os grupos. $O$ valor de magnificação das telerradiografias em norma lateral foi da ordem de $6 \% 94$.

\subsubsection{Precisão da Metodologia}

Para verificar a confiabilidade desse trabalho, procuroutse minimizar os erros dos métodos de mensuração empregados. Calculou-se a precisão do investigador pelo erro intra-examinador casual e sistemático na mensuração das grandezas cefalométricas nas telerradiografias em norma lateral e pelo coeficiente Kappa na avaliação dos estágios de calcificação dos segundos molares nas radiografias panorâmicas.

O erro casual refere-se à dificuldade encontrada pelo examinador em identificar e definir certos pontos radiográficos utilizados nas medições cefalométricas ${ }^{55}$. Os erros casuais neste trabalho variaram de 0,37 a 1,27 (TABELA 10), sendo que estes erros apresentaram valores maiores nas grandezas lineares Co-A $(0,88)$ e Co-Gn $(1,27)$. O erro casual nas medidas Co-A e Co-Gn não gerou maior preocupação, pois, essas medidas apresentaram equilíbrio entre os valores sub e superestimados, verificado pelo teste $\mathrm{t}$ pareado, não apresentando diferenças estatisticamente significantes, portanto, não afetando o erro sistemático (TABELA 10).

Segundo HOUSTON55, o erro sistemático reflete uma falta de padronização do método, uma vez que o examinador tende a sub ou superestimar os valores de suas medições de maneira inconsciente, de modo a direcionar os resultados de acordo com as suas expectativas em relação às conclusões do estudo $5,47,55,124$. Dentre as 5 medidas 
realizadas, apenas a grandeza cefalométrica SNB apresentou erro sistemático estatisticamente significante (TABELA 10). No entanto, a diferença média entre os valores da $1^{\text {a }}$ e $2^{\text {a }}$ medição para a grandeza cefalométrica SNB foi da ordem de 0,5250, portanto, incapaz de modificar a interpretação do examinador quanto ao posicionamento sagital da mandíbula em relação a base do crânio.

Baseando-se nessas informações e observando que a quantidade de variáveis que apresentou erros casuais ou sistemáticos é similar ou menor que as descritas na literatura, pode-se afirmar que os erros obtidos na verificação da precisão da metodologia desse estudo estão de acordo com a normalidade e promovem resultados transparentes e fidedignos.

O erro do método na avaliação dos estágios de calcificação dos segundos molares por meio de radiografias panorâmicas foi realizado com a utilização do coeficiente Kappa. Este coeficiente verifica a quantidade de concordância entre os dados categóricos em duas avaliações distintas subtraindo deste valor o número de concordâncias que possam ter ocorrido por mero acaso. Sendo assim, 20 radiografias panorâmicas foram selecionadas aleatoriamente e os estágios de calcificação dos segundos molares foram reavaliados. Houve $65 \%$ de concordância entre as categorias o que corresponde a um valor de coeficiente Kappa de 0,55. De acordo com LANDIS; $\mathrm{KOCH}^{80}$ este valor é considerado satisfatório em uma avaliação de concordância entre dados categóricos. Nas duas avaliações, os valores dos estágios de calcificação de Nolla nunca excederam a um estágio.

\subsubsection{O método de Karber}

O método de Karber utilizado para cálculo da idade média de erupção dos dentes permanentes foi introduzido na literatura no ano de 1958 por HAYES; MANTEL53. Estes autores enumeram as vantagens de utilização deste método que realiza o cálculo da idade média levando em conta a 
proporção de dentes irrompidos em cada idade. A fórmula original do método de Karber sofreu algumas adaptações devido ao fato de se ter trabalhado com intervalos anuais e não mensais. Isto faz com que ocorra um aumento dos desvios padrão das idades médias de erupção dos dentes permanentes. Contudo, este aumento ocorreu nos dois grupos indistintamente (modelos com relação molar de Classe I e com relação molar de Classe II) e portanto, não influenciou a comparação entre as idades médias de erupção dos dentes permanentes dos dois grupos considerados.

Para seleção dos modelos de gesso, utilizou-se o método transversal e a preocupação em se obter um número estatisticamente satisfatório de modelos de gesso nas idades de 5 a 13 anos. Esta faixa etária foi a escolhida, uma vez que para a aplicação do método de Karber é essencial que as idades testadas cubram praticamente todo o intervalo de erupção dos dentes permanentes ${ }^{19}$. Por isso, estabeleceu-se que a idade mínima dos jovens da amostra deveria ser de 5 anos e a idade máxima de 13 anos.

Em relação ao fato de ser um método transversal de coleta de dados, este pode ser utilizado com a mesma eficácia de um método longitudinal17, 18, desde que se utilize uma análise estatística adequada para a interpretação dos dados. CAMPOS et al. ${ }^{17}$ não encontraram diferenças entre os métodos longitudinal e transversal. A coleta de dados em um método transversal é mais rápida, porém o seu processamento é mais trabalhoso. Na verdade, em diversas idades os modelos de gesso avaliados eram de um mesmo indivíduo, no entanto o número de indivíduos que possuíam modelos de gesso em todas as idades da faixa etária dos 5 aos 13 anos de idade era estatisticamente pequeno, o que iria comprometer significantemente os resultados se fosse optado pela realização de um estudo longitudinal.

O número de modelos de gesso avaliados foi diferente entre as idades estudadas (TABELA 6), no entanto esta variação pode ocorrer desde 
que não seja acentuada ${ }^{17}$. Quando os modelos de gesso foram distribuídos quanto ao gênero, observou-se uma distribuição homogênea, sendo que a maior diferença entre os gêneros ocorreu na idade de 12 anos para o grupo com relação molar de Classe I em que se verificou a presença de 15 modelos de jovens do gênero feminino e 10 modelos de jovens do gênero masculino. Esta pequena diferença não compromete os resultados obtidos, uma vez que nesta idade quase todos os dentes permanentes já estavam presentes nos modelos de gesso dos jovens com relação molar de Classe I (em 25 modelos de gesso analisados, apenas em 4 não havia a presença de todos os dentes permanentes na idade de 12 anos).

Considerando o número de modelos de gesso analisados (527) e o entendimento das limitações e exigências para aplicação do método de Karber acima relacionados, os resultados aqui apresentados são bastante confiáveis.

\subsection{Discussão dos resultados}

\subsubsection{Telerradiografias em norma lateral}

Com o objetivo de caracterizar cefalometricamente os grupos estudados, obteve-se a média e 0 desvio padrão das grandezas cefalométricas SNA, SNB, ANB, Co-A e Co-Gn (TABELA 7). A fim de realizar a comparação entre os grupos, verificou-se no Atlas de Crescimento Craniofacial94 os padrões destas grandezas cefalométricas aos 8 anos de idade.

Primeiramente, verificourse que as médias obtidas para os jovens do grupo de Classe I estão em consonância com as médias fornecidas pelo Atlas de Crescimento Craniofacial94 levando-se em conta o desvio padrão de cada grandeza cefalométrica. A única diferença verificada é que, segundo - Atlas, a grandeza cefalométrica Co-Gn, aos 8 anos de idade, apresenta 
dimorfismo entre os gêneros estatisticamente significante para $p<0,05$, porém, os jovens do grupo de Classe I não apresentaram este dimorfismo nesta mesma variável (Co-Gn) (TABELA 8). É interessante salientar que a diferença entre as médias da grandeza Co-Gn entre os jovens do gênero masculino e feminino no grupo Classe I (2,2667 mm) (TABELA 8) é bem próxima da diferença entre as médias obtida no Atlas $(2,4 \mathrm{~mm})$. A possível explicação para este fato é que o número de jovens avaliados no grupo de Classe I, que foi de 15 para cada gênero, é menor do que o número de jovens avaliados no Atlas, que foi de 22 para cada gênero, e esta diferença pode ter contribuído no nível de significância estatística. No entanto, quando o grupo Classe II foi distribuído quanto ao gênero, a variável Co-Gn apresentou dimorfismo entre os gêneros estatisticamente significante para $p<0,05$ e isto ocorreu devido a uma maior diferença entre as médias entre os indivíduos do gênero feminino e masculino $(3,2667)$ (TABELA 9).

Na comparação entre os grupos Classe I e Classe II, verificou-se uma diferença estatisticamente significante para $p<0,05$ nas variáveis SNB e ANB e para $p<0,01$ na variável Co-A (TABELA 7). Esta diferença na variável SNB já era esperada, uma vez que vérios artigos $33,35,71,72,114,115$ relatam a presença de um retrognatismo mandibular em indivíduos portadores de uma má-oclusão de Classe II de Angle verificado pela diminuição do ângulo SNB. A diferença entre os grupos em relação a variável ANB se deve ao fato de indivíduos com má-oclusão de Classe II apresentarem uma pior relação entre as bases apicais que pode ser verificada por um aumento no valor do ângulo ANB. O comprimento efetivo da maxila, representado pela variável Co-A, apresentou-se significantemente aumentada nos jovens portadores de má-oclusão de Classe II (TABELA 7). Esta diferença ocorreu devido a um posicionamento mais para anterior do ponto $A$ nos indivíduos com máoclusão de Classe II62. Este posicionamento mais para anterior do ponto $A$ não refletiu em um valor de SNA maior nos indivíduos do grupo Classe II em relação aos indivíduos do grupo Classe I. Isto é perfeitamente compreensível devido ao grande número de fatores que podem mascarar o real 
posicionamento sagital da maxila como a deflexão da base do crânio e a rotação das bases apicais $57,58,61,62,66$.

\subsubsection{Radiografias Panorâmicas}

Não houve diferença estatisticamente significante nos estágios de calcificação dos segundos molares entre os grupos Classe I e Classe II (TABELA 11). No entanto, pode-se verificar que em indivíduos com relação molar de Classe I, os segundos molares inferiores apresentam estágios de calcificação mais avançados do que os segundos molares superiores (TABELA 11). O inverso ocorre nos jovens com má-oclusão de Classe II de Angle, ou seja, os segundos molares superiores apresentam uma maior maturidade de calcificação quando comparado com os segundos molares inferiores. Este resultado confirma os resultados obtidos por HARUKI; KANOMI; SHIMONO52 em que os indivíduos com Classe II de Angle obtiveram estágios de calcificação mais avançados para os segundos molares superiores quando comparados aos segundos molares inferiores.

Quando os grupos Classe I e Classe II foram divididos quanto ao gênero, verificou-se a presença de dimorfismo entre os gêneros estatisticamente significante para $p<0,01$ nos estágios de calcificação dos segundos molares no grupo Classe I (TABELA 12). Este resultado confirma as impressões de NOLLA108 que apesar de não diferenciar em seu método a calcificação em indivíduos do gênero masculino e feminino, reconhece que o gênero feminino inicia e cessa o desenvolvimento dentário em idades mais precoces do que o gênero masculino. 


\subsubsection{Análise de correlação}

A comparação dos resultados encontrados neste trabalho deve ser conduzida com cautela devido aos diferentes métodos de medição do comprimento efetivo das bases apicais $52,65,98$. Mesmo diante dessa variação, torna-se possível estabelecer parâmetros e avaliar a correlação existente entre os estágios de calcificação dos segundos molares e as grandezas cefalométricas SNA, SNB, ANB, Co-A e Co-Gn.

$\mathrm{Na}$ literatura consultada, verificourse inúmeras formas de mensuração do comprimento efetivo das bases apicais. HARUKI; KANOMI; SHIMONO52 utilizaram em seu trabalho o método proposto por JARABAK; FIZZELL 65 em que o comprimento efetivo maxilar é representado pela grandeza ANS-PNS (distância entre a espinha nasal anterior e a espinha nasal posterior) e 0 comprimento mandibular pela grandeza Xi-PM (distância entre o centro geométrico do ramo ascendente da mandíbula e um ponto localizado na sínfise mandibular onde a curvatura da borda anterior passa de côncava a convexa). Na realidade, a forma de mensuração do comprimento das bases apicais na análise de Jarabak é derivada de pontos cefalométricos propostos por RICKETTS ${ }^{126}$ em sua análise cefalométrica. O presente estudo utilizou as grandezas cefalométricas Co-A e Co-Gn como representativas do comprimento efetivo da maxila e mandíbula respectivamente e que pertencem a análise idealizada por McNAMARA98 e que é comumente utilizada pela Disciplina de Ortodontia desta Faculdade.

Não foi observada nenhuma correlação estatisticamente significante entre os estágios de calcificação dos segundos molares e as grandezas cefalométricas SNA, SNB, ANB, Co-A e Co-Gn (TABELAS 13, 14, 15 e 16). O estudo de HARUKI; KANOMI; SHIMONO52 mostrou a existência de correlação entre estas variáveis, sendo que esta correlação é melhor evidenciada em indivíduos portadores de má-oclusão de Classe III de Angle. Quando a correlação foi verificada em jovens com Classe II de Angle, 
apenas a variável ANS-PNS (comprimento maxilar) mostrou correlação com os estágios de calcificação dos segundos molares inferiores estatisticamente significante para $p<0,01$. Diante dos resultados expostos, torna-se lícito concluir que a correlação entre estas variáveis é mais forte em jovens com má-oclusão de Classe III de Angle quando comparados àqueles com máoclusão de Classe II de Angle.

\subsubsection{Modelos de gesso}

Conforme discutido anteriormente, a cronologia de erupção dos dentes permanentes foi determinada utilizando-se modelos de gesso e aplicando-se o método de Karber para o cálculo da idade média de erupção dos dentes permanentes.

O critério adotado para considerar um dente irrompido foi o da emergência gengival, na qual um dente é considerado irrompido quando qualquer parte da coroa estiver visível na cavidade bucal. Este critério é simples, prático e amplamente utilizado na literatura consultada1, 3, 19, 39, 51, $100,129,132,136,142,149,156$. No entanto, o critério da emergência gengival foi utilizado avaliando-se modelos de gesso. Outros estudos já relataram a utilização do critério da emergência gengival em modelos de gesso, obtendo resultados satisfatórios 75,146 .

Foram avaliados 527 pares de modelos de gesso distribuídos na faixa etária dos 5 aos 13 anos de idade e também conforme a relação molar apresentada (TABELA 6). Quando os modelos de gesso foram distribuídos quanto ao gênero, verificou-se uma distribuição bastante homogênea, uma vez que a maior diferença ocorreu na idade de 12 anos para os jovens que apresentavam uma relação molar de Classe I, sendo que neste grupo, dos 25 modelos de gesso avaliados (TABELA 6), 15 eram de jovens do gênero feminino e 10 do gênero masculino. 
Primeiramente, os valores de desvio padrão obtidos neste trabalho estão aumentados (TABELAS 17 a 23) em comparação com outros estudos presentes na literatura que empregaram a mesma metodologia. No trabalho de HAYES; MANTEL53, a fórmula original do método de Karber foi idealizada para trabalhar com intervalos mensais, e por essa razão os valores de desvio padrão apresentados são menores do que os obtidos neste trabalho. Posteriormente, SOUZA-FREITAS; ALVARES; LOPES139 utilizaram a mesma metodologia, porém em intervalos semestrais e CARRARA $^{19}$ realizou modificações na fórmula original, a fim de trabalhar com intervalos trimestrais de avaliação. No presente estudo, a fórmula foi adaptada com o intuito de trabalhar com intervalos anuais de avaliação. Essa modificação acarreta logicamente um maior aumento do valor do desvio padrão obtido. Contudo, este aumento não interferiu nos resultados obtidos, uma vez que o valor aumentado do desvio padrão atingiu os dois grupos de forma semelhante e o objetivo deste trabalho não consiste em obter valores normativos para as idades médias de erupção dos dentes permanentes.

$\mathrm{Na}$ comparação das idades médias de erupção dos dentes permanentes entre os grupos Classe I e Classe II, observa-se que o grupo Classe I apresentou valores menores da idade média de erupção e portanto uma maior precocidade eruptiva de todos os dentes permanentes, com exceção dos dentes 16, 26, 41 e para o dente 32 em que a idade média encontrada foi a mesma (TABELA 17). Esta diferença na cronologia de erupção foi estatisticamente significante para o dente 23 quando $p<0,05$ e estatisticamente significante para todos os segundos molares e para os dentes 15, 45 e 34 quando $p<0,01$ (TABELA 17). Diante dos resultados obtidos, observa-se que a diferença na cronologia eruptiva dos dentes permanentes entre indivíduos com relação molar de Classe I e Classe II de Angle é melhor evidenciada em idades mais avançadas, como por exemplo no segundo período transitório da dentadura mista ou início da dentição permanente e que em idades mais precoces, como no primeiro período 
transitório da dentadura mista, esta diferença na cronologia de erupção dos dentes permanentes é praticamente inexistente ou acontece em menor proporção (TABELA 17). Um aspecto interessante de observar é que quando os grupos Classe I e Classe II foram comparados, por meio de radiografias panorâmicas, quanto aos estágios de calcificação dos segundos molares, não se verificou diferença estatisticamente significante entre os grupos (TABELA 11). No entanto, verificou-se diferença estatisticamente para $p<0,01$ na cronologia de erupção de todos os segundos molares quando os grupos Classe I e Classe II foram comparados (TABELA 17). A possível explicação para este fato é que os estágios de calcificação dos segundos molares foram avaliados na idade de 8 anos e a idade de visualização dos segundos molares por meio de modelos de gesso ocorreu, em média, nas idades de 11 e 12 anos (TABELA 17). Este resultado está em consonância com o afirmado anteriormente de que as diferenças no processo eruptivo entre os indivíduos com Classe I e Classe II de Angle são melhor evidenciadas em idades mais avançadas e por isso não foi verificada aos 8 anos de idade e esteve bem evidente na idade de irrompimento dos segundos molares na cavidade bucal que ocorreu por volta dos 11 e 12 anos de idade (TABELA 17).

Quando os indivíduos do grupo Classe I foram distribuídos de acordo com o gênero, verificourse que o gênero feminino apresentou uma precocidade eruptiva de todos os dentes permanentes quando comparado ao gênero masculino (TABELA 18). Esta diferença na cronologia de erupção dos dentes permanentes entre os gêneros do grupo Classe 1 foi estatisticamente significante para $p<0,05$ nos dentes $13,21,37,34,32,42$, 46 e estatisticamente significante para $p<0,01$ nos dentes $11,33,43,44,45$ (TABELA 18). Este resultado corrobora a literatura consultada que é praticamente unânime em afirmar que o gênero feminino apresenta uma precocidade na erupção de todos os dentes permanentes $16,18,21,24,39,41$, $51,54,56,74,75,93,95,100,132,133,139,143,145,149,150$. 
Quando os indivíduos do grupo Classe II foram distribuídos de acordo com o gênero, não se verificou um dimorfismo tão evidente como observado no grupo Classe I (TABELA 19). Na realidade, dos 28 dentes permanentes avaliados, em 15 deles houve uma precocidade eruptiva do gênero masculino em relação ao feminino (TABELA 19). A diferença na cronologia de erupção dos dentes permanentes no grupo Classe II foi estatisticamente significante somente para os dentes 25 e 46 para $p<0,01$ e para o dente 41 para $p<0,05$ (TABELA 19). É interessante ressaltar que em todos os dentes que apresentaram diferença estatisticamente significante, houve uma precocidade de erupção do gênero masculino em relação ao feminino (TABELA 19). Este resultado não era esperado, já que na quase totalidade dos trabalhos avaliados na literatura, o gênero feminino irrompe os dentes permanentes em idades mais precoces do que o masculino. No entanto, há na literatura uma escassez de trabalhos que enfocam o dimorfismo entre os gêneros na cronologia de erupção dos dentes permanentes em indivíduos portadores de má-oclusão de Classe II de Angle e esta é uma sugestão para um estudo futuro.

Em cada um dos grupos considerados realizou-se uma comparação das idades médias de erupção dos dentes permanentes do lado direito e do lado esquerdo dos arcos dentários (TABELAS 20 e 21). Tanto no grupo de Classe I como no grupo de Classe II, não foi verificada diferença estatisticamente significante entre as idades médias de erupção dos dentes permanentes dos lados direito e esquerdo (TABELAS 20 e 21). Este resultado já era esperado que ocorresse, uma vez vários artigos da literatura mostram que não há diferença na época de erupção dos dentes permanentes dos lados direito e esquerdo 1, 21, 41, 75, 84, 93, 132, 143, 146.

$\mathrm{Na}$ comparação entre as idades médias de erupção dos dentes permanentes superiores e inferiores no grupo Classe I, observou-se uma tendência dos dentes inferiores irromperem antes que os dentes superiores (TABELA 22). Esta diferença foi estatisticamente significante para $p<0,01$ 
nos incisivos e caninos e para os segundos molares do lado direito (TABELA 22). Os únicos dentes em que se verificou uma precocidade de erupção no arco superior em relação ao inferior foram os segundos pré-molares e os primeiros pré-molares do lado esquerdo, no entanto esta diferença foi muito pequena (TABELA 22). Esta mesma avaliação foi realizada no grupo Classe Il e os resultados obtidos foram semelhantes (TABELA 23). Neste grupo também se observou uma tendência dos dentes inferiores irromperem antes que os superiores. Esta diferença foi estatisticamente significante para $p<0,01$ em todos os incisivos e caninos (TABELA 23). Estes resultados também estão em consonância com inúmeros artigos da literatura em que se evidenciou uma tendência dos dentes inferiores irromperem em idades mais precoces do que os dentes superiores $24,36,41,75,93,104,133,139,143,146$. No entanto, alguns autores reconhecem esta precocidade dos dentes inferiores em relação aos superiores somente nos incisivos e caninos 41,75 , 104, 146. A erupção dos segundos pré-molares superiores antes dos seus correspondentes inferiores em ambos os grupos é explicada devido a seqüências de erupção diferentes na maxila e na mandíbula. Na mandíbula, os pré-molares irrompem depois dos caninos, ao passo que na maxila a erupção dos pré-molares antecede a erupção dos caninos.

A partir da cronologia média de erupção dos dentes permanentes nos dois grupos estudados (TABELA 17), obteve-se a seqüência de erupção dos dentes permanentes mais comumente encontrada nos grupos Classe I e Classe II (TABELA 24, na página seguinte). No arco superior, os dois grupos apresentaram seqüências de erupção dos dentes permanentes idênticas e esta seqüência é a mais freqüentemente encontrada na literatura por diversos autores 16, 75, 84, 116, 146, 149 (TABELA 24, na página seguinte). No arco inferior, no grupo Classe I não houve diferença entre as seqüências de erupção dos incisivos centrais e primeiros molares e no grupo Classe II houve uma precocidade mínima para os incisivos centrais em relação aos primeiros molares. Na literatura pesquisada também não há consenso entre a seqüência de erupção dos dentes permanentes mais comumente 
encontrada no arco inferior. Alguns autores $16,84,116,149$ afirmam que os primeiros molares irrompem antes dos incisivos centrais e outros ${ }^{16}, 75,146$ que há uma precocidade dos incisivos centrais em relação aos primeiros molares. Segundo BURDI; MOYERS16 não há nenhuma implicação clínica se a seqüência de erupção no arco inferior for 1-6 ou 6-1 e que na realidade há uma diferença entre as velocidades de erupção destes dois dentes, uma vez que em um grande número de casos pode parecer que o incisivo central irrompeu antes que o primeiro molar, mas de fato o primeiro molar 0 precedeu, mas ele se move tão lentamente que o incisivo o ultrapassa. SMITH; GARN 136 atribuem a existência de resultados divergentes na literatura ao curto intervalo de tempo entre as épocas de erupção desses dentes. Um outro aspecto que chamou a atenção é que no grupo Classe I o primeiro pré-molar inferior irrompeu em idade mais precoce que o canino inferior. Esta inversão na seqüência de erupção em jovens com Classe I é extremamente favorável e utilizada na clínica nos programas de extração seriada99, 123, no qual se deseja que o primeiro pré-molar inferior irrompa antes que o canino inferior.

TABELA 24 - Seqüência de erupção dos dentes permanentes mais comumente encontrada nos grupos Classe I e Classe II.

\begin{tabular}{l|c|c}
\hline & CLASSE I & CLASSE II \\
\hline MAXILA & $6-1-2-4-5-3-7$ & $6-1-2-4-5-3-7$ \\
\hline MANDÍBULA & $(6-1)-2-4-3-5-7$ & $(1-6)-2-3-4-5-7$
\end{tabular}

O estudo da cronologia e seqüência de erupção dos dentes permanentes é certamente um assunto de grande complexidade devido a grande variabilidade existente entre os indivíduos e ao grande número de fatores interferentes deste processo $16,21,41,46,49,74,99,133,136,139,141$, 146. 
7. Conclusões 


\section{CONCLUSÕES}

Baseando-se nos resultados obtidos nesse trabalho e de acordo com a metodologia empregada julgourse lícito concluir que:

1. Há uma tendência dos dentes permanentes irromperem em idades mais precoces em indivíduos com Classe I de Angle quando comparados com indivíduos Classe II de Angle.

2. Não há diferença estatisticamente significante nos estágios de calcificação dos segundos molares permanentes entre indivíduos com Classe I e Classe II de Angle.

3. Não há correlação entre a maturidade dentária dos segundos molares permanentes e as grandezas cefalométricas SNA, SNB, ANB, Co-A e Co-Gn em indivíduos com Classe I e Classe II de Angle. 


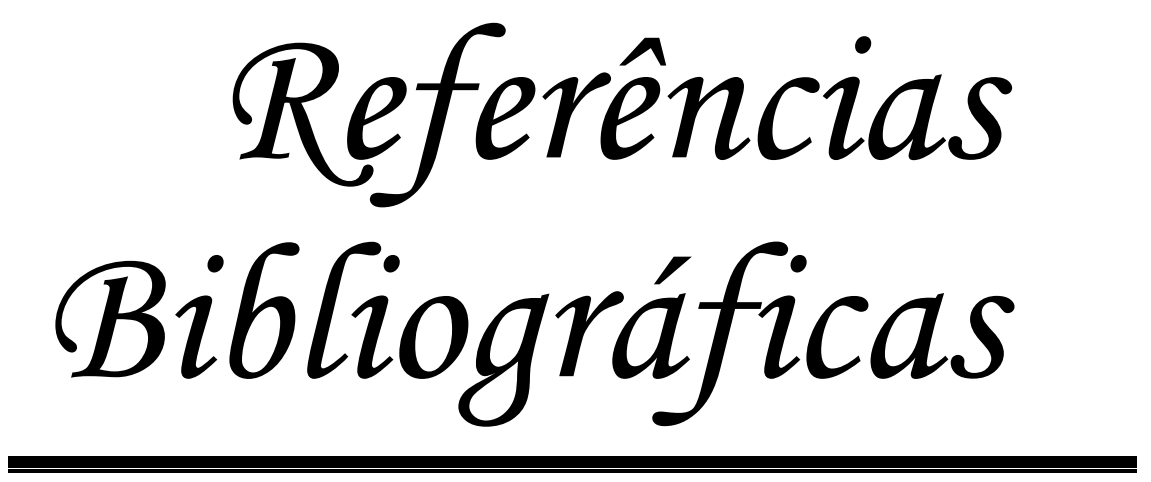




\section{REFERÊNCIAS BIBLIOGRÁFICAS*}

1. ABRAMOWICZ, M. Contribuição para o estudo da cronologia da erupção dos dentes permanentes, em Judeus do grupo étnico Ashkenazim, de níveis sócio-econômicos elevados. Sua aplicação na estimativa da idade. Rev. Fac. Odont. USP, v.2, n.1, p.91-146, jan.-jun. 1964.

2. ALTINI, M. Age determination from the teeth - a review. J. dent. Ass. S. Afr., v.38, n.5, p.275-9, May 1983.

3. ARBENZ, G.O.; ABRAMOWICZ, M. Contribuição para o estudo da seqüência e cronologia de erupção dos dentes permanentes. Estudo comparativo entre brasileiros brancos e Judeus Ashkenazim da cidade de São Paulo. Rev. Fac. Odont. USP, v.2, n.2, p.221-34, jul.-dez. 1964.

4. ARRUDA, C.C. et al. Desequilíbrio na rizogênese de pré-molares. Rev. Ass. paul. cirurg. Dent., v.54, n.1, p.55-60, jan./fev. 2000.

5. BAUMRIND, S.; FRANTZ, R. The reability of head film measurements. Am. J. Orthod., v.60, n.2, p.111-27, Aug. 1971.

6. BEAN Stature and eruption of the permanent teeth of American, GermanAmerican, and Filipino children. Amer. J. Anat., v.17, p.113, 1914-15.

7. BECKER, A.; CHAUSHU, S. Dental age in maxillary canine ectopia. Amer. J. Orthodont. Dentofac. Orthop., v.117, n.6, p.657-62, June 2000.

8. BECKER, A.; SHOCHAT, S. Submergence of a deciduous tooth: Its ramifications on the dentition and treatment of the resulting malocclusion. Amer. J. Orthodont., v.81, n.3, p.240-4, Mar. 1982.

\footnotetext{
* Normas recomendadas para uso no âmbito da Universidade de São Paulo, com base no documento "Referências Bibliográficas: exemplos", emanado do Conselho Supervisor do Sistema Integrado de Bibliotecas da USP, em reunião de 20 de setembro de 1990.
} 
9. BEKISZ, O.; DARIMONT, F.; ROMPEN, E.H. Diffuse but unilateral gingival enlargement associated with von Recklinghausen neurofibromatosis. A case report. J. clin. Periodont., v.27, n.5, p.361-5, May 2000.

10. BENGTSON, A.L.; BENGTSON, N.G. Dentes decíduos e o desvio na erupção. Rev. Ass. paul. cirurg. Dent., v.44, n.5, p.287-90, set./out. 1990.

11. BOSCO, V.L.; SILVA, R.H.H. Relação entre crescimento e erupção dentária. Rev. gaúcha Odont., v.39, n.3, p.189-90, maio/jun. 1991.

12. BOSCO, V.L.; SILVA, R.H.H. Relação entre crescimento e erupção dentária. Rev. gaúcha Odont., v.39, n.5, p.368-70, set./out. 1991.

13. BOSCO, V.L.; SILVA, R.H.H. Relação entre crescimento e erupção dentária. Rev. gaúcha Odont., v.40, n.3, p.214-8, maio/jun. 1992.

14. BRADLEY, R.E. The relationship between eruption, calcification, and crowding of certain mandibular teeth. Angle Orthodont., v.31, n.4, p.230-6, Oct. 1961.

15. BROOK, A.H.; BARKER, D.K. Eruption of teeth among the racial groups of eastern New Guinea: a correlation of tooth eruption with calendar age. Arch. oral Biol., v.17, n.4, p.751-9, Apr. 1972.

16. BURDI, A.R.; MOYERS, R.E. Desenvolvimento da dentição e da oclusão. In: MOYERS, R.E. Ortodontia. 4.ed. Rio de Janeiro, Guanabara Koogan S.A., 1991. Cap.6, p.86-126.

17. CAMPOS, S.M. et al. Comparação entre os métodos longitudinal e transversal, no estudo da cronologia e seqüência de erupção dos dentes primários. Rev. Fac. Farm. Odont. Ribeirão Preto, v.8, n.2, p.71-88, jul./dez. 1971. 
18. CARR, L.M. Eruption ages of permanent teeth. Aust. dent. J., v.7, n.5, p.367-73, Oct. 1962.

19. CARRARA, C.F.D.C. Estudo da cronologia e seqüência de erupção e das agenesias dos dentes permanentes em indivíduos brasileiros, leucodermas, portadores de fissura transforame incisivo unilateral. Bauru, 2000. 107p. Dissertação (Mestrado) - Faculdade de Odontologia de Bauru, Universidade de São Paulo.

20. CARVALHO, A.A.F.; CARVALHO, A.; SANTOS-PINTO, M.C. Estudo radiográfico do desenvolvimento da dentição permanente de crianças brasileiras com idade cronológica variando entre 84 e 131 meses. Rev. Odont. UNESP, v.19, n.1, p.31-9, 1990.

21. CATTELL, P. The eruption and growth of the permanent teeth. J. dent. Res., v.8, n.2, p.279-87, Mar./Apr. 1928.

22. CHANG, H. Assessment of anteroposterior jaw relationship. Amer. J. Orthodont. Dentofac. Orthop., v.92, n.2, p.117-22, Aug. 1987.

23. CHATTOPADHYAY, A.; SRINIVAS, K. Transposition of teeth and genetic etiology. Angle Orthodont., v.66, n.2, p.147-52, 1996.

24. COHEN, J.T. The dates of eruption of the permanent teeth in a group of Minneapolis children: a preliminary report. J. Amer. dent. Ass., v.15, n.2, p.2337-41, July-Dec. 1928.

25. COLL, J.A.; SADRIAN, R. Predicting pulpectomy success and its relationship to exfoliation and succedaneous dentition. Pediat. Dent., v.18, n.1, p.57-63, Jan./Feb. 1996.

26. CORDEIRO, R.C.L. et al. Calcificação dos dentes permanentes em relação às idades óssea e cronológica em crianças. Rev. Ass. paul. cirurg. Dent., v.51, n.5, p.481-7, set./out. 1997. 
27. CORDEIRO, R.C.L. et al. Estágios de calcificação e erupção de dentes permanentes de crianças da zona rural de Araraquara/SP. J. bras. Ortod. Ortop. maxilar, v.5, n.26, p.47-53, mar./abr. 2000.

28. COUTINHO, T.C.L.; SOUZA, I.P.R. Contribuição ao estudo da anquilose de molares decíduos em crianças e sua relação com os dentes permanentes sucessores. Rev. bras. Odont., v.51, n.5, p.18-23, set./out. 1994.

29. DAHLBERG, G. Statistical methods for medical and biological students. New York, Interscience, 1940.

30. DEMIRJIAN, A. et al. Interrelationships among measures of somatic, skeletal, dental, and sexual maturity. Amer. J. Orthodont., v.88, n.5, p.433-8, Nov. 1985.

31. DEMIRJIAN, A.; GOLDSTEIN, H.; TANNER, J.M. A new system of dental age assessment. Hum. Biol., v.45, n.2, p.211-27, May 1973.

32. DEMIRJIAN, A.; LEVESQUE, G.Y. Sexual differences in dental development and prediction of emergence. J. dent. Res., v.59, n.7, p.1110-22, May-Aug. 1980.

33. DEMISCH, A.; INGERVALL, B.; THÜER, U. Mandibular displacement in Angle Class II, Division 2 malocclusion. Amer. J. Orthodont. Dentofac. Orthop., v.102, n.6, p.509-18, Dec. 1992.

34. ELBADRAWY, H.E. Dental development in optimal and suboptimal fluoride communities. J. Canad. dent. Ass., v.50, n.2, p.761-4, Aug.-Dec. 1984. 
35. FALCK, F.; FRÄNKEL, R. Clinical relevance of step-by-step mandibular advancement in the treatment of mandibular retrusion using the Fränkel appliance. Amer. J. Orthodont. Dentofac. Orthop., v.96, n.4, p.33341, Oct. 1989.

36. FERREIRA, F.V. Desenvolvimento da dentição. In: Ortodontia: diagnóstico e planejamento clínico. 3.ed. São Paulo, Artes Médicas, 1998. Cap.3, p.59-71.

37. FERREIRA, F.V. Ortodontia: diagnóstico e planejamento clínico. 3.ed. São Paulo, Artes Médicas, 1998.

38. FRANKLIN, D.L.; ROBERTS, G.J. Delayed tooth eruption in congenital hypertrichosis lanuginosa. Pediat. Dent., v.20, n.3, p.192-4, May/June 1998.

39. GALVÃO, C.A.A.N. Seqüência e cronologia da erupção de caninos e prémolares. Estudo em escolares na faixa etária de 10 a 15 anos. Rev. Odont. UNESP, v.20, n.1, p.227-36, 1991.

40. GARDUCCI, M.G.; LINO, A.P. Influência da fluoretação da água sobre os processos de rizólise e rizogênese. Rev. Ass. paul. cirurg. Dent., v.46, n.4, p.835-9, jul./ago. 1992.

41. GARN, S.M.; BURDI, A.R. Prenatal ordering and postnatal sequence in dental development. J. dent. Res., v.50, n.6, p.1407-14, Nov./Dec. 1971.

42. GARN, S.M. et al. Variability of tooth formation. J. dent. Res., v.38, n.1, p.135-48, Jan./Feb. 1959.

43. GARN, S.M. et al. The sex difference in tooth calcification. J. dent. Res., v.37, n.3, p.561-7, June 1958. 
44. GARN, S.M.; ROHMANN, C.G.; SILVERMAN, F.N. Radiografic standards for postnatal ossification and tooth calcification. Med. Radiogr. and Photogr., v.43, p.45-66, 1967.

45. GATES, R.E. Eruption of permanent teeth of New South Wales school children. Part I. Ages of eruption. Aust. dent. J., v.9, n.3, p.211-18, June 1964.

46. GRABER, T.M. Crecimiento y desarrollo. In: Ortodontia. 1.ed. Buenos Aires, Editorial Mundi, 1965. Cap.2, p.29-79.

47. GRAVELY, J.F.; BENZIES, P.M. The clinical significance of tracing error in cephalometry. Br. J. Orthod., v.1, n.3, p.95-101, 1974.

48. GREULICH, W.W.; PYLE, S.I. Radiographic atlas of skeletal development of the hand wrist. 2.ed. Standford, Standford University Press, 1959.

49. GUEDES-PINTO, A.C. Erupção dentária. In: Odontopediatria. 6.ed. São Paulo, Editora Santos, 1997. Cap.2, p.17-34.

50. HÄGG, U.; TARANGER, J. Dental development assessed by tooth counts and its correlations to somatic development during puberty. Europ. J. Orthodont., v.6, n.1, p.55-64, Feb. 1984.

51. HÄGG, U.; TARANGER, J. Dental development, dental age and tooth counts. Angle Orthodont., v.55, n.2, p.93-107, Apr. 1985.

52. HARUKI, T.; KANOMI, R.; SHIMONO, T. The differences in the chronology and calcification of second molars between Angle class III and class II occlusions in Japanese children. J. Dent. Child., v.64, n.6, p.400-4, Nov./Dec. 1997. 
53. HAYES, R.L.; MANTEL, N. Procedures for computing the mean age of eruption of human teeth. J. dent. Res., v.37, n.5, p.938-47, Sept./Oct. 1958.

54. HÖFFDING, J. et al. Emergence of permanent teeth and onset of dental stages in Japanese children. Community Dent. oral Epidem., v.12, n.1, p.55-8, Feb. 1984.

55. HOUSTON, W.J.B. The analysis of errors in orthodontic measurements. Am. J. Orthod., v.83, n.5, p.382-90, May 1983.

56. HURME, V.O. Ranges of normalcy in the eruption of permanent teeth. J. Dent. Child., v.16, n.2, p.11-5, Second Quarter 1949.

57. HUSSELS, W.; NANDA, R.S. Analysis of factors affecting angle ANB. Amer. J. Orthodont., v.85, n.5, p.411-23, May 1984.

58. HUSSELS, W.; NANDA, R.S. Clinical application of a method to correct angle ANB for geometric effects. Amer. J. Orthodont. Dentofac. Orthop., v.92, n.6, p.506-10, Dec. 1987.

59. INOUE, N. et al. Influence of tooth-to-denture-base discrepancy on space closure following premature loss of deciduous teeth. Amer. J. Orthodont., v.83, n.5, p.428-34, May 1983.

60. IV, R.L.G. et al. Secretion of CSF-1 and its inhibtion in rat dental follicle cells: implications for tooth eruption. Europ. J. oral Sci., v.106, n.3, p.808-15, June 1998.

61. JACOBSON, A. The "Wits" appraisal of jaw disharmony. Amer. J. Orthodont., v.67, n.2, p.125-38, Feb. 1975.

62. JACOBSON, R.L.; JACOBSON, A. Point A revisited. Amer. J. Orthodont., v.77, n.1, p.92-6, Jan. 1980. 
63. JAMISON, J.E. et al. Longitudinal changes in the maxilla and the maxillarymandibular relationship between 8 and 17 years of age. Amer. J. Orthodont., v.82, n.3, p.217-30, Sept. 1982.

64. JANSON, G.R.P. et al. Dental maturation in subjects with extreme vertical facial types. Europ. J. Orthodont., v.20, n.1, p.73-8, Feb. 1998.

65. JARABAK, J.R.; FIZZELL, J.A. Technique and treatment with light-wire edgewise appliance. 2.ed. St. Louis, The C. V. Mosby Company, 1972.

66. JÄRVINEN, S. An analysis of the variation of the ANB angle: A statistical appraisal. Amer. J. Orthodont., v.87, n.2, p.144-6, Feb. 1985.

67. JOHAL, A.S. Case report: infra-occluded deciduous molars: a review and alternative treatment approach. Europ. J. Prosthodont. Restorat. Dent., v.5, n.1, p.5-9, Mar. 1997.

68. JOHANNSDOTTIR, B.; WISTH, P.J.; MAGNUSSON, T.E. Prevalence of malocclusion in 6-year-old Icelandic children. Acta odont. scand., v.55, n.6, p.398-402, Dec. 1997.

69. KALK, W.W.I.; BATENBURG, R.H.K.; VISSINK, A. Dentin dysplasia type I. Oral Surg., v.86, n.2, p.175-8, Aug. 1998.

70. KARDOS, T.B. The mechanism of tooth eruption. Brit. dent. J., v.181, n.3, p.91-5, Aug. 1996.

71. KEELING, S.D. et al. Anteroposterior skeletal and dental changes after early Class II treatment with bionators and headgear. Amer. J. Orthodont. Dentofac. Orthop., v.113, n.1, p.40-50, Jan. 1998. 
72. KEIM, R.G. et al. Two phase treatment of a severe Class II, Division I malocclusion. Amer. J. Orthodont. Dentofac. Orthop., v.109, n.5, p.461-5, May 1996.

73. KIESER, J.A.; GROENEVELD, H.T.; SILVA, P. Delayed tooth formation in children exposed to tobacco smoke. J. clin. pediat. Dent., v.20, n.2, p.97-100, Winter 1996.

74. KLEIN, H.; CODY, J.F. Graphic charts which depict the variations in numbers of erupted permanent teeth in grade school children. J. Amer. dent. Ass., v.26, n.4, p.609-11, Apr. 1939.

75. KNOTT, V.B.; MEREDITH, H.V. Statistics on eruption of the permanent dentition from serial data for North American white children. Angle Orthodont., v.36, n.1, p.68-79, Jan. 1966.

76. KOCHHAR, R.; RICHARDSON, A. The chronology and sequence of eruption of human permanent teeth in Northern Ireland. Int. J. Paed. Dent., v.8, n.4, p.243-52, Dec. 1998.

77. KRONFELD, S.M. The effects of premature loss of primary teeth and sequence of eruption of permanent teeth on malocclusion. J. Dent. Child., v.20, n.1, p.2-13, 1953.

78. KRUMHOLT, L.; ROED-PETERSEN, B.; PINDBORG, J.J. Eruption times of the permanent teeth in 622 Ugandan children. Arch. oral Biol., v.16, n.2, p.1281-8, July-Dec. 1971.

79. KUROL, J.; KOCH, G. The effect of extraction of infraoccluded deciduous molars: A longitudinal study. Amer. J. Orthodont., v.87, n.1, p.46-55, Jan. 1985.

80. LANDIS, J.R.; KOCH, G.G. The measurement of observer agreement for categorical data. Biometrics, v.33, n.1, p.159-74, Mar. 1977. 
81. LEHTINEN, A. et al. Advanced dental maturity in children with juvenile rheumatoid arthritis. Eur. J. oral Sci., v.108, n.3, p.184-8, June 2000.

82. LEVESQUE, G.Y.; DEMIRJIAN, A.; TANGUAY, R. Sexual dimorphism in the development, emergence, and agenesis of the mandibular third molar. J. dent. Res., v.60, n.10, p.1735-41, Oct. 1981.

83. LIVERSIDGE, H.M. Dental maturation of 18th and 19th century British children using Demirjian's method. Int. J. Paed. Dent., v.9, n.2, p.1115, June 1999.

84. LO, R.T.; MOYERS, R.E. Studies in the etiology and prevention of malocclusion. Amer. J. Orthodont., v.39, n.6, p.460-7, June 1953.

85. LOEVY, H.T. Maturation of permanent teeth in Black and Latino children. Acta odont. pediat., v.4, n.2, p.59-62, dic. 1983.

86. LOEVY, H.T. The effect of primary tooth extraction on the eruption of succedaneous premolars. J. Amer. dent. Ass., v.118, n.6, p.715-8, June 1989.

87. LOEVY, H.T.; CRAWFORD, J.G. Effect of pulpotomies on eruption of succedaneous premolars. Quintessence Int., v.22, n.10, p.795-800, Oct. 1991.

88. LOEVY, H.T.; GOLDBERG, A.F. Shifts in tooth maturation patterns in nonFrench Canadian boys. Int. J. Paed. Dent., v.9, n.2, p.105-10, June 1999.

89. LOGAN, W.J.G.; KRONFELD, R. Development of the human jaws and surrounding structures from birth to age of fifteen years. J. Amer. dent. Ass., v.20, n.3, p.379-427, Mar. 1933. 
90. LUNDSTRÖM, A. The significance of early loss of deciduous teeth in the etiology of malocclusion. Amer. J. Orthodont., v.41, n.11, p.819-26, Nov. 1955.

91. MAKI, K. et al. The impact of race on tooth formation. J. Dent. Child., v.66, n.5, p.353-6, Sept./Oct. 1999.

92. MAPPES, M.S.; HARRIS, E.F.; BEHRENTS, R.G. An example of regional variation in the tempos of tooth mineralization and hand-wrist ossification. Amer. J. Orthodont. Dentofac. Orthop., v.101, n.2, p.145-51, Feb. 1992.

93. MARQUES, G.D.; GUEDES-PINTO, A.C.; ABRAMOWICZ, M. Estudo da cronologia de erupção dos dentes permanentes em crianças da cidade de São Paulo. Rev. Fac. Odont. USP, v.16, n.1, p.177-85, jan.-jun. 1978.

94. MARTINS, D.R. et al. Atlas de crescimento craniofacial. 1.ed. São Paulo, Ed. Santos, 1998.

95. MASSLER, M.; SCHOUR, I. Studies in tooth development: theories of eruption. Amer. J. Orthodont. oral Surg., v.27, p.552-76, Jan.-Dec. 1941.

96. McNAMARA, C.M. et al. Premature dental eruption: report of case. J. Dent. Child., v.66, n.1, p.70-2, Jan./Feb. 1999.

97. McNAMARA, C.M. et al. Cleidocranial dysplasia: radiological appearances on dental panoramic radiography. Dentomaxillofac. Radiol., v.28, n.2, p.89-97, Mar. 1999.

98. McNAMARA, J.A. A method of cephalometric evaluation. Amer. J. Orthodont., v.86, n.6, p.449-69, Dec. 1984. 
99. MERCADANTE, M.M.N. Extrações seriadas. In: FERREIRA, F.V. Ortodontia: diagnóstico e planejamento clínico. 3.ed. São Paulo, Artes Médicas, 1998. Cap.9, p.171-86.

100. MILLER, J.; HOBSON, P.; GASKELL, T.J. A serial study of the chronology of exfoliation of deciduous teeth and eruption of permanent teeth. Arch. oral Biol., v.10, n.5, p.805-18, Sept./Oct. 1965.

101. MOLINA, I.; VIÑAS, L.; GARCÍA-GODOY, F.M. Erupción clínica de los dientes permanentes en niños con impedimentos mentales de Santo Domingo. Acta odont. pediat., v.3, n.2, p.69-73, dic. 1982.

102. MOORREES, C.F.A. et al. Age variation or formation stages for ten permanent teeth. J. dent. Res., v.42, n.6, p.1490-1502, Nov./Dec. 1963.

103. NADLER, G.L. Earlier dental maturation: fact or fiction? Angle Orthodont., v.68, n.6, p.535-8, Dec. 1998.

104. NANDA, R.S. Eruption of human teeth. Amer. J. Orthodont., v.46, n.5, p.363-78, May 1960.

105. NGAN, P.; ALKIRE, R.G.; FIELDS JUNIOR, H. Management of space problems in the primary and mixed dentitions. J. Amer. dent. Ass., v.130, n.9, p.1330-9, Sept. 1999.

106. NISWANDER, J.D. Effects of heredity and environment on development of dentition. J. dent. Res., v.42, n.6, p.1288-96, 1963.

107. NOGUEIRA, A.S. et al. Principais transtornos ocasionados por dentes inclusos. Rev. Ass. paul. cirurg. Dent., v.51, n.3, p.247-9, maio/jun. 1997. 
108. NOLLA, C.M. The development of the permanent teeth. J. Dent. Child., v.27, n.4, p.254-66, Fourth Quarter 1960.

109. O'CONNELL, A.C.; MARINI, J.C. Evaluation of oral problems in an osteogenesis imperfecta population. Oral Surg., v.87, n.2, p.189-96, Feb. 1999.

110. O'CONNELL, A.C. et al. Delayed eruption of permanent teeth in hyperimmunoglobulinemia E recurrent infection syndrome. Oral Surg., v.89, n.2, p.177-85, Feb. 2000.

111. PACKOTA, G.V.; PHAROAH, M.J.; PETRIKOWSKI, C.G. Radiographic features of segmental odontomaxillary dysplasia. A study of 12 cases. Oral Surg., v.82, n.5, p.577-84, Nov. 1996.

112. PAHKALA, R.; PAHKALA, A.; LAINE, T. Eruption pattern of permanent teeth in a rural community in northeastern Finland. Acta Odontol. Scand., v.49, n.6, p.341-9, Dec. 1991.

113. PAIVA, S.M.; CIAMPONI, A.L. Aspectos de biologia molecular envolvidos no processo de erupção dentária. Rev. Pós-Grad. Fac. Odont. USP, v.5, n.1, p.13-6, jan.-mar. 1998.

114. PANCHERZ, H. A cephalometric analysis of skeletal and dental changes contributing to Class II correction in activator treatment. Amer. J. Orthodont., v.85, n.2, p.125-34, Feb. 1984.

115. PARK, C.O.; CHO, K.H. Nonextraction treatment of a Class II, Division 1 malocclusion. Amer. J. Orthodont. Dentofac. Orthop., v.109, n.3, p.227-33, Mar. 1996.

116. PARREIRA, M.L.J. et al. Estudo da seqüência de erupção dos dentes permanentes em crianças - sexo masculino. Arch. Cent. Est. Curso Odont. Univ. Fed. M. Gerais, v.19, n.1, p.101-12, jan.-jun. 1982. 
117. PEREIRA, R.M.; RODRIGUES, C.R.M.D. Prevalência de anquilose em molares decíduos nas crianças do município de São Paulo. Rev. paul. Odont., v.21, n.5, p.36-40, set./out. 1999.

118. PHILBRICK, W.M. et al. Parathyroid hormone-related protein is required for tooth eruption. Proc. nat. Acad. Sci., v.95, n.20, p.11846-51, Sept. 1998.

119. PINHEIRO, G.A.; CASADO, L.E.M.; ASSUNÇÃO, V.A. Erupção dentária. Fenômeno fisiológico ou patológico? Odont. mod., v.20, n.3, p.28-33, mai./jun. 1993.

120. POSEN, A.L. The effect of premature loss of deciduous molars on premolar eruption. Angle Orthodont., v.35, n.3, p.249-52, July 1965.

121. QUE, B.G.; WISE, G.E. Tooth eruption molecules enhance MCP-1 gene expression in the dental follicle of therat. Develop. Dynamics, v.212, n.3, p.346-51, July 1998.

122. RASMUSSEN, P.; KOTSAKI, A. Inherited retarded eruption in the permanent dentition. J. clin. pediat. Dent., v.21, n.3, p.205-11, Spring 1997.

123. RAVELI, D.B. et al. Extração seriada - relato de um caso clínico. J. bras. Ortod. Ortop. Maxilar, v.2, n.10, p.45-50, jul./ago. 1997.

124. RICHARDSON, A. A comparision of traditional and computadorized methods of cephalometric analysis. Eur. J. Orthod., v.3, n.1, p.15-20, 1981.

125. RICHARDSON, M.E. Mesial migration of lower molars in relation to facial growth and eruption. Austr. Orthodont. J., v.14, n.2, p.87-91, Mar. 1996. 
126. RICKETTS, R.M. The influence of orthodontic treatment on facial growth and development. Angle Orthodont., v.30, n.3, p.103-33, July 1960.

127. ROSENBLUM, S.H. Delayed dental development in a patient with Gorlin syndrome: case report. Pediat. Dent., v.20, n.5, p.355-8, Sept./Oct. 1998.

128. ROSSI, R.R.; AMORIM, S.G.; PACHECO, M.C.T. Correlação entre estágios de mineralização dos dentes e estimativa da maturação esquelética. Ortodontia, v.32, n.3, p.48-58, set.-dez. 1999.

129. SALEEMI, M.A. et al. Dental development, dental age and tooth counts. A prospective longitudinal study of Pakistani children. Swed. dent. J., v.20, n.1-2, p.61-7, 1996.

130. SALIBA, C.A. et al. Estimativa da idade pela mineralização dos dentes, através de radiografias panorâmicas. ROBRAC, v.6, n.22, p.14-6, dez. 1997.

131. SATAKE, K.U.; SILVA, R.H.H. Relação entre crescimento e erupção dentária. Rev. gaúcha Odont., v.38, n.3, p.183-7, maio/jun. 1990.

132. SAVARA, B.S.; STEEN, J.C. Timing and sequence of eruption of permanent teeth in a longitudinal sample of children from Oregon. J. Amer. dent. Ass., v.97, n.2, p.209-14, Aug. 1978.

133. SCHOUR, I.; MASSLER, M. The development of the human dentition. J. Amer. dent. Ass., v.28, n.7, p.1153-60, July 1941.

134. SICHER, H. Tooth eruption: axial movement of teeth with limited growth. J. dent. Res., v.21, n.4, p.395-402, Aug. 1942. 
135. SILVA, G.C.H.; BOLOGNESE, A.M. Avaliação do surto de crescimento puberal através do exame clínico e radiográfico dos estágios de calcificação do segundo pré-molar inferior. Rev. Soc. bras. Ortodont., v.3, n.8, p.313-22, jul./dez. 1999.

136. SMITH, B.H.; GARN, S.M. Polymorphisms in eruption sequence of permanent teeth in American children. Amer. J. phys. Anthrop., v.74, n.3, p.289-303, Nov. 1987.

137. SO, L.L.Y. Correlation of sexual maturation with stature and body weight \& dental maturation in southern chinese girls. Austr. Orthodont. J., v.14, n.1, p.18-20, Oct. 1995.

138. SOUZA-FREITAS, J.A. Estudo das principais tabelas de avaliação da idade cronológica, através do desenvolvimento dental, visando sua aplicação em brasileiros leucodermas da região de Bauru. Bauru, 1969. 98p. Dissertação (Mestrado) - Faculdade de Odontologia de Bauru, Universidade de São Paulo.

139. SOUZA-FREITAS, J.A.; ALVARES, L.C.; LOPES, E.S. Aspectos da cronologia de erupção dos dentes permanentes em crianças brasileiras brancas de terceira geração. Estomat. Cult., v.4, n.2, p.201-8, jul.-dez. 1970.

140. SOUZA-FREITAS, J.A. et al. Variabilidade das fases de formação e erupção dos dentes permanentes. Ortodontia, v.23, n.2, p.29-39, maio-ago. 1990.

141. SOUZA-FREITAS, J.A. et al. Influência da fluoretação na cronologia de erupção dos dentes permanentes. Estomat. Cult., v.5, n.2, p.156-65, jul.-dez. 1971. 
142. SOUZA-FREITAS, J.A.; LOPES, E.S.; DAMANTE, J.H. Cronologia de mineralização e de erupção dos dentes permanentes. Rev. bras. Odont., v.48, n.2, p.2-7, mar./abr. 1991.

143. STEGGERDA, M.; HILL, T.J. Eruption time of teeth among whites, negroes, and indians. Amer. J. Orthodont., v.28, n.6, p.361-70, June 1942.

144. STEINER, C.C. Cephalometrics for you and me. Amer. J. Orthod., v.39, n.10, p.729-55, Oct. 1953.

145. STONES, H.H. et al. Time of eruption of permanent teeth and time of shedding of deciduous teeth. Brit. dent. J., v.90, n.1, p.1-7, Jan. 1951.

146. STURDIVANT, J.E.; KNOTT, V.B.; MEREDITH, H.V. Interrelations from serial data for eruption of the permanent dentition. Angle Orthodont., v.32, n.1, p.1-13, Jan. 1962.

147. SYMONS, A.L.; TAVERNE, A.A.R. A family case report: disturbances in tooth form and eruption of the second premolar. Austr. Orthodont. J., v.14, n.3, p.168-71, Oct. 1996.

148. TAKAGI, S.; KOYAMA, S. Guided eruption of an impacted second premolar associated with a dentigerous cyst in the maxillary sinus of a 6-year-old child. J. oral Maxillofac. Surg., v.56, n.2, p.237-9, Feb. 1998.

149. TITLEY, K.C. A comparative investigation of permanent tooth emergence timing of Northern Ontario Indians. J. Canad. dent. Ass., v.50, n.10, p.775-8, Oct. 1984. 
150. TOLEDO, O.A. Aspectos da cronologia da erupção dos dentes permanentes em escolares primários, brasileiros, brancos, da cidade de Araçatuba. Considerações sobre o efeito da urbanização nas alterações da cronologia eruptiva. Araçatuba, 1963. 90p. Tese (Livre-Docência) - Faculdade de Farmácia e Odontologia de Araçatuba, Universidade Estadual Paulista.

151. TOMES, J. A system of dental surgery. 2.ed. Philadelphia, Lindsay and Blakiston, 1859.

152. TROTTER, M.; HIXON, B.B.; MACDONALD, B.J. Development and size of the teeth of Macaca mulatta. Amer. J. Anat., v.150, n.1, p.109-26, Sept. 1977.

153. VALLADARES-NETO, J.; SILVA, F.A.; KAADI, O.B. Retardo eruptivo de incisivo permanente associado à retenção prolongada do predecessor decíduo: obstrutivo, traumático, desenvolvimental ou idiopático? Discussão através de um caso clínico. ROBRAC, v.5, n.15, p.4-10, ago. 1995.

154. VAN DER LINDEN, F.P.G.M. Ortodontia: desenvolvimento da dentição. 1.ed. São Paulo, Quintessence editora Itda, 1986.

155. VIANNA, L.S. et al. Estudo da seqüência de erupção dos dentes permanentes em crianças do sexo feminino. Arch. Cent. Est. Curso Odont. Univ. Fed. M. Gerais, v.16, n.1/2, p.69-82, 1979.

156. VIRTANEN, J.I.; BLOIGU, R.S.; LARMAS, M.A. Timing of eruption of permanent teeth: standard finnish patient documents. Community Dent. oral Epidem., v.22, n.5 pt 1, p.286-8, Oct. 1994.

157. WEIDE, Y.S.; PRAHL-ANDERSEN, B.; BOSMAN, F. Tooth formation in patients with oligodontia. Angle Orthodont., v.63, n.1, p.31-7, Spring 1993. 
158. WEYMAN, J. The effect of irradiation on developing teeth. Oral Surg., v.25, n.4, p.623-9, Apr. 1968.

159. WISE, G.E. The biology of tooth eruption. J. dent. Res., v.77, n.8, p.1576-9, Aug. 1998.

160. YARED, F.N.F.G. Estudo das relações entre desenvolvimento somático e erupção dentária, em escolares caucasóides, da cidade de Araraquara, estado de São Paulo, segundo a faixa etária, o sexo e o nível sócio-econômico. Araraquara, 1994. 168p. Tese (Doutorado) - Faculdade de Odontologia de Araraquara, Universidade Estadual Paulista.

161. YONEMOCHI, H.; NODA, T.; SAKU, T. Pericoronal hamartomatous lesions in the opercula of teeth delayed in eruption: an immunohistochemical study of the extracellular matrix. J. oral Path. Med., v.27, n.9, p.441-52, Oct. 1998. 
Abstract 


\section{ABSTRACT}

Comparative study of the chronology of eruption of permanent teeth and calcification of second molars in Angle Class I and Class II malocclusions.

The objective of this study was to compare the chronology of eruption of permanent teeth and the stages of calcification of the second molars in Angle Class I and Class II malocclusions, as well as to investigate if there is any correlation between these stages of calcification and the cephalometric measurements SNA, SNB, ANB, Co-A, Co-Gn. For evaluation of the chronology of eruption of permanent teeth (except for the third molars), 527 pairs of dental casts of young subjects aged 5 to 13 years old were employed, which were divided in two groups. Group 1 comprised dental casts presenting Angle Class I molar relationship, whereas Group 2 included those displaying an Angle Class II molar relationship. The mean age of eruption of the permanent teeth was determined by means of the Karber's method. Comparison between groups was evaluated by the independent $t$ test. For evaluation of the stages of calcification of the second molars and presence of correlation with the cephalometric measurements SNA, SNB, ANB, Co-A, Co-Gn, 60 panoramic radiographs and 60 lateral cephalograms of the same subjects were used, which had been obtained at 8 years old. These radiographs were also divided in two groups. Group 1 comprised radiographs of young individuals presenting Class I molar relationship, and Group 2 involved subjects with Class II molar relationship. The stages of calcification of the second molars were determined as suggested by Nolla. Comparison between groups was accomplished through the nonparametric Mann-Whitney's test. The results demonstrated that, in general, individuals presenting Class I molar relationship presented earlier mean ages of eruption of the permanent teeth when compared to those subjects with Class II molar relationship. This difference was statistically significant for all second molars, as well as for the teeth $15,23,34$ and 45 . No statistically significant differences could be found between the stages of calcification of the second molars in the evaluated groups; moreover, there was no correlation between the cephalometric measurements analyzed and the stages of calcification for either group. 


\section{Apêndices}




\section{APÊNDICES}

$\mathrm{Na}$ tabela A-1 estão apresentadas as características dos jovens dos grupos Classe I e Classe II e os valores individuais das grandezas cefalométricas SNA, SNB, ANB, Co-A e Co-Gn.

Na tabela A-2 estão demonstrados os valores individuais dos estágios de calcificação dos segundos molares dos jovens dos grupos Classe I e Classe II.

As tabelas A-3 a A-20 referem-se a classificação dos dentes permanentes em presentes $(P)$ ou ausentes (-), para cada jovem de ambos os grupos considerados, na faixa etária dos 5 aos 13 anos de idade. As tabelas com numeração ímpar referem-se aos dentes do arco superior e as com numeração par aos dentes do arco inferior. 
TABELA A-1

\begin{tabular}{|c|c|c|c|c|c|c|c|c|}
\hline Nome & Grupo & Gênero & Idade & SNA & SNB & ANB & Co-A & Co-Gn \\
\hline A.P.T. & Classe I & $F$ & 8,58 & 79 & 72 & 7 & 73 & 92 \\
\hline T.M.L. & Classe I & $\mathrm{F}$ & 8,58 & 84 & 80 & 4 & 80 & 103 \\
\hline A.C.M. & Classe I & $F$ & 8,66 & 79 & 75 & 4 & 82 & 106 \\
\hline E.P.P. & Classe I & $\mathrm{F}$ & 8,83 & 79 & 74 & 5 & 82 & 102 \\
\hline D.F.C. & Classe I & $F$ & 8,16 & 86 & 80 & 6 & 83 & 102 \\
\hline P.S.E. & Classe I & $F$ & 8,41 & 77 & 76 & 1 & 76 & 101 \\
\hline M.L.P. & Classe I & $F$ & 8,83 & 78 & 77 & 1 & 78 & 103 \\
\hline M.P.P. & Classe I & $\bar{F}$ & 8,50 & 82 & 82 & 0 & 81 & 106 \\
\hline A.P.M.B. & Classe I & $\bar{F}$ & 8,00 & 82 & 79 & 3 & 82,5 & 100 \\
\hline A.C.D. & Classe I & $\mathrm{F}$ & 8,50 & 78 & 77 & 1 & 74 & 98 \\
\hline A.L.T.P. & Classe I & $F$ & 8,33 & 78 & 72 & 6 & 86 & 104 \\
\hline C.B.J. & Classe I & $F$ & 8,41 & 83 & 77,5 & 5,5 & 84 & 106 \\
\hline A.Z.C. & Classe I & $F$ & 8,75 & 74 & 74 & 0 & 86 & 107 \\
\hline E.C.M. & Classe I & $\mathrm{F}$ & 8,91 & 80 & 73,5 & 6,5 & 82 & 103 \\
\hline L.C.V. & Classe I & $F$ & 8,75 & 78 & 74 & 4 & 87 & 108 \\
\hline J.M.R.M. & Classe I & $\bar{M}$ & 8,75 & 76 & 72 & 4 & 82 & 103 \\
\hline C.C.L.L. & Classe I & $\bar{M}$ & 8,25 & 83 & 82,5 & 0,5 & 81 & 106 \\
\hline R.A.A. & Classe I & $\mathrm{M}$ & 8,83 & 78 & 73 & 5 & 87 & 104 \\
\hline D.F.D. & Classe I & $\mathrm{M}$ & 8,08 & 77,5 & 73,5 & 4 & 81 & 100 \\
\hline C.J.C.F. & Classe I & $\bar{M}$ & 8,33 & 83,5 & 79 & 4,5 & 82 & 108 \\
\hline L.F.S.G. & Classe I & $\bar{M}$ & 8,25 & 82 & 81 & 1 & 80 & 108 \\
\hline R.C.M. & Classe I & $\mathrm{M}$ & 8,50 & 87 & 83 & 4 & 86 & 112 \\
\hline J.R.N. & Classe I & $\mathrm{M}$ & 8,91 & 78 & 75 & 3 & 91 & 110 \\
\hline T.F.D. & Classe I & $\bar{M}$ & 8,08 & 85 & 83 & 2 & 78 & 99 \\
\hline G.S.M. & Classe I & $\mathrm{M}$ & 8,50 & 83 & 78,5 & 4,5 & 72 & 98 \\
\hline M.Q.B. & Classe I & $\bar{M}$ & 8,66 & 87 & 81,5 & 5,5 & 92 & 114 \\
\hline H.J.S.S & Classe I & $\mathrm{M}$ & 8,75 & 82 & 77,5 & 4,5 & 84 & 109 \\
\hline R.V.D. & Classe I & $\mathrm{M}$ & 8,16 & 85 & 80 & 5 & 80 & 101 \\
\hline F.S. & Classe I & $\mathrm{M}$ & 8,50 & 81,5 & 77,5 & 4 & 78 & 100 \\
\hline W.R.N. & Classe I & $\mathrm{M}$ & 8,66 & 74 & 72 & 2 & 80 & 103 \\
\hline F.B.A. & Classe II & $\mathrm{F}$ & 8,33 & 80,5 & 77 & 3,5 & 86 & 109 \\
\hline M.F.G. & Classe II & $F$ & 8,08 & 77 & 73 & 4 & 81 & 101,5 \\
\hline S.R.C. & Classe II & $\mathrm{F}$ & 8,50 & 79 & 73,5 & 5,5 & 88 & 104 \\
\hline R.A.S.S. & Classe II & $F$ & 8,33 & 77,5 & 74 & 3,5 & 77 & 96 \\
\hline C.S. & Classe II & $\mathrm{F}$ & 8,91 & 84,5 & 80 & 4,5 & 84 & 103 \\
\hline T.C.C.C. & Classe II & $\bar{F}$ & 8,58 & 79,5 & 79 & 0,5 & 78 & 100 \\
\hline F.B. & Classe II & $F$ & 8,58 & 78 & 71 & 7 & 81 & 98 \\
\hline G.P. & Classe II & $F$ & 8,91 & 81 & 78 & 3 & 82 & 102 \\
\hline P.B.B.M. & Classe II & $F$ & 8,83 & 81 & 78,5 & 2,5 & 90 & 112 \\
\hline R.B.R. & Classe II & $F$ & 8,91 & 75,5 & 70 & 5,5 & 85 & 105 \\
\hline M.T.. & Classe II & $\bar{F}$ & 8,91 & 86,5 & 81 & 5,5 & 82 & 100 \\
\hline E.F.Z & Classe II & $F$ & 8,33 & 75 & 70 & 5 & 86 & 102 \\
\hline C.V.E. & Classe II & $\mathrm{F}$ & 8,33 & 79 & 77 & 2 & 83,5 & 107 \\
\hline S.D. & Classe II & $\bar{F}$ & 8,91 & 81 & 77,5 & 3,5 & 85 & 106 \\
\hline F.B.R. & Classe II & $F$ & 8,91 & 75 & 69 & 6 & 83 & 99 \\
\hline A.F.G. & Classe II & $\mathrm{M}$ & 8,58 & 77 & 73,5 & 3,5 & 80 & 108 \\
\hline A.G.M. & Classe II & $\mathrm{M}$ & 8,41 & 80 & 74 & 6 & 88,5 & 109 \\
\hline T.S.N.J. & Classe II & $\mathrm{M}$ & 8,58 & 80 & 74 & 6 & 89 & 110 \\
\hline P.B.J. & Classe II & $\mathrm{M}$ & 8,66 & 77 & 74 & 3 & 78 & 99 \\
\hline J.C.M.J. & Classe II & $\bar{M}$ & 8,91 & 80 & 77,5 & 2,5 & 90 & 111,5 \\
\hline M.A.P.T. & Classe II & $\bar{M}$ & 8,00 & 80 & 73 & 7 & 83,5 & 101 \\
\hline O.C. & Classe II & $\bar{M}$ & 8,08 & 75 & 67 & 8 & 88 & 102 \\
\hline B.M.L. & Classe II & $\mathrm{M}$ & 8,16 & 83 & 82 & 1 & 82 & 104 \\
\hline J.A.R.C. & Classe II & $\bar{M}$ & 8,00 & 81 & 77 & 4 & 85 & 104 \\
\hline R.O.B.A. & Classe II & $\mathrm{M}$ & 8,50 & 81,5 & 75,5 & 6 & 93 & 109 \\
\hline J.A.A.C. & Classe II & $\mathrm{M}$ & 8,91 & 79,5 & 73 & 6,5 & 91 & 107 \\
\hline R.F.B. & Classe II & $\mathrm{M}$ & 8,66 & 77 & 74 & 3 & 81 & 104 \\
\hline A.R.F. & Classe II & $\bar{M}$ & 8,91 & 80 & 72,5 & 7,5 & 91 & 112 \\
\hline M.G.T. & Classe II & $\bar{M}$ & 8,66 & 82 & 76 & 6 & 89 & 110 \\
\hline R.R.D. & Classe II & $\mathrm{M}$ & 8,00 & 84 & 77 & 7 & 85 & 103 \\
\hline
\end{tabular}


TABELA A-2

\begin{tabular}{|c|c|c|c|c|c|c|c|}
\hline NOME & Grupo & Gênero & Idade & 17 & 27 & 37 & 47 \\
\hline A.P.T. & Classe I & $\mathrm{F}$ & 8,58 & 4 & 4 & 6 & 6 \\
\hline I.M.L. & Classe I & $F$ & 8,58 & 6,5 & 6,5 & 7 & 7 \\
\hline A.C.M. & Classe I & $\mathrm{F}$ & 8,66 & 5 & 5 & 4 & 4 \\
\hline E.P.P. & Classe I & $\mathrm{F}$ & 8,83 & 6 & 6 & 7 & 7 \\
\hline D.F.C. & Classe I & $\mathrm{F}$ & 8,16 & 4 & 4 & 4,5 & 4,5 \\
\hline P.S.E. & Classe I & $F$ & 8,41 & 6 & 6 & 6,5 & 6,5 \\
\hline M.L.P. & Classe I & $F$ & 8,83 & 4 & 4 & 6 & 6 \\
\hline M.P.P. & Classe I & $F$ & 8,50 & 6 & 6 & 6,5 & 6,5 \\
\hline A.P.M.B. & Classe I & $\mathrm{F}$ & 8,00 & 5 & 5 & 7 & 7 \\
\hline A.C.D. & Classe I & $F$ & 8,50 & 5 & 5 & 5 & 5 \\
\hline A.L.T.P. & Classe I & $\mathrm{F}$ & 8,33 & 5 & 5 & 6 & 6 \\
\hline C.B.J. & Classe I & $F$ & 8,41 & 5 & 5 & 6,5 & 6,5 \\
\hline A.Z.C. & Classe I & $F$ & 8,75 & 6 & 6 & 7 & 7 \\
\hline E.C.M. & Classe I & $F$ & 8,91 & 6 & 6 & 6,5 & 6,5 \\
\hline L.C.V. & Classe I & $F$ & 8,75 & 6 & 6 & 7 & 7 \\
\hline J.M.R.M. & Classe I & $\mathrm{M}$ & 8,75 & 6 & 6 & 7 & 7 \\
\hline C.C.L.L. & Classe I & $\mathrm{M}$ & 8,25 & 4,5 & 4,5 & 5,5 & 5,5 \\
\hline R.A.A. & Classe I & $\bar{M}$ & 8,83 & 4,5 & 4,5 & 4,5 & 4,5 \\
\hline D.F.D. & Classe I & $\bar{M}$ & 8,08 & 4 & 4 & 5 & 5 \\
\hline C.J.C.F. & Classe I & $\bar{M}$ & 8,33 & 6 & 6 & 6,5 & 6,5 \\
\hline L.F.S.G. & Classe I & $\mathrm{M}$ & 8,25 & 6 & 6 & 6,5 & 6,5 \\
\hline R.C.M. & Classe I & $\bar{M}$ & 8,50 & 5 & 5 & 5 & 5 \\
\hline J.R.N. & Classe I & $\mathrm{M}$ & 8,91 & 5 & 5 & 5 & 5 \\
\hline T.F.D. & Classe I & $\mathrm{M}$ & 8,08 & 5 & 5 & 5 & 5 \\
\hline G.S.M. & Classe I & $\bar{M}$ & 8,50 & 4 & 4 & 4 & 4 \\
\hline M.Q.B. & Classe I & $\bar{M}$ & 8,66 & 4,5 & 4,5 & 5 & 5 \\
\hline H.J.S.S. & Classe I & $\mathrm{M}$ & 8,75 & 6 & 6 & 6 & 6 \\
\hline R.V.D. & Classe I & $\bar{M}$ & 8,16 & 4,5 & 4,5 & 4,5 & 4,5 \\
\hline F.S. & Classe I & $\mathrm{M}$ & 8,50 & 4 & 4 & 4,5 & 4,5 \\
\hline W.R.N. & Classe I & $\mathrm{M}$ & 8,66 & 4 & 4 & 5 & 5 \\
\hline F.B.A. & Classe II & $\mathrm{F}$ & 8,33 & 4,5 & 4,5 & 5 & 5 \\
\hline M.F.G. & Classe II & $F$ & 8,08 & 4,5 & 4,5 & 6 & 6 \\
\hline S.R.C. & Classe II & $F$ & 8,50 & 6 & 6 & 6,5 & 6,5 \\
\hline R.A.S.S. & Classe II & $F$ & 8,33 & 3,5 & 3,5 & 4 & 4 \\
\hline C.S. & Classe II & $\mathrm{F}$ & 8,91 & 6 & 6 & 6 & 6 \\
\hline T.C.C.C. & Classe II & $F$ & 8,58 & 4,5 & 4,5 & 5 & 5 \\
\hline F.B. & Classe II & $F$ & 8,58 & 5,5 & 5,5 & 6,5 & 6,5 \\
\hline G.P. & Classe II & $F$ & 8,91 & 6 & 6 & 6,5 & 6,5 \\
\hline P.B.B.M. & Classe II & $\mathrm{F}$ & 8,83 & 6 & 6 & 6,5 & 6,5 \\
\hline R.B.R. & Classe II & $\mathrm{F}$ & 8,91 & 4 & 4 & 4 & 4 \\
\hline M.T.. & Classe II & $F$ & 8,91 & 4 & 4 & 4 & 4 \\
\hline E.F.Z & Classe II & $\mathrm{F}$ & 8,33 & 5 & 5 & 6 & 6 \\
\hline C.V.E. & Classe II & $\mathrm{F}$ & 8,33 & 6 & 6 & 7 & 7 \\
\hline S.D. & Classe II & $\mathrm{F}$ & 8,91 & 5 & 5 & 5 & 5 \\
\hline F.B.R. & Classe II & $F$ & 8,91 & 5 & 5 & 5 & 5 \\
\hline A.F.G. & Classe II & $\bar{M}$ & 8,58 & 6,5 & 6,5 & 6,5 & 6,5 \\
\hline A.G.M. & Classe II & $\bar{M}$ & 8,41 & 6 & 6 & 6 & 6 \\
\hline T.S.N.J. & Classe II & $\bar{M}$ & 8,58 & 5 & 5 & 4,5 & 4,5 \\
\hline P.B.J. & Classe II & $\mathrm{M}$ & 8,66 & 5 & 5 & 5 & 5 \\
\hline J.C.M.J. & Classe II & $\mathrm{M}$ & 8,91 & 4 & 4 & 4 & 4 \\
\hline M.A.P.T. & Classe II & $\bar{M}$ & 8,00 & 5 & 5 & 5 & 5 \\
\hline O.C. & Classe II & $\mathrm{M}$ & 8,08 & 6 & 6 & 6 & 6 \\
\hline B.M.L. & Classe II & $\bar{M}$ & 8,16 & 4 & 4 & 4,5 & 4,5 \\
\hline J.A.R.C. & Classe II & $\mathrm{M}$ & 8,00 & 5 & 5 & 5 & 5 \\
\hline R.O.B.A. & Classe II & $\mathrm{M}$ & 8,50 & 4 & 4 & 4 & 4 \\
\hline J.A.A.C. & Classe II & $\mathrm{M}$ & 8,91 & 5 & 5 & 4,5 & 4,5 \\
\hline R.F.B. & Classe II & $\mathrm{M}$ & 8,66 & 6 & 6 & 7 & 7 \\
\hline A.R.F. & Classe II & $\bar{M}$ & 8,91 & 5 & 5 & 5 & 5 \\
\hline M.G.T. & Classe II & $\bar{M}$ & 8,66 & 6 & 6 & 6,5 & 6,5 \\
\hline R.R.D. & Classe II & $\bar{M}$ & 8,00 & 5 & 5 & 5 & 5 \\
\hline
\end{tabular}




\section{TABELA A-3}

\begin{tabular}{|c|c|c|c|c|c|c|c|c|c|c|c|c|c|c|c|c|c|}
\hline Nome & Classe & Idade & Gênero & 17 & 16 & 15 & 14 & 13 & 12 & 11 & 21 & 22 & 23 & 24 & 25 & 26 & 27 \\
\hline A.P.T. & $\mathrm{T}$ & 5,50 & $F$ & - & - & - & - & - & - & - & - & - & - & - & - & - & - \\
\hline J.M.R.M. & I & 5,41 & $M$ & - & - & - & - & - & - & - & - & - & - & - & - & - & - \\
\hline T.S.C. & $\mathrm{T}$ & 5,08 & $\bar{M}$ & - & - & - & - & - & - & - & - & - & - & - & - & - & - \\
\hline D.F.D & $\mathrm{I}$ & 5,66 & $M$ & - & - & - & - & - & - & - & - & - & - & - & - & - & - \\
\hline G.R.C. & $\mathrm{I}$ & 5,00 & $M$ & - & - & - & - & - & - & - & - & - & - & - & - & - & - \\
\hline A.C.M. & $\mathrm{T}$ & 5,58 & $F$ & - & - & - & - & - & - & - & - & - & - & - & - & - & - \\
\hline E.P.P. & $\mathrm{I}$ & 5,75 & $\mathrm{~F}$ & - & - & - & - & - & - & $\mathrm{P}$ & - & - & - & - & - & - & - \\
\hline P.S.P.C. & $\mathrm{I}$ & 5,08 & $\bar{M}$ & - & - & - & - & - & - & - & - & - & - & - & - & - & - \\
\hline E.C.M. & I & 5,91 & $\mathrm{~F}$ & - & - & - & - & - & - & - & - & - & - & - & - & - & - \\
\hline A.L.M. & $\mathrm{T}$ & 5,16 & $\mathrm{~F}$ & - & - & - & - & - & - & - & - & - & - & - & - & - & - \\
\hline E.D.B. & $T$ & 5,66 & $\mathrm{~F}$ & - & - & - & - & - & - & - & - & - & - & - & - & - & - \\
\hline V.M.A.C. & $\mathrm{I}$ & 5,33 & $\mathrm{~F}$ & - & - & - & - & - & - & $\mathrm{P}$ & - & - & - & - & - & - & - \\
\hline C.C.L.L. & $T$ & 5,50 & $\bar{M}$ & - & - & - & - & - & - & - & - & - & - & - & - & - & - \\
\hline A.C.D. & I & 5,16 & $\mathrm{~F}$ & - & - & - & - & - & - & - & - & - & - & - & - & - & - \\
\hline F.B.C. & $\mathrm{I}$ & 5,25 & $\bar{M}$ & - & - & - & - & - & - & - & - & - & - & - & - & - & - \\
\hline C.J.C.F. & I & 5,25 & $\bar{M}$ & - & - & - & - & - & - & - & - & - & - & - & - & - & - \\
\hline D.F.C. & $\mathrm{T}$ & 5,66 & $\mathrm{~F}$ & - & - & - & - & - & - & - & - & - & - & - & - & - & - \\
\hline R.F.E. & $\mathrm{I}$ & 5,25 & $\bar{M}$ & - & - & - & - & - & - & - & - & - & - & - & - & - & - \\
\hline S.T.G. & 1 & 5,00 & $M$ & - & - & - & - & - & - & - & - & - & - & - & - & - & - \\
\hline M.P.P. & $\mathrm{T}$ & 5,33 & $F$ & - & - & - & - & - & - & - & - & - & - & - & - & - & - \\
\hline T.F.D. & I & 5,08 & $\bar{M}$ & - & - & - & - & - & - & - & - & - & - & - & - & - & - \\
\hline C.L.C. & $\mathrm{I}$ & 5,25 & $\mathrm{~F}$ & - & - & - & - & - & - & - & - & - & - & - & - & - & - \\
\hline D.E.H. & 1 & 5,25 & $\mathrm{~F}$ & - & - & - & - & - & - & - & - & - & - & - & - & - & - \\
\hline M.L.P. & 1 & 5,58 & $F$ & - & - & - & - & - & - & - & - & - & - & - & - & - & - \\
\hline A.P.M.B. & 1 & 5,83 & $\mathrm{~F}$ & - & $\mathrm{P}$ & - & - & - & - & - & - & - & - & - & - & - & - \\
\hline P.S.E. & 1 & 5,50 & $\mathrm{~F}$ & - & - & - & - & - & - & - & - & - & - & - & - & - & - \\
\hline E.L.C.S. & $\mathrm{I}$ & 5,91 & $\mathrm{M}$ & - & - & - & - & - & - & - & - & - & - & - & - & - & - \\
\hline H.J.S.S. & 1 & 5,58 & $\mathrm{M}$ & - & - & - & - & - & - & - & - & - & - & - & - & - & - \\
\hline M.S. & 1 & 5,16 & $M$ & - & - & - & - & - & - & - & - & - & - & - & - & - & - \\
\hline E.A. & $\mathrm{I}$ & 5,75 & $M$ & - & - & - & - & - & - & - & - & - & - & - & - & - & - \\
\hline R.A.A.P.R. & II & 5,75 & $\mathrm{~F}$ & - & - & - & - & - & - & - & - & - & - & - & - & - & - \\
\hline A.I.M.B. & II & 5,08 & $\mathrm{~F}$ & - & - & - & - & - & - & - & - & - & - & - & - & - & - \\
\hline D.A.M. & II & 5,25 & $M$ & - & - & - & - & - & - & - & - & - & - & - & - & - & - \\
\hline T.V.S. & II & 5,58 & $\bar{M}$ & - & - & - & - & - & - & - & - & - & - & - & - & - & - \\
\hline J.C.M.J. & II & 5,75 & $\bar{M}$ & - & - & - & - & - & - & - & - & - & - & - & - & - & - \\
\hline A.F.G. & II & 5,66 & $\bar{M}$ & - & $\mathrm{P}$ & - & - & - & - & - & - & - & - & - & - & $\mathrm{P}$ & - \\
\hline P.B.J. & II & 5,33 & $M$ & - & - & - & - & - & - & - & - & - & - & - & - & - & - \\
\hline R.G.M. & II & 5,25 & $M$ & - & - & - & - & - & - & - & - & - & - & - & - & - & - \\
\hline T.C.C.C. & II & 5,58 & $\mathrm{~F}$ & - & - & - & - & - & - & - & - & - & - & - & - & - & - \\
\hline C.H.T. & II & 5,91 & $M$ & - & $\mathrm{P}$ & - & - & - & - & - & - & - & - & - & - & $\mathrm{P}$ & - \\
\hline R.P.F. & II & 5,83 & $\bar{M}$ & - & - & - & - & - & - & - & - & - & - & - & - & - & - \\
\hline E.C.L. & II & 5,66 & $F$ & - & - & - & - & - & - & - & - & - & - & - & - & - & - \\
\hline R.F.B. & II & 5,83 & $\bar{M}$ & - & - & - & - & - & - & - & - & - & - & - & - & - & - \\
\hline R.R.D. & II & 5,66 & $M$ & - & - & - & - & - & - & - & - & - & - & - & - & - & - \\
\hline J.A.M. & II & 5,91 & $M$ & - & - & - & - & - & - & - & - & - & - & - & - & - & - \\
\hline R.O.B.A. & II & 5,58 & $\bar{M}$ & - & - & - & - & - & - & - & - & - & - & - & - & - & - \\
\hline C.F.Z.S. & II & 5,16 & $F$ & - & - & - & - & - & - & - & - & - & - & - & - & - & - \\
\hline R.A.S.S. & II & 5,16 & $\mathrm{~F}$ & - & - & - & - & - & - & - & - & - & - & - & - & - & - \\
\hline F.B.A. & II & 5,08 & $\mathrm{~F}$ & - & - & - & - & - & - & - & - & - & - & - & - & - & - \\
\hline M.F.G. & II & 5,66 & $\mathrm{~F}$ & - & - & - & - & - & - & - & - & - & - & - & - & $P$ & - \\
\hline D.D. & II & 5,91 & $F$ & - & - & - & - & - & - & - & - & - & - & - & - & - & - \\
\hline F.B.R. & II & 5,08 & $\mathrm{~F}$ & - & - & - & - & - & - & - & - & - & - & - & - & - & - \\
\hline E.F.Z. & II & 5,33 & $F$ & - & - & - & - & - & - & - & - & - & - & - & - & - & - \\
\hline A.R.F. & II & 5,91 & $M$ & - & $\mathrm{P}$ & - & - & - & - & - & - & - & - & - & - & $\mathrm{P}$ & - \\
\hline M.G.T. & II & 5,66 & $\mathrm{M}$ & - & $\mathrm{P}$ & - & - & - & - & - & - & - & - & - & - & $\mathrm{P}$ & - \\
\hline T.S.N.J. & II & 5,25 & $\mathrm{M}$ & - & - & - & - & - & - & - & - & - & - & - & - & - & - \\
\hline O.C.C. & II & 5,66 & $\bar{M}$ & - & - & - & - & - & - & - & - & - & - & - & - & - & - \\
\hline J.A.A.C. & II & 5,83 & $\mathrm{M}$ & - & $\mathrm{P}$ & - & - & - & - & - & - & - & - & - & - & $\mathrm{P}$ & \\
\hline F.B. & II & 5,58 & $\mathrm{~F}$ & - & - & - & - & - & - & - & - & - & - & - & - & - & - \\
\hline C.B.J. & II & 5,33 & $\mathrm{~F}$ & - & - & - & - & - & - & - & - & - & - & - & - & - & - \\
\hline
\end{tabular}




\section{TABELA A-4}

\begin{tabular}{|c|c|c|c|c|c|c|c|c|c|c|c|c|c|c|c|c|c|}
\hline Nome & Classe & Idade & Gênero & 37 & 36 & 35 & 34 & 33 & 32 & 31 & 41 & 42 & 43 & 44 & 45 & 46 & 47 \\
\hline A.P.T. & $\mathrm{T}$ & 5,50 & $F$ & - & - & - & - & - & - & - & - & - & - & - & - & - & - \\
\hline J.M.R.M. & I & 5,41 & $M$ & - & - & - & - & - & - & - & - & - & - & - & - & - & - \\
\hline T.S.C. & $\mathrm{T}$ & 5,08 & $\bar{M}$ & - & - & - & - & - & - & - & - & - & - & - & - & - & - \\
\hline D.F.D & $\mathrm{I}$ & 5,66 & $M$ & - & - & - & - & - & - & - & - & - & - & - & - & - & - \\
\hline G.R.C. & $\mathrm{I}$ & 5,00 & $M$ & - & - & - & - & - & - & - & - & - & - & - & - & - & - \\
\hline A.C.M. & $\mathrm{T}$ & 5,58 & $\mathrm{~F}$ & - & - & - & - & - & - & - & - & - & - & - & - & - & - \\
\hline E.P.P. & $\mathrm{I}$ & 5,75 & $\mathrm{~F}$ & - & - & - & - & - & - & - & $\mathrm{P}$ & - & - & - & - & - & - \\
\hline P.S.P.C. & $\mathrm{I}$ & 5,08 & $\bar{M}$ & - & - & - & - & - & - & - & - & - & - & - & - & - & - \\
\hline E.C.M. & I & 5,91 & $\mathrm{~F}$ & - & - & - & - & - & - & - & - & - & - & - & - & - & - \\
\hline A.L.M. & $\mathrm{I}$ & 5,16 & $\mathrm{~F}$ & - & - & - & - & - & - & - & - & - & - & - & - & - & - \\
\hline E.D.B. & $T$ & 5,66 & $\mathrm{~F}$ & - & - & - & - & - & - & - & - & - & - & - & - & - & - \\
\hline V.M.A.C. & $\mathrm{I}$ & 5,33 & $\mathrm{~F}$ & - & $\mathrm{P}$ & - & - & - & - & - & - & - & - & - & - & $\mathrm{P}$ & - \\
\hline C.C.L.L. & $\mathrm{I}$ & 5,50 & $\bar{M}$ & - & - & - & - & - & - & - & - & - & - & - & - & - & - \\
\hline A.C.D. & I & 5,16 & $\mathrm{~F}$ & - & - & - & - & - & - & - & - & - & - & - & - & - & - \\
\hline F.B.C. & $\mathrm{I}$ & 5,25 & $\bar{M}$ & - & - & - & - & - & - & - & - & - & - & - & - & - & - \\
\hline C.J.C.F. & I & 5,25 & $\bar{M}$ & - & - & - & - & - & - & - & - & - & - & - & - & - & - \\
\hline D.F.C. & $\mathrm{T}$ & 5,66 & $\mathrm{~F}$ & - & - & - & - & - & - & - & - & - & - & - & - & - & - \\
\hline R.F.E. & $\mathrm{I}$ & 5,25 & $\bar{M}$ & - & - & - & - & - & - & - & - & - & - & - & - & - & - \\
\hline S.T.G. & 1 & 5,00 & $M$ & - & - & - & - & - & - & - & - & - & - & - & - & - & - \\
\hline M.P.P. & $\mathrm{T}$ & 5,33 & $F$ & - & - & - & - & - & - & - & - & - & - & - & - & - & - \\
\hline T.F.D. & I & 5,08 & $\bar{M}$ & - & - & - & - & - & - & - & - & - & - & - & - & - & - \\
\hline C.L.C. & $\mathrm{I}$ & 5,25 & $\mathrm{~F}$ & - & - & - & - & - & - & - & - & - & - & - & - & - & - \\
\hline D.E.H. & 1 & 5,25 & $\mathrm{~F}$ & - & - & - & - & - & - & - & - & - & - & - & - & - & - \\
\hline M.L.P. & 1 & 5,58 & $\mathrm{~F}$ & - & $\mathrm{P}$ & - & - & - & - & - & - & - & - & - & - & $\mathrm{P}$ & - \\
\hline A.P.M.B. & 1 & 5,83 & $\mathrm{~F}$ & - & $\mathrm{P}$ & - & - & - & - & $\mathrm{P}$ & $\mathrm{P}$ & - & - & - & - & $\mathrm{P}$ & - \\
\hline P.S.E. & 1 & 5,50 & $\mathrm{~F}$ & - & - & - & - & - & - & - & - & - & - & - & - & - & - \\
\hline E.L.C.S. & $\mathrm{I}$ & 5,91 & $\mathrm{M}$ & - & $\mathrm{P}$ & - & - & - & - & - & - & - & - & - & - & - & - \\
\hline H.J.S.S. & 1 & 5,58 & $\mathrm{M}$ & - & - & - & - & - & - & - & - & - & - & - & - & - & - \\
\hline M.S. & 1 & 5,16 & $M$ & - & - & - & - & - & - & - & - & - & - & - & - & - & - \\
\hline E.A. & $\mathrm{I}$ & 5,75 & $M$ & - & - & - & - & - & - & - & - & - & - & - & - & - & - \\
\hline R.A.A.P.R. & II & 5,75 & $\mathrm{~F}$ & - & - & - & - & - & - & - & - & - & - & - & - & - & - \\
\hline A.I.M.B. & II & 5,08 & $\mathrm{~F}$ & - & - & - & - & - & - & - & - & - & - & - & - & - & - \\
\hline D.A.M. & II & 5,25 & $M$ & - & - & - & - & - & - & - & - & - & - & - & - & - & - \\
\hline T.V.S. & II & 5,58 & $\bar{M}$ & - & - & - & - & - & - & - & - & - & - & - & - & - & - \\
\hline J.C.M.J. & II & 5,75 & $\bar{M}$ & - & - & - & - & - & - & - & - & - & - & - & - & - & - \\
\hline A.F.G. & II & 5,66 & $\bar{M}$ & - & $\mathrm{P}$ & - & - & - & - & - & $\mathrm{P}$ & - & - & - & - & $\mathrm{P}$ & - \\
\hline P.B.J. & II & 5,33 & $M$ & - & - & - & - & - & - & - & - & - & - & - & - & - & - \\
\hline R.G.M. & II & 5,25 & $M$ & - & - & - & - & - & - & - & $\mathrm{P}$ & - & - & - & - & - & - \\
\hline T.C.C.C. & II & 5,58 & $\mathrm{~F}$ & - & - & - & - & - & - & - & - & - & - & - & - & - & - \\
\hline C.H.T. & II & 5,91 & $M$ & - & $\mathrm{P}$ & - & - & - & - & $\mathrm{P}$ & - & - & - & - & - & - & - \\
\hline R.P.F. & II & 5,83 & $\bar{M}$ & - & - & - & - & - & - & - & - & - & - & - & - & - & - \\
\hline E.C.L. & II & 5,66 & $F$ & - & - & - & - & - & - & - & - & - & - & - & - & - & - \\
\hline R.F.B. & II & 5,83 & $\mathrm{M}$ & - & - & - & - & - & - & - & - & - & - & - & - & - & - \\
\hline R.R.D. & II & 5,66 & $M$ & - & - & - & - & - & - & - & - & - & - & - & - & - & - \\
\hline J.A.M. & II & 5,91 & $M$ & - & - & - & - & - & - & - & - & - & - & - & - & - & - \\
\hline R.O.B.A. & II & 5,58 & $\bar{M}$ & - & - & - & - & - & - & - & - & - & - & - & - & - & - \\
\hline C.F.Z.S. & II & 5,16 & $F$ & - & - & - & - & - & - & - & - & - & - & - & - & - & - \\
\hline R.A.S.S. & II & 5,16 & $\mathrm{~F}$ & - & - & - & - & - & - & - & - & - & - & - & - & - & - \\
\hline F.B.A. & II & 5,08 & $\mathrm{~F}$ & - & - & - & - & - & - & - & - & - & - & - & - & - & - \\
\hline M.F.G. & II & 5,66 & $\mathrm{~F}$ & - & - & - & - & - & - & - & - & - & - & - & - & - & - \\
\hline D.D. & II & 5,91 & $F$ & - & - & - & - & - & - & $\mathrm{P}$ & $\mathrm{P}$ & - & - & - & - & - & - \\
\hline F.B.R. & II & 5,08 & $\mathrm{~F}$ & - & - & - & - & - & - & - & - & - & - & - & - & - & - \\
\hline E.F.Z. & II & 5,33 & $F$ & - & - & - & - & - & - & - & - & - & - & - & - & - & - \\
\hline A.R.F. & II & 5,91 & $M$ & - & - & - & - & - & - & - & $\mathrm{P}$ & - & - & - & - & - & - \\
\hline M.G.T. & II & 5,66 & $\mathrm{M}$ & - & $\mathrm{P}$ & - & - & - & - & $\mathrm{P}$ & $\mathrm{P}$ & - & - & - & - & $\mathrm{P}$ & - \\
\hline T.S.N.J. & II & 5,25 & $\mathrm{M}$ & - & - & - & - & - & - & - & - & - & - & - & - & - & - \\
\hline O.C.C. & II & 5,66 & $\bar{M}$ & - & - & - & - & - & - & - & - & - & - & - & - & - & - \\
\hline J.A.A.C. & II & 5,83 & $\mathrm{M}$ & - & - & - & - & - & - & - & $\mathrm{P}$ & - & - & - & - & - & - \\
\hline F.B. & II & 5,58 & $\mathrm{~F}$ & - & - & - & - & - & - & - & - & - & - & - & - & - & - \\
\hline C.B.J. & II & 5,33 & $\mathrm{~F}$ & - & - & - & - & - & - & - & - & - & - & - & - & - & - \\
\hline
\end{tabular}


TABELA A-5

\begin{tabular}{|c|c|c|c|c|c|c|c|c|c|c|c|c|c|c|c|c|c|}
\hline Nome & Classe & Idade & Gênero & 17 & 16 & 15 & 14 & 13 & 12 & 11 & 21 & 22 & 23 & 24 & 25 & 26 & 27 \\
\hline A.P.T. & $\mathrm{I}$ & 6,66 & $\mathrm{~F}$ & - & - & - & - & - & - & - & - & - & - & - & - & - & - \\
\hline R.A.A. & $\mathrm{I}$ & 6,33 & $M$ & - & $\mathrm{P}$ & - & - & - & - & - & - & - & - & - & - & $\mathrm{P}$ & - \\
\hline G.R.C. & $\mathrm{I}$ & 6,16 & $M$ & - & $\mathrm{P}$ & - & - & - & - & - & - & - & - & - & - & $P$ & - \\
\hline E.P.P. & $\mathrm{I}$ & 6,75 & $F$ & - & $\mathrm{P}$ & - & - & - & - & $\mathrm{P}$ & $\mathrm{P}$ & - & - & - & - & $\mathrm{P}$ & - \\
\hline P.S.P.C. & $\mathrm{I}$ & 6,50 & $\bar{M}$ & - & - & - & - & - & - & - & - & - & - & - & - & - & - \\
\hline E.C.M. & $\mathrm{T}$ & 6,91 & $\mathrm{~F}$ & - & - & - & - & - & - & - & - & - & - & - & - & - & - \\
\hline E.D.B. & I & 6,91 & $\mathrm{~F}$ & - & $\mathrm{P}$ & - & - & - & - & $\mathrm{P}$ & $\mathrm{P}$ & - & - & - & - & $\mathrm{P}$ & - \\
\hline V.M.A.C. & $T$ & 6,75 & $F$ & - & $\mathrm{P}$ & - & - & - & $P$ & $\mathrm{P}$ & $\mathrm{P}$ & $\mathrm{P}$ & - & - & - & $\mathrm{P}$ & - \\
\hline A.C.D. & $\mathrm{I}$ & 6,50 & $F$ & - & $\mathrm{P}$ & - & - & - & - & $P$ & $\mathrm{P}$ & - & - & - & - & $\mathrm{P}$ & - \\
\hline C.J.C.F. & $\mathrm{I}$ & 6,25 & $\bar{M}$ & - & $\mathrm{P}$ & - & - & - & - & $\mathrm{P}$ & - & - & - & - & - & $\mathrm{P}$ & - \\
\hline F.S. & $T$ & 6,33 & $\bar{M}$ & - & - & - & - & - & - & - & $\mathrm{P}$ & - & - & - & - & - & - \\
\hline R.F.E. & $\mathrm{I}$ & 6,25 & $\bar{M}$ & - & $\mathrm{P}$ & - & - & - & - & - & - & - & - & - & - & - & - \\
\hline S.T.G. & $\mathrm{T}$ & 6,41 & $\bar{M}$ & - & - & - & - & - & - & $P$ & $P$ & - & - & - & - & - & - \\
\hline M.Q.B. & 1 & 6,66 & $M$ & - & $\mathrm{P}$ & - & - & - & - & $\mathrm{P}$ & $\mathrm{P}$ & - & - & - & - & $\mathrm{P}$ & - \\
\hline M.P.P. & $\mathrm{T}$ & 6,58 & $\mathrm{~F}$ & - & - & - & - & - & - & $\mathrm{P}$ & $\mathrm{P}$ & - & - & - & - & $\mathrm{P}$ & - \\
\hline T.F.D. & $\mathrm{I}$ & 6,25 & $\bar{M}$ & - & $\mathrm{P}$ & - & - & - & - & - & - & - & - & - & - & - & - \\
\hline C.L.C. & $T$ & 6,41 & $\mathrm{~F}$ & - & $\mathrm{P}$ & - & - & - & - & - & $\mathrm{P}$ & - & - & - & - & $\mathrm{P}$ & - \\
\hline D.E.H. & $\mathrm{I}$ & 6,66 & $\mathrm{~F}$ & - & - & - & - & - & - & - & - & - & - & - & - & $P$ & - \\
\hline P.S.E. & $\mathrm{T}$ & 6,41 & $F$ & - & $\mathrm{P}$ & - & - & - & - & - & - & - & - & - & - & $\mathrm{P}$ & - \\
\hline J.R.N. & $T$ & 6,83 & $\bar{M}$ & - & $\mathrm{P}$ & - & - & - & - & - & - & - & - & - & - & $\mathrm{P}$ & - \\
\hline E.A. & $\mathrm{T}$ & 6,66 & $\bar{M}$ & - & $\mathrm{P}$ & - & - & - & - & - & - & - & - & - & - & $P$ & - \\
\hline R.A.C.M. & $\mathrm{I}$ & 6,58 & $M$ & - & - & - & - & - & - & - & - & - & - & - & - & - & - \\
\hline L.F.S.G. & 1 & 6,33 & $\mathrm{M}$ & - & - & - & - & - & - & - & - & - & - & - & - & - & - \\
\hline R.Q. & 1 & 6,83 & $\mathrm{M}$ & - & $\mathrm{P}$ & - & - & - & - & - & - & - & - & - & - & $\mathrm{P}$ & - \\
\hline E.L.C.S. & $\mathrm{I}$ & 6,91 & $M$ & - & $\mathrm{P}$ & - & - & - & - & - & - & - & - & - & - & $\mathrm{P}$ & - \\
\hline H.J.S.S. & I & 6,75 & M & - & $\mathrm{P}$ & - & - & - & - & - & - & - & - & - & - & $\mathrm{P}$ & - \\
\hline M.S. & $\mathrm{I}$ & 6,91 & $\mathrm{M}$ & - & $\mathrm{P}$ & - & - & - & - & - & - & - & - & - & - & $\mathrm{P}$ & - \\
\hline L.C.V. & 1 & 6,83 & $\mathrm{~F}$ & - & $\mathrm{P}$ & - & - & - & - & $\mathrm{P}$ & $\mathrm{P}$ & - & - & - & - & $\mathrm{P}$ & - \\
\hline A.L.T.P. & I & 6,91 & $\mathrm{~F}$ & - & $\mathrm{P}$ & - & - & - & - & $\mathrm{P}$ & - & - & - & - & - & $\mathrm{P}$ & - \\
\hline A.Z.C. & $\mathrm{I}$ & 6,91 & $\mathrm{~F}$ & - & $\mathrm{P}$ & - & - & - & - & $\mathrm{P}$ & $\mathrm{P}$ & - & - & - & - & $\mathrm{P}$ & - \\
\hline G.F.P. & II & 6,08 & $\mathrm{~F}$ & - & $\mathrm{P}$ & - & - & - & - & $\mathrm{P}$ & $\mathrm{P}$ & - & - & - & - & $\mathrm{P}$ & - \\
\hline A.I.M.B. & II & 6,50 & $\mathrm{~F}$ & - & - & - & - & - & - & $\mathrm{P}$ & $\mathrm{P}$ & - & - & - & - & - & - \\
\hline D.A.M. & II & 6,50 & $M$ & - & $\mathrm{P}$ & - & - & - & - & $\mathrm{P}$ & - & - & - & - & - & $\mathrm{P}$ & - \\
\hline J.C.M.J. & II & 6,91 & $\bar{M}$ & - & - & - & - & - & - & - & - & - & - & - & - & - & - \\
\hline A.F.G. & II & 6,83 & $\bar{M}$ & - & $\mathrm{P}$ & - & - & - & - & - & - & - & - & - & - & $\mathrm{P}$ & - \\
\hline M.A.P.T. & II & 6,08 & $\bar{M}$ & - & - & - & - & - & - & - & - & - & - & - & - & - & - \\
\hline P.B.J. & II & 6,75 & $M$ & - & $\mathrm{P}$ & - & - & - & - & - & - & - & - & - & - & $\mathrm{P}$ & - \\
\hline T.C.C.C. & II & 6,66 & $\mathrm{~F}$ & - & $\mathrm{P}$ & - & - & - & - & $\mathrm{P}$ & $\mathrm{P}$ & - & - & - & - & $\mathrm{P}$ & - \\
\hline R.P.F. & II & 6,75 & $\bar{M}$ & - & $\mathrm{P}$ & - & - & - & - & - & - & - & - & - & - & $\mathrm{P}$ & - \\
\hline E.C.L. & II & 6,75 & $F$ & - & - & - & - & - & - & - & - & - & - & - & - & - & - \\
\hline R.R.D. & II & 6,58 & $\bar{M}$ & - & $\mathrm{P}$ & - & - & - & - & - & - & - & - & - & - & $\mathrm{P}$ & - \\
\hline J.A.M. & II & 6,91 & $\bar{M}$ & - & - & - & - & - & - & - & - & - & - & - & - & - & - \\
\hline B.M.L. & II & 6,16 & $\bar{M}$ & - & - & - & - & - & - & - & - & - & - & - & - & $P$ & - \\
\hline R.O.B.A. & II & 6,41 & $M$ & - & - & - & - & - & - & - & - & - & - & - & - & - & - \\
\hline C.F.Z.S. & II & 6,16 & $\mathrm{~F}$ & - & - & - & - & - & - & - & - & - & - & - & - & - & - \\
\hline R.A.S.S. & II & 6,50 & $F$ & - & - & - & - & - & - & - & - & - & - & - & - & - & - \\
\hline R.B.R. & II & 6,25 & $F$ & - & $\mathrm{P}$ & - & - & - & - & - & - & - & - & - & - & $\mathrm{P}$ & - \\
\hline F.B.A. & II & 6,41 & $\mathrm{~F}$ & - & $\mathrm{P}$ & - & - & - & - & - & - & - & - & - & - & $\mathrm{P}$ & - \\
\hline M.F.G. & II & 6,58 & $F$ & - & $\mathrm{P}$ & - & - & - & - & $P$ & - & - & - & - & - & $P$ & - \\
\hline D.D. & II & 6,91 & $\mathrm{~F}$ & - & $P$ & - & - & - & - & $P$ & $\mathrm{P}$ & - & - & - & - & $P$ & - \\
\hline F.B.R. & II & 6,00 & $F$ & - & - & - & - & - & - & - & - & - & - & - & - & - & - \\
\hline E.F.Z. & II & 6,50 & $\mathrm{~F}$ & - & - & - & - & - & - & - & - & - & - & - & - & - & - \\
\hline A.R.F. & II & 6,91 & $\mathrm{M}$ & - & $\mathrm{P}$ & - & - & - & - & - & $\mathrm{P}$ & - & - & - & - & $\mathrm{P}$ & - \\
\hline M.G.T. & II & 6,58 & $M$ & - & $\mathrm{P}$ & - & - & - & - & $\mathrm{P}$ & $\mathrm{P}$ & - & - & - & - & $\mathrm{P}$ & - \\
\hline C.V.E. & II & 6,41 & $\mathrm{~F}$ & - & $\mathrm{P}$ & - & - & - & - & $\mathrm{P}$ & $\mathrm{P}$ & - & - & - & - & $\mathrm{P}$ & - \\
\hline R.T.D.G. & II & 6,91 & $\mathrm{M}$ & - & $\mathrm{P}$ & - & - & - & - & - & - & - & - & - & - & $\mathrm{P}$ & - \\
\hline J.A.A.C. & II & 6,91 & $\mathrm{M}$ & - & $\mathrm{P}$ & - & - & - & - & - & - & - & - & - & - & $\mathrm{P}$ & - \\
\hline P.B.B.M. & II & 6,75 & $F$ & - & $\mathrm{P}$ & - & - & - & - & - & - & - & - & - & - & $\mathrm{P}$ & - \\
\hline M.H.T. & II & 6,25 & $\mathrm{~F}$ & - & - & - & - & - & - & - & - & - & - & - & - & - & - \\
\hline F.B. & II & 6,66 & $F$ & - & $\mathrm{P}$ & - & - & - & - & - & $P$ & - & - & - & - & $\mathrm{P}$ & - \\
\hline
\end{tabular}


TABELA A-6

\begin{tabular}{|c|c|c|c|c|c|c|c|c|c|c|c|c|c|c|c|c|c|}
\hline Nome & Classe & Idade & Gênero & 37 & 36 & 35 & 34 & 33 & 32 & 31 & 41 & 42 & 43 & 44 & 45 & 46 & 47 \\
\hline A.P.T. & $\mathrm{I}$ & 6,66 & $\mathrm{~F}$ & - & - & - & - & - & - & - & - & - & - & - & - & - & - \\
\hline R.A.A. & $\mathrm{I}$ & 6,33 & $M$ & - & $\mathrm{P}$ & - & - & - & - & - & $P$ & $P$ & - & - & - & $\mathrm{P}$ & - \\
\hline G.R.C. & $\mathrm{I}$ & 6,16 & $M$ & - & $\mathrm{P}$ & - & - & - & - & $P$ & $P$ & - & - & - & - & $P$ & - \\
\hline E.P.P. & $\mathrm{I}$ & 6,75 & $\mathrm{~F}$ & - & $\mathrm{P}$ & - & - & - & $P$ & $\mathrm{P}$ & $\mathrm{P}$ & $\mathrm{P}$ & - & - & - & $\mathrm{P}$ & - \\
\hline P.S.P.C. & $\mathrm{I}$ & 6,50 & $\bar{M}$ & - & - & - & - & - & - & $\mathrm{P}$ & $\mathrm{P}$ & - & - & - & - & - & - \\
\hline E.C.M. & $\mathrm{T}$ & 6,91 & $\mathrm{~F}$ & - & $\mathrm{P}$ & - & - & - & - & $\mathrm{P}$ & $\mathrm{P}$ & - & - & - & - & $\mathrm{P}$ & - \\
\hline E.D.B. & $\mathrm{I}$ & 6,91 & $\mathrm{~F}$ & - & $\mathrm{P}$ & - & - & - & - & $\mathrm{P}$ & $\mathrm{P}$ & - & - & - & - & $\mathrm{P}$ & - \\
\hline V.M.A.C. & $\mathrm{I}$ & 6,75 & $F$ & - & $\mathrm{P}$ & - & - & - & $P$ & $\mathrm{P}$ & $\mathrm{P}$ & $\mathrm{P}$ & - & - & - & $\mathrm{P}$ & - \\
\hline A.C.D. & $\mathrm{I}$ & 6,50 & $\mathrm{~F}$ & - & $P$ & - & - & - & $P$ & $P$ & $\mathrm{P}$ & $\mathrm{P}$ & - & - & - & $P$ & - \\
\hline C.J.C.F. & $\mathrm{I}$ & 6,25 & $\bar{M}$ & - & $\mathrm{P}$ & - & - & - & - & $\mathrm{P}$ & $\mathrm{P}$ & - & - & - & - & $\mathrm{P}$ & - \\
\hline F.S. & $\mathrm{T}$ & 6,33 & $\bar{M}$ & - & - & - & - & - & - & - & - & - & - & - & - & - & - \\
\hline R.F.E. & $\mathrm{I}$ & 6,25 & $\bar{M}$ & - & $\mathrm{P}$ & - & - & - & - & - & - & - & - & - & - & $\mathrm{P}$ & - \\
\hline S.T.G. & $\mathrm{I}$ & 6,41 & $\bar{M}$ & - & - & - & - & - & - & $P$ & $P$ & - & - & - & - & - & - \\
\hline M.Q.B. & $\mathrm{I}$ & 6,66 & $M$ & - & $\mathrm{P}$ & - & - & - & $P$ & $\mathrm{P}$ & $\mathrm{P}$ & $\mathrm{P}$ & - & - & - & $\mathrm{P}$ & - \\
\hline M.P.P. & $\mathrm{I}$ & 6,58 & $\mathrm{~F}$ & - & $\mathrm{P}$ & - & - & - & - & $\mathrm{P}$ & $\mathrm{P}$ & - & - & - & - & $\mathrm{P}$ & - \\
\hline T.F.D. & $\mathrm{I}$ & 6,25 & $\bar{M}$ & - & $\mathrm{P}$ & - & - & - & - & $\mathrm{P}$ & $\mathrm{P}$ & - & - & - & - & $\mathrm{P}$ & - \\
\hline C.L.C. & $\mathrm{T}$ & 6,41 & $F$ & - & $\mathrm{P}$ & - & - & - & - & $\mathrm{P}$ & $\mathrm{P}$ & $\mathrm{P}$ & - & - & - & $\mathrm{P}$ & - \\
\hline D.E.H. & $\mathrm{I}$ & 6,66 & $\mathrm{~F}$ & - & $P$ & - & - & - & - & $P$ & $P$ & - & - & - & - & $P$ & - \\
\hline P.S.E. & $\mathrm{I}$ & 6,41 & $F$ & - & $\mathrm{P}$ & - & - & - & - & - & - & - & - & - & - & - & - \\
\hline J.R.N. & $\mathrm{T}$ & 6,83 & $\bar{M}$ & - & - & - & - & - & - & $\mathrm{P}$ & $\mathrm{P}$ & - & - & - & - & - & - \\
\hline E.A. & $\mathrm{T}$ & 6,66 & $\bar{M}$ & - & - & - & - & - & - & - & - & - & - & - & - & - & - \\
\hline R.A.C.M. & 1 & 6,58 & $M$ & - & - & - & - & - & - & $\mathrm{P}$ & $\mathrm{P}$ & - & - & - & - & - & - \\
\hline L.F.S.G. & 1 & 6,33 & $\mathrm{M}$ & - & - & - & - & - & - & $\mathrm{P}$ & $\mathrm{P}$ & $\mathrm{P}$ & - & - & - & - & - \\
\hline R.Q. & 1 & 6,83 & $\mathrm{M}$ & - & $\mathrm{P}$ & - & - & - & - & $\mathrm{P}$ & - & - & - & - & - & $\mathrm{P}$ & - \\
\hline E.L.C.S. & $\mathrm{I}$ & 6,91 & $M$ & - & $\mathrm{P}$ & - & - & - & $\mathrm{P}$ & $\mathrm{P}$ & $\mathrm{P}$ & $\mathrm{P}$ & - & - & - & $\mathrm{P}$ & - \\
\hline H.J.S.S. & I & 6,75 & M & - & $\mathrm{P}$ & - & - & - & - & $\mathrm{P}$ & $\mathrm{P}$ & - & - & - & - & $\mathrm{P}$ & - \\
\hline M.S. & $\mathrm{I}$ & 6,91 & $\mathrm{M}$ & - & $\mathrm{P}$ & - & - & - & - & - & - & - & - & - & - & $\mathrm{P}$ & - \\
\hline L.C.V. & 1 & 6,83 & $\mathrm{~F}$ & - & $\mathrm{P}$ & - & - & - & $\mathrm{P}$ & $\mathrm{P}$ & $\mathrm{P}$ & $\mathrm{P}$ & - & - & - & $\mathrm{P}$ & - \\
\hline A.L.T.P. & I & 6,91 & $\mathrm{~F}$ & - & $\mathrm{P}$ & - & - & - & - & $\mathrm{P}$ & $\mathrm{P}$ & - & - & - & - & $\mathrm{P}$ & - \\
\hline A.Z.C. & $\mathrm{I}$ & 6,91 & $\mathrm{~F}$ & - & $\mathrm{P}$ & - & - & - & $\mathrm{P}$ & $\mathrm{P}$ & $\mathrm{P}$ & $\mathrm{P}$ & - & - & - & $\mathrm{P}$ & - \\
\hline G.F.P. & II & 6,08 & $\mathrm{~F}$ & - & $\mathrm{P}$ & - & - & - & - & $\mathrm{P}$ & $\mathrm{P}$ & - & - & - & - & $\mathrm{P}$ & - \\
\hline A.I.M.B. & II & 6,50 & $\mathrm{~F}$ & - & - & - & - & - & - & $\mathrm{P}$ & $\mathrm{P}$ & - & - & - & - & - & - \\
\hline D.A.M. & II & 6,50 & $M$ & - & $\mathrm{P}$ & - & - & - & $\mathrm{P}$ & $\mathrm{P}$ & $\mathrm{P}$ & - & - & - & - & $\mathrm{P}$ & - \\
\hline J.C.M.J. & II & 6,91 & $\bar{M}$ & - & - & - & - & - & - & - & $\mathrm{P}$ & - & - & - & - & - & - \\
\hline A.F.G. & II & 6,83 & $\bar{M}$ & - & $\mathrm{P}$ & - & - & - & - & $\mathrm{P}$ & $\mathrm{P}$ & - & - & - & - & $\mathrm{P}$ & - \\
\hline M.A.P.T. & II & 6,08 & $\bar{M}$ & - & $\mathrm{P}$ & - & - & - & - & $\mathrm{P}$ & $\mathrm{P}$ & - & - & - & - & $\mathrm{P}$ & - \\
\hline P.B.J. & II & 6,75 & $M$ & - & $\mathrm{P}$ & - & - & - & - & - & - & - & - & - & - & $\mathrm{P}$ & - \\
\hline T.C.C.C. & II & 6,66 & $\mathrm{~F}$ & - & $\mathrm{P}$ & - & - & - & - & $\mathrm{P}$ & $\mathrm{P}$ & - & - & - & - & $\mathrm{P}$ & - \\
\hline R.P.F. & II & 6,75 & $\bar{M}$ & - & $\mathrm{P}$ & - & - & - & - & $\mathrm{P}$ & $\mathrm{P}$ & - & - & - & - & $\mathrm{P}$ & - \\
\hline E.C.L. & II & 6,75 & $F$ & - & $\mathrm{P}$ & - & - & - & - & - & - & - & - & - & - & $\mathrm{P}$ & - \\
\hline R.R.D. & II & 6,58 & $\bar{M}$ & - & - & - & - & - & - & $P$ & $P$ & - & - & - & - & $\mathrm{P}$ & - \\
\hline J.A.M. & II & 6,91 & $\bar{M}$ & - & $\mathrm{P}$ & - & - & - & - & $\mathrm{P}$ & $\mathrm{P}$ & - & - & - & - & $\mathrm{P}$ & - \\
\hline B.M.L. & II & 6,16 & $\bar{M}$ & - & $P$ & - & - & - & - & - & - & - & - & - & - & $P$ & - \\
\hline R.O.B.A. & II & 6,41 & $M$ & - & - & - & - & - & - & - & $\mathrm{P}$ & - & - & - & - & - & - \\
\hline C.F.Z.S. & II & 6,16 & $\mathrm{~F}$ & - & - & - & - & - & - & $\mathrm{P}$ & $\mathrm{P}$ & - & - & - & - & - & - \\
\hline R.A.S.S. & II & 6,50 & $F$ & - & - & - & - & - & - & - & - & - & - & - & - & - & - \\
\hline R.B.R. & II & 6,25 & $F$ & - & $\mathrm{P}$ & - & - & - & - & - & - & - & - & - & - & - & - \\
\hline F.B.A. & II & 6,41 & $F$ & - & $\mathrm{P}$ & - & - & - & $P$ & $\mathrm{P}$ & $\mathrm{P}$ & $\mathrm{P}$ & - & - & - & - & - \\
\hline M.F.G. & II & 6,58 & $F$ & - & $\mathrm{P}$ & - & - & - & - & $P$ & $P$ & - & - & - & - & $P$ & - \\
\hline D.D. & II & 6,91 & $\mathrm{~F}$ & - & $\mathrm{P}$ & - & - & - & $P$ & $\mathrm{P}$ & $\mathrm{P}$ & $\mathrm{P}$ & - & - & - & $\mathrm{P}$ & - \\
\hline F.B.R. & II & 6,00 & $F$ & - & - & - & - & - & - & - & - & - & - & - & - & - & - \\
\hline E.F.Z. & II & 6,50 & $\mathrm{~F}$ & - & - & - & - & - & - & - & - & - & - & - & - & - & - \\
\hline A.R.F. & II & 6,91 & $\bar{M}$ & - & $\mathrm{P}$ & - & - & - & - & $P$ & $\mathrm{P}$ & $P$ & - & - & - & $P$ & - \\
\hline M.G.T. & II & 6,58 & $M$ & - & $\mathrm{P}$ & - & - & - & $\mathrm{P}$ & $\mathrm{P}$ & $\mathrm{P}$ & $\mathrm{P}$ & - & - & - & $\mathrm{P}$ & - \\
\hline C.V.E. & II & 6,41 & $\mathrm{~F}$ & - & $\mathrm{P}$ & - & - & - & $P$ & $\mathrm{P}$ & $\mathrm{P}$ & $\mathrm{P}$ & - & - & - & $\mathrm{P}$ & - \\
\hline R.T.D.G. & II & 6,91 & $\mathrm{M}$ & - & $\mathrm{P}$ & - & - & - & - & $\mathrm{P}$ & $\mathrm{P}$ & - & - & - & - & $\mathrm{P}$ & - \\
\hline J.A.A.C. & II & 6,91 & $\mathrm{M}$ & - & $\mathrm{P}$ & - & - & - & $P$ & $\mathrm{P}$ & $\mathrm{P}$ & - & - & - & - & $\mathrm{P}$ & - \\
\hline P.B.B.M. & II & 6,75 & $F$ & - & $\mathrm{P}$ & - & - & - & $P$ & $\mathrm{P}$ & $\mathrm{P}$ & $\mathrm{P}$ & - & - & - & $\mathrm{P}$ & - \\
\hline M.H.T. & II & 6,25 & $\mathrm{~F}$ & - & - & - & - & - & - & - & - & - & - & - & - & - & - \\
\hline F.B. & II & 6,66 & $\mathrm{~F}$ & - & $\mathrm{P}$ & - & - & - & - & $\mathrm{P}$ & $\mathrm{P}$ & - & - & - & - & $\mathrm{P}$ & - \\
\hline
\end{tabular}


TABELA A-7

\begin{tabular}{|c|c|c|c|c|c|c|c|c|c|c|c|c|c|c|c|c|c|}
\hline Nome & Classe & Idade & Gênero & 17 & 16 & 15 & 14 & 13 & 12 & 11 & 21 & 22 & 23 & 24 & 25 & 26 & 27 \\
\hline A.P.T. & $\mathrm{T}$ & 7,75 & $\mathrm{~F}$ & - & $\mathrm{P}$ & - & - & - & $P$ & $\mathrm{P}$ & $P$ & $\mathrm{P}$ & - & - & - & $\mathrm{P}$ & - \\
\hline J.M.R.M. & I & 7,91 & $\bar{M}$ & - & $P$ & - & - & - & - & $\mathrm{P}$ & $P$ & - & - & - & - & $\mathrm{P}$ & - \\
\hline T.S.C. & I & 7,33 & $M$ & - & $P$ & - & - & - & - & - & - & - & - & - & - & $P$ & - \\
\hline R.A.A. & I & 7,75 & $\mathrm{M}$ & - & $P$ & - & - & - & - & $P$ & $\mathrm{P}$ & - & - & - & - & $\mathrm{P}$ & - \\
\hline D.F.D & I & 7,08 & $M$ & - & $P$ & - & - & - & - & $P$ & $P$ & - & - & - & - & $\mathrm{P}$ & - \\
\hline G.R.C. & $\mathrm{I}$ & 7,25 & $\bar{M}$ & - & $P$ & - & - & - & - & $P$ & $\mathrm{P}$ & - & - & - & - & $\mathrm{P}$ & - \\
\hline A.C.M. & I & 7,58 & $\mathrm{~F}$ & - & $P$ & - & - & - & - & $\mathrm{P}$ & $\mathrm{P}$ & - & - & - & - & $\mathrm{P}$ & - \\
\hline E.P.P. & 1 & 7,83 & $\mathrm{~F}$ & - & $P$ & $P$ & - & - & $P$ & $P$ & $\mathrm{P}$ & $P$ & - & - & - & $P$ & - \\
\hline P.S.P.C. & 1 & 7,58 & $\bar{M}$ & - & $P$ & - & - & - & - & $P$ & $P$ & - & - & - & - & $\mathrm{P}$ & - \\
\hline E.C.M. & 1 & 7,83 & $\mathrm{~F}$ & - & $\mathrm{P}$ & - & - & - & - & $P$ & - & - & - & - & - & $\mathrm{P}$ & - \\
\hline A.L.M. & I & 7,25 & $\mathrm{~F}$ & - & $P$ & - & - & - & - & $P$ & $P$ & - & - & - & - & $\mathrm{P}$ & - \\
\hline E.D.B. & I & 7,91 & $\mathrm{~F}$ & - & $P$ & - & - & - & $P$ & $P$ & $P$ & $P$ & - & - & - & $\mathrm{P}$ & - \\
\hline V.M.A.C. & $\mathrm{I}$ & 7,83 & $\mathrm{~F}$ & - & $P$ & - & $P$ & - & $\mathrm{P}$ & $P$ & $P$ & $\mathrm{P}$ & - & $P$ & - & $P$ & - \\
\hline C.C.L.L. & I & 7,33 & $M$ & - & $P$ & - & - & - & - & - & - & - & - & - & - & $\mathrm{P}$ & - \\
\hline A.C.D. & 1 & 7.58 & $\mathrm{~F}$ & - & $\mathrm{P}$ & - & - & - & $P$ & $\mathrm{P}$ & $P$ & $P$ & - & - & - & $P$ & - \\
\hline F.B.C. & I & 7,33 & $\bar{M}$ & - & $P$ & - & - & - & $P$ & $P$ & $\mathrm{P}$ & $\mathrm{P}$ & - & - & - & $\mathrm{P}$ & - \\
\hline C.J.C.F. & $\mathrm{I}$ & 7,25 & $\mathrm{M}$ & - & $\mathrm{P}$ & - & - & - & $\mathrm{P}$ & $\mathrm{P}$ & $\mathrm{P}$ & $\mathrm{P}$ & - & - & - & $\mathrm{P}$ & - \\
\hline D.F.C. & $\mathrm{I}$ & 7.08 & $\mathrm{~F}$ & - & $\mathrm{P}$ & - & - & - & - & - & - & - & - & - & - & $P$ & - \\
\hline R.F.E. & I & 7,16 & $\mathrm{M}$ & - & $P$ & - & - & - & - & - & - & - & - & - & - & $P$ & - \\
\hline S.T.G. & $\mathrm{I}$ & 7,41 & $\bar{M}$ & - & $P$ & - & - & - & - & $P$ & $P$ & - & - & - & - & $\mathrm{P}$ & - \\
\hline M.P.P. & $\mathrm{I}$ & 7,66 & $\mathrm{~F}$ & - & $P$ & - & - & - & $P$ & $P$ & $\mathrm{P}$ & - & - & - & - & $P$ & - \\
\hline T.F.D. & $\mathrm{I}$ & 7,00 & $\bar{M}$ & - & $\mathrm{P}$ & - & - & - & - & $\mathrm{P}$ & $\mathrm{P}$ & - & - & - & - & $\mathrm{P}$ & - \\
\hline M.Q.B. & I & 7,50 & $\bar{M}$ & - & $P$ & - & - & - & $P$ & $P$ & $\mathrm{P}$ & $P$ & - & $P$ & - & $P$ & - \\
\hline C.L.C. & $\mathrm{I}$ & 7,16 & $\mathrm{~F}$ & - & $\mathrm{P}$ & $\mathrm{P}$ & - & - & - & $\mathrm{P}$ & $\mathrm{P}$ & $\mathrm{P}$ & - & - & - & $\mathrm{P}$ & - \\
\hline M.L.P. & I & 7,00 & $\mathrm{~F}$ & - & $\mathrm{P}$ & - & - & - & - & $P$ & $P$ & - & - & - & - & $P$ & - \\
\hline A.P.M.B. & I & 7,00 & $\mathrm{~F}$ & - & $P$ & - & - & - & - & $P$ & $P$ & - & - & - & - & $\mathrm{P}$ & - \\
\hline R.Q. & $\mathrm{I}$ & 7,83 & $\bar{M}$ & - & $P$ & - & - & - & - & - & - & - & - & - & - & $\mathrm{P}$ & - \\
\hline P.S.E. & $\mathrm{I}$ & 7,33 & $\mathrm{~F}$ & - & $\mathrm{P}$ & - & - & - & - & - & - & - & - & - & - & $\mathrm{P}$ & - \\
\hline E.A. & $\mathrm{I}$ & 7,83 & $\bar{M}$ & - & $P$ & - & - & - & - & - & $P$ & - & - & - & - & $P$ & - \\
\hline M.S. & I & 7,16 & $\mathrm{M}$ & - & $\mathrm{P}$ & - & - & - & - & $P$ & $\mathrm{P}$ & - & - & - & - & $\mathrm{P}$ & - \\
\hline T.V.S. & II & 7,00 & $\mathrm{M}$ & - & $P$ & - & - & - & - & - & - & - & - & - & - & $\mathrm{P}$ & - \\
\hline G.F.P. & II & 7,16 & $\bar{F}$ & - & $\mathrm{P}$ & - & - & - & - & $\mathrm{P}$ & $\mathrm{P}$ & - & - & - & - & $\mathrm{P}$ & - \\
\hline D.A.M. & II & 7,58 & $\bar{M}$ & - & $\mathrm{P}$ & - & - & - & $\mathrm{P}$ & $\mathrm{P}$ & $P$ & $\mathrm{P}$ & - & $\mathrm{P}$ & - & $\mathrm{P}$ & - \\
\hline A.F.G. & II & 7,66 & $M$ & - & $\mathrm{P}$ & - & - & - & $\mathrm{P}$ & $\mathrm{P}$ & $\mathrm{P}$ & $\mathrm{P}$ & - & - & - & $\mathrm{P}$ & - \\
\hline P.B.J. & II & 7,83 & $M$ & - & $\mathrm{P}$ & - & - & - & - & $\mathrm{P}$ & $\mathrm{P}$ & - & - & - & - & $\mathrm{P}$ & - \\
\hline R.G.M. & II & 7,16 & $M$ & - & $\mathrm{P}$ & - & - & - & - & $\mathrm{P}$ & $\mathrm{P}$ & $P$ & - & - & - & $\mathrm{P}$ & - \\
\hline T.C.C.C. & II & 7,50 & $\mathrm{~F}$ & - & $\mathrm{P}$ & - & - & - & $P$ & $\mathrm{P}$ & $\mathrm{P}$ & $\mathrm{P}$ & - & - & - & $\mathrm{P}$ & - \\
\hline R.P.F. & II & 7,75 & M & - & $\mathrm{P}$ & - & - & - & - & $\mathrm{P}$ & $P$ & - & - & - & - & $P$ & - \\
\hline E.C.L. & II & 7,66 & $\mathrm{~F}$ & - & $P$ & - & - & - & - & $\mathrm{P}$ & $P$ & - & - & - & - & $\mathrm{P}$ & - \\
\hline R.F.B. & II & 7,75 & $\bar{M}$ & - & $\mathrm{P}$ & - & - & - & - & $P$ & $\mathrm{P}$ & - & - & - & - & $\mathrm{P}$ & - \\
\hline R.R.D. & II & 7,66 & $M$ & - & $\mathrm{P}$ & - & - & - & - & $P$ & $\mathrm{P}$ & - & - & - & - & $P$ & - \\
\hline J.A.M. & II & 7,91 & $M$ & - & $\mathrm{P}$ & - & - & - & - & - & $\mathrm{P}$ & - & - & - & - & $\mathrm{P}$ & - \\
\hline B.M.L. & II & 7,33 & $\bar{M}$ & - & $\mathrm{P}$ & - & - & - & - & $\mathrm{P}$ & $\mathrm{P}$ & - & - & - & - & $\mathrm{P}$ & - \\
\hline R.O.B.A. & II & 7,50 & $M$ & - & $\mathrm{P}$ & - & - & - & - & - & - & - & - & - & - & $\mathrm{P}$ & - \\
\hline R.B.R. & II & 7,33 & $\mathrm{~F}$ & - & $\mathrm{P}$ & - & - & - & - & - & - & - & - & - & - & $\mathrm{P}$ & - \\
\hline F.B.A. & II & 7,33 & $F$ & - & $P$ & - & - & - & - & $\mathrm{P}$ & $\mathrm{P}$ & - & - & - & - & $P$ & - \\
\hline D.D. & II & 7,83 & $F$ & - & $\mathrm{P}$ & - & - & - & $\mathrm{P}$ & $\mathrm{P}$ & $\mathrm{P}$ & $\mathrm{P}$ & - & - & - & $\mathrm{P}$ & - \\
\hline F.B.R. & II & 7,08 & $\mathrm{~F}$ & - & $\mathrm{P}$ & - & - & - & - & - & - & - & - & - & - & $P$ & - \\
\hline E.F.Z. & II & 7,75 & $\mathrm{~F}$ & - & $\mathrm{P}$ & - & - & - & $\mathrm{P}$ & $\mathrm{P}$ & $\mathrm{P}$ & $\mathrm{P}$ & - & - & - & $\mathrm{P}$ & - \\
\hline A.R.F. & II & 7,83 & $M$ & - & $\mathrm{P}$ & - & - & - & $\mathrm{P}$ & $P$ & $\mathrm{P}$ & - & - & - & - & $\mathrm{P}$ & - \\
\hline M.G.T. & II & 7,66 & $M$ & - & $\mathrm{P}$ & - & - & - & $\mathrm{P}$ & $\mathrm{P}$ & $\mathrm{P}$ & $P$ & - & $P$ & - & $P$ & - \\
\hline C.V.E. & II & 7,41 & $\mathrm{~F}$ & - & $P$ & - & - & - & - & $P$ & $\mathrm{P}$ & $\mathrm{P}$ & - & - & - & $\mathrm{P}$ & - \\
\hline R.T.D.G. & II & 7,75 & 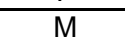 & - & $\mathrm{P}$ & - & - & - & - & $P$ & $P$ & - & - & - & - & $P$ & - \\
\hline T.S.N.J. & II & 7,83 & $M$ & - & $\mathrm{P}$ & - & - & - & - & $P$ & $\mathrm{P}$ & - & - & - & - & $\mathrm{P}$ & - \\
\hline O.C.C. & II & 7,25 & $M$ & - & $\mathrm{P}$ & - & - & - & - & $P$ & $P$ & - & - & - & - & $P$ & - \\
\hline P.B.B.M. & II & 7,83 & $\mathrm{~F}$ & - & $\mathrm{P}$ & - & - & - & $P$ & $P$ & $\mathrm{P}$ & - & - & - & - & $\mathrm{P}$ & - \\
\hline M.H.T. & II & 7,08 & $\mathrm{~F}$ & - & $\mathrm{P}$ & - & - & - & - & - & - & - & - & - & - & $\mathrm{P}$ & - \\
\hline F.B. & II & 7,50 & $\mathrm{~F}$ & - & $P$ & - & - & - & - & $P$ & $\mathrm{P}$ & $P$ & - & - & - & $P$ & - \\
\hline A.B.S.M. & II & 7,91 & $\mathrm{~F}$ & - & $\mathrm{P}$ & - & - & - & - & $P$ & $P$ & - & - & - & - & $\mathrm{P}$ & - \\
\hline C.B.J. & II & 7,58 & $\mathrm{~F}$ & - & $\mathrm{P}$ & - & - & - & - & $\mathrm{P}$ & $P$ & - & - & - & - & $\mathrm{P}$ & - \\
\hline
\end{tabular}


TABELA A-8

\begin{tabular}{|c|c|c|c|c|c|c|c|c|c|c|c|c|c|c|c|c|c|}
\hline Nome & Classe & Idade & Gênero & 37 & 36 & 35 & 34 & 33 & 32 & 31 & 41 & 42 & 43 & 44 & 45 & 46 & 47 \\
\hline A.P.T. & I & 7,75 & $\mathrm{~F}$ & - & - & - & - & - & $\mathrm{P}$ & $\mathrm{P}$ & $\mathrm{P}$ & $\mathrm{P}$ & - & - & - & $\mathrm{P}$ & - \\
\hline J.M.R.M. & I & 7,91 & $M$ & - & $\mathrm{P}$ & - & - & - & $P$ & $P$ & $\mathrm{P}$ & $P$ & - & - & - & $\mathrm{P}$ & - \\
\hline T.S.C. & I & 7,33 & $M$ & - & $P$ & - & - & - & - & $P$ & $P$ & - & - & - & - & $P$ & - \\
\hline R.A.A. & I & 7,75 & $\mathrm{M}$ & - & $P$ & - & - & - & $P$ & $P$ & $\mathrm{P}$ & - & - & - & - & $\mathrm{P}$ & - \\
\hline D.F.D & I & 7,08 & $M$ & - & $P$ & - & - & - & - & $P$ & $P$ & - & - & - & - & $\mathrm{P}$ & - \\
\hline G.R.C. & $\mathrm{I}$ & 7,25 & $\bar{M}$ & - & $P$ & - & - & - & $P$ & $P$ & $\mathrm{P}$ & $\mathrm{P}$ & - & - & - & $\mathrm{P}$ & - \\
\hline A.C.M. & I & 7,58 & $\mathrm{~F}$ & - & $P$ & - & - & - & $P$ & $\mathrm{P}$ & $\mathrm{P}$ & $\mathrm{P}$ & - & - & - & $\mathrm{P}$ & - \\
\hline E.P.P. & 1 & 7,83 & $\mathrm{~F}$ & - & $P$ & - & - & - & $P$ & $P$ & $\mathrm{P}$ & $P$ & - & - & - & $P$ & - \\
\hline P.S.P.C. & 1 & 7,58 & $\bar{M}$ & - & $P$ & - & - & - & $P$ & $P$ & $P$ & $\mathrm{P}$ & - & - & - & $\mathrm{P}$ & - \\
\hline E.C.M. & 1 & 7,83 & $\mathrm{~F}$ & - & $\mathrm{P}$ & - & - & - & $P$ & $P$ & $P$ & - & - & - & - & $\mathrm{P}$ & - \\
\hline A.L.M. & I & 7,25 & $\mathrm{~F}$ & - & $P$ & - & - & - & $P$ & $P$ & $\mathrm{P}$ & $\mathrm{P}$ & - & - & - & $\mathrm{P}$ & - \\
\hline E.D.B. & I & 7,91 & $\mathrm{~F}$ & - & $P$ & - & - & - & $P$ & $P$ & $P$ & $\mathrm{P}$ & - & - & - & $\mathrm{P}$ & - \\
\hline V.M.A.C. & $\mathrm{I}$ & 7,83 & $\mathrm{~F}$ & - & $P$ & - & - & - & $P$ & $P$ & $P$ & $\mathrm{P}$ & - & - & - & $P$ & - \\
\hline C.C.L.L. & I & 7,33 & $M$ & - & $P$ & - & - & - & - & $P$ & $\mathrm{P}$ & - & - & - & - & $\mathrm{P}$ & - \\
\hline A.C.D. & 1 & 7.58 & $\mathrm{~F}$ & - & $\mathrm{P}$ & - & - & - & $P$ & $P$ & $P$ & $P$ & - & - & - & $P$ & - \\
\hline F.B.C. & I & 7,33 & $\bar{M}$ & - & $P$ & - & - & - & $P$ & $P$ & $\mathrm{P}$ & $\mathrm{P}$ & - & - & - & $\mathrm{P}$ & - \\
\hline C.J.C.F. & $\mathrm{I}$ & 7,25 & $\mathrm{M}$ & - & $\mathrm{P}$ & - & - & - & $\mathrm{P}$ & $\mathrm{P}$ & $\mathrm{P}$ & $\mathrm{P}$ & - & - & - & $\mathrm{P}$ & - \\
\hline D.F.C. & I & 7.08 & $\mathrm{~F}$ & - & $\mathrm{P}$ & - & - & - & - & $\mathrm{P}$ & $P$ & - & - & - & - & $P$ & - \\
\hline R.F.E. & I & 7,16 & $\mathrm{M}$ & - & $P$ & - & - & - & - & $P$ & $P$ & - & - & - & - & $P$ & - \\
\hline S.T.G. & $\mathrm{I}$ & 7,41 & $\bar{M}$ & - & $P$ & - & - & - & $P$ & $P$ & $P$ & $\mathrm{P}$ & - & - & - & $\mathrm{P}$ & - \\
\hline M.P.P. & $\mathrm{I}$ & 7,66 & $\mathrm{~F}$ & - & $P$ & - & - & - & $P$ & $P$ & $\mathrm{P}$ & $\mathrm{P}$ & - & - & - & $P$ & - \\
\hline T.F.D. & $\mathrm{I}$ & 7,00 & $\bar{M}$ & - & $\mathrm{P}$ & - & - & - & - & $\mathrm{P}$ & $\mathrm{P}$ & $\mathrm{P}$ & - & - & - & $\mathrm{P}$ & - \\
\hline M.Q.B. & I & 7,50 & $\bar{M}$ & - & $P$ & - & - & - & $P$ & $P$ & $\mathrm{P}$ & $P$ & - & - & - & $P$ & - \\
\hline C.L.C. & $\mathrm{I}$ & 7,16 & $\mathrm{~F}$ & - & $\mathrm{P}$ & - & - & - & $\mathrm{P}$ & $\mathrm{P}$ & $\mathrm{P}$ & $\mathrm{P}$ & - & - & - & $\mathrm{P}$ & - \\
\hline M.L.P. & I & 7,00 & $\mathrm{~F}$ & - & $\mathrm{P}$ & - & - & - & $P$ & $P$ & $P$ & $\mathrm{P}$ & - & - & - & $P$ & - \\
\hline A.P.M.B. & I & 7,00 & $\mathrm{~F}$ & - & $P$ & - & - & - & $P$ & $P$ & $P$ & $P$ & - & - & - & $\mathrm{P}$ & - \\
\hline R.Q. & $\mathrm{I}$ & 7,83 & $\bar{M}$ & - & $P$ & - & - & - & - & $\mathrm{P}$ & $\mathrm{P}$ & - & - & - & - & $\mathrm{P}$ & - \\
\hline P.S.E. & $\mathrm{I}$ & 7,33 & $\mathrm{~F}$ & - & $\mathrm{P}$ & - & - & - & - & $\mathrm{P}$ & $\mathrm{P}$ & - & - & - & - & $\mathrm{P}$ & - \\
\hline E.A. & I & 7,83 & $\bar{M}$ & - & $P$ & - & - & - & - & $\mathrm{P}$ & $P$ & - & - & - & - & $P$ & - \\
\hline M.S. & $\mathrm{I}$ & 7,16 & $M$ & - & $P$ & - & - & - & - & $P$ & $P$ & - & - & - & - & $P$ & - \\
\hline T.V.S. & II & 7,00 & $M$ & - & $P$ & - & - & - & - & $P$ & $P$ & - & - & - & - & $P$ & - \\
\hline G.F.P. & II & 7,16 & $\bar{F}$ & - & $\mathrm{P}$ & - & - & - & $\mathrm{P}$ & $\mathrm{P}$ & $\mathrm{P}$ & $\mathrm{P}$ & - & - & - & $\mathrm{P}$ & - \\
\hline D.A.M. & II & 7,58 & $\bar{M}$ & - & $\mathrm{P}$ & - & - & - & $\mathrm{P}$ & $\mathrm{P}$ & $P$ & $\mathrm{P}$ & - & - & - & $\mathrm{P}$ & - \\
\hline A.F.G. & II & 7,66 & $M$ & - & $\mathrm{P}$ & - & - & - & $\mathrm{P}$ & $\mathrm{P}$ & $\mathrm{P}$ & $\mathrm{P}$ & - & - & - & $\mathrm{P}$ & - \\
\hline P.B.J. & II & 7,83 & $M$ & - & $\mathrm{P}$ & - & - & - & $\mathrm{P}$ & $\mathrm{P}$ & $\mathrm{P}$ & $\mathrm{P}$ & - & - & - & $\mathrm{P}$ & - \\
\hline R.G.M. & II & 7,16 & $M$ & - & $\mathrm{P}$ & - & - & - & $\mathrm{P}$ & $\mathrm{P}$ & $\mathrm{P}$ & $P$ & - & - & - & $\mathrm{P}$ & - \\
\hline T.C.C.C. & II & 7,50 & $\mathrm{~F}$ & - & $\mathrm{P}$ & - & - & - & $P$ & $\mathrm{P}$ & $\mathrm{P}$ & $\mathrm{P}$ & - & - & - & $\mathrm{P}$ & - \\
\hline R.P.F. & II & 7,75 & M & - & $\mathrm{P}$ & - & - & - & - & $\mathrm{P}$ & $P$ & - & - & - & - & $P$ & - \\
\hline E.C.L. & II & 7,66 & $\mathrm{~F}$ & - & $P$ & - & - & - & $P$ & $\mathrm{P}$ & $P$ & $\mathrm{P}$ & - & - & - & $\mathrm{P}$ & - \\
\hline R.F.B. & II & 7,75 & $\bar{M}$ & - & $\mathrm{P}$ & - & - & - & $P$ & $P$ & $\mathrm{P}$ & $P$ & - & - & - & $\mathrm{P}$ & - \\
\hline R.R.D. & II & 7,66 & $M$ & - & $\mathrm{P}$ & - & - & - & $P$ & $P$ & $\mathrm{P}$ & $P$ & - & - & - & $P$ & - \\
\hline J.A.M. & II & 7,91 & $M$ & - & $\mathrm{P}$ & - & - & - & - & $\mathrm{P}$ & $\mathrm{P}$ & - & - & - & - & $\mathrm{P}$ & - \\
\hline B.M.L. & II & 7,33 & $\bar{M}$ & - & $\mathrm{P}$ & - & - & - & $\mathrm{P}$ & $\mathrm{P}$ & $\mathrm{P}$ & - & - & - & - & $\mathrm{P}$ & - \\
\hline R.O.B.A. & II & 7,50 & $M$ & - & $\mathrm{P}$ & - & - & - & - & $\mathrm{P}$ & $\mathrm{P}$ & $\mathrm{P}$ & - & - & - & $\mathrm{P}$ & - \\
\hline R.B.R. & II & 7,33 & $\mathrm{~F}$ & - & $\mathrm{P}$ & - & - & - & - & $\mathrm{P}$ & $\mathrm{P}$ & - & - & - & - & $P$ & - \\
\hline F.B.A. & II & 7,33 & $F$ & - & $P$ & - & - & - & $\mathrm{P}$ & $\mathrm{P}$ & $\mathrm{P}$ & $\mathrm{P}$ & - & - & - & $P$ & - \\
\hline D.D. & II & 7,83 & $F$ & - & $\mathrm{P}$ & - & - & - & $\mathrm{P}$ & $\mathrm{P}$ & $\mathrm{P}$ & $\mathrm{P}$ & - & - & - & $\mathrm{P}$ & - \\
\hline F.B.R. & II & 7,08 & $\mathrm{~F}$ & - & $\mathrm{P}$ & - & - & - & - & $\mathrm{P}$ & $\mathrm{P}$ & - & - & - & - & $P$ & - \\
\hline E.F.Z. & II & 7,75 & $\mathrm{~F}$ & - & $\mathrm{P}$ & - & - & - & $\mathrm{P}$ & $\mathrm{P}$ & $\mathrm{P}$ & $\mathrm{P}$ & - & - & - & $\mathrm{P}$ & - \\
\hline A.R.F. & II & 7,83 & $M$ & - & $\mathrm{P}$ & - & - & - & $\mathrm{P}$ & $P$ & $\mathrm{P}$ & $\mathrm{P}$ & - & - & - & $\mathrm{P}$ & - \\
\hline M.G.T. & II & 7,66 & $M$ & - & $\mathrm{P}$ & - & - & - & $\mathrm{P}$ & $\mathrm{P}$ & $\mathrm{P}$ & $P$ & - & $P$ & - & $P$ & - \\
\hline C.V.E. & II & 7,41 & $\mathrm{~F}$ & - & $P$ & - & - & - & $P$ & $P$ & $\mathrm{P}$ & $P$ & - & - & - & $\mathrm{P}$ & - \\
\hline R.T.D.G. & II & 7,75 & 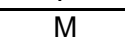 & - & $\mathrm{P}$ & - & - & - & $P$ & $P$ & $P$ & $P$ & - & - & - & $P$ & - \\
\hline T.S.N.J. & II & 7,83 & $M$ & - & $\mathrm{P}$ & - & - & - & $\mathrm{P}$ & $P$ & $\mathrm{P}$ & $\mathrm{P}$ & - & - & - & $\mathrm{P}$ & - \\
\hline O.C.C. & II & 7,25 & $M$ & - & $\mathrm{P}$ & - & - & - & $P$ & $P$ & $P$ & $P$ & - & - & - & $P$ & - \\
\hline P.B.B.M. & II & 7,83 & $\mathrm{~F}$ & - & $\mathrm{P}$ & - & - & - & $P$ & $P$ & $\mathrm{P}$ & $P$ & - & - & - & $\mathrm{P}$ & - \\
\hline M.H.T. & II & 7,08 & $F$ & - & $\mathrm{P}$ & - & - & - & - & - & - & - & - & - & - & $\mathrm{P}$ & - \\
\hline F.B. & II & 7,50 & $\mathrm{~F}$ & - & $P$ & - & - & - & $P$ & $P$ & $\mathrm{P}$ & $P$ & - & - & - & $P$ & - \\
\hline A.B.S.M. & II & 7,91 & $\mathrm{~F}$ & - & $\mathrm{P}$ & - & - & - & $P$ & $P$ & $P$ & $\mathrm{P}$ & - & - & - & $\mathrm{P}$ & - \\
\hline C.B.J. & II & 7,58 & $\mathrm{~F}$ & - & $P$ & - & - & - & $\mathrm{P}$ & $\mathrm{P}$ & $P$ & $\mathrm{P}$ & - & - & - & $\mathrm{P}$ & - \\
\hline
\end{tabular}


TABELA A-9

\begin{tabular}{|c|c|c|c|c|c|c|c|c|c|c|c|c|c|c|c|c|c|}
\hline Nome & Classe & Idade & Gênero & 17 & 16 & 15 & 14 & 13 & 12 & 11 & 21 & 22 & 23 & 24 & 25 & 26 & 27 \\
\hline E.P.P. & $\mathrm{I}$ & 8,91 & $F$ & - & $\mathrm{P}$ & $\mathrm{P}$ & $\mathrm{P}$ & - & $P$ & $P$ & $P$ & $P$ & - & - & - & $\mathrm{P}$ & - \\
\hline E.C.M. & I & 8,91 & $\mathrm{~F}$ & - & $P$ & - & - & - & - & $P$ & $P$ & - & - & - & - & $\mathrm{P}$ & - \\
\hline A.L.M. & $\mathrm{I}$ & 8,33 & $\mathrm{~F}$ & - & $\mathrm{P}$ & - & - & - & $\mathrm{P}$ & $\mathrm{P}$ & $\mathrm{P}$ & - & - & - & - & $\mathrm{P}$ & - \\
\hline A.P.T. & I & 8,66 & $F$ & - & $\mathrm{P}$ & - & - & - & $P$ & $\mathrm{P}$ & $P$ & $\mathrm{P}$ & - & - & - & $P$ & - \\
\hline J.M.R.M. & I & 8,83 & $M$ & - & $\mathrm{P}$ & - & - & - & - & $\mathrm{P}$ & $\mathrm{P}$ & $\mathrm{P}$ & - & - & - & $\mathrm{P}$ & - \\
\hline D.F.D & $\mathrm{T}$ & 8,08 & $\bar{M}$ & - & $P$ & - & - & - & - & $P$ & $P$ & - & - & - & - & $P$ & - \\
\hline A.C.M. & I & 8,66 & $F$ & - & $P$ & - & - & - & $P$ & $P$ & $P$ & $P$ & - & - & - & $P$ & - \\
\hline E.D.B. & I & 8,83 & $\mathrm{~F}$ & - & $\mathrm{P}$ & - & $\mathrm{P}$ & - & $\mathrm{P}$ & $\mathrm{P}$ & $\mathrm{P}$ & $\mathrm{P}$ & - & - & - & $\mathrm{P}$ & - \\
\hline V.M.A.C. & I & 8,66 & $\mathrm{~F}$ & - & $\mathrm{P}$ & - & $\mathrm{P}$ & - & $\mathrm{P}$ & $\mathrm{P}$ & $\mathrm{P}$ & $\mathrm{P}$ & - & $\mathrm{P}$ & - & $\mathrm{P}$ & - \\
\hline A.C.D. & $T$ & 8,50 & $F$ & - & $\mathrm{P}$ & - & - & - & $P$ & $P$ & $P$ & $\mathrm{P}$ & - & - & - & $P$ & - \\
\hline C.J.C.F. & $\mathrm{I}$ & 8,33 & $\mathrm{M}$ & - & $\mathrm{P}$ & - & - & - & $\mathrm{P}$ & $\mathrm{P}$ & $\mathrm{P}$ & $\mathrm{P}$ & - & - & - & $\mathrm{P}$ & - \\
\hline D.F.C. & 1 & 8,16 & $\mathrm{~F}$ & - & $\mathrm{P}$ & - & - & - & - & $\mathrm{P}$ & $\mathrm{P}$ & - & - & - & - & $\mathrm{P}$ & - \\
\hline F.S. & 1 & 8,50 & $\mathrm{M}$ & - & $\mathrm{P}$ & - & - & - & $\mathrm{P}$ & $\mathrm{P}$ & $\mathrm{P}$ & $\mathrm{P}$ & - & - & - & $\mathrm{P}$ & - \\
\hline R.F.E. & 1 & 8,25 & $M$ & - & $\mathrm{P}$ & - & - & - & $\mathrm{P}$ & $\mathrm{P}$ & $\mathrm{P}$ & $\mathrm{P}$ & - & - & - & $\mathrm{P}$ & - \\
\hline M.Q.B. & 1 & 8,66 & $M$ & - & $\mathrm{P}$ & - & - & - & $\mathrm{P}$ & $\mathrm{P}$ & $\mathrm{P}$ & $\mathrm{P}$ & $\mathrm{P}$ & $\mathrm{P}$ & - & $\mathrm{P}$ & - \\
\hline M.P.P. & 1 & 8,50 & $\mathrm{~F}$ & - & $\mathrm{P}$ & - & - & - & $\mathrm{P}$ & $\mathrm{P}$ & $\mathrm{P}$ & $\mathrm{P}$ & - & - & - & $\mathrm{P}$ & - \\
\hline T.F.D. & 1 & 8,08 & $\mathrm{M}$ & - & $\mathrm{P}$ & - & - & - & $\mathrm{P}$ & $\mathrm{P}$ & $\mathrm{P}$ & $\mathrm{P}$ & - & - & - & $\mathrm{P}$ & - \\
\hline M.L.P. & 1 & 8,00 & $F$ & - & $\mathrm{P}$ & - & - & - & $\mathrm{P}$ & $\mathrm{P}$ & $\mathrm{P}$ & $\mathrm{P}$ & - & - & - & $\mathrm{P}$ & - \\
\hline A.P.M.B. & I & 8,00 & $\mathrm{~F}$ & - & $\mathrm{P}$ & - & - & - & $\mathrm{P}$ & $\mathrm{P}$ & $\mathrm{P}$ & $\mathrm{P}$ & - & - & - & $\mathrm{P}$ & - \\
\hline P.S.E. & $\mathrm{I}$ & 8,41 & $F$ & - & $\mathrm{P}$ & - & - & - & - & $\mathrm{P}$ & $\mathrm{P}$ & - & - & - & - & $\mathrm{P}$ & - \\
\hline R.Q. & 1 & 8,83 & $\mathrm{M}$ & - & $\mathrm{P}$ & - & - & - & - & $\mathrm{P}$ & $\mathrm{P}$ & $\mathrm{P}$ & - & - & - & $\mathrm{P}$ & - \\
\hline E.L.C.S. & $\mathrm{I}$ & 8,91 & $\mathrm{M}$ & - & $\mathrm{P}$ & - & - & - & $\mathrm{P}$ & $\mathrm{P}$ & $\mathrm{P}$ & $\mathrm{P}$ & - & - & - & - & - \\
\hline J.R.N. & $\mathrm{I}$ & 8,91 & $M$ & - & $\mathrm{P}$ & - & - & - & $\mathrm{P}$ & $\mathrm{P}$ & $\mathrm{P}$ & $\mathrm{P}$ & - & - & - & $\mathrm{P}$ & - \\
\hline H.J.S.S. & $\mathrm{T}$ & 8,75 & $\bar{M}$ & - & $\mathrm{P}$ & - & - & - & $\mathrm{P}$ & $\mathrm{P}$ & $\mathrm{P}$ & - & - & - & - & $\mathrm{P}$ & - \\
\hline E.A. & $\mathrm{I}$ & 8,75 & $\mathrm{M}$ & - & $\mathrm{P}$ & - & - & - & - & $\mathrm{P}$ & $\mathrm{P}$ & - & - & - & - & $\mathrm{P}$ & - \\
\hline M.S. & I & 8,08 & $M$ & - & $\mathrm{P}$ & - & $\mathrm{P}$ & - & - & $\mathrm{P}$ & $\mathrm{P}$ & - & - & - & - & $\mathrm{P}$ & - \\
\hline L.C.V. & $\mathrm{I}$ & 8,75 & $\mathrm{~F}$ & - & $\mathrm{P}$ & - & - & - & $\mathrm{P}$ & $\mathrm{P}$ & $\mathrm{P}$ & $\mathrm{P}$ & - & - & - & $\mathrm{P}$ & - \\
\hline A.L.T.P. & $\mathrm{I}$ & 8,33 & $\mathrm{~F}$ & - & $\mathrm{P}$ & - & - & - & $\mathrm{P}$ & $\mathrm{P}$ & $\mathrm{P}$ & $\mathrm{P}$ & - & $\mathrm{P}$ & - & $\mathrm{P}$ & - \\
\hline R.A.C.M. & $\mathrm{I}$ & 8,50 & $\bar{M}$ & - & $\mathrm{P}$ & $\mathrm{P}$ & - & - & $\mathrm{P}$ & $\mathrm{P}$ & $\mathrm{P}$ & $\mathrm{P}$ & - & - & - & $\mathrm{P}$ & - \\
\hline L.F.S.G. & $\mathrm{I}$ & 8,25 & $\mathrm{M}$ & - & $\mathrm{P}$ & - & - & - & $\mathrm{P}$ & $\mathrm{P}$ & $\mathrm{P}$ & $\mathrm{P}$ & - & - & - & $\mathrm{P}$ & - \\
\hline R.A.A.P.R. & II & 8,91 & $\mathrm{~F}$ & - & $\mathrm{P}$ & - & - & - & $\mathrm{P}$ & $\mathrm{P}$ & $\mathrm{P}$ & $\mathrm{P}$ & - & - & - & $\mathrm{P}$ & - \\
\hline A.I.M.B. & II & 8,41 & $\mathrm{~F}$ & - & $\mathrm{P}$ & - & - & - & $P$ & $P$ & $\mathrm{P}$ & $\mathrm{P}$ & - & - & - & $\mathrm{P}$ & - \\
\hline T.V.S. & II & 8,00 & $\bar{M}$ & - & $\mathrm{P}$ & - & - & - & $\mathrm{P}$ & $\mathrm{P}$ & $\mathrm{P}$ & $\mathrm{P}$ & - & $\mathrm{P}$ & - & $\mathrm{P}$ & - \\
\hline J.C.M.J. & II & 8,00 & $\bar{M}$ & - & $\mathrm{P}$ & - & - & - & - & $\mathrm{P}$ & $\mathrm{P}$ & - & - & - & - & $\mathrm{P}$ & - \\
\hline A.F.G. & II & 8,58 & $\bar{M}$ & - & $\mathrm{P}$ & - & - & - & $\mathrm{P}$ & $\mathrm{P}$ & $\mathrm{P}$ & $\mathrm{P}$ & - & - & - & $\mathrm{P}$ & - \\
\hline M.A.P.T. & II & 8,00 & $\bar{M}$ & - & $\mathrm{P}$ & - & - & - & $\mathrm{P}$ & $\mathrm{P}$ & $\mathrm{P}$ & $\mathrm{P}$ & - & - & - & $\mathrm{P}$ & - \\
\hline P.B.J. & II & 8,66 & $M$ & - & $\mathrm{P}$ & - & - & - & $\mathrm{P}$ & $\mathrm{P}$ & $\mathrm{P}$ & $\mathrm{P}$ & - & $\mathrm{P}$ & $\mathrm{P}$ & $\mathrm{P}$ & - \\
\hline T.C.C.C. & II & 8,58 & $\mathrm{~F}$ & - & $\mathrm{P}$ & - & - & - & $\mathrm{P}$ & $\mathrm{P}$ & $\mathrm{P}$ & $\mathrm{P}$ & - & $\mathrm{P}$ & - & $\mathrm{P}$ & - \\
\hline C.H.T. & II & 8,91 & $\bar{M}$ & - & $\mathrm{P}$ & - & - & - & $P$ & $\mathrm{P}$ & $P$ & $\mathrm{P}$ & - & - & - & $\mathrm{P}$ & - \\
\hline R.P.F. & II & 8,83 & $M$ & - & $\mathrm{P}$ & - & - & - & $\mathrm{P}$ & $\mathrm{P}$ & $P$ & $\mathrm{P}$ & - & - & - & $\mathrm{P}$ & - \\
\hline E.C.L. & II & 8,66 & $\mathrm{~F}$ & - & $\mathrm{P}$ & - & - & - & $\mathrm{P}$ & $\mathrm{P}$ & $\mathrm{P}$ & $\mathrm{P}$ & - & - & - & $\mathrm{P}$ & - \\
\hline R.F.B. & II & 8,66 & $\bar{M}$ & - & $\mathrm{P}$ & - & - & - & - & $\mathrm{P}$ & $\mathrm{P}$ & $\mathrm{P}$ & - & - & - & $\mathrm{P}$ & - \\
\hline R.R.D. & II & 8,66 & $M$ & - & $\mathrm{P}$ & $\mathrm{P}$ & - & - & - & $\mathrm{P}$ & $\mathrm{P}$ & $\mathrm{P}$ & - & - & - & $\mathrm{P}$ & - \\
\hline J.A.M. & II & 8,91 & $M$ & - & $\mathrm{P}$ & - & - & - & - & $\mathrm{P}$ & $\mathrm{P}$ & - & - & - & - & $\mathrm{P}$ & - \\
\hline B.M.L. & II & 8,16 & $M$ & - & $\mathrm{P}$ & - & - & - & $\mathrm{P}$ & $\mathrm{P}$ & $\mathrm{P}$ & $\mathrm{P}$ & - & - & - & $\mathrm{P}$ & - \\
\hline R.O.B.A. & II & 8,50 & $\mathrm{M}$ & - & $\mathrm{P}$ & - & - & - & $P$ & $P$ & $\mathrm{P}$ & $P$ & - & - & - & $\mathrm{P}$ & - \\
\hline C.F.Z.S. & II & 8,16 & $F$ & - & $\mathrm{P}$ & - & - & - & $\mathrm{P}$ & $\mathrm{P}$ & $\mathrm{P}$ & $\mathrm{P}$ & - & - & - & $\mathrm{P}$ & - \\
\hline R.A.S.S. & II & 8,33 & $\mathrm{~F}$ & - & $\mathrm{P}$ & - & - & - & - & - & - & - & - & - & - & $\mathrm{P}$ & - \\
\hline R.B.R. & II & 8,16 & $\mathrm{~F}$ & - & $\mathrm{P}$ & - & - & - & - & - & - & - & - & - & - & $\mathrm{P}$ & - \\
\hline F.B.A. & II & 8,33 & $\mathrm{~F}$ & - & $\mathrm{P}$ & - & - & - & $\mathrm{P}$ & $\mathrm{P}$ & $P$ & $\mathrm{P}$ & - & - & - & $\mathrm{P}$ & - \\
\hline M.F.G. & II & 8,08 & $\mathrm{~F}$ & - & $\mathrm{P}$ & - & - & - & $\mathrm{P}$ & $\mathrm{P}$ & $P$ & $\mathrm{P}$ & - & - & - & $\mathrm{P}$ & - \\
\hline D.D. & II & 8,91 & $\mathrm{~F}$ & - & $\mathrm{P}$ & - & $\mathrm{P}$ & - & $\mathrm{P}$ & $\mathrm{P}$ & $\mathrm{P}$ & $\mathrm{P}$ & - & - & - & $\mathrm{P}$ & - \\
\hline F.B.R. & II & 8,08 & $\mathrm{~F}$ & - & $\mathrm{P}$ & - & - & - & - & $\mathrm{P}$ & $\mathrm{P}$ & - & - & - & - & $\mathrm{P}$ & - \\
\hline E.F.Z. & II & 8,33 & $\mathrm{~F}$ & - & $\mathrm{P}$ & - & - & - & $\mathrm{P}$ & $\mathrm{P}$ & $\mathrm{P}$ & $\mathrm{P}$ & - & - & - & $\mathrm{P}$ & - \\
\hline A.R.F. & II & 8,91 & $\bar{M}$ & - & $\mathrm{P}$ & - & - & - & $\mathrm{P}$ & $\mathrm{P}$ & $\mathrm{P}$ & $\mathrm{P}$ & - & - & - & $\mathrm{P}$ & - \\
\hline T.S.N.J. & II & 8,50 & $M$ & - & $\mathrm{P}$ & - & - & - & $\mathrm{P}$ & $\mathrm{P}$ & $\mathrm{P}$ & - & - & - & - & $\mathrm{P}$ & - \\
\hline O.C.C. & II & 8,08 & $\bar{M}$ & - & $P$ & - & - & - & $P$ & $\mathrm{P}$ & $P$ & $\mathrm{P}$ & - & - & - & $P$ & - \\
\hline J.A.A.C. & II & 8,83 & $\bar{M}$ & - & $\mathrm{P}$ & - & - & - & $\mathrm{P}$ & $P$ & $P$ & $P$ & - & - & - & $\mathrm{P}$ & - \\
\hline P.B.B.M. & II & 8,83 & $\mathrm{~F}$ & - & $\mathrm{P}$ & - & - & - & $\mathrm{P}$ & $\mathrm{P}$ & $\mathrm{P}$ & $\mathrm{P}$ & - & - & - & $\mathrm{P}$ & - \\
\hline M.H.T. & II & 8,25 & $F$ & - & $\mathrm{P}$ & - & - & - & - & $\mathrm{P}$ & $P$ & - & - & - & - & $\mathrm{P}$ & - \\
\hline
\end{tabular}


TABELA A-10

\begin{tabular}{|c|c|c|c|c|c|c|c|c|c|c|c|c|c|c|c|c|c|}
\hline Nome & Classe & Idade & Gênero & 37 & 36 & 35 & 34 & 33 & 32 & 31 & 41 & 42 & 43 & 44 & 45 & 46 & 47 \\
\hline E.P.P. & $\mathrm{I}$ & 8,91 & $\mathrm{~F}$ & - & $\mathrm{P}$ & - & - & - & $\mathrm{P}$ & $\mathrm{P}$ & $\mathrm{P}$ & $\mathrm{P}$ & - & - & - & $\mathrm{P}$ & - \\
\hline E.C.M. & $\mathrm{I}$ & 8,91 & $\mathrm{~F}$ & - & $P$ & - & - & - & $\mathrm{P}$ & $\mathrm{P}$ & $P$ & $\mathrm{P}$ & - & - & - & $\mathrm{P}$ & - \\
\hline A.L.M. & $\mathrm{I}$ & 8,33 & $\mathrm{~F}$ & - & $\mathrm{P}$ & - & - & - & $\mathrm{P}$ & $\mathrm{P}$ & $\mathrm{P}$ & $\mathrm{P}$ & - & - & - & $\mathrm{P}$ & - \\
\hline A.P.T. & $\mathrm{I}$ & 8,66 & $F$ & - & $\mathrm{P}$ & - & - & - & $\mathrm{P}$ & $\mathrm{P}$ & $P$ & $\mathrm{P}$ & - & - & - & $\mathrm{P}$ & - \\
\hline J.M.R.M. & I & 8,83 & $M$ & - & $\mathrm{P}$ & - & - & - & $\mathrm{P}$ & $\mathrm{P}$ & $\mathrm{P}$ & $\mathrm{P}$ & - & - & - & $\mathrm{P}$ & - \\
\hline D.F.D & $\mathrm{T}$ & 8,08 & $\bar{M}$ & - & $P$ & - & - & - & $P$ & $P$ & $P$ & $\mathrm{P}$ & - & - & - & $P$ & - \\
\hline A.C.M. & $\mathrm{I}$ & 8,66 & $F$ & - & $\mathrm{P}$ & - & - & - & $P$ & $\mathrm{P}$ & $P$ & $\mathrm{P}$ & - & - & - & $\mathrm{P}$ & - \\
\hline E.D.B. & I & 8,83 & $\mathrm{~F}$ & - & $\mathrm{P}$ & - & $\mathrm{P}$ & $\mathrm{P}$ & $\mathrm{P}$ & $\mathrm{P}$ & $\mathrm{P}$ & $\mathrm{P}$ & - & - & - & $\mathrm{P}$ & - \\
\hline V.M.A.C. & $\mathrm{I}$ & 8,66 & $\mathrm{~F}$ & - & $\mathrm{P}$ & - & - & $\mathrm{P}$ & $\mathrm{P}$ & $\mathrm{P}$ & $\mathrm{P}$ & $\mathrm{P}$ & - & $\mathrm{P}$ & - & $\mathrm{P}$ & - \\
\hline A.C.D. & $\mathrm{T}$ & 8,50 & $F$ & - & $\mathrm{P}$ & - & $\mathrm{P}$ & $P$ & $\mathrm{P}$ & $\mathrm{P}$ & $P$ & $\mathrm{P}$ & $\mathrm{P}$ & - & - & $\mathrm{P}$ & - \\
\hline C.J.C.F. & $\mathrm{I}$ & 8,33 & $\mathrm{M}$ & - & $\mathrm{P}$ & - & - & - & $\mathrm{P}$ & $\mathrm{P}$ & $\mathrm{P}$ & $\mathrm{P}$ & - & - & - & $\mathrm{P}$ & - \\
\hline D.F.C. & 1 & 8,16 & $\mathrm{~F}$ & - & $\mathrm{P}$ & - & - & - & $\mathrm{P}$ & $\mathrm{P}$ & $\mathrm{P}$ & $\mathrm{P}$ & - & - & - & $\mathrm{P}$ & - \\
\hline F.S. & 1 & 8,50 & $\mathrm{M}$ & - & $\mathrm{P}$ & - & - & - & $\mathrm{P}$ & $\mathrm{P}$ & $\mathrm{P}$ & - & - & - & - & $\mathrm{P}$ & - \\
\hline R.F.E. & 1 & 8,25 & $M$ & - & $\mathrm{P}$ & - & - & - & $\mathrm{P}$ & $\mathrm{P}$ & $\mathrm{P}$ & $\mathrm{P}$ & - & - & - & $\mathrm{P}$ & - \\
\hline M.Q.B. & 1 & 8,66 & $\mathrm{M}$ & - & $\mathrm{P}$ & - & $\mathrm{P}$ & $\mathrm{P}$ & $\mathrm{P}$ & $\mathrm{P}$ & $\mathrm{P}$ & $\mathrm{P}$ & $\mathrm{P}$ & $\mathrm{P}$ & - & $\mathrm{P}$ & - \\
\hline M.P.P. & 1 & 8,50 & $\mathrm{~F}$ & - & $\mathrm{P}$ & - & - & - & $\mathrm{P}$ & $\mathrm{P}$ & $\mathrm{P}$ & $\mathrm{P}$ & - & - & - & $\mathrm{P}$ & - \\
\hline T.F.D. & 1 & 8,08 & $\mathrm{M}$ & - & $\mathrm{P}$ & - & - & - & $\mathrm{P}$ & $\mathrm{P}$ & $\mathrm{P}$ & $\mathrm{P}$ & - & - & - & $\mathrm{P}$ & - \\
\hline M.L.P. & 1 & 8,00 & $\mathrm{~F}$ & - & $\mathrm{P}$ & - & - & - & $\mathrm{P}$ & $\mathrm{P}$ & $\mathrm{P}$ & $\mathrm{P}$ & - & - & - & $\mathrm{P}$ & - \\
\hline A.P.M.B. & I & 8,00 & $\mathrm{~F}$ & - & $\mathrm{P}$ & - & - & - & $\mathrm{P}$ & $\mathrm{P}$ & $\mathrm{P}$ & $\mathrm{P}$ & - & - & - & $\mathrm{P}$ & - \\
\hline P.S.E. & $\mathrm{I}$ & 8,41 & $F$ & - & $\mathrm{P}$ & - & - & - & $\mathrm{P}$ & $\mathrm{P}$ & $\mathrm{P}$ & $\mathrm{P}$ & - & - & - & $\mathrm{P}$ & - \\
\hline R.Q. & 1 & 8,83 & $\mathrm{M}$ & - & $\mathrm{P}$ & - & - & - & $\mathrm{P}$ & $\mathrm{P}$ & $\mathrm{P}$ & $\mathrm{P}$ & - & - & - & $\mathrm{P}$ & - \\
\hline E.L.C.S. & $\mathrm{I}$ & 8,91 & $\mathrm{M}$ & - & $\mathrm{P}$ & - & - & - & $\mathrm{P}$ & $\mathrm{P}$ & $\mathrm{P}$ & $\mathrm{P}$ & - & $\mathrm{P}$ & - & $\mathrm{P}$ & - \\
\hline J.R.N. & $\mathrm{I}$ & 8,91 & $M$ & - & $\mathrm{P}$ & - & - & - & $\mathrm{P}$ & $\mathrm{P}$ & $\mathrm{P}$ & $\mathrm{P}$ & - & - & - & $\mathrm{P}$ & - \\
\hline H.J.S.S. & $\mathrm{T}$ & 8,75 & $\bar{M}$ & - & $\mathrm{P}$ & - & - & - & $\mathrm{P}$ & $\mathrm{P}$ & $\mathrm{P}$ & $\mathrm{P}$ & - & - & - & $\mathrm{P}$ & - \\
\hline E.A. & $\mathrm{I}$ & 8,75 & $\mathrm{M}$ & - & $\mathrm{P}$ & - & - & - & - & $\mathrm{P}$ & $\mathrm{P}$ & $\mathrm{P}$ & - & - & - & $\mathrm{P}$ & - \\
\hline M.S. & I & 8,08 & $M$ & - & $\mathrm{P}$ & - & - & - & $\mathrm{P}$ & $\mathrm{P}$ & $\mathrm{P}$ & $\mathrm{P}$ & - & - & - & $\mathrm{P}$ & - \\
\hline L.C.V. & $\mathrm{I}$ & 8,75 & $\mathrm{~F}$ & - & $\mathrm{P}$ & - & - & $\mathrm{P}$ & $\mathrm{P}$ & $\mathrm{P}$ & $\mathrm{P}$ & $\mathrm{P}$ & $\mathrm{P}$ & - & - & $\mathrm{P}$ & - \\
\hline A.L.T.P. & $\mathrm{I}$ & 8,33 & $\mathrm{~F}$ & - & $\mathrm{P}$ & - & - & - & $\mathrm{P}$ & $\mathrm{P}$ & $\mathrm{P}$ & $\mathrm{P}$ & - & - & - & $\mathrm{P}$ & - \\
\hline R.A.C.M. & $\mathrm{I}$ & 8,50 & $\bar{M}$ & - & $\mathrm{P}$ & - & - & - & $\mathrm{P}$ & $\mathrm{P}$ & $\mathrm{P}$ & $\mathrm{P}$ & - & - & - & $\mathrm{P}$ & - \\
\hline L.F.S.G. & $\mathrm{I}$ & 8,25 & $\mathrm{M}$ & - & $\mathrm{P}$ & - & - & - & $\mathrm{P}$ & $\mathrm{P}$ & $\mathrm{P}$ & $\mathrm{P}$ & - & - & - & $\mathrm{P}$ & - \\
\hline R.A.A.P.R. & II & 8,91 & $\mathrm{~F}$ & - & $\mathrm{P}$ & - & - & - & $\mathrm{P}$ & $\mathrm{P}$ & $\mathrm{P}$ & $\mathrm{P}$ & - & - & - & $\mathrm{P}$ & - \\
\hline A.I.M.B. & II & 8,41 & $\mathrm{~F}$ & - & $\mathrm{P}$ & - & - & - & $P$ & $P$ & $\mathrm{P}$ & $\mathrm{P}$ & - & - & - & $\mathrm{P}$ & - \\
\hline T.V.S. & II & 8,00 & $\bar{M}$ & - & $\mathrm{P}$ & - & - & - & $\mathrm{P}$ & $\mathrm{P}$ & $\mathrm{P}$ & $\mathrm{P}$ & - & - & - & $\mathrm{P}$ & - \\
\hline J.C.M.J. & II & 8,00 & $\bar{M}$ & - & $\mathrm{P}$ & - & - & - & - & $\mathrm{P}$ & $\mathrm{P}$ & - & - & - & - & $\mathrm{P}$ & - \\
\hline A.F.G. & II & 8,58 & $\bar{M}$ & - & $\mathrm{P}$ & - & - & - & $\mathrm{P}$ & $\mathrm{P}$ & $\mathrm{P}$ & $\mathrm{P}$ & - & - & - & $\mathrm{P}$ & - \\
\hline M.A.P.T. & II & 8,00 & $\bar{M}$ & - & $\mathrm{P}$ & - & - & - & $\mathrm{P}$ & $\mathrm{P}$ & $\mathrm{P}$ & $\mathrm{P}$ & - & - & - & $\mathrm{P}$ & - \\
\hline P.B.J. & II & 8,66 & $M$ & - & $\mathrm{P}$ & - & - & - & $\mathrm{P}$ & $\mathrm{P}$ & $\mathrm{P}$ & $\mathrm{P}$ & - & - & - & $\mathrm{P}$ & - \\
\hline T.C.C.C. & II & 8,58 & $\mathrm{~F}$ & - & $\mathrm{P}$ & - & - & $\mathrm{P}$ & $\mathrm{P}$ & $\mathrm{P}$ & $\mathrm{P}$ & $\mathrm{P}$ & - & - & - & $\mathrm{P}$ & - \\
\hline C.H.T. & II & 8,91 & $\bar{M}$ & - & $\mathrm{P}$ & - & - & - & $P$ & $\mathrm{P}$ & $P$ & $\mathrm{P}$ & - & - & - & $\mathrm{P}$ & - \\
\hline R.P.F. & II & 8,83 & $M$ & - & $\mathrm{P}$ & - & - & - & $\mathrm{P}$ & $\mathrm{P}$ & $P$ & $\mathrm{P}$ & - & - & - & $\mathrm{P}$ & - \\
\hline E.C.L. & II & 8,66 & $\mathrm{~F}$ & - & $\mathrm{P}$ & - & - & - & $\mathrm{P}$ & $\mathrm{P}$ & $\mathrm{P}$ & $\mathrm{P}$ & $\mathrm{P}$ & - & - & $\mathrm{P}$ & - \\
\hline R.F.B. & II & 8,66 & $\bar{M}$ & - & $\mathrm{P}$ & - & - & - & $\mathrm{P}$ & $\mathrm{P}$ & $\mathrm{P}$ & $\mathrm{P}$ & - & - & - & $\mathrm{P}$ & - \\
\hline R.R.D. & II & 8,66 & $M$ & - & $\mathrm{P}$ & - & - & - & $\mathrm{P}$ & $\mathrm{P}$ & $\mathrm{P}$ & $\mathrm{P}$ & - & - & - & $\mathrm{P}$ & - \\
\hline J.A.M. & II & 8,91 & $M$ & - & $\mathrm{P}$ & - & - & - & $\mathrm{P}$ & $\mathrm{P}$ & $\mathrm{P}$ & $\mathrm{P}$ & - & - & - & $\mathrm{P}$ & - \\
\hline B.M.L. & II & 8,16 & $M$ & - & $\mathrm{P}$ & - & - & - & $\mathrm{P}$ & $\mathrm{P}$ & $\mathrm{P}$ & $\mathrm{P}$ & - & - & - & $\mathrm{P}$ & - \\
\hline R.O.B.A. & II & 8,50 & $\mathrm{M}$ & - & $\mathrm{P}$ & - & - & - & $P$ & $P$ & $\mathrm{P}$ & $P$ & - & - & - & $\mathrm{P}$ & - \\
\hline C.F.Z.S. & II & 8,16 & $F$ & - & $\mathrm{P}$ & - & - & - & $\mathrm{P}$ & $\mathrm{P}$ & $\mathrm{P}$ & $\mathrm{P}$ & - & - & - & $\mathrm{P}$ & - \\
\hline R.A.S.S. & II & 8,33 & $\mathrm{~F}$ & - & $\mathrm{P}$ & - & - & - & - & $\mathrm{P}$ & $\mathrm{P}$ & - & - & - & - & $\mathrm{P}$ & - \\
\hline R.B.R. & II & 8,16 & $\mathrm{~F}$ & - & $\mathrm{P}$ & - & - & - & - & $\mathrm{P}$ & $\mathrm{P}$ & - & - & - & - & $\mathrm{P}$ & - \\
\hline F.B.A. & II & 8,33 & $\mathrm{~F}$ & - & $\mathrm{P}$ & - & - & - & $\mathrm{P}$ & $\mathrm{P}$ & $P$ & $\mathrm{P}$ & - & - & - & $\mathrm{P}$ & - \\
\hline M.F.G. & II & 8,08 & $\mathrm{~F}$ & - & $\mathrm{P}$ & - & - & - & $\mathrm{P}$ & $\mathrm{P}$ & $P$ & $\mathrm{P}$ & - & - & - & $\mathrm{P}$ & - \\
\hline D.D. & II & 8,91 & $\mathrm{~F}$ & - & $\mathrm{P}$ & - & - & $\mathrm{P}$ & $\mathrm{P}$ & $\mathrm{P}$ & $\mathrm{P}$ & $\mathrm{P}$ & $\mathrm{P}$ & - & - & $\mathrm{P}$ & - \\
\hline F.B.R. & II & 8,08 & $\mathrm{~F}$ & - & $\mathrm{P}$ & - & - & - & $\mathrm{P}$ & $\mathrm{P}$ & $\mathrm{P}$ & $\mathrm{P}$ & - & - & - & $\mathrm{P}$ & - \\
\hline E.F.Z. & II & 8,33 & $\mathrm{~F}$ & - & $\mathrm{P}$ & - & - & - & $\mathrm{P}$ & $\mathrm{P}$ & $\mathrm{P}$ & $\mathrm{P}$ & - & - & - & $\mathrm{P}$ & - \\
\hline A.R.F. & II & 8,91 & $\bar{M}$ & - & $\mathrm{P}$ & - & - & $\mathrm{P}$ & $\mathrm{P}$ & $\mathrm{P}$ & $\mathrm{P}$ & $\mathrm{P}$ & - & - & - & $\mathrm{P}$ & - \\
\hline T.S.N.J. & II & 8,50 & $M$ & - & $\mathrm{P}$ & - & - & - & $\mathrm{P}$ & $\mathrm{P}$ & $\mathrm{P}$ & $\mathrm{P}$ & - & - & - & $\mathrm{P}$ & - \\
\hline O.C.C. & II & 8,08 & $\bar{M}$ & - & $P$ & - & - & - & $P$ & $\mathrm{P}$ & $P$ & $\mathrm{P}$ & - & - & - & $P$ & - \\
\hline J.A.A.C. & II & 8,83 & $M$ & - & $\mathrm{P}$ & - & - & - & $\mathrm{P}$ & $\mathrm{P}$ & $\mathrm{P}$ & $\mathrm{P}$ & - & - & - & $\mathrm{P}$ & - \\
\hline P.B.B.M. & II & 8,83 & $\mathrm{~F}$ & - & $\mathrm{P}$ & - & - & - & $\mathrm{P}$ & $\mathrm{P}$ & $\mathrm{P}$ & $\mathrm{P}$ & - & - & - & $\mathrm{P}$ & - \\
\hline M.H.T. & II & 8,25 & $F$ & - & $\mathrm{P}$ & - & - & - & $\mathrm{P}$ & $\mathrm{P}$ & $P$ & $\mathrm{P}$ & - & - & - & $\mathrm{P}$ & - \\
\hline
\end{tabular}


TABELA A-11

\begin{tabular}{|c|c|c|c|c|c|c|c|c|c|c|c|c|c|c|c|c|c|}
\hline Nome & Classe & Idade & Gênero & 17 & 16 & 15 & 14 & 13 & 12 & 11 & 21 & 22 & 23 & 24 & 25 & 26 & 27 \\
\hline A.P.T. & $\mathrm{I}$ & 9,75 & $F$ & - & $\mathrm{P}$ & - & - & - & $\mathrm{P}$ & $P$ & $P$ & $P$ & - & - & - & $P$ & - \\
\hline J.M.R.M. & $\mathrm{I}$ & 9,91 & $M$ & - & $\mathrm{P}$ & - & - & - & $\mathrm{P}$ & $\mathrm{P}$ & $\mathrm{P}$ & $\mathrm{P}$ & - & $\mathrm{P}$ & $\mathrm{P}$ & $\mathrm{P}$ & - \\
\hline T.S.C. & $\mathrm{I}$ & 9,33 & $\bar{M}$ & - & $\mathrm{P}$ & - & - & - & $\mathrm{P}$ & $\mathrm{P}$ & $\mathrm{P}$ & $\mathrm{P}$ & - & - & - & $\mathrm{P}$ & - \\
\hline V.M.A.C. & $\mathrm{I}$ & 9,83 & $\mathrm{~F}$ & - & $\mathrm{P}$ & $\mathrm{P}$ & $\mathrm{P}$ & $\mathrm{P}$ & $\mathrm{P}$ & $\mathrm{P}$ & $\mathrm{P}$ & $\mathrm{P}$ & $\mathrm{P}$ & $\mathrm{P}$ & $\mathrm{P}$ & $\mathrm{P}$ & - \\
\hline R.A.A. & I & 9,66 & $M$ & - & $\mathrm{P}$ & - & - & - & $\mathrm{P}$ & $\mathrm{P}$ & $\mathrm{P}$ & - & - & - & - & $\mathrm{P}$ & - \\
\hline D.F.D & I & 9,00 & $\bar{M}$ & - & $\mathrm{P}$ & - & - & - & $\mathrm{P}$ & $P$ & $\mathrm{P}$ & $\mathrm{P}$ & - & - & - & $\mathrm{P}$ & - \\
\hline A.C.M. & I & 9,66 & $F$ & - & $P$ & - & - & - & $P$ & $P$ & $P$ & $P$ & - & $P$ & $P$ & $P$ & - \\
\hline E.P.P. & I & 9,83 & $\mathrm{~F}$ & - & $\mathrm{P}$ & $\mathrm{P}$ & $\mathrm{P}$ & - & $\mathrm{P}$ & $\mathrm{P}$ & $\mathrm{P}$ & $\mathrm{P}$ & - & $\mathrm{P}$ & - & $\mathrm{P}$ & - \\
\hline E.C.M. & $\mathrm{I}$ & 9,91 & $F$ & - & $\mathrm{P}$ & - & - & - & $P$ & $P$ & $P$ & $P$ & - & - & - & $P$ & - \\
\hline A.L.M. & 1 & 9,16 & $\mathrm{~F}$ & - & $\mathrm{P}$ & $\mathrm{P}$ & $\mathrm{P}$ & - & $\mathrm{P}$ & $\mathrm{P}$ & $\mathrm{P}$ & $P$ & - & $P$ & $\mathrm{P}$ & $\mathrm{P}$ & - \\
\hline A.C.D. & $\mathrm{I}$ & 9,58 & $\mathrm{~F}$ & - & $\mathrm{P}$ & $P$ & - & - & $\mathrm{P}$ & $P$ & $\mathrm{P}$ & $\mathrm{P}$ & - & $\mathrm{P}$ & - & $\mathrm{P}$ & - \\
\hline F.S. & 1 & 9,41 & $\mathrm{M}$ & - & $\mathrm{P}$ & - & - & - & $\mathrm{P}$ & $\mathrm{P}$ & $\mathrm{P}$ & $\mathrm{P}$ & - & $\mathrm{P}$ & - & $\mathrm{P}$ & - \\
\hline R.F.E. & 1 & 9,25 & $\mathrm{M}$ & $\mathrm{P}$ & $P$ & - & $\mathrm{P}$ & - & $\mathrm{P}$ & $\mathrm{P}$ & $\mathrm{P}$ & $P$ & - & $\mathrm{P}$ & - & $\mathrm{P}$ & - \\
\hline S.T.G. & 1 & 9,50 & $\mathrm{M}$ & - & $\mathrm{P}$ & - & - & - & $\mathrm{P}$ & $\mathrm{P}$ & $\mathrm{P}$ & $P$ & - & - & - & $\mathrm{P}$ & - \\
\hline M.Q.B. & 1 & 9,58 & $\mathrm{M}$ & - & $\mathrm{P}$ & - & $\mathrm{P}$ & $\mathrm{P}$ & $\mathrm{P}$ & $\mathrm{P}$ & $\mathrm{P}$ & $P$ & $\mathrm{P}$ & $\mathrm{P}$ & - & $\mathrm{P}$ & - \\
\hline M.P.P. & 1 & 9,58 & $\mathrm{~F}$ & - & $\mathrm{P}$ & - & - & - & $\mathrm{P}$ & $\mathrm{P}$ & $\mathrm{P}$ & $P$ & - & - & - & $\mathrm{P}$ & - \\
\hline T.F.D. & 1 & 9,08 & $\mathrm{M}$ & - & $\mathrm{P}$ & - & - & - & $\mathrm{P}$ & $\mathrm{P}$ & $\mathrm{P}$ & $P$ & - & - & - & $\mathrm{P}$ & - \\
\hline C.L.C. & 1 & 9,33 & $F$ & - & $\mathrm{P}$ & $\mathrm{P}$ & $\mathrm{P}$ & - & $\mathrm{P}$ & $\mathrm{P}$ & $\mathrm{P}$ & $\mathrm{P}$ & - & - & $\mathrm{P}$ & $\mathrm{P}$ & - \\
\hline D.E.H. & I & 9,75 & $F$ & - & $\mathrm{P}$ & - & $\mathrm{P}$ & $\mathrm{P}$ & $\mathrm{P}$ & $\mathrm{P}$ & $\mathrm{P}$ & $\mathrm{P}$ & $\mathrm{P}$ & $\mathrm{P}$ & - & $\mathrm{P}$ & - \\
\hline M.L.P. & I & 9,00 & $F$ & - & $\mathrm{P}$ & - & - & - & $\mathrm{P}$ & $\mathrm{P}$ & $\mathrm{P}$ & $P$ & - & - & - & $\mathrm{P}$ & - \\
\hline P.S.E. & 1 & 9,41 & $\mathrm{~F}$ & - & $\mathrm{P}$ & - & - & - & $\mathrm{P}$ & $\mathrm{P}$ & $\mathrm{P}$ & $P$ & - & - & - & $\mathrm{P}$ & - \\
\hline J.R.N. & $\mathrm{I}$ & 9,83 & $M$ & - & $\mathrm{P}$ & - & - & - & $\mathrm{P}$ & $\mathrm{P}$ & $\mathrm{P}$ & $\mathrm{P}$ & - & - & - & $\mathrm{P}$ & - \\
\hline R.Q. & $\mathrm{I}$ & 9,83 & $M$ & - & $\mathrm{P}$ & - & - & - & $\mathrm{P}$ & $\mathrm{P}$ & $\mathrm{P}$ & $\mathrm{P}$ & - & $\mathrm{P}$ & - & $\mathrm{P}$ & - \\
\hline E.L.C.S. & $\mathrm{T}$ & 9,91 & $\bar{M}$ & - & $\mathrm{P}$ & - & - & - & $\mathrm{P}$ & $\mathrm{P}$ & $\mathrm{P}$ & $P$ & - & $P$ & $\mathrm{P}$ & $\mathrm{P}$ & - \\
\hline H.J.S.S. & $\mathrm{I}$ & 9,66 & $M$ & - & $\mathrm{P}$ & - & - & - & $\mathrm{P}$ & $\mathrm{P}$ & $\mathrm{P}$ & $\mathrm{P}$ & - & - & - & $\mathrm{P}$ & - \\
\hline E.A. & I & 9,83 & $M$ & - & $\mathrm{P}$ & - & - & - & $\mathrm{P}$ & $\mathrm{P}$ & $\mathrm{P}$ & $\mathrm{P}$ & - & - & - & $\mathrm{P}$ & - \\
\hline M.S. & $\mathrm{I}$ & 9,25 & $M$ & - & $\mathrm{P}$ & - & $\mathrm{P}$ & - & $\mathrm{P}$ & $\mathrm{P}$ & $\mathrm{P}$ & $\mathrm{P}$ & - & $\mathrm{P}$ & - & $\mathrm{P}$ & - \\
\hline L.C.V. & $\mathrm{I}$ & 9,83 & $\mathrm{~F}$ & - & $\mathrm{P}$ & - & - & - & $\mathrm{P}$ & $\mathrm{P}$ & $\mathrm{P}$ & $\mathrm{P}$ & - & - & - & $\mathrm{P}$ & - \\
\hline A.L.F. & $\mathrm{I}$ & 9,00 & $\bar{M}$ & - & $\mathrm{P}$ & - & - & - & $\mathrm{P}$ & $\mathrm{P}$ & $\mathrm{P}$ & $\mathrm{P}$ & - & - & - & $\mathrm{P}$ & - \\
\hline R.A.C.M. & $\mathrm{I}$ & 9,50 & $M$ & - & $\mathrm{P}$ & $\mathrm{P}$ & - & - & $\mathrm{P}$ & $\mathrm{P}$ & $\mathrm{P}$ & $\mathrm{P}$ & - & - & $\mathrm{P}$ & $\mathrm{P}$ & - \\
\hline T.V.S. & II & 9,00 & $M$ & - & $\mathrm{P}$ & - & - & - & $\mathrm{P}$ & $\mathrm{P}$ & $\mathrm{P}$ & $\mathrm{P}$ & - & $\mathrm{P}$ & - & $\mathrm{P}$ & - \\
\hline J.C.M.J. & II & 9,00 & $\bar{M}$ & - & $\mathrm{P}$ & - & - & - & - & $\mathrm{P}$ & $\mathrm{P}$ & - & - & - & - & $\mathrm{P}$ & - \\
\hline A.F.G. & II & 9,50 & $\bar{M}$ & - & $\mathrm{P}$ & - & $\mathrm{P}$ & $\mathrm{P}$ & $\mathrm{P}$ & $\mathrm{P}$ & $\mathrm{P}$ & $\mathrm{P}$ & $\mathrm{P}$ & $\mathrm{P}$ & - & $\mathrm{P}$ & - \\
\hline M.A.P.T. & II & 9,16 & $\bar{M}$ & - & $P$ & - & - & - & $\mathrm{P}$ & $\mathrm{P}$ & $\mathrm{P}$ & $\mathrm{P}$ & - & - & - & $\mathrm{P}$ & - \\
\hline P.B.J. & II & 9,91 & $M$ & - & $\mathrm{P}$ & - & - & - & $\mathrm{P}$ & $\mathrm{P}$ & $\mathrm{P}$ & $\mathrm{P}$ & - & $\mathrm{P}$ & $\mathrm{P}$ & $\mathrm{P}$ & - \\
\hline R.G.M. & II & 9,25 & $\bar{M}$ & - & $\mathrm{P}$ & - & - & - & $\mathrm{P}$ & $\mathrm{P}$ & $\mathrm{P}$ & $\mathrm{P}$ & - & $\mathrm{P}$ & $\mathrm{P}$ & $\mathrm{P}$ & - \\
\hline T.C.C.C. & II & 9,58 & $\mathrm{~F}$ & - & $\mathrm{P}$ & - & - & - & $\mathrm{P}$ & $\mathrm{P}$ & $\mathrm{P}$ & $\mathrm{P}$ & - & $\mathrm{P}$ & - & $\mathrm{P}$ & - \\
\hline C.H.T. & II & 9,91 & $M$ & - & $\mathrm{P}$ & - & - & - & $\mathrm{P}$ & $\mathrm{P}$ & $\mathrm{P}$ & $\mathrm{P}$ & - & - & - & $\mathrm{P}$ & - \\
\hline R.P.F. & II & 9,75 & $\bar{M}$ & - & $P$ & - & - & - & $\mathrm{P}$ & $P$ & $P$ & $\mathrm{P}$ & - & - & - & $\mathrm{P}$ & - \\
\hline E.C.L. & II & 9,83 & $F$ & - & $\mathrm{P}$ & - & - & - & $\mathrm{P}$ & $\mathrm{P}$ & $\mathrm{P}$ & $\mathrm{P}$ & - & - & - & $\mathrm{P}$ & - \\
\hline R.F.B. & II & 9,58 & $\bar{M}$ & - & $P$ & - & - & - & $\mathrm{P}$ & $\mathrm{P}$ & $\mathrm{P}$ & $\mathrm{P}$ & - & $\mathrm{P}$ & $\mathrm{P}$ & $\mathrm{P}$ & - \\
\hline R.R.D. & II & 9,75 & $\bar{M}$ & - & $\mathrm{P}$ & $\mathrm{P}$ & $\mathrm{P}$ & - & $\mathrm{P}$ & $\mathrm{P}$ & $\mathrm{P}$ & $\mathrm{P}$ & - & $\mathrm{P}$ & - & $\mathrm{P}$ & - \\
\hline J.A.M. & II & 9,83 & $M$ & - & $\mathrm{P}$ & - & - & - & $\mathrm{P}$ & $\mathrm{P}$ & $\mathrm{P}$ & $\mathrm{P}$ & - & - & - & $\mathrm{P}$ & - \\
\hline R.O.B.A. & II & 9,41 & $M$ & - & $\mathrm{P}$ & - & - & - & $\mathrm{P}$ & $\mathrm{P}$ & $\mathrm{P}$ & $\mathrm{P}$ & - & - & - & $\mathrm{P}$ & - \\
\hline C.F.Z.S. & II & 9,08 & $\mathrm{~F}$ & - & $\mathrm{P}$ & - & - & - & $\mathrm{P}$ & $\mathrm{P}$ & $\mathrm{P}$ & $\mathrm{P}$ & - & - & - & $\mathrm{P}$ & - \\
\hline R.B.R. & II & 9,25 & $\mathrm{~F}$ & - & $\mathrm{P}$ & - & - & - & - & $\mathrm{P}$ & $\mathrm{P}$ & - & - & - & - & $\mathrm{P}$ & - \\
\hline F.B.A. & II & 9,41 & $F$ & - & $\mathrm{P}$ & - & - & - & $\mathrm{P}$ & $\mathrm{P}$ & $\mathrm{P}$ & $\mathrm{P}$ & - & - & - & $\mathrm{P}$ & - \\
\hline M.F.G. & II & 9,00 & $\mathrm{~F}$ & - & $\mathrm{P}$ & - & - & - & $\mathrm{P}$ & $\mathrm{P}$ & $\mathrm{P}$ & $\mathrm{P}$ & - & - & - & $\mathrm{P}$ & - \\
\hline D.D. & II & 9,91 & $\mathrm{~F}$ & - & $\mathrm{P}$ & - & $P$ & - & $\mathrm{P}$ & $P$ & $P$ & $\mathrm{P}$ & - & $P$ & - & $P$ & - \\
\hline F.B.R. & II & 9,00 & $\mathrm{~F}$ & - & $\mathrm{P}$ & - & - & - & $\mathrm{P}$ & $\mathrm{P}$ & $P$ & $\mathrm{P}$ & - & - & - & $\mathrm{P}$ & - \\
\hline E.F.Z. & II & 9,41 & $\mathrm{~F}$ & - & $\mathrm{P}$ & - & - & - & $\mathrm{P}$ & $\mathrm{P}$ & $\mathrm{P}$ & $\mathrm{P}$ & - & - & - & $\mathrm{P}$ & - \\
\hline T.S.N.J. & II & 9,58 & $M$ & - & $\mathrm{P}$ & - & - & - & $\mathrm{P}$ & $\mathrm{P}$ & $\mathrm{P}$ & $\mathrm{P}$ & - & - & - & $\mathrm{P}$ & - \\
\hline O.C.C. & II & 9,25 & $\bar{M}$ & - & $\mathrm{P}$ & - & - & - & $\mathrm{P}$ & $\mathrm{P}$ & $\mathrm{P}$ & $\mathrm{P}$ & - & - & - & $\mathrm{P}$ & - \\
\hline J.A.A.C. & II & 9,83 & $M$ & - & $\mathrm{P}$ & - & - & - & $\mathrm{P}$ & $\mathrm{P}$ & $P$ & $\mathrm{P}$ & - & - & - & $\mathrm{P}$ & - \\
\hline P.B.B.M. & II & 9,75 & $\mathrm{~F}$ & - & $\mathrm{P}$ & - & - & - & $\mathrm{P}$ & $\mathrm{P}$ & $\mathrm{P}$ & $\mathrm{P}$ & - & - & - & $\mathrm{P}$ & - \\
\hline M.H.T. & II & 9,25 & $\mathrm{~F}$ & - & $\mathrm{P}$ & - & - & - & $\mathrm{P}$ & $\mathrm{P}$ & $\mathrm{P}$ & $\mathrm{P}$ & - & - & - & $\mathrm{P}$ & - \\
\hline A.R.F. & II & 9,91 & $\bar{M}$ & - & $\mathrm{P}$ & - & - & - & $\mathrm{P}$ & $\mathrm{P}$ & $\mathrm{P}$ & $\mathrm{P}$ & - & - & - & $\mathrm{P}$ & - \\
\hline M.G.T. & II & 9,58 & $\bar{M}$ & - & $P$ & $\mathrm{P}$ & $\mathrm{P}$ & - & $\mathrm{P}$ & $\mathrm{P}$ & $\mathrm{P}$ & $P$ & $\mathrm{P}$ & $\mathrm{P}$ & $\mathrm{P}$ & $\mathrm{P}$ & - \\
\hline C.V.E. & II & 9,41 & $\mathrm{~F}$ & - & $\mathrm{P}$ & - & - & - & $\mathrm{P}$ & $\mathrm{P}$ & $\mathrm{P}$ & $\mathrm{P}$ & - & - & - & $\mathrm{P}$ & - \\
\hline F.B. & II & 9,58 & $F$ & - & $\mathrm{P}$ & - & $\mathrm{P}$ & - & $\mathrm{P}$ & $\mathrm{P}$ & $\mathrm{P}$ & $\mathrm{P}$ & - & $\mathrm{P}$ & $\mathrm{P}$ & $\mathrm{P}$ & - \\
\hline
\end{tabular}


TABELA A-12

\begin{tabular}{|c|c|c|c|c|c|c|c|c|c|c|c|c|c|c|c|c|c|}
\hline Nome & Classe & Idade & Gênero & 37 & 36 & 35 & 34 & 33 & 32 & 31 & 41 & 42 & 43 & 44 & 45 & 46 & 47 \\
\hline A.P.T. & $\mathrm{I}$ & 9,75 & $\mathrm{~F}$ & - & $\mathrm{P}$ & - & $\mathrm{P}$ & $\mathrm{P}$ & $\mathrm{P}$ & $\mathrm{P}$ & $\mathrm{P}$ & $\mathrm{P}$ & $\mathrm{P}$ & $\mathrm{P}$ & - & $\mathrm{P}$ & - \\
\hline J.M.R.M. & I & 9,91 & $M$ & - & $\mathrm{P}$ & - & - & $\mathrm{P}$ & $\mathrm{P}$ & $\mathrm{P}$ & $\mathrm{P}$ & $\mathrm{P}$ & $\mathrm{P}$ & $\mathrm{P}$ & - & $\mathrm{P}$ & - \\
\hline T.S.C. & $\mathrm{I}$ & 9,33 & $\bar{M}$ & - & $\mathrm{P}$ & - & - & - & $\mathrm{P}$ & $P$ & $\mathrm{P}$ & $P$ & - & - & - & $P$ & - \\
\hline V.M.A.C. & $\mathrm{I}$ & 9,83 & $F$ & - & $\mathrm{P}$ & $\mathrm{P}$ & $\mathrm{P}$ & $\mathrm{P}$ & $\mathrm{P}$ & $\mathrm{P}$ & $P$ & $\mathrm{P}$ & $\mathrm{P}$ & $P$ & $\mathrm{P}$ & $P$ & $P$ \\
\hline R.A.A. & $\mathrm{I}$ & 9,66 & $\bar{M}$ & - & $\mathrm{P}$ & - & - & - & $\mathrm{P}$ & $P$ & $P$ & $\mathrm{P}$ & - & - & - & $P$ & - \\
\hline D.F.D & $\mathrm{I}$ & 9,00 & $\bar{M}$ & - & $\mathrm{P}$ & - & - & - & $\mathrm{P}$ & $\mathrm{P}$ & $\mathrm{P}$ & $\mathrm{P}$ & - & - & - & $\mathrm{P}$ & - \\
\hline A.C.M. & 1 & 9,66 & $\mathrm{~F}$ & - & $\mathrm{P}$ & - & $\mathrm{P}$ & $\mathrm{P}$ & $\mathrm{P}$ & $\mathrm{P}$ & $\mathrm{P}$ & $\mathrm{P}$ & $\mathrm{P}$ & - & $\mathrm{P}$ & $\mathrm{P}$ & - \\
\hline E.P.P. & $\mathrm{I}$ & 9,83 & $\mathrm{~F}$ & - & $\mathrm{P}$ & - & $\mathrm{P}$ & $\mathrm{P}$ & $\mathrm{P}$ & $\mathrm{P}$ & $\mathrm{P}$ & $\mathrm{P}$ & $\mathrm{P}$ & - & - & $\mathrm{P}$ & - \\
\hline E.C.M. & 1 & 9,91 & $\mathrm{~F}$ & - & $\mathrm{P}$ & - & - & - & $\mathrm{P}$ & $\mathrm{P}$ & $\mathrm{P}$ & $\mathrm{P}$ & - & $\mathrm{P}$ & - & $\mathrm{P}$ & - \\
\hline A.L.M. & $\mathrm{I}$ & 9,16 & $F$ & - & $\mathrm{P}$ & - & - & - & $\mathrm{P}$ & $\mathrm{P}$ & $P$ & $\mathrm{P}$ & - & $P$ & $\mathrm{P}$ & $\mathrm{P}$ & - \\
\hline A.C.D. & $\mathrm{I}$ & 9,58 & $\mathrm{~F}$ & $\mathrm{P}$ & $\mathrm{P}$ & $\mathrm{P}$ & $\mathrm{P}$ & $\mathrm{P}$ & $\mathrm{P}$ & $\mathrm{P}$ & $\mathrm{P}$ & $\mathrm{P}$ & $\mathrm{P}$ & $\mathrm{P}$ & $\mathrm{P}$ & $\mathrm{P}$ & $\mathrm{P}$ \\
\hline F.S. & 1 & 9,41 & $M$ & - & $\mathrm{P}$ & - & - & - & $\mathrm{P}$ & $\mathrm{P}$ & $\mathrm{P}$ & $\mathrm{P}$ & - & - & - & $\mathrm{P}$ & - \\
\hline R.F.E. & $\mathrm{I}$ & 9,25 & $\mathrm{M}$ & $\mathrm{P}$ & $\mathrm{P}$ & - & $\mathrm{P}$ & $\mathrm{P}$ & $\mathrm{P}$ & $\mathrm{P}$ & $\mathrm{P}$ & $\mathrm{P}$ & $\mathrm{P}$ & $\mathrm{P}$ & $\mathrm{P}$ & $\mathrm{P}$ & $\mathrm{P}$ \\
\hline S.T.G. & 1 & 9,50 & $\mathrm{M}$ & - & $\mathrm{P}$ & - & - & - & $\mathrm{P}$ & $\mathrm{P}$ & $\mathrm{P}$ & $\mathrm{P}$ & - & - & - & $\mathrm{P}$ & - \\
\hline M.Q.B. & $\mathrm{I}$ & 9,58 & $\mathrm{M}$ & - & $\mathrm{P}$ & - & $\mathrm{P}$ & $\mathrm{P}$ & $\mathrm{P}$ & $\mathrm{P}$ & $\mathrm{P}$ & $\mathrm{P}$ & $\mathrm{P}$ & $\mathrm{P}$ & - & $\mathrm{P}$ & $\mathrm{P}$ \\
\hline M.P.P. & $\mathrm{I}$ & 9,58 & $F$ & - & $\mathrm{P}$ & - & - & - & $\mathrm{P}$ & $\mathrm{P}$ & $\mathrm{P}$ & $\mathrm{P}$ & - & - & - & $\mathrm{P}$ & - \\
\hline T.F.D. & $\mathrm{I}$ & 9,08 & $\bar{M}$ & - & $\mathrm{P}$ & - & - & $\mathrm{P}$ & $\mathrm{P}$ & $\mathrm{P}$ & $P$ & $\mathrm{P}$ & - & - & - & $\mathrm{P}$ & - \\
\hline C.L.C. & 1 & 9,33 & $\mathrm{~F}$ & - & $\mathrm{P}$ & $\mathrm{P}$ & - & $\mathrm{P}$ & $\mathrm{P}$ & $\mathrm{P}$ & $\mathrm{P}$ & $\mathrm{P}$ & $\mathrm{P}$ & - & $\mathrm{P}$ & $\mathrm{P}$ & - \\
\hline D.E.H. & $\mathrm{I}$ & 9,75 & $\mathrm{~F}$ & - & $\mathrm{P}$ & $\mathrm{P}$ & $\mathrm{P}$ & $\mathrm{P}$ & $\mathrm{P}$ & $\mathrm{P}$ & $\mathrm{P}$ & $\mathrm{P}$ & $\mathrm{P}$ & $\mathrm{P}$ & $\mathrm{P}$ & $\mathrm{P}$ & - \\
\hline M.L.P. & $\mathrm{I}$ & 9,00 & $\mathrm{~F}$ & - & $\mathrm{P}$ & - & - & $\mathrm{P}$ & $\mathrm{P}$ & $\mathrm{P}$ & $P$ & $\mathrm{P}$ & $\mathrm{P}$ & $P$ & - & $\mathrm{P}$ & - \\
\hline P.S.E. & $\mathrm{I}$ & 9,41 & $\mathrm{~F}$ & - & $\mathrm{P}$ & - & - & - & $\mathrm{P}$ & $\mathrm{P}$ & $\mathrm{P}$ & $\mathrm{P}$ & - & $\mathrm{P}$ & - & $\mathrm{P}$ & - \\
\hline J.R.N. & $\mathrm{I}$ & 9,83 & $M$ & - & $\mathrm{P}$ & - & $\mathrm{P}$ & - & $\mathrm{P}$ & $\mathrm{P}$ & $\mathrm{P}$ & $\mathrm{P}$ & - & - & - & $\mathrm{P}$ & - \\
\hline R.Q. & I & 9,83 & $M$ & - & $\mathrm{P}$ & - & $\mathrm{P}$ & - & $\mathrm{P}$ & $\mathrm{P}$ & $\mathrm{P}$ & $\mathrm{P}$ & - & - & - & $\mathrm{P}$ & - \\
\hline E.L.C.S. & I & 9,91 & $\bar{M}$ & - & $\mathrm{P}$ & $\mathrm{P}$ & - & - & $\mathrm{P}$ & $\mathrm{P}$ & $\mathrm{P}$ & $\mathrm{P}$ & $\mathrm{P}$ & $\mathrm{P}$ & - & $\mathrm{P}$ & - \\
\hline H.J.S.S. & $\mathrm{I}$ & 9,66 & $M$ & - & $\mathrm{P}$ & - & - & - & $\mathrm{P}$ & $\mathrm{P}$ & $\mathrm{P}$ & $\mathrm{P}$ & - & - & - & $\mathrm{P}$ & - \\
\hline E.A. & I & 9,83 & $M$ & - & $\mathrm{P}$ & - & - & - & $\mathrm{P}$ & $\mathrm{P}$ & $\mathrm{P}$ & $\mathrm{P}$ & - & - & - & $\mathrm{P}$ & - \\
\hline M.S. & $\mathrm{I}$ & 9,25 & $\bar{M}$ & - & $\mathrm{P}$ & - & $\mathrm{P}$ & - & $\mathrm{P}$ & $\mathrm{P}$ & $\mathrm{P}$ & $\mathrm{P}$ & - & $\mathrm{P}$ & - & $\mathrm{P}$ & - \\
\hline L.C.V. & $\mathrm{I}$ & 9,83 & $\mathrm{~F}$ & - & $\mathrm{P}$ & - & $\mathrm{P}$ & $\mathrm{P}$ & $\mathrm{P}$ & $\mathrm{P}$ & $\mathrm{P}$ & $\mathrm{P}$ & $\mathrm{P}$ & $\mathrm{P}$ & - & $\mathrm{P}$ & - \\
\hline A.L.F. & $\mathrm{I}$ & 9,00 & $M$ & - & $\mathrm{P}$ & - & - & - & $\mathrm{P}$ & $\mathrm{P}$ & $\mathrm{P}$ & $\mathrm{P}$ & - & - & - & $P$ & - \\
\hline R.A.C.M. & I & 9,50 & $M$ & - & $\mathrm{P}$ & $\mathrm{P}$ & $\mathrm{P}$ & - & $\mathrm{P}$ & $\mathrm{P}$ & $\mathrm{P}$ & $\mathrm{P}$ & - & - & - & $\mathrm{P}$ & - \\
\hline T.V.S. & II & 9,00 & $\bar{M}$ & - & $\mathrm{P}$ & - & $\mathrm{P}$ & - & $\mathrm{P}$ & $\mathrm{P}$ & $\mathrm{P}$ & $\mathrm{P}$ & - & $\mathrm{P}$ & - & $\mathrm{P}$ & - \\
\hline J.C.M.J. & II & 9,00 & $\bar{M}$ & - & $\mathrm{P}$ & - & - & - & - & $\mathrm{P}$ & $\mathrm{P}$ & $\mathrm{P}$ & - & - & - & $\mathrm{P}$ & - \\
\hline A.F.G. & II & 9,50 & $\bar{M}$ & - & $P$ & - & - & $\mathrm{P}$ & $\mathrm{P}$ & $\mathrm{P}$ & $\mathrm{P}$ & $\mathrm{P}$ & $\mathrm{P}$ & $\mathrm{P}$ & - & $\mathrm{P}$ & $P$ \\
\hline M.A.P.T. & II & 9,16 & $\bar{M}$ & - & $\mathrm{P}$ & - & - & - & $\mathrm{P}$ & $\mathrm{P}$ & $\mathrm{P}$ & $\mathrm{P}$ & - & - & - & $\mathrm{P}$ & - \\
\hline P.B.J. & II & 9,91 & $M$ & - & $\mathrm{P}$ & - & $\mathrm{P}$ & - & $\mathrm{P}$ & $\mathrm{P}$ & $\mathrm{P}$ & $\mathrm{P}$ & - & $\mathrm{P}$ & - & $\mathrm{P}$ & - \\
\hline R.G.M. & II & 9,25 & $\bar{M}$ & - & $\mathrm{P}$ & - & - & $\mathrm{P}$ & $\mathrm{P}$ & $\mathrm{P}$ & $\mathrm{P}$ & $\mathrm{P}$ & $\mathrm{P}$ & $\mathrm{P}$ & - & $\mathrm{P}$ & - \\
\hline T.C.C.C. & II & 9,58 & $F$ & - & $\mathrm{P}$ & - & - & $\mathrm{P}$ & $P$ & $P$ & $P$ & $P$ & $P$ & $P$ & $P$ & $P$ & - \\
\hline C.H.T. & II & 9,91 & M & - & $\mathrm{P}$ & - & - & - & $\mathrm{P}$ & $\mathrm{P}$ & $P$ & $\mathrm{P}$ & $\mathrm{P}$ & - & - & $P$ & - \\
\hline R.P.F. & II & 9,75 & $\bar{M}$ & - & $\mathrm{P}$ & - & - & - & $\mathrm{P}$ & $P$ & $\mathrm{P}$ & $\mathrm{P}$ & - & - & - & $\mathrm{P}$ & - \\
\hline E.C.L. & II & 9,83 & $\mathrm{~F}$ & - & $\mathrm{P}$ & - & - & $\mathrm{P}$ & $\mathrm{P}$ & $\mathrm{P}$ & $\mathrm{P}$ & $\mathrm{P}$ & $\mathrm{P}$ & - & - & $\mathrm{P}$ & - \\
\hline R.F.B. & II & 9,58 & $M$ & - & $\mathrm{P}$ & - & - & - & $\mathrm{P}$ & $\mathrm{P}$ & $\mathrm{P}$ & $\mathrm{P}$ & - & - & - & $\mathrm{P}$ & - \\
\hline R.R.D. & II & 9,75 & $M$ & - & $\mathrm{P}$ & - & - & - & $\mathrm{P}$ & $\mathrm{P}$ & $\mathrm{P}$ & $\mathrm{P}$ & - & - & - & $\mathrm{P}$ & - \\
\hline J.A.M. & II & 9,83 & $M$ & - & $\mathrm{P}$ & - & - & - & $\mathrm{P}$ & $\mathrm{P}$ & $\mathrm{P}$ & $\mathrm{P}$ & - & - & - & $\mathrm{P}$ & - \\
\hline R.O.B.A. & II & 9,41 & $\mathrm{M}$ & - & $\mathrm{P}$ & - & - & - & $\mathrm{P}$ & $\mathrm{P}$ & $\mathrm{P}$ & $\mathrm{P}$ & - & - & - & $\mathrm{P}$ & - \\
\hline C.F.Z.S. & II & 9,08 & $\mathrm{~F}$ & - & $\mathrm{P}$ & - & - & - & $\mathrm{P}$ & $\mathrm{P}$ & $\mathrm{P}$ & $\mathrm{P}$ & - & - & - & $\mathrm{P}$ & - \\
\hline R.B.R. & II & 9,25 & $\mathrm{~F}$ & - & $\mathrm{P}$ & - & - & - & $\mathrm{P}$ & $\mathrm{P}$ & $\mathrm{P}$ & $\mathrm{P}$ & - & - & - & $\mathrm{P}$ & - \\
\hline F.B.A. & II & 9,41 & $\mathrm{~F}$ & - & $\mathrm{P}$ & - & - & $\mathrm{P}$ & $\mathrm{P}$ & $\mathrm{P}$ & $\mathrm{P}$ & $\mathrm{P}$ & $\mathrm{P}$ & - & - & $\mathrm{P}$ & - \\
\hline M.F.G. & II & 9,00 & $\mathrm{~F}$ & - & $\mathrm{P}$ & - & - & - & $\mathrm{P}$ & $\mathrm{P}$ & $P$ & $\mathrm{P}$ & - & - & - & $\mathrm{P}$ & - \\
\hline D.D. & II & 9,91 & $\mathrm{~F}$ & - & $\mathrm{P}$ & - & $\mathrm{P}$ & $\mathrm{P}$ & $\mathrm{P}$ & $\mathrm{P}$ & $\mathrm{P}$ & $\mathrm{P}$ & $\mathrm{P}$ & $\mathrm{P}$ & - & $\mathrm{P}$ & - \\
\hline F.B.R. & II & 9,00 & $\mathrm{~F}$ & - & $\mathrm{P}$ & - & - & - & $\mathrm{P}$ & $\mathrm{P}$ & $\mathrm{P}$ & $\mathrm{P}$ & - & - & - & $\mathrm{P}$ & - \\
\hline E.F.Z. & II & 9,41 & $\mathrm{~F}$ & - & $\mathrm{P}$ & - & - & - & $\mathrm{P}$ & $\mathrm{P}$ & $\mathrm{P}$ & $\mathrm{P}$ & - & - & - & $\mathrm{P}$ & - \\
\hline T.S.N.J. & II & 9,58 & $M$ & - & $\mathrm{P}$ & - & - & $\mathrm{P}$ & $\mathrm{P}$ & $\mathrm{P}$ & $\mathrm{P}$ & $\mathrm{P}$ & - & - & - & $\mathrm{P}$ & - \\
\hline O.C.C. & II & 9,25 & $\bar{M}$ & - & $\mathrm{P}$ & - & - & - & $\mathrm{P}$ & $\mathrm{P}$ & $\mathrm{P}$ & $\mathrm{P}$ & - & - & - & $\mathrm{P}$ & - \\
\hline J.A.A.C. & II & 9,83 & $M$ & - & $\mathrm{P}$ & - & - & - & $\mathrm{P}$ & $\mathrm{P}$ & $P$ & $\mathrm{P}$ & - & - & - & $P$ & - \\
\hline P.B.B.M. & II & 9,75 & $\mathrm{~F}$ & - & $\mathrm{P}$ & - & - & - & $\mathrm{P}$ & $\mathrm{P}$ & $P$ & $\mathrm{P}$ & $\mathrm{P}$ & - & - & $P$ & - \\
\hline M.H.T. & II & 9,25 & $\mathrm{~F}$ & - & $\mathrm{P}$ & - & - & - & $\mathrm{P}$ & $\mathrm{P}$ & $\mathrm{P}$ & $\mathrm{P}$ & - & - & - & $\mathrm{P}$ & - \\
\hline A.R.F. & II & 9,91 & $\bar{M}$ & - & $\mathrm{P}$ & - & $\mathrm{P}$ & $\mathrm{P}$ & $\mathrm{P}$ & $\mathrm{P}$ & $P$ & $\mathrm{P}$ & $\mathrm{P}$ & $P$ & - & $P$ & - \\
\hline M.G.T. & II & 9,58 & $\mathrm{M}$ & - & $\mathrm{P}$ & $\mathrm{P}$ & $\mathrm{P}$ & $\mathrm{P}$ & $\mathrm{P}$ & $\mathrm{P}$ & $\mathrm{P}$ & $\mathrm{P}$ & $\mathrm{P}$ & $\mathrm{P}$ & $\mathrm{P}$ & $\mathrm{P}$ & - \\
\hline C.V.E. & II & 9,41 & $\mathrm{~F}$ & $\mathrm{P}$ & $\mathrm{P}$ & - & $\mathrm{P}$ & $\mathrm{P}$ & $\mathrm{P}$ & $\mathrm{P}$ & $\mathrm{P}$ & $\mathrm{P}$ & $\mathrm{P}$ & $\mathrm{P}$ & - & $\mathrm{P}$ & $\mathrm{P}$ \\
\hline F.B. & II & 9,58 & $F$ & - & $\mathrm{P}$ & - & - & - & $\mathrm{P}$ & $\mathrm{P}$ & $\mathrm{P}$ & $\mathrm{P}$ & $\mathrm{P}$ & - & - & $\mathrm{P}$ & - \\
\hline
\end{tabular}


TABELA A-13

\begin{tabular}{|c|c|c|c|c|c|c|c|c|c|c|c|c|c|c|c|c|c|}
\hline Nome & Classe & Idade & Gênero & 17 & 16 & 15 & 14 & 13 & 12 & 11 & 21 & 22 & 23 & 24 & 25 & 26 & 27 \\
\hline A.P.T. & $\mathrm{I}$ & 10,66 & $\mathrm{~F}$ & - & $\mathrm{P}$ & - & - & - & $\mathrm{P}$ & $\mathrm{P}$ & $\mathrm{P}$ & $P$ & - & - & - & $\mathrm{P}$ & - \\
\hline J.M.R.M. & $\mathrm{I}$ & 10,91 & $\bar{M}$ & - & $\mathrm{P}$ & $P$ & $\mathrm{P}$ & - & $\mathrm{P}$ & $\mathrm{P}$ & $P$ & $P$ & - & $P$ & $P$ & $\mathrm{P}$ & - \\
\hline R.A.A. & $\mathrm{I}$ & 10,75 & $\bar{M}$ & - & $\mathrm{P}$ & - & $\mathrm{P}$ & - & $\mathrm{P}$ & $\mathrm{P}$ & $\mathrm{P}$ & $\mathrm{P}$ & - & $\mathrm{P}$ & - & $\mathrm{P}$ & - \\
\hline D.F.D & $\mathrm{I}$ & 10,08 & $M$ & - & $\mathrm{P}$ & - & $\mathrm{P}$ & - & $\mathrm{P}$ & $\mathrm{P}$ & $\mathrm{P}$ & $\mathrm{P}$ & - & $\mathrm{P}$ & - & $\mathrm{P}$ & - \\
\hline A.C.M. & I & 10,66 & $\mathrm{~F}$ & $\mathrm{P}$ & $\mathrm{P}$ & $\mathrm{P}$ & $\mathrm{P}$ & $\mathrm{P}$ & $\mathrm{P}$ & $\mathrm{P}$ & $\mathrm{P}$ & $\mathrm{P}$ & $\mathrm{P}$ & $\mathrm{P}$ & $\mathrm{P}$ & $\mathrm{P}$ & $\mathrm{P}$ \\
\hline E.P.P. & $\mathrm{I}$ & 10,91 & $\mathrm{~F}$ & - & $\mathrm{P}$ & $P$ & $P$ & $\mathrm{P}$ & $\mathrm{P}$ & $P$ & $\mathrm{P}$ & $\mathrm{P}$ & - & $\mathrm{P}$ & $\mathrm{P}$ & $\mathrm{P}$ & - \\
\hline P.S.P.C. & $\mathrm{I}$ & 10,50 & $M$ & - & $\mathrm{P}$ & - & $P$ & - & $\mathrm{P}$ & $\mathrm{P}$ & $P$ & $P$ & - & $P$ & $\mathrm{P}$ & $\mathrm{P}$ & - \\
\hline E.C.M. & I & 10,83 & $\mathrm{~F}$ & - & $\mathrm{P}$ & $\mathrm{P}$ & $\mathrm{P}$ & - & $\mathrm{P}$ & $\mathrm{P}$ & $\mathrm{P}$ & $\mathrm{P}$ & - & - & - & $\mathrm{P}$ & - \\
\hline A.L.M. & $\mathrm{I}$ & 10,25 & $F$ & - & $\mathrm{P}$ & $P$ & $\mathrm{P}$ & - & $\mathrm{P}$ & $\mathrm{P}$ & $P$ & $P$ & $P$ & $P$ & $\mathrm{P}$ & $\mathrm{P}$ & - \\
\hline V.M.A.C. & $T$ & 10,66 & $F$ & - & $\mathrm{P}$ & $\mathrm{P}$ & $\mathrm{P}$ & $P$ & $\mathrm{P}$ & $\mathrm{P}$ & $P$ & $\mathrm{P}$ & $\mathrm{P}$ & $P$ & $\mathrm{P}$ & $\mathrm{P}$ & - \\
\hline A.C.D. & $\mathrm{I}$ & 10,58 & $\mathrm{~F}$ & $P$ & $\mathrm{P}$ & $P$ & $P$ & $\mathrm{P}$ & $\mathrm{P}$ & $P$ & $\mathrm{P}$ & $\mathrm{P}$ & $P$ & $\mathrm{P}$ & $\mathrm{P}$ & $\mathrm{P}$ & $\mathrm{P}$ \\
\hline F.S. & $\mathrm{I}$ & 10,33 & $M$ & - & $\mathrm{P}$ & $\mathrm{P}$ & $\mathrm{P}$ & - & $\mathrm{P}$ & $\mathrm{P}$ & $\mathrm{P}$ & $\mathrm{P}$ & - & $\mathrm{P}$ & - & $\mathrm{P}$ & - \\
\hline R.F.E. & 1 & 10,33 & $\mathrm{M}$ & $\mathrm{P}$ & $\mathrm{P}$ & $\mathrm{P}$ & $\mathrm{P}$ & $\mathrm{P}$ & $\mathrm{P}$ & $\mathrm{P}$ & $\mathrm{P}$ & $\mathrm{P}$ & $\mathrm{P}$ & $\mathrm{P}$ & $\mathrm{P}$ & $\mathrm{P}$ & $\mathrm{P}$ \\
\hline S.T.G. & 1 & 10,41 & $\mathrm{M}$ & - & $\mathrm{P}$ & - & - & - & $\mathrm{P}$ & $\mathrm{P}$ & $\mathrm{P}$ & $\mathrm{P}$ & - & - & - & $\mathrm{P}$ & - \\
\hline M.Q.B. & 1 & 10,41 & $\mathrm{M}$ & - & $\mathrm{P}$ & $\mathrm{P}$ & $\mathrm{P}$ & $\mathrm{P}$ & $\mathrm{P}$ & $\mathrm{P}$ & $\mathrm{P}$ & $\mathrm{P}$ & $\mathrm{P}$ & $\mathrm{P}$ & $\mathrm{P}$ & $\mathrm{P}$ & - \\
\hline M.P.P. & 1 & 10,58 & $\mathrm{~F}$ & - & $\mathrm{P}$ & - & - & - & $\mathrm{P}$ & $\mathrm{P}$ & $\mathrm{P}$ & $\mathrm{P}$ & - & $\mathrm{P}$ & - & $\mathrm{P}$ & - \\
\hline T.F.D. & 1 & 10,00 & $\mathrm{M}$ & - & $\mathrm{P}$ & $\mathrm{P}$ & $\mathrm{P}$ & - & $\mathrm{P}$ & $\mathrm{P}$ & $\mathrm{P}$ & $\mathrm{P}$ & $\mathrm{P}$ & $\mathrm{P}$ & - & $\mathrm{P}$ & - \\
\hline C.L.C. & 1 & 10,25 & $\mathrm{~F}$ & - & $\mathrm{P}$ & $\mathrm{P}$ & $\mathrm{P}$ & - & $\mathrm{P}$ & $\mathrm{P}$ & $\mathrm{P}$ & $\mathrm{P}$ & $\mathrm{P}$ & $\mathrm{P}$ & $\mathrm{P}$ & $\mathrm{P}$ & - \\
\hline D.E.H. & I & 10,66 & $\mathrm{~F}$ & - & $\mathrm{P}$ & $\mathrm{P}$ & $\mathrm{P}$ & $\mathrm{P}$ & $\mathrm{P}$ & $\mathrm{P}$ & $\mathrm{P}$ & $\mathrm{P}$ & $\mathrm{P}$ & $\mathrm{P}$ & $\mathrm{P}$ & $\mathrm{P}$ & - \\
\hline M.L.P. & $\mathrm{I}$ & 10,00 & $F$ & - & $\mathrm{P}$ & - & $\mathrm{P}$ & $\mathrm{P}$ & $\mathrm{P}$ & $\mathrm{P}$ & $\mathrm{P}$ & $\mathrm{P}$ & $\mathrm{P}$ & $\mathrm{P}$ & - & $\mathrm{P}$ & - \\
\hline A.P.M.B. & 1 & 10,00 & $\mathrm{~F}$ & - & $\mathrm{P}$ & - & $\mathrm{P}$ & $\mathrm{P}$ & $\mathrm{P}$ & $\mathrm{P}$ & $\mathrm{P}$ & $\mathrm{P}$ & $\mathrm{P}$ & $\mathrm{P}$ & - & $\mathrm{P}$ & - \\
\hline P.S.E. & $\mathrm{I}$ & 10,33 & $\mathrm{~F}$ & - & $\mathrm{P}$ & - & - & - & $\mathrm{P}$ & $\mathrm{P}$ & $\mathrm{P}$ & $\mathrm{P}$ & - & - & - & $\mathrm{P}$ & - \\
\hline J.R.N. & $\mathrm{I}$ & 10,91 & $M$ & - & $\mathrm{P}$ & - & - & - & $\mathrm{P}$ & $\mathrm{P}$ & $\mathrm{P}$ & $\mathrm{P}$ & - & - & - & $\mathrm{P}$ & - \\
\hline R.Q. & $\mathrm{T}$ & 10,75 & $\bar{M}$ & - & $\mathrm{P}$ & $\mathrm{P}$ & $\mathrm{P}$ & - & $\mathrm{P}$ & $\mathrm{P}$ & $\mathrm{P}$ & $P$ & - & $P$ & - & $\mathrm{P}$ & - \\
\hline E.L.C.S. & $\mathrm{I}$ & 10,83 & $\bar{M}$ & - & $\mathrm{P}$ & $\mathrm{P}$ & $\mathrm{P}$ & - & $\mathrm{P}$ & $\mathrm{P}$ & $\mathrm{P}$ & $\mathrm{P}$ & - & $\mathrm{P}$ & $\mathrm{P}$ & $\mathrm{P}$ & - \\
\hline M.S. & I & 10,25 & $M$ & - & $\mathrm{P}$ & - & $\mathrm{P}$ & - & $\mathrm{P}$ & $\mathrm{P}$ & $\mathrm{P}$ & $\mathrm{P}$ & $\mathrm{P}$ & $\mathrm{P}$ & $\mathrm{P}$ & $\mathrm{P}$ & - \\
\hline E.A. & $\mathrm{I}$ & 10,91 & $\bar{M}$ & $\mathrm{P}$ & $\mathrm{P}$ & $\mathrm{P}$ & $\mathrm{P}$ & - & $\mathrm{P}$ & $\mathrm{P}$ & $\mathrm{P}$ & $\mathrm{P}$ & - & - & - & $\mathrm{P}$ & - \\
\hline A.L.F. & $\mathrm{I}$ & 10,00 & $M$ & - & $\mathrm{P}$ & - & - & - & $\mathrm{P}$ & $\mathrm{P}$ & $\mathrm{P}$ & $\mathrm{P}$ & - & - & - & $\mathrm{P}$ & - \\
\hline R.A.C.M. & $\mathrm{I}$ & 10,33 & $\bar{M}$ & - & $\mathrm{P}$ & $\mathrm{P}$ & - & - & $\mathrm{P}$ & $\mathrm{P}$ & $\mathrm{P}$ & $\mathrm{P}$ & - & $\mathrm{P}$ & $\mathrm{P}$ & $\mathrm{P}$ & - \\
\hline C.S.D. & $\mathrm{I}$ & 10,08 & $\mathrm{~F}$ & - & $\mathrm{P}$ & - & - & - & $\mathrm{P}$ & $\mathrm{P}$ & $\mathrm{P}$ & $\mathrm{P}$ & - & - & - & $\mathrm{P}$ & - \\
\hline R.A.A.P.R. & II & 10,83 & $\mathrm{~F}$ & - & $\mathrm{P}$ & - & - & - & $\mathrm{P}$ & $\mathrm{P}$ & $\mathrm{P}$ & $\mathrm{P}$ & - & - & - & $\mathrm{P}$ & - \\
\hline T.V.S. & II & 10,00 & $\bar{M}$ & - & $\mathrm{P}$ & - & - & - & $\mathrm{P}$ & $\mathrm{P}$ & $\mathrm{P}$ & $\mathrm{P}$ & - & $\mathrm{P}$ & $\mathrm{P}$ & $\mathrm{P}$ & - \\
\hline J.C.M.J. & II & 10,08 & $\bar{M}$ & - & $P$ & - & - & - & $\mathrm{P}$ & $\mathrm{P}$ & $\mathrm{P}$ & $\mathrm{P}$ & - & - & $\mathrm{P}$ & $\mathrm{P}$ & - \\
\hline A.F.G. & II & 10,58 & $\bar{M}$ & - & $\mathrm{P}$ & $\mathrm{P}$ & $\mathrm{P}$ & $\mathrm{P}$ & $\mathrm{P}$ & $\mathrm{P}$ & $\mathrm{P}$ & $\mathrm{P}$ & $\mathrm{P}$ & $\mathrm{P}$ & $\mathrm{P}$ & $\mathrm{P}$ & $\mathrm{P}$ \\
\hline M.A.P.T. & II & 10,25 & $\bar{M}$ & - & $\mathrm{P}$ & - & - & - & $\mathrm{P}$ & $\mathrm{P}$ & $\mathrm{P}$ & $\mathrm{P}$ & - & - & - & $\mathrm{P}$ & - \\
\hline P.B.J. & II & 10,91 & $\bar{M}$ & - & $\mathrm{P}$ & $\mathrm{P}$ & $\mathrm{P}$ & - & $\mathrm{P}$ & $\mathrm{P}$ & $\mathrm{P}$ & $\mathrm{P}$ & - & $\mathrm{P}$ & $\mathrm{P}$ & $\mathrm{P}$ & - \\
\hline R.G.M. & II & 10,16 & $M$ & - & $\mathrm{P}$ & - & - & - & $\mathrm{P}$ & $\mathrm{P}$ & $\mathrm{P}$ & $\mathrm{P}$ & $\mathrm{P}$ & $\mathrm{P}$ & $\mathrm{P}$ & $\mathrm{P}$ & - \\
\hline T.C.C.C. & II & 10,50 & $\mathrm{~F}$ & - & $\mathrm{P}$ & - & $\mathrm{P}$ & $\mathrm{P}$ & $\mathrm{P}$ & $\mathrm{P}$ & $\mathrm{P}$ & $\mathrm{P}$ & - & $\mathrm{P}$ & - & $\mathrm{P}$ & - \\
\hline R.P.F. & II & 10,66 & $\bar{M}$ & - & $\mathrm{P}$ & - & $\mathrm{P}$ & - & $\mathrm{P}$ & $P$ & $P$ & $\mathrm{P}$ & - & $\mathrm{P}$ & - & $\mathrm{P}$ & - \\
\hline E.C.L. & II & 10,75 & $F$ & $\mathrm{P}$ & $\mathrm{P}$ & - & $\mathrm{P}$ & $\mathrm{P}$ & $\mathrm{P}$ & $\mathrm{P}$ & $\mathrm{P}$ & $\mathrm{P}$ & $P$ & $\mathrm{P}$ & - & $\mathrm{P}$ & $\mathrm{P}$ \\
\hline R.F.B. & II & 10,75 & $\bar{M}$ & - & $\mathrm{P}$ & - & $\mathrm{P}$ & - & $\mathrm{P}$ & $\mathrm{P}$ & $\mathrm{P}$ & $\mathrm{P}$ & - & $\mathrm{P}$ & $\mathrm{P}$ & $\mathrm{P}$ & - \\
\hline R.R.D. & II & 10,75 & $\bar{M}$ & - & $\mathrm{P}$ & $\mathrm{P}$ & $\mathrm{P}$ & - & $\mathrm{P}$ & $\mathrm{P}$ & $\mathrm{P}$ & $\mathrm{P}$ & - & $\mathrm{P}$ & $\mathrm{P}$ & $\mathrm{P}$ & - \\
\hline J.A.M. & II & 10,91 & $\bar{M}$ & - & $\mathrm{P}$ & - & - & - & $\mathrm{P}$ & $\mathrm{P}$ & $\mathrm{P}$ & $\mathrm{P}$ & - & - & - & $\mathrm{P}$ & - \\
\hline B.M.L. & II & 10,25 & $M$ & - & $\mathrm{P}$ & - & $\mathrm{P}$ & - & $\mathrm{P}$ & $\mathrm{P}$ & $\mathrm{P}$ & $\mathrm{P}$ & - & $P$ & - & $\mathrm{P}$ & - \\
\hline R.O.B.A. & II & 10,50 & $M$ & - & $\mathrm{P}$ & - & $\mathrm{P}$ & $\mathrm{P}$ & $\mathrm{P}$ & $\mathrm{P}$ & $\mathrm{P}$ & $\mathrm{P}$ & $\mathrm{P}$ & $\mathrm{P}$ & - & $\mathrm{P}$ & - \\
\hline C.F.Z.S. & II & 10,00 & $\mathrm{~F}$ & - & $\mathrm{P}$ & - & $P$ & - & $\mathrm{P}$ & $P$ & $\mathrm{P}$ & $\mathrm{P}$ & - & $\mathrm{P}$ & - & $\mathrm{P}$ & - \\
\hline R.A.S.S. & II & 10,41 & $F$ & - & $\mathrm{P}$ & - & - & - & - & $\mathrm{P}$ & $\mathrm{P}$ & - & - & - & - & $\mathrm{P}$ & - \\
\hline R.B.R. & II & 10,25 & $\mathrm{~F}$ & - & $\mathrm{P}$ & - & $\mathrm{P}$ & $\mathrm{P}$ & $\mathrm{P}$ & $\mathrm{P}$ & $\mathrm{P}$ & $\mathrm{P}$ & - & $P$ & - & $\mathrm{P}$ & - \\
\hline F.B.A. & II & 10,41 & $\bar{F}$ & - & $\mathrm{P}$ & - & $\mathrm{P}$ & $\mathrm{P}$ & $\mathrm{P}$ & $\mathrm{P}$ & $\mathrm{P}$ & $\mathrm{P}$ & $\mathrm{P}$ & $\mathrm{P}$ & - & $\mathrm{P}$ & - \\
\hline M.F.G. & II & 10,16 & $\mathrm{~F}$ & - & $\mathrm{P}$ & - & $\mathrm{P}$ & - & $\mathrm{P}$ & $\mathrm{P}$ & $P$ & $\mathrm{P}$ & - & $P$ & - & $\mathrm{P}$ & - \\
\hline T.S.N.J. & II & 10,91 & M & - & $\mathrm{P}$ & - & $\mathrm{P}$ & $\mathrm{P}$ & $\mathrm{P}$ & $\mathrm{P}$ & $\mathrm{P}$ & $\mathrm{P}$ & $P$ & $P$ & - & $\mathrm{P}$ & - \\
\hline O.C.C. & II & 10,16 & $M$ & - & $\mathrm{P}$ & - & $\mathrm{P}$ & - & $\mathrm{P}$ & $\mathrm{P}$ & $\mathrm{P}$ & $\mathrm{P}$ & - & - & - & $\mathrm{P}$ & - \\
\hline E.F.Z. & II & 10,50 & $\mathrm{~F}$ & - & $P$ & $\mathrm{P}$ & $\mathrm{P}$ & - & $\mathrm{P}$ & $\mathrm{P}$ & $\mathrm{P}$ & $\mathrm{P}$ & - & - & - & $\mathrm{P}$ & - \\
\hline J.A.A.C. & II & 10,75 & $M$ & - & $\mathrm{P}$ & - & - & - & $\mathrm{P}$ & $\mathrm{P}$ & $\mathrm{P}$ & $\mathrm{P}$ & - & - & - & $\mathrm{P}$ & - \\
\hline P.B.B.M. & II & 10,83 & $\mathrm{~F}$ & - & $\mathrm{P}$ & $\mathrm{P}$ & $\mathrm{P}$ & $\mathrm{P}$ & $\mathrm{P}$ & $\mathrm{P}$ & $\mathrm{P}$ & $\mathrm{P}$ & $\mathrm{P}$ & $\mathrm{P}$ & - & $\mathrm{P}$ & - \\
\hline M.H.T. & II & 10,08 & $\mathrm{~F}$ & - & $\mathrm{P}$ & - & - & - & $\mathrm{P}$ & $\mathrm{P}$ & $\mathrm{P}$ & $\mathrm{P}$ & - & - & - & $\mathrm{P}$ & - \\
\hline M.G.T. & II & 10,66 & $\bar{M}$ & $\mathrm{P}$ & $\mathrm{P}$ & $\mathrm{P}$ & $\mathrm{P}$ & $\mathrm{P}$ & $\mathrm{P}$ & $\mathrm{P}$ & $\mathrm{P}$ & $\mathrm{P}$ & $\mathrm{P}$ & $\mathrm{P}$ & $\mathrm{P}$ & $\mathrm{P}$ & $P$ \\
\hline F.B. & II & 10,50 & $\mathrm{~F}$ & - & $P$ & $\mathrm{P}$ & $\mathrm{P}$ & - & $\mathrm{P}$ & $\mathrm{P}$ & $\mathrm{P}$ & $\mathrm{P}$ & $\mathrm{P}$ & $\mathrm{P}$ & $\mathrm{P}$ & $\mathrm{P}$ & - \\
\hline C.B.J. & II & 10,50 & $\mathrm{~F}$ & $\mathrm{P}$ & $\mathrm{P}$ & - & - & - & $\mathrm{P}$ & $\mathrm{P}$ & $\mathrm{P}$ & $\mathrm{P}$ & - & - & - & $\mathrm{P}$ & $\mathrm{P}$ \\
\hline R.T.D.G. & II & 10,83 & $\bar{M}$ & - & $\mathrm{P}$ & $\mathrm{P}$ & - & - & $\mathrm{P}$ & $\mathrm{P}$ & $P$ & $\mathrm{P}$ & - & - & - & $\mathrm{P}$ & - \\
\hline
\end{tabular}


TABELA A-14

\begin{tabular}{|c|c|c|c|c|c|c|c|c|c|c|c|c|c|c|c|c|c|}
\hline Nome & Classe & Idade & Gênero & 37 & 36 & 35 & 34 & 33 & 32 & 31 & 41 & 42 & 43 & 44 & 45 & 46 & 47 \\
\hline A.P.T. & $\mathrm{I}$ & 10,66 & $\mathrm{~F}$ & - & $\mathrm{P}$ & - & $\mathrm{P}$ & $\mathrm{P}$ & $\mathrm{P}$ & $\mathrm{P}$ & $\mathrm{P}$ & $P$ & $\mathrm{P}$ & $P$ & - & $\mathrm{P}$ & - \\
\hline J.M.R.M. & $\mathrm{I}$ & 10,91 & $\bar{M}$ & - & $\mathrm{P}$ & - & $\mathrm{P}$ & $P$ & $\mathrm{P}$ & $\mathrm{P}$ & $P$ & $P$ & $P$ & $P$ & $\mathrm{P}$ & $\mathrm{P}$ & $P$ \\
\hline R.A.A. & $\mathrm{I}$ & 10,75 & $\bar{M}$ & - & $\mathrm{P}$ & - & - & - & $\mathrm{P}$ & $\mathrm{P}$ & $\mathrm{P}$ & $\mathrm{P}$ & - & - & - & $\mathrm{P}$ & - \\
\hline D.F.D & I & 10,08 & $\bar{M}$ & - & $\mathrm{P}$ & - & $\mathrm{P}$ & - & $\mathrm{P}$ & $\mathrm{P}$ & $\mathrm{P}$ & $P$ & $\mathrm{P}$ & $\mathrm{P}$ & - & $\mathrm{P}$ & - \\
\hline A.C.M. & I & 10,66 & $\mathrm{~F}$ & $\mathrm{P}$ & $\mathrm{P}$ & $\mathrm{P}$ & $\mathrm{P}$ & $\mathrm{P}$ & $\mathrm{P}$ & $\mathrm{P}$ & $\mathrm{P}$ & $\mathrm{P}$ & $\mathrm{P}$ & $\mathrm{P}$ & $\mathrm{P}$ & $\mathrm{P}$ & $\mathrm{P}$ \\
\hline E.P.P. & $\mathrm{I}$ & 10,91 & $\mathrm{~F}$ & - & $\mathrm{P}$ & $P$ & $P$ & $\mathrm{P}$ & $\mathrm{P}$ & $P$ & $\mathrm{P}$ & $\mathrm{P}$ & $P$ & $P$ & $\mathrm{P}$ & $\mathrm{P}$ & - \\
\hline P.S.P.C. & $\mathrm{I}$ & 10,50 & $M$ & - & $\mathrm{P}$ & - & $P$ & $P$ & $\mathrm{P}$ & $\mathrm{P}$ & $P$ & $\mathrm{P}$ & $\mathrm{P}$ & $P$ & - & $\mathrm{P}$ & - \\
\hline E.C.M. & I & 10,83 & $\mathrm{~F}$ & - & $\mathrm{P}$ & - & $\mathrm{P}$ & $\mathrm{P}$ & $\mathrm{P}$ & $\mathrm{P}$ & $\mathrm{P}$ & $\mathrm{P}$ & $\mathrm{P}$ & $\mathrm{P}$ & - & $\mathrm{P}$ & - \\
\hline A.L.M. & $\mathrm{I}$ & 10,25 & $F$ & - & $\mathrm{P}$ & - & $\mathrm{P}$ & $P$ & $\mathrm{P}$ & $\mathrm{P}$ & $P$ & $P$ & $P$ & $P$ & $\mathrm{P}$ & $\mathrm{P}$ & $P$ \\
\hline V.M.A.C. & $T$ & 10,66 & $F$ & $\mathrm{P}$ & $\mathrm{P}$ & $\mathrm{P}$ & $\mathrm{P}$ & $P$ & $\mathrm{P}$ & $\mathrm{P}$ & $P$ & $\mathrm{P}$ & $\mathrm{P}$ & $P$ & $\mathrm{P}$ & $\mathrm{P}$ & $P$ \\
\hline A.C.D. & $\mathrm{I}$ & 10,58 & $\mathrm{~F}$ & $P$ & $\mathrm{P}$ & $P$ & $P$ & $\mathrm{P}$ & $\mathrm{P}$ & $P$ & $\mathrm{P}$ & $\mathrm{P}$ & $P$ & $P$ & $\mathrm{P}$ & $\mathrm{P}$ & $\mathrm{P}$ \\
\hline F.S. & $\mathrm{I}$ & 10,33 & $M$ & - & $\mathrm{P}$ & - & - & - & $\mathrm{P}$ & $\mathrm{P}$ & $\mathrm{P}$ & $\mathrm{P}$ & - & - & - & $\mathrm{P}$ & - \\
\hline R.F.E. & 1 & 10,33 & $\mathrm{M}$ & $\mathrm{P}$ & $\mathrm{P}$ & $\mathrm{P}$ & $\mathrm{P}$ & $\mathrm{P}$ & $\mathrm{P}$ & $\mathrm{P}$ & $\mathrm{P}$ & $\mathrm{P}$ & $\mathrm{P}$ & $\mathrm{P}$ & $\mathrm{P}$ & $\mathrm{P}$ & $\mathrm{P}$ \\
\hline S.T.G. & 1 & 10,41 & $\mathrm{M}$ & - & $\mathrm{P}$ & - & - & - & $\mathrm{P}$ & $\mathrm{P}$ & $\mathrm{P}$ & $\mathrm{P}$ & - & - & - & $\mathrm{P}$ & - \\
\hline M.Q.B. & 1 & 10,41 & $\mathrm{M}$ & $\mathrm{P}$ & $\mathrm{P}$ & $\mathrm{P}$ & $\mathrm{P}$ & $\mathrm{P}$ & $\mathrm{P}$ & $\mathrm{P}$ & $\mathrm{P}$ & $\mathrm{P}$ & $\mathrm{P}$ & $\mathrm{P}$ & $\mathrm{P}$ & $\mathrm{P}$ & $\mathrm{P}$ \\
\hline M.P.P. & 1 & 10,58 & $\mathrm{~F}$ & - & $\mathrm{P}$ & - & - & $\mathrm{P}$ & $\mathrm{P}$ & $\mathrm{P}$ & $\mathrm{P}$ & $\mathrm{P}$ & - & - & - & $\mathrm{P}$ & - \\
\hline T.F.D. & 1 & 10,00 & $\mathrm{M}$ & - & $\mathrm{P}$ & $\mathrm{P}$ & $\mathrm{P}$ & $\mathrm{P}$ & $\mathrm{P}$ & $\mathrm{P}$ & $\mathrm{P}$ & $\mathrm{P}$ & $\mathrm{P}$ & $P$ & $\mathrm{P}$ & $\mathrm{P}$ & - \\
\hline C.L.C. & 1 & 10,25 & $\mathrm{~F}$ & - & $\mathrm{P}$ & $\mathrm{P}$ & $\mathrm{P}$ & $\mathrm{P}$ & $\mathrm{P}$ & $\mathrm{P}$ & $\mathrm{P}$ & $\mathrm{P}$ & $\mathrm{P}$ & $\mathrm{P}$ & $\mathrm{P}$ & $\mathrm{P}$ & - \\
\hline D.E.H. & I & 10,66 & $\mathrm{~F}$ & - & $\mathrm{P}$ & $\mathrm{P}$ & $\mathrm{P}$ & $\mathrm{P}$ & $\mathrm{P}$ & $\mathrm{P}$ & $\mathrm{P}$ & $\mathrm{P}$ & $\mathrm{P}$ & $\mathrm{P}$ & $\mathrm{P}$ & $\mathrm{P}$ & - \\
\hline M.L.P. & $\mathrm{I}$ & 10,00 & $F$ & $\mathrm{P}$ & $\mathrm{P}$ & - & $\mathrm{P}$ & $\mathrm{P}$ & $\mathrm{P}$ & $\mathrm{P}$ & $\mathrm{P}$ & $\mathrm{P}$ & $\mathrm{P}$ & $\mathrm{P}$ & $\mathrm{P}$ & $\mathrm{P}$ & $\mathrm{P}$ \\
\hline A.P.M.B. & $\mathrm{I}$ & 10,00 & $\mathrm{~F}$ & $\mathrm{P}$ & $\mathrm{P}$ & $\mathrm{P}$ & $\mathrm{P}$ & $\mathrm{P}$ & $\mathrm{P}$ & $\mathrm{P}$ & $\mathrm{P}$ & $\mathrm{P}$ & $\mathrm{P}$ & $\mathrm{P}$ & $\mathrm{P}$ & $\mathrm{P}$ & $\mathrm{P}$ \\
\hline P.S.E. & $\mathrm{I}$ & 10,33 & $\mathrm{~F}$ & - & $\mathrm{P}$ & - & $\mathrm{P}$ & - & $\mathrm{P}$ & $\mathrm{P}$ & $\mathrm{P}$ & $\mathrm{P}$ & - & $\mathrm{P}$ & - & $\mathrm{P}$ & - \\
\hline J.R.N. & $\mathrm{I}$ & 10,91 & $M$ & - & $\mathrm{P}$ & - & $\mathrm{P}$ & $\mathrm{P}$ & $\mathrm{P}$ & $\mathrm{P}$ & $\mathrm{P}$ & $\mathrm{P}$ & - & - & $\mathrm{P}$ & $\mathrm{P}$ & - \\
\hline R.Q. & $\mathrm{T}$ & 10,75 & $\bar{M}$ & - & $\mathrm{P}$ & - & $\mathrm{P}$ & $\mathrm{P}$ & $\mathrm{P}$ & $\mathrm{P}$ & $\mathrm{P}$ & $P$ & - & - & - & $\mathrm{P}$ & - \\
\hline E.L.C.S. & $\mathrm{I}$ & 10,83 & $\bar{M}$ & - & $\mathrm{P}$ & $\mathrm{P}$ & $\mathrm{P}$ & $\mathrm{P}$ & $\mathrm{P}$ & $\mathrm{P}$ & $\mathrm{P}$ & $\mathrm{P}$ & $\mathrm{P}$ & $\mathrm{P}$ & $\mathrm{P}$ & $\mathrm{P}$ & - \\
\hline M.S. & I & 10,25 & $M$ & - & $\mathrm{P}$ & $\mathrm{P}$ & $\mathrm{P}$ & - & $\mathrm{P}$ & $\mathrm{P}$ & $\mathrm{P}$ & $\mathrm{P}$ & $\mathrm{P}$ & $\mathrm{P}$ & - & $\mathrm{P}$ & - \\
\hline E.A. & $\mathrm{I}$ & 10,91 & $\bar{M}$ & - & $\mathrm{P}$ & $\mathrm{P}$ & - & - & $\mathrm{P}$ & $\mathrm{P}$ & $\mathrm{P}$ & $\mathrm{P}$ & - & - & - & $\mathrm{P}$ & - \\
\hline A.L.F. & $\mathrm{I}$ & 10,00 & $M$ & - & $\mathrm{P}$ & - & $\mathrm{P}$ & - & $\mathrm{P}$ & $\mathrm{P}$ & $\mathrm{P}$ & $\mathrm{P}$ & - & - & - & $\mathrm{P}$ & - \\
\hline R.A.C.M. & $\mathrm{I}$ & 10,33 & $\bar{M}$ & - & $\mathrm{P}$ & $\mathrm{P}$ & $\mathrm{P}$ & - & $\mathrm{P}$ & $\mathrm{P}$ & $\mathrm{P}$ & $\mathrm{P}$ & - & - & - & $\mathrm{P}$ & - \\
\hline C.S.D. & $\mathrm{I}$ & 10,08 & $\mathrm{~F}$ & - & $\mathrm{P}$ & - & $\mathrm{P}$ & $\mathrm{P}$ & $\mathrm{P}$ & $\mathrm{P}$ & $\mathrm{P}$ & $\mathrm{P}$ & $\mathrm{P}$ & $\mathrm{P}$ & $\mathrm{P}$ & $\mathrm{P}$ & - \\
\hline R.A.A.P.R. & II & 10,83 & $\mathrm{~F}$ & - & $\mathrm{P}$ & - & - & $\mathrm{P}$ & $\mathrm{P}$ & $\mathrm{P}$ & $\mathrm{P}$ & $\mathrm{P}$ & $\mathrm{P}$ & - & - & $\mathrm{P}$ & - \\
\hline T.V.S. & II & 10,00 & $\bar{M}$ & - & $\mathrm{P}$ & - & $P$ & $\mathrm{P}$ & $\mathrm{P}$ & $\mathrm{P}$ & $\mathrm{P}$ & $\mathrm{P}$ & $P$ & $P$ & - & $\mathrm{P}$ & - \\
\hline J.C.M.J. & II & 10,08 & $\bar{M}$ & - & $P$ & - & - & - & $\mathrm{P}$ & $\mathrm{P}$ & $\mathrm{P}$ & $\mathrm{P}$ & - & - & - & $\mathrm{P}$ & - \\
\hline A.F.G. & II & 10,58 & $\bar{M}$ & - & $\mathrm{P}$ & $\mathrm{P}$ & $\mathrm{P}$ & $\mathrm{P}$ & $\mathrm{P}$ & $\mathrm{P}$ & $\mathrm{P}$ & $\mathrm{P}$ & $\mathrm{P}$ & $P$ & $\mathrm{P}$ & $\mathrm{P}$ & $\mathrm{P}$ \\
\hline M.A.P.T. & II & 10,25 & $\bar{M}$ & - & $\mathrm{P}$ & - & - & - & $\mathrm{P}$ & $\mathrm{P}$ & $\mathrm{P}$ & $\mathrm{P}$ & - & - & $\mathrm{P}$ & $\mathrm{P}$ & - \\
\hline P.B.J. & II & 10,91 & $\bar{M}$ & $\mathrm{P}$ & $\mathrm{P}$ & $\mathrm{P}$ & $\mathrm{P}$ & - & $\mathrm{P}$ & $\mathrm{P}$ & $\mathrm{P}$ & $\mathrm{P}$ & - & $P$ & $\mathrm{P}$ & $\mathrm{P}$ & - \\
\hline R.G.M. & II & 10,16 & $M$ & - & $\mathrm{P}$ & - & $\mathrm{P}$ & $\mathrm{P}$ & $\mathrm{P}$ & $\mathrm{P}$ & $\mathrm{P}$ & $\mathrm{P}$ & $\mathrm{P}$ & $P$ & - & $\mathrm{P}$ & - \\
\hline T.C.C.C. & II & 10,50 & $\mathrm{~F}$ & - & $\mathrm{P}$ & $\mathrm{P}$ & $\mathrm{P}$ & $\mathrm{P}$ & $\mathrm{P}$ & $\mathrm{P}$ & $\mathrm{P}$ & $\mathrm{P}$ & $\mathrm{P}$ & $\mathrm{P}$ & $\mathrm{P}$ & $\mathrm{P}$ & - \\
\hline R.P.F. & II & 10,66 & $\bar{M}$ & - & $\mathrm{P}$ & - & $\mathrm{P}$ & $P$ & $\mathrm{P}$ & $P$ & $P$ & $\mathrm{P}$ & $\mathrm{P}$ & $P$ & - & $\mathrm{P}$ & - \\
\hline E.C.L. & II & 10,75 & $F$ & $\mathrm{P}$ & $\mathrm{P}$ & $P$ & $\mathrm{P}$ & $\mathrm{P}$ & $\mathrm{P}$ & $\mathrm{P}$ & $\mathrm{P}$ & $\mathrm{P}$ & $P$ & $\mathrm{P}$ & $\mathrm{P}$ & $\mathrm{P}$ & $\mathrm{P}$ \\
\hline R.F.B. & II & 10,75 & $\bar{M}$ & - & $\mathrm{P}$ & - & $\mathrm{P}$ & $\mathrm{P}$ & $\mathrm{P}$ & $\mathrm{P}$ & $\mathrm{P}$ & $\mathrm{P}$ & $\mathrm{P}$ & $\mathrm{P}$ & - & $\mathrm{P}$ & - \\
\hline R.R.D. & II & 10,75 & $\bar{M}$ & - & $\mathrm{P}$ & - & - & $\mathrm{P}$ & $\mathrm{P}$ & $\mathrm{P}$ & $\mathrm{P}$ & $\mathrm{P}$ & $\mathrm{P}$ & $\mathrm{P}$ & - & $\mathrm{P}$ & - \\
\hline J.A.M. & II & 10,91 & $\bar{M}$ & - & $\mathrm{P}$ & - & - & - & $\mathrm{P}$ & $\mathrm{P}$ & $\mathrm{P}$ & $\mathrm{P}$ & - & - & - & $\mathrm{P}$ & - \\
\hline B.M.L. & II & 10,25 & $M$ & - & $\mathrm{P}$ & - & $\mathrm{P}$ & - & $\mathrm{P}$ & $\mathrm{P}$ & $\mathrm{P}$ & $\mathrm{P}$ & - & $P$ & - & $\mathrm{P}$ & - \\
\hline R.O.B.A. & II & 10,50 & $M$ & - & $\mathrm{P}$ & $\mathrm{P}$ & $\mathrm{P}$ & $\mathrm{P}$ & $\mathrm{P}$ & $\mathrm{P}$ & $\mathrm{P}$ & $\mathrm{P}$ & $\mathrm{P}$ & $\mathrm{P}$ & $\mathrm{P}$ & $\mathrm{P}$ & - \\
\hline C.F.Z.S. & II & 10,00 & $\mathrm{~F}$ & - & $\mathrm{P}$ & - & $P$ & - & $\mathrm{P}$ & $P$ & $\mathrm{P}$ & $P$ & - & $P$ & - & $\mathrm{P}$ & - \\
\hline R.A.S.S. & II & 10,41 & $F$ & - & $\mathrm{P}$ & - & - & - & $\mathrm{P}$ & $\mathrm{P}$ & $\mathrm{P}$ & $\mathrm{P}$ & - & - & - & $\mathrm{P}$ & - \\
\hline R.B.R. & II & 10,25 & $\mathrm{~F}$ & - & $\mathrm{P}$ & - & $\mathrm{P}$ & $\mathrm{P}$ & $\mathrm{P}$ & $\mathrm{P}$ & $\mathrm{P}$ & $\mathrm{P}$ & $\mathrm{P}$ & $P$ & $\mathrm{P}$ & $\mathrm{P}$ & - \\
\hline F.B.A. & II & 10,41 & $\mathrm{~F}$ & - & $\mathrm{P}$ & - & $\mathrm{P}$ & $\mathrm{P}$ & $\mathrm{P}$ & $\mathrm{P}$ & $\mathrm{P}$ & $\mathrm{P}$ & $\mathrm{P}$ & $\mathrm{P}$ & - & $\mathrm{P}$ & - \\
\hline M.F.G. & II & 10,16 & $\mathrm{~F}$ & - & $\mathrm{P}$ & - & - & - & $\mathrm{P}$ & $\mathrm{P}$ & $\mathrm{P}$ & $\mathrm{P}$ & - & - & - & $\mathrm{P}$ & - \\
\hline T.S.N.J. & II & 10,91 & M & - & $\mathrm{P}$ & - & $P$ & $\mathrm{P}$ & $\mathrm{P}$ & $\mathrm{P}$ & $\mathrm{P}$ & $\mathrm{P}$ & $P$ & $P$ & - & $\mathrm{P}$ & - \\
\hline O.C.C. & II & 10,16 & $M$ & - & $\mathrm{P}$ & - & - & - & $\mathrm{P}$ & $\mathrm{P}$ & $\mathrm{P}$ & $\mathrm{P}$ & - & $\mathrm{P}$ & - & $\mathrm{P}$ & - \\
\hline E.F.Z. & II & 10,50 & $\mathrm{~F}$ & - & $P$ & $\mathrm{P}$ & $\mathrm{P}$ & $\mathrm{P}$ & $\mathrm{P}$ & $\mathrm{P}$ & $\mathrm{P}$ & $\mathrm{P}$ & $\mathrm{P}$ & $\mathrm{P}$ & - & $\mathrm{P}$ & - \\
\hline J.A.A.C. & II & 10,75 & $M$ & - & $\mathrm{P}$ & - & $\mathrm{P}$ & $\mathrm{P}$ & $\mathrm{P}$ & $\mathrm{P}$ & $\mathrm{P}$ & $\mathrm{P}$ & - & - & - & $\mathrm{P}$ & - \\
\hline P.B.B.M. & II & 10,83 & $\mathrm{~F}$ & $\mathrm{P}$ & $\mathrm{P}$ & $\mathrm{P}$ & $\mathrm{P}$ & $\mathrm{P}$ & $\mathrm{P}$ & $\mathrm{P}$ & $\mathrm{P}$ & $\mathrm{P}$ & $\mathrm{P}$ & $\mathrm{P}$ & - & $\mathrm{P}$ & $P$ \\
\hline M.H.T. & II & 10,08 & $\mathrm{~F}$ & - & $\mathrm{P}$ & - & - & - & $\mathrm{P}$ & $\mathrm{P}$ & $\mathrm{P}$ & $\mathrm{P}$ & - & - & - & $\mathrm{P}$ & - \\
\hline M.G.T. & II & 10,66 & $\bar{M}$ & $\mathrm{P}$ & $\mathrm{P}$ & $\mathrm{P}$ & $\mathrm{P}$ & $\mathrm{P}$ & $\mathrm{P}$ & $\mathrm{P}$ & $\mathrm{P}$ & $\mathrm{P}$ & $\mathrm{P}$ & $\mathrm{P}$ & $\mathrm{P}$ & $\mathrm{P}$ & $P$ \\
\hline F.B. & II & 10,50 & $\mathrm{~F}$ & - & $P$ & $\mathrm{P}$ & $\mathrm{P}$ & $\mathrm{P}$ & $\mathrm{P}$ & $\mathrm{P}$ & $\mathrm{P}$ & $\mathrm{P}$ & $\mathrm{P}$ & $\mathrm{P}$ & - & $\mathrm{P}$ & - \\
\hline C.B.J. & II & 10,50 & $\mathrm{~F}$ & - & $\mathrm{P}$ & - & - & $\mathrm{P}$ & $\mathrm{P}$ & $\mathrm{P}$ & $\mathrm{P}$ & $\mathrm{P}$ & $\mathrm{P}$ & $\mathrm{P}$ & - & $\mathrm{P}$ & $\mathrm{P}$ \\
\hline R.T.D.G. & II & 10,83 & $\bar{M}$ & - & $\mathrm{P}$ & - & - & $P$ & $\mathrm{P}$ & $\mathrm{P}$ & $P$ & $\mathrm{P}$ & $\mathrm{P}$ & - & - & $\mathrm{P}$ & - \\
\hline
\end{tabular}


TABELA A-15

\begin{tabular}{|c|c|c|c|c|c|c|c|c|c|c|c|c|c|c|c|c|c|}
\hline Nome & Classe & Idade & Gênero & 17 & 16 & 15 & 14 & 13 & 12 & 11 & 21 & 22 & 23 & 24 & 25 & 26 & 27 \\
\hline R.A.A. & $\mathrm{I}$ & 11,66 & $\bar{M}$ & - & $\mathrm{P}$ & - & $\mathrm{P}$ & - & $P$ & $\mathrm{P}$ & $P$ & $P$ & - & $\mathrm{P}$ & - & $P$ & - \\
\hline D.F.D & $\mathrm{I}$ & 11,00 & $\bar{M}$ & - & $\mathrm{P}$ & $P$ & $\mathrm{P}$ & $\mathrm{P}$ & $P$ & $\mathrm{P}$ & $P$ & $P$ & $P$ & $\mathrm{P}$ & $\mathrm{P}$ & $\mathrm{P}$ & - \\
\hline A.C.M. & $\mathrm{I}$ & 11,66 & $\mathrm{~F}$ & $\mathrm{P}$ & $\mathrm{P}$ & $\mathrm{P}$ & $\mathrm{P}$ & $\mathrm{P}$ & $\mathrm{P}$ & $\mathrm{P}$ & $\mathrm{P}$ & $\mathrm{P}$ & $\mathrm{P}$ & $\mathrm{P}$ & $\mathrm{P}$ & $\mathrm{P}$ & $\mathrm{P}$ \\
\hline E.P.P. & $\mathrm{I}$ & 11,91 & $\mathrm{~F}$ & $\mathrm{P}$ & $\mathrm{P}$ & $\mathrm{P}$ & $\mathrm{P}$ & $\mathrm{P}$ & $\mathrm{P}$ & $\mathrm{P}$ & $P$ & $\mathrm{P}$ & $\mathrm{P}$ & $\mathrm{P}$ & $\mathrm{P}$ & $\mathrm{P}$ & $\mathrm{P}$ \\
\hline P.S.P.C. & I & 11,41 & $M$ & - & $\mathrm{P}$ & $\mathrm{P}$ & $\mathrm{P}$ & - & $P$ & $\mathrm{P}$ & $\mathrm{P}$ & $\mathrm{P}$ & $\mathrm{P}$ & $\mathrm{P}$ & $\mathrm{P}$ & $P$ & - \\
\hline E.C.M. & $\mathrm{I}$ & 11,91 & $\mathrm{~F}$ & $\mathrm{P}$ & $\mathrm{P}$ & $P$ & $P$ & $\mathrm{P}$ & $P$ & $P$ & $\mathrm{P}$ & $P$ & $\mathrm{P}$ & $P$ & $\mathrm{P}$ & $P$ & $P$ \\
\hline M.Q.B. & I & 11,58 & $\mathrm{M}$ & $\mathrm{P}$ & $\mathrm{P}$ & $\mathrm{P}$ & $\mathrm{P}$ & $\mathrm{P}$ & $P$ & $P$ & $\mathrm{P}$ & $\mathrm{P}$ & $\mathrm{P}$ & $\mathrm{P}$ & $\mathrm{P}$ & $P$ & $P$ \\
\hline A.C.D. & $\mathrm{I}$ & 11,50 & $\mathrm{~F}$ & $\mathrm{P}$ & $\mathrm{P}$ & $\mathrm{P}$ & $\mathrm{P}$ & $\mathrm{P}$ & $\mathrm{P}$ & $\mathrm{P}$ & $\mathrm{P}$ & $\mathrm{P}$ & $\mathrm{P}$ & $\mathrm{P}$ & $\mathrm{P}$ & $\mathrm{P}$ & $\mathrm{P}$ \\
\hline F.S. & $\mathrm{I}$ & 11,58 & $\bar{M}$ & - & $\mathrm{P}$ & $\mathrm{P}$ & $\mathrm{P}$ & - & $\mathrm{P}$ & $\mathrm{P}$ & $\mathrm{P}$ & $\mathrm{P}$ & - & $\mathrm{P}$ & $\mathrm{P}$ & $\mathrm{P}$ & $P$ \\
\hline R.F.E. & $T$ & 11,00 & $\bar{M}$ & $\mathrm{P}$ & $\mathrm{P}$ & $\mathrm{P}$ & $\mathrm{P}$ & $\mathrm{P}$ & $\mathrm{P}$ & $\mathrm{P}$ & $\bar{P}$ & $\mathrm{P}$ & $\mathrm{P}$ & $\mathrm{P}$ & $\mathrm{P}$ & $\mathrm{P}$ & $P$ \\
\hline S.T.G. & $\mathrm{I}$ & 11,25 & $\bar{M}$ & - & $\mathrm{P}$ & $P$ & $\mathrm{P}$ & - & $P$ & $P$ & $P$ & $P$ & - & $P$ & $\mathrm{P}$ & $P$ & - \\
\hline M.P.P. & $\mathrm{I}$ & 11,50 & $\mathrm{~F}$ & - & $\mathrm{P}$ & - & $\mathrm{P}$ & - & $P$ & $\mathrm{P}$ & $P$ & $P$ & $\mathrm{P}$ & $\mathrm{P}$ & - & $P$ & - \\
\hline C.L.C. & 1 & 11,33 & $\mathrm{~F}$ & - & $\mathrm{P}$ & $\mathrm{P}$ & $\mathrm{P}$ & $\mathrm{P}$ & $\mathrm{P}$ & $\mathrm{P}$ & $\mathrm{P}$ & $\mathrm{P}$ & $\mathrm{P}$ & $\mathrm{P}$ & $\mathrm{P}$ & $\mathrm{P}$ & $\mathrm{P}$ \\
\hline D.E.H. & 1 & 11,58 & $\mathrm{~F}$ & $\mathrm{P}$ & $\mathrm{P}$ & $\mathrm{P}$ & $\mathrm{P}$ & $\mathrm{P}$ & $\mathrm{P}$ & $\mathrm{P}$ & $P$ & $\mathrm{P}$ & $\mathrm{P}$ & $\mathrm{P}$ & $\mathrm{P}$ & $\mathrm{P}$ & $P$ \\
\hline M.L.P. & $\mathrm{I}$ & 11,00 & $\mathrm{~F}$ & $\mathrm{P}$ & $\mathrm{P}$ & $\mathrm{P}$ & $\mathrm{P}$ & $\mathrm{P}$ & $\mathrm{P}$ & $\mathrm{P}$ & $\mathrm{P}$ & $\mathrm{P}$ & $\mathrm{P}$ & $\mathrm{P}$ & $\mathrm{P}$ & $\mathrm{P}$ & $\mathrm{P}$ \\
\hline A.P.M.B. & I & 11,08 & $\mathrm{~F}$ & $\mathrm{P}$ & $\mathrm{P}$ & $\mathrm{P}$ & $\mathrm{P}$ & $\mathrm{P}$ & $P$ & $P$ & $\mathrm{P}$ & $\mathrm{P}$ & $\mathrm{P}$ & $\mathrm{P}$ & $\mathrm{P}$ & $P$ & $\mathrm{P}$ \\
\hline P.S.E. & $\mathrm{I}$ & 11,41 & $\mathrm{~F}$ & $\mathrm{P}$ & $\mathrm{P}$ & - & - & - & $\mathrm{P}$ & $\mathrm{P}$ & $\mathrm{P}$ & $\mathrm{P}$ & - & - & - & $\mathrm{P}$ & $\mathrm{P}$ \\
\hline J.R.N. & $\mathrm{I}$ & 11,91 & $\bar{M}$ & - & $P$ & - & $\mathrm{P}$ & - & $\mathrm{P}$ & $\mathrm{P}$ & $\mathrm{P}$ & $\mathrm{P}$ & $\mathrm{P}$ & $\mathrm{P}$ & - & $\mathrm{P}$ & - \\
\hline E.A. & 1 & 11,83 & M & $\mathrm{P}$ & $\mathrm{P}$ & $\mathrm{P}$ & $\mathrm{P}$ & $\mathrm{P}$ & $\mathrm{P}$ & $\mathrm{P}$ & $\mathrm{P}$ & $\mathrm{P}$ & - & $\mathrm{P}$ & $\mathrm{P}$ & $\mathrm{P}$ & $P$ \\
\hline R.Q. & $\mathrm{I}$ & 11,83 & $\mathrm{M}$ & - & $\mathrm{P}$ & $\mathrm{P}$ & $\mathrm{P}$ & - & $\mathrm{P}$ & $\mathrm{P}$ & $\mathrm{P}$ & $\mathrm{P}$ & $\mathrm{P}$ & $\mathrm{P}$ & - & $\mathrm{P}$ & - \\
\hline E.L.C.S. & $\mathrm{I}$ & 11,91 & $\mathrm{M}$ & $\mathrm{P}$ & $\mathrm{P}$ & $\mathrm{P}$ & $\mathrm{P}$ & $\mathrm{P}$ & $\mathrm{P}$ & $\mathrm{P}$ & $\mathrm{P}$ & $\mathrm{P}$ & $\mathrm{P}$ & $\mathrm{P}$ & $\mathrm{P}$ & $\mathrm{P}$ & $\mathrm{P}$ \\
\hline M.S. & 1 & 11,33 & M & $\mathrm{P}$ & $\mathrm{P}$ & $\mathrm{P}$ & $\mathrm{P}$ & $\mathrm{P}$ & $\mathrm{P}$ & $\mathrm{P}$ & $\mathrm{P}$ & $\mathrm{P}$ & $\mathrm{P}$ & $\mathrm{P}$ & $\mathrm{P}$ & $\mathrm{P}$ & $\mathrm{P}$ \\
\hline R.C.L.A. & $\mathrm{I}$ & 11,66 & $\mathrm{~F}$ & $\mathrm{P}$ & $P$ & $\mathrm{P}$ & $\mathrm{P}$ & $\mathrm{P}$ & $\mathrm{P}$ & $\mathrm{P}$ & $\mathrm{P}$ & $\mathrm{P}$ & $\mathrm{P}$ & $\mathrm{P}$ & $\mathrm{P}$ & $\mathrm{P}$ & $P$ \\
\hline C.S.D. & $\mathrm{I}$ & 11,00 & $\mathrm{~F}$ & - & $\mathrm{P}$ & $\mathrm{P}$ & $\mathrm{P}$ & - & $\mathrm{P}$ & $\mathrm{P}$ & $\mathrm{P}$ & $\mathrm{P}$ & - & $\mathrm{P}$ & $P$ & $\mathrm{P}$ & - \\
\hline V.C.P. & $\mathrm{I}$ & 11,16 & $\mathrm{~F}$ & - & $\mathrm{P}$ & - & $\mathrm{P}$ & - & $\mathrm{P}$ & $\mathrm{P}$ & $\mathrm{P}$ & $\mathrm{P}$ & $\mathrm{P}$ & $\mathrm{P}$ & - & $\mathrm{P}$ & - \\
\hline R.V.D. & I & 11,25 & $M$ & - & $\mathrm{P}$ & $\mathrm{P}$ & $\mathrm{P}$ & - & $\mathrm{P}$ & $\mathrm{P}$ & $\mathrm{P}$ & $\mathrm{P}$ & - & $\mathrm{P}$ & $\mathrm{P}$ & $\mathrm{P}$ & $\mathrm{P}$ \\
\hline D.C.G.O. & 1 & 11,33 & $\mathrm{~F}$ & $\mathrm{P}$ & $\mathrm{P}$ & $\mathrm{P}$ & $\mathrm{P}$ & $\mathrm{P}$ & $\mathrm{P}$ & $\mathrm{P}$ & $\mathrm{P}$ & $\mathrm{P}$ & $\mathrm{P}$ & $\mathrm{P}$ & $\mathrm{P}$ & $\mathrm{P}$ & $\mathrm{P}$ \\
\hline C.Q. & $\mathrm{I}$ & 11,25 & $\mathrm{~F}$ & - & $\mathrm{P}$ & - & - & $\mathrm{P}$ & $\mathrm{P}$ & $\mathrm{P}$ & $\mathrm{P}$ & $\mathrm{P}$ & - & $\mathrm{P}$ & - & $\mathrm{P}$ & - \\
\hline I.M.L. & $\mathrm{I}$ & 11,58 & $\mathrm{~F}$ & $\mathrm{P}$ & $\mathrm{P}$ & $\mathrm{P}$ & $\mathrm{P}$ & $\mathrm{P}$ & $\mathrm{P}$ & $\mathrm{P}$ & $\mathrm{P}$ & $\mathrm{P}$ & $\mathrm{P}$ & $\mathrm{P}$ & - & $\mathrm{P}$ & $P$ \\
\hline T.V.S. & II & 11,00 & $M$ & - & $\mathrm{P}$ & - & $\mathrm{P}$ & - & $\mathrm{P}$ & $\mathrm{P}$ & $\mathrm{P}$ & $\mathrm{P}$ & $\mathrm{P}$ & $\mathrm{P}$ & $\mathrm{P}$ & $\mathrm{P}$ & - \\
\hline J.C.M.J. & II & 11,00 & $M$ & - & $P$ & $\mathrm{P}$ & $\mathrm{P}$ & - & $\mathrm{P}$ & $\mathrm{P}$ & $\mathrm{P}$ & $\mathrm{P}$ & - & $\mathrm{P}$ & $\mathrm{P}$ & $\mathrm{P}$ & - \\
\hline M.A.P.T. & II & 11,00 & $\bar{M}$ & - & $\mathrm{P}$ & $P$ & $\mathrm{P}$ & - & $P$ & $P$ & $\mathrm{P}$ & $\mathrm{P}$ & - & $P$ & $P$ & $P$ & - \\
\hline R.G.M. & II & 11,25 & $\bar{M}$ & - & $\mathrm{P}$ & - & $\mathrm{P}$ & $\mathrm{P}$ & $\mathrm{P}$ & $\mathrm{P}$ & $P$ & $\mathrm{P}$ & $\mathrm{P}$ & $\mathrm{P}$ & $\mathrm{P}$ & $\mathrm{P}$ & - \\
\hline T.C.C.C. & II & 11,58 & $\mathrm{~F}$ & $\mathrm{P}$ & $\mathrm{P}$ & $\mathrm{P}$ & $\mathrm{P}$ & $\mathrm{P}$ & $\mathrm{P}$ & $\mathrm{P}$ & $\mathrm{P}$ & $\mathrm{P}$ & $\mathrm{P}$ & $\mathrm{P}$ & $\mathrm{P}$ & $\mathrm{P}$ & $\mathrm{P}$ \\
\hline R.A.S.S. & II & 11,33 & $\mathrm{~F}$ & - & $\mathrm{P}$ & - & - & - & $P$ & $\mathrm{P}$ & $\mathrm{P}$ & $\mathrm{P}$ & - & - & - & $\mathrm{P}$ & - \\
\hline R.B.R. & II & 11,16 & $F$ & - & $P$ & $\mathrm{P}$ & $\mathrm{P}$ & $\mathrm{P}$ & $P$ & $\mathrm{P}$ & $\mathrm{P}$ & $\mathrm{P}$ & $\mathrm{P}$ & $\mathrm{P}$ & $\mathrm{P}$ & $\mathrm{P}$ & - \\
\hline F.B.A. & II & 11,33 & $\mathrm{~F}$ & - & $\mathrm{P}$ & $\mathrm{P}$ & $\mathrm{P}$ & $\mathrm{P}$ & $\mathrm{P}$ & $\mathrm{P}$ & $\mathrm{P}$ & $\mathrm{P}$ & $\mathrm{P}$ & $\mathrm{P}$ & $\mathrm{P}$ & $\mathrm{P}$ & - \\
\hline M.F.G. & II & 11,00 & $\mathrm{~F}$ & - & $\mathrm{P}$ & - & $\mathrm{P}$ & $\mathrm{P}$ & $\mathrm{P}$ & $\mathrm{P}$ & $\mathrm{P}$ & $\mathrm{P}$ & - & $\mathrm{P}$ & $\mathrm{P}$ & $\mathrm{P}$ & - \\
\hline D.D. & II & 11,00 & $\mathrm{~F}$ & - & $P$ & $\mathrm{P}$ & $\mathrm{P}$ & $\mathrm{P}$ & $P$ & $\mathrm{P}$ & $P$ & $\mathrm{P}$ & $\mathrm{P}$ & $\mathrm{P}$ & - & $\mathrm{P}$ & - \\
\hline R.P.F. & II & 11,75 & $\bar{M}$ & $\mathrm{P}$ & $\mathrm{P}$ & $\mathrm{P}$ & $\mathrm{P}$ & $\mathrm{P}$ & $P$ & $\mathrm{P}$ & $\mathrm{P}$ & $\mathrm{P}$ & $\mathrm{P}$ & $\mathrm{P}$ & $\mathrm{P}$ & $P$ & - \\
\hline E.C.L. & II & 11,83 & $\mathrm{~F}$ & $\mathrm{P}$ & $P$ & $\mathrm{P}$ & $\mathrm{P}$ & $\mathrm{P}$ & $P$ & $\mathrm{P}$ & $\mathrm{P}$ & $\mathrm{P}$ & $\mathrm{P}$ & $\mathrm{P}$ & $\mathrm{P}$ & $P$ & $P$ \\
\hline R.R.D. & II & 11,75 & $\bar{M}$ & - & $\mathrm{P}$ & $\mathrm{P}$ & $\mathrm{P}$ & $\mathrm{P}$ & $P$ & $\mathrm{P}$ & $\mathrm{P}$ & $\mathrm{P}$ & $\mathrm{P}$ & $\mathrm{P}$ & $\mathrm{P}$ & $\mathrm{P}$ & - \\
\hline J.A.M. & II & 11,91 & $\bar{M}$ & - & $P$ & - & $\mathrm{P}$ & - & $P$ & $\mathrm{P}$ & $\mathrm{P}$ & $\mathrm{P}$ & - & - & - & $\mathrm{P}$ & - \\
\hline B.M.L. & II & 11,08 & $M$ & - & $P$ & $\mathrm{P}$ & $\mathrm{P}$ & $P$ & $\mathrm{P}$ & $\mathrm{P}$ & $\mathrm{P}$ & $\mathrm{P}$ & $P$ & $\mathrm{P}$ & $\mathrm{P}$ & $\mathrm{P}$ & - \\
\hline C.F.Z.S. & II & 11,08 & $F$ & - & $\mathrm{P}$ & - & $P$ & - & $P$ & $P$ & $P$ & $P$ & - & $P$ & $P$ & $P$ & - \\
\hline T.S.N.J. & II & 11,58 & $\bar{M}$ & - & $\mathrm{P}$ & $\mathrm{P}$ & $\mathrm{P}$ & $P$ & $\mathrm{P}$ & $\mathrm{P}$ & $\mathrm{P}$ & $P$ & $P$ & $P$ & $\mathrm{P}$ & $\mathrm{P}$ & - \\
\hline E.F.Z. & II & 11,50 & $\mathrm{~F}$ & - & $\mathrm{P}$ & $P$ & $\mathrm{P}$ & $P$ & $P$ & $P$ & $\mathrm{P}$ & $P$ & - & $P$ & - & $P$ & - \\
\hline J.A.A.C. & II & 11,91 & $\bar{M}$ & - & $\mathrm{P}$ & $\mathrm{P}$ & $\mathrm{P}$ & $\mathrm{P}$ & $\mathrm{P}$ & $\mathrm{P}$ & $\mathrm{P}$ & $\mathrm{P}$ & $\mathrm{P}$ & $\mathrm{P}$ & $\mathrm{P}$ & $\mathrm{P}$ & $P$ \\
\hline P.B.B.M. & II & 11,83 & $F$ & $\mathrm{P}$ & $\mathrm{P}$ & $\mathrm{P}$ & $\mathrm{P}$ & $\mathrm{P}$ & $\mathrm{P}$ & $\mathrm{P}$ & $\mathrm{P}$ & $\mathrm{P}$ & $\mathrm{P}$ & $\mathrm{P}$ & $\mathrm{P}$ & $\mathrm{P}$ & $P$ \\
\hline M.H.T. & II & 11,25 & $\mathrm{~F}$ & - & $\mathrm{P}$ & - & $\mathrm{P}$ & $\mathrm{P}$ & $\mathrm{P}$ & $\mathrm{P}$ & $\mathrm{P}$ & $\mathrm{P}$ & - & $\mathrm{P}$ & - & $\mathrm{P}$ & - \\
\hline M.G.T. & II & 11,66 & M & $\mathrm{P}$ & $\mathrm{P}$ & $P$ & $\mathrm{P}$ & $\mathrm{P}$ & $P$ & $\mathrm{P}$ & $\mathrm{P}$ & $\mathrm{P}$ & $P$ & $\mathrm{P}$ & $P$ & $\mathrm{P}$ & $P$ \\
\hline F.B. & II & 11,58 & $\mathrm{~F}$ & $\mathrm{P}$ & $\mathrm{P}$ & $P$ & $\mathrm{P}$ & $\mathrm{P}$ & $P$ & $\mathrm{P}$ & $P$ & $\mathrm{P}$ & $P$ & $\mathrm{P}$ & $\mathrm{P}$ & $\mathrm{P}$ & $P$ \\
\hline A.B.S.M. & II & 11,00 & $\mathrm{~F}$ & - & $\mathrm{P}$ & - & $\mathrm{P}$ & - & $\mathrm{P}$ & $\mathrm{P}$ & $\mathrm{P}$ & $\mathrm{P}$ & - & - & - & $\mathrm{P}$ & - \\
\hline R.T.D.G. & II & 11,91 & $M$ & $\mathrm{P}$ & $\mathrm{P}$ & $\mathrm{P}$ & $\mathrm{P}$ & $\mathrm{P}$ & $\mathrm{P}$ & $\mathrm{P}$ & $\mathrm{P}$ & $\mathrm{P}$ & $\mathrm{P}$ & $\mathrm{P}$ & $\mathrm{P}$ & $\mathrm{P}$ & - \\
\hline C.B.J. & II & 11,41 & $\mathrm{~F}$ & $\mathrm{P}$ & $\mathrm{P}$ & $\mathrm{P}$ & $\mathrm{P}$ & $\mathrm{P}$ & $P$ & $\mathrm{P}$ & $\mathrm{P}$ & $\mathrm{P}$ & $\mathrm{P}$ & $\mathrm{P}$ & - & $\mathrm{P}$ & $P$ \\
\hline G.C.T.N. & II & 11,00 & $\bar{M}$ & - & $\mathrm{P}$ & - & $\mathrm{P}$ & - & $P$ & $\mathrm{P}$ & $\mathrm{P}$ & $\mathrm{P}$ & - & $\mathrm{P}$ & - & $\mathrm{P}$ & - \\
\hline D.A.M. & II & 11,75 & $\mathrm{M}$ & - & $\mathrm{P}$ & $\mathrm{P}$ & $\mathrm{P}$ & - & $\mathrm{P}$ & $\mathrm{P}$ & $\mathrm{P}$ & $\mathrm{P}$ & - & $\mathrm{P}$ & - & $\mathrm{P}$ & - \\
\hline L.B. & II & 11,66 & $\mathrm{~F}$ & $\mathrm{P}$ & $\mathrm{P}$ & $P$ & $P$ & $\mathrm{P}$ & $\mathrm{P}$ & $\mathrm{P}$ & $\mathrm{P}$ & $\bar{P}$ & $P$ & $\mathrm{P}$ & $\mathrm{P}$ & $\mathrm{P}$ & $P$ \\
\hline G.S.M. & II & 11,58 & $M$ & $\mathrm{P}$ & $\mathrm{P}$ & $\mathrm{P}$ & $\mathrm{P}$ & $\mathrm{P}$ & $\mathrm{P}$ & $\mathrm{P}$ & $P$ & $P$ & $\mathrm{P}$ & $\mathrm{P}$ & $\mathrm{P}$ & $\mathrm{P}$ & $P$ \\
\hline
\end{tabular}


TABELA A-16

\begin{tabular}{|c|c|c|c|c|c|c|c|c|c|c|c|c|c|c|c|c|c|}
\hline Nome & Classe & Idade & Gênero & 37 & 36 & 35 & 34 & 33 & 32 & 31 & 41 & 42 & 43 & 44 & 45 & 46 & 47 \\
\hline R.A.A. & $\mathrm{I}$ & 11,66 & $M$ & - & $P$ & - & - & - & $P$ & $\mathrm{P}$ & $P$ & $P$ & $\mathrm{P}$ & - & - & $P$ & - \\
\hline D.F.D & $\mathrm{I}$ & 11,00 & $\bar{M}$ & - & $\mathrm{P}$ & $P$ & $\mathrm{P}$ & $\mathrm{P}$ & $P$ & $\mathrm{P}$ & $P$ & $P$ & $P$ & $\mathrm{P}$ & $\mathrm{P}$ & $\mathrm{P}$ & $P$ \\
\hline A.C.M. & $\mathrm{I}$ & 11,66 & $\mathrm{~F}$ & $\mathrm{P}$ & $\mathrm{P}$ & $\mathrm{P}$ & $\mathrm{P}$ & $\mathrm{P}$ & $\mathrm{P}$ & $\mathrm{P}$ & $\mathrm{P}$ & $\mathrm{P}$ & $\mathrm{P}$ & $\mathrm{P}$ & $\mathrm{P}$ & $\mathrm{P}$ & $\mathrm{P}$ \\
\hline E.P.P. & $\mathrm{I}$ & 11,91 & $\mathrm{~F}$ & $\mathrm{P}$ & $\mathrm{P}$ & $\mathrm{P}$ & $\mathrm{P}$ & $\mathrm{P}$ & $\mathrm{P}$ & $\mathrm{P}$ & $P$ & $\mathrm{P}$ & $\mathrm{P}$ & $\mathrm{P}$ & $\mathrm{P}$ & $\mathrm{P}$ & $\mathrm{P}$ \\
\hline P.S.P.C. & I & 11,41 & $M$ & - & $\mathrm{P}$ & - & $\mathrm{P}$ & $\mathrm{P}$ & $\mathrm{P}$ & $\mathrm{P}$ & $\mathrm{P}$ & $\mathrm{P}$ & $\mathrm{P}$ & $\mathrm{P}$ & - & $P$ & - \\
\hline E.C.M. & $\mathrm{I}$ & 11,91 & $\mathrm{~F}$ & $\mathrm{P}$ & $P$ & $P$ & $P$ & $P$ & $P$ & $P$ & $\mathrm{P}$ & $P$ & $\mathrm{P}$ & $P$ & $\mathrm{P}$ & $P$ & $P$ \\
\hline M.Q.B. & I & 11,58 & $\mathrm{M}$ & $\mathrm{P}$ & $\mathrm{P}$ & $\mathrm{P}$ & $\mathrm{P}$ & $\mathrm{P}$ & $\mathrm{P}$ & $P$ & $\mathrm{P}$ & $\mathrm{P}$ & $\mathrm{P}$ & $\mathrm{P}$ & $\mathrm{P}$ & $P$ & $P$ \\
\hline A.C.D. & $\mathrm{I}$ & 11,50 & $\mathrm{~F}$ & $\mathrm{P}$ & $\mathrm{P}$ & $\mathrm{P}$ & $\mathrm{P}$ & $\mathrm{P}$ & $\mathrm{P}$ & $\mathrm{P}$ & $\mathrm{P}$ & $\mathrm{P}$ & $\mathrm{P}$ & $\mathrm{P}$ & $\mathrm{P}$ & $\mathrm{P}$ & $\mathrm{P}$ \\
\hline F.S. & $\mathrm{I}$ & 11,58 & $\bar{M}$ & $\mathrm{P}$ & $\mathrm{P}$ & $\mathrm{P}$ & $\mathrm{P}$ & $\mathrm{P}$ & $\mathrm{P}$ & $\mathrm{P}$ & $\mathrm{P}$ & $\mathrm{P}$ & $\mathrm{P}$ & $\mathrm{P}$ & $\mathrm{P}$ & $\mathrm{P}$ & $P$ \\
\hline R.F.E. & $\mathrm{I}$ & 11,00 & $\bar{M}$ & $\mathrm{P}$ & $\mathrm{P}$ & $\mathrm{P}$ & $\mathrm{P}$ & $\mathrm{P}$ & $\mathrm{P}$ & $\mathrm{P}$ & $\mathrm{P}$ & $\mathrm{P}$ & $\mathrm{P}$ & $\mathrm{P}$ & $\mathrm{P}$ & $\mathrm{P}$ & $\mathrm{P}$ \\
\hline S.T.G. & $\mathrm{I}$ & 11,25 & $\bar{M}$ & - & $P$ & $P$ & $\mathrm{P}$ & $P$ & $P$ & $P$ & $P$ & $P$ & $P$ & $P$ & - & $P$ & - \\
\hline M.P.P. & $\mathrm{I}$ & 11,50 & $\mathrm{~F}$ & $\mathrm{P}$ & $P$ & - & $\mathrm{P}$ & $\mathrm{P}$ & $\mathrm{P}$ & $\mathrm{P}$ & $P$ & $P$ & $\mathrm{P}$ & $\mathrm{P}$ & - & $P$ & - \\
\hline C.L.C. & 1 & 11,33 & $\mathrm{~F}$ & $\mathrm{P}$ & $\mathrm{P}$ & $\mathrm{P}$ & $\mathrm{P}$ & $\mathrm{P}$ & $\mathrm{P}$ & $\mathrm{P}$ & $\mathrm{P}$ & $\mathrm{P}$ & $\mathrm{P}$ & $\mathrm{P}$ & $\mathrm{P}$ & $\mathrm{P}$ & $\mathrm{P}$ \\
\hline D.E.H. & 1 & 11,58 & $\mathrm{~F}$ & $\mathrm{P}$ & $\mathrm{P}$ & $\mathrm{P}$ & $\mathrm{P}$ & $\mathrm{P}$ & $\mathrm{P}$ & $\mathrm{P}$ & $P$ & $\mathrm{P}$ & $\mathrm{P}$ & $\mathrm{P}$ & $\mathrm{P}$ & $\mathrm{P}$ & $P$ \\
\hline M.L.P. & $\mathrm{I}$ & 11,00 & $\mathrm{~F}$ & $\mathrm{P}$ & $\mathrm{P}$ & $\mathrm{P}$ & $\mathrm{P}$ & $\mathrm{P}$ & $\mathrm{P}$ & $\mathrm{P}$ & $\mathrm{P}$ & $\mathrm{P}$ & $\mathrm{P}$ & $\mathrm{P}$ & $\mathrm{P}$ & $\mathrm{P}$ & $\mathrm{P}$ \\
\hline A.P.M.B. & I & 11,08 & $\mathrm{~F}$ & $\mathrm{P}$ & $\mathrm{P}$ & $\mathrm{P}$ & $\mathrm{P}$ & $\mathrm{P}$ & $\mathrm{P}$ & $P$ & $\mathrm{P}$ & $\mathrm{P}$ & $\mathrm{P}$ & $\mathrm{P}$ & $\mathrm{P}$ & $P$ & $\mathrm{P}$ \\
\hline P.S.E. & $\mathrm{I}$ & 11,41 & $F$ & - & $\mathrm{P}$ & - & $\mathrm{P}$ & $\mathrm{P}$ & $\mathrm{P}$ & $\mathrm{P}$ & $\mathrm{P}$ & $\mathrm{P}$ & $\mathrm{P}$ & $\mathrm{P}$ & - & $\mathrm{P}$ & - \\
\hline J.R.N. & $\mathrm{I}$ & 11,91 & $\bar{M}$ & - & $\mathrm{P}$ & $\mathrm{P}$ & $\mathrm{P}$ & $\mathrm{P}$ & $\mathrm{P}$ & $\mathrm{P}$ & $\mathrm{P}$ & $\mathrm{P}$ & $\mathrm{P}$ & $\mathrm{P}$ & $\mathrm{P}$ & $\mathrm{P}$ & - \\
\hline E.A. & 1 & 11,83 & M & $\mathrm{P}$ & $\mathrm{P}$ & $\mathrm{P}$ & $\mathrm{P}$ & - & $\mathrm{P}$ & $\mathrm{P}$ & $\mathrm{P}$ & $\mathrm{P}$ & - & $\mathrm{P}$ & $\mathrm{P}$ & $\mathrm{P}$ & $P$ \\
\hline R.Q. & $\mathrm{I}$ & 11,83 & $\mathrm{M}$ & $\mathrm{P}$ & $\mathrm{P}$ & - & $\mathrm{P}$ & $\mathrm{P}$ & $\mathrm{P}$ & $\mathrm{P}$ & $\mathrm{P}$ & $\mathrm{P}$ & $\mathrm{P}$ & $\mathrm{P}$ & - & $\mathrm{P}$ & $P$ \\
\hline E.L.C.S. & $\mathrm{I}$ & 11,91 & $\mathrm{M}$ & $\mathrm{P}$ & $\mathrm{P}$ & $\mathrm{P}$ & $\mathrm{P}$ & $\mathrm{P}$ & $\mathrm{P}$ & $\mathrm{P}$ & $\mathrm{P}$ & $\mathrm{P}$ & $\mathrm{P}$ & $\mathrm{P}$ & $\mathrm{P}$ & $\mathrm{P}$ & $\mathrm{P}$ \\
\hline M.S. & 1 & 11,33 & M & $\mathrm{P}$ & $\mathrm{P}$ & $\mathrm{P}$ & $\mathrm{P}$ & $\mathrm{P}$ & $\mathrm{P}$ & $\mathrm{P}$ & $\mathrm{P}$ & $\mathrm{P}$ & $\mathrm{P}$ & $\mathrm{P}$ & $\mathrm{P}$ & $\mathrm{P}$ & $\mathrm{P}$ \\
\hline R.C.L.A. & $\mathrm{I}$ & 11,66 & $\mathrm{~F}$ & $\mathrm{P}$ & $\mathrm{P}$ & $\mathrm{P}$ & $\mathrm{P}$ & $\mathrm{P}$ & $\mathrm{P}$ & $\mathrm{P}$ & $\mathrm{P}$ & $\mathrm{P}$ & $\mathrm{P}$ & $\mathrm{P}$ & $\mathrm{P}$ & $\mathrm{P}$ & $P$ \\
\hline C.S.D. & $\mathrm{I}$ & 11,00 & $\mathrm{~F}$ & - & $\mathrm{P}$ & $\mathrm{P}$ & $\mathrm{P}$ & $\mathrm{P}$ & $\mathrm{P}$ & $\mathrm{P}$ & $\mathrm{P}$ & $\mathrm{P}$ & $\mathrm{P}$ & $\mathrm{P}$ & $P$ & $\mathrm{P}$ & - \\
\hline V.C.P. & $\mathrm{I}$ & 11,16 & $\mathrm{~F}$ & $\mathrm{P}$ & $\mathrm{P}$ & $\mathrm{P}$ & $\mathrm{P}$ & $\mathrm{P}$ & $\mathrm{P}$ & $\mathrm{P}$ & $\mathrm{P}$ & $\mathrm{P}$ & $\mathrm{P}$ & $\mathrm{P}$ & $\mathrm{P}$ & $\mathrm{P}$ & $\mathrm{P}$ \\
\hline R.V.D. & I & 11,25 & $M$ & $\mathrm{P}$ & $\mathrm{P}$ & $\mathrm{P}$ & - & - & $\mathrm{P}$ & $\mathrm{P}$ & $\mathrm{P}$ & $\mathrm{P}$ & - & - & - & $\mathrm{P}$ & $\mathrm{P}$ \\
\hline D.C.G.O. & 1 & 11,33 & $\mathrm{~F}$ & $\mathrm{P}$ & $\mathrm{P}$ & - & $\mathrm{P}$ & $\mathrm{P}$ & $\mathrm{P}$ & $\mathrm{P}$ & $\mathrm{P}$ & $\mathrm{P}$ & $\mathrm{P}$ & $\mathrm{P}$ & $\mathrm{P}$ & $\mathrm{P}$ & $\mathrm{P}$ \\
\hline C.Q. & $\mathrm{I}$ & 11,25 & $\mathrm{~F}$ & - & $\mathrm{P}$ & $\mathrm{P}$ & $\mathrm{P}$ & $\mathrm{P}$ & $\mathrm{P}$ & $\mathrm{P}$ & $\mathrm{P}$ & $\mathrm{P}$ & $\mathrm{P}$ & $\mathrm{P}$ & $\mathrm{P}$ & $\mathrm{P}$ & - \\
\hline I.M.L. & $\mathrm{I}$ & 11,58 & $\mathrm{~F}$ & $\mathrm{P}$ & $\mathrm{P}$ & - & $\mathrm{P}$ & $\mathrm{P}$ & $\mathrm{P}$ & $\mathrm{P}$ & $\mathrm{P}$ & $\mathrm{P}$ & $\mathrm{P}$ & $\mathrm{P}$ & - & $\mathrm{P}$ & $P$ \\
\hline T.V.S. & II & 11,00 & $M$ & - & $\mathrm{P}$ & - & $\mathrm{P}$ & $\mathrm{P}$ & $\mathrm{P}$ & $\mathrm{P}$ & $\mathrm{P}$ & $\mathrm{P}$ & $\mathrm{P}$ & $\mathrm{P}$ & - & $\mathrm{P}$ & - \\
\hline J.C.M.J. & II & 11,00 & $M$ & - & $\mathrm{P}$ & - & - & - & $\mathrm{P}$ & $\mathrm{P}$ & $\mathrm{P}$ & $\mathrm{P}$ & - & - & - & $\mathrm{P}$ & - \\
\hline M.A.P.T. & II & 11,00 & $\bar{M}$ & $\mathrm{P}$ & $P$ & - & - & - & $P$ & $P$ & $\mathrm{P}$ & $P$ & $\mathrm{P}$ & - & $\mathrm{P}$ & $P$ & - \\
\hline R.G.M. & II & 11,25 & $\bar{M}$ & - & $\mathrm{P}$ & $\mathrm{P}$ & $\mathrm{P}$ & $\mathrm{P}$ & $\mathrm{P}$ & $\mathrm{P}$ & $P$ & $\mathrm{P}$ & $\mathrm{P}$ & $\mathrm{P}$ & $\mathrm{P}$ & $\mathrm{P}$ & - \\
\hline T.C.C.C. & II & 11,58 & $\mathrm{~F}$ & $\mathrm{P}$ & $\mathrm{P}$ & $\mathrm{P}$ & $\mathrm{P}$ & $\mathrm{P}$ & $\mathrm{P}$ & $\mathrm{P}$ & $\mathrm{P}$ & $\mathrm{P}$ & $\mathrm{P}$ & $\mathrm{P}$ & $\mathrm{P}$ & $\mathrm{P}$ & $\mathrm{P}$ \\
\hline R.A.S.S. & II & 11,33 & $\mathrm{~F}$ & - & $\mathrm{P}$ & $\mathrm{P}$ & $\mathrm{P}$ & $\mathrm{P}$ & $\mathrm{P}$ & $\mathrm{P}$ & $P$ & $\mathrm{P}$ & $\mathrm{P}$ & - & - & $\mathrm{P}$ & - \\
\hline R.B.R. & II & 11,16 & $F$ & - & $P$ & $\mathrm{P}$ & $\mathrm{P}$ & $\mathrm{P}$ & $\mathrm{P}$ & $\mathrm{P}$ & $\mathrm{P}$ & $\mathrm{P}$ & $\mathrm{P}$ & $\mathrm{P}$ & $\mathrm{P}$ & $\mathrm{P}$ & - \\
\hline F.B.A. & II & 11,33 & $\mathrm{~F}$ & - & $\mathrm{P}$ & $\mathrm{P}$ & $\mathrm{P}$ & $\mathrm{P}$ & $\mathrm{P}$ & $\mathrm{P}$ & $\mathrm{P}$ & $\mathrm{P}$ & $\mathrm{P}$ & $\mathrm{P}$ & $\mathrm{P}$ & $\mathrm{P}$ & - \\
\hline M.F.G. & II & 11,00 & $\mathrm{~F}$ & - & $\mathrm{P}$ & - & $\mathrm{P}$ & - & $\mathrm{P}$ & $\mathrm{P}$ & $\mathrm{P}$ & $\mathrm{P}$ & $\mathrm{P}$ & $\mathrm{P}$ & - & $\mathrm{P}$ & - \\
\hline D.D. & II & 11,00 & $\mathrm{~F}$ & - & $P$ & - & $\mathrm{P}$ & $\mathrm{P}$ & $\mathrm{P}$ & $\mathrm{P}$ & $P$ & $\mathrm{P}$ & $\mathrm{P}$ & $\mathrm{P}$ & - & $\mathrm{P}$ & - \\
\hline R.P.F. & II & 11,75 & $\bar{M}$ & - & $\mathrm{P}$ & - & $\mathrm{P}$ & $\mathrm{P}$ & $P$ & $\mathrm{P}$ & $\mathrm{P}$ & $\mathrm{P}$ & $\mathrm{P}$ & $\mathrm{P}$ & $\mathrm{P}$ & $P$ & $P$ \\
\hline E.C.L. & II & 11,83 & $\mathrm{~F}$ & $\mathrm{P}$ & $P$ & $\mathrm{P}$ & $\mathrm{P}$ & $\mathrm{P}$ & $\mathrm{P}$ & $\mathrm{P}$ & $\mathrm{P}$ & $\mathrm{P}$ & $\mathrm{P}$ & $\mathrm{P}$ & $\mathrm{P}$ & $P$ & $\mathrm{P}$ \\
\hline R.R.D. & II & 11,75 & $\bar{M}$ & - & $\mathrm{P}$ & $\mathrm{P}$ & $\mathrm{P}$ & $\mathrm{P}$ & $\mathrm{P}$ & $\mathrm{P}$ & $\mathrm{P}$ & $\mathrm{P}$ & $\mathrm{P}$ & $\mathrm{P}$ & $\mathrm{P}$ & $\mathrm{P}$ & - \\
\hline J.A.M. & II & 11,91 & $\bar{M}$ & - & $P$ & $\mathrm{P}$ & - & $\mathrm{P}$ & $\mathrm{P}$ & $\mathrm{P}$ & $\mathrm{P}$ & $P$ & $\mathrm{P}$ & - & $\mathrm{P}$ & $\mathrm{P}$ & - \\
\hline B.M.L. & II & 11,08 & $M$ & - & $P$ & $\mathrm{P}$ & $\mathrm{P}$ & $\mathrm{P}$ & $\mathrm{P}$ & $\mathrm{P}$ & $\mathrm{P}$ & $P$ & $\mathrm{P}$ & $\mathrm{P}$ & - & $\mathrm{P}$ & $P$ \\
\hline C.F.Z.S. & II & 11,08 & $F$ & - & $P$ & $P$ & $P$ & $P$ & $P$ & $P$ & $P$ & $P$ & $P$ & $P$ & $\mathrm{P}$ & $P$ & - \\
\hline T.S.N.J. & II & 11,58 & $\bar{M}$ & - & $\mathrm{P}$ & $\mathrm{P}$ & $\mathrm{P}$ & $\mathrm{P}$ & $P$ & $\mathrm{P}$ & $\mathrm{P}$ & $\mathrm{P}$ & $P$ & $P$ & - & $\mathrm{P}$ & - \\
\hline E.F.Z. & II & 11,50 & $\mathrm{~F}$ & - & $P$ & $P$ & $\mathrm{P}$ & $P$ & $P$ & $P$ & $\mathrm{P}$ & $P$ & $P$ & $P$ & - & $P$ & - \\
\hline J.A.A.C. & II & 11,91 & $M$ & - & $P$ & $\mathrm{P}$ & $\mathrm{P}$ & $\mathrm{P}$ & $P$ & $P$ & $P$ & $\mathrm{P}$ & $P$ & $P$ & $\mathrm{P}$ & $P$ & - \\
\hline P.B.B.M. & II & 11,83 & $\mathrm{~F}$ & $P$ & $\mathrm{P}$ & $\mathrm{P}$ & $P$ & $P$ & $P$ & $P$ & $\mathrm{P}$ & $\mathrm{P}$ & $P$ & $P$ & $P$ & $P$ & $P$ \\
\hline M.H.T. & II & 11,25 & $F$ & - & $\mathrm{P}$ & - & - & $\mathrm{P}$ & $\mathrm{P}$ & $\mathrm{P}$ & $\mathrm{P}$ & $\mathrm{P}$ & $\mathrm{P}$ & - & - & $\mathrm{P}$ & - \\
\hline M.G.T. & II & 11,66 & M & $\mathrm{P}$ & $\mathrm{P}$ & $P$ & $P$ & $\mathrm{P}$ & $\mathrm{P}$ & $\mathrm{P}$ & $\mathrm{P}$ & $\mathrm{P}$ & $\mathrm{P}$ & $P$ & $\mathrm{P}$ & $\mathrm{P}$ & $P$ \\
\hline F.B. & II & 11,58 & $\mathrm{~F}$ & $\mathrm{P}$ & $\mathrm{P}$ & $P$ & $\mathrm{P}$ & $\mathrm{P}$ & $P$ & $\mathrm{P}$ & $P$ & $P$ & $P$ & $\mathrm{P}$ & $\mathrm{P}$ & $\mathrm{P}$ & $P$ \\
\hline A.B.S.M. & II & 11,00 & $\mathrm{~F}$ & - & $\mathrm{P}$ & - & - & $\mathrm{P}$ & $\mathrm{P}$ & $\mathrm{P}$ & $\mathrm{P}$ & $\mathrm{P}$ & $\mathrm{P}$ & - & - & $\mathrm{P}$ & - \\
\hline R.T.D.G. & II & 11,91 & $M$ & $\mathrm{P}$ & $\mathrm{P}$ & - & $\mathrm{P}$ & $\mathrm{P}$ & $\mathrm{P}$ & $\mathrm{P}$ & $\mathrm{P}$ & $\mathrm{P}$ & $\mathrm{P}$ & $\mathrm{P}$ & - & $\mathrm{P}$ & - \\
\hline C.B.J. & II & 11,41 & $\mathrm{~F}$ & $\mathrm{P}$ & $\mathrm{P}$ & - & $\mathrm{P}$ & $\mathrm{P}$ & $\mathrm{P}$ & $\mathrm{P}$ & $\mathrm{P}$ & $\mathrm{P}$ & $\mathrm{P}$ & $\mathrm{P}$ & $\mathrm{P}$ & $\mathrm{P}$ & $P$ \\
\hline G.C.T.N. & II & 11,00 & $M$ & - & $\mathrm{P}$ & - & $\mathrm{P}$ & - & $\mathrm{P}$ & $\mathrm{P}$ & $\mathrm{P}$ & $\mathrm{P}$ & $\mathrm{P}$ & $\mathrm{P}$ & - & $\mathrm{P}$ & - \\
\hline D.A.M. & II & 11,75 & $\mathrm{M}$ & $\mathrm{P}$ & $\mathrm{P}$ & $\mathrm{P}$ & $\mathrm{P}$ & $\mathrm{P}$ & $\mathrm{P}$ & $\mathrm{P}$ & $\mathrm{P}$ & $\mathrm{P}$ & $\mathrm{P}$ & $\mathrm{P}$ & - & $\mathrm{P}$ & $P$ \\
\hline L.B. & II & 11,66 & $\mathrm{~F}$ & $\mathrm{P}$ & $\mathrm{P}$ & $P$ & $P$ & $\mathrm{P}$ & $\mathrm{P}$ & $\mathrm{P}$ & $\bar{P}$ & $\mathrm{P}$ & $P$ & $\mathrm{P}$ & $P$ & $\mathrm{P}$ & $P$ \\
\hline G.S.M. & II & 11,58 & $M$ & $\mathrm{P}$ & $\mathrm{P}$ & $\mathrm{P}$ & $\mathrm{P}$ & $\mathrm{P}$ & $\mathrm{P}$ & $\mathrm{P}$ & $P$ & $\mathrm{P}$ & $\mathrm{P}$ & $\mathrm{P}$ & $\mathrm{P}$ & $\mathrm{P}$ & $P$ \\
\hline
\end{tabular}


TABELA A-17

\begin{tabular}{|c|c|c|c|c|c|c|c|c|c|c|c|c|c|c|c|c|c|}
\hline Nome & Classe & Idade & Gênero & 17 & 16 & \begin{tabular}{|l|}
15 \\
\end{tabular} & 14 & 13 & \begin{tabular}{|l|}
12 \\
\end{tabular} & 11 & 21 & \begin{tabular}{|l|}
22 \\
\end{tabular} & 23 & 24 & 25 & \begin{tabular}{|l|}
26 \\
\end{tabular} & 27 \\
\hline A.C.M. & $\mathrm{I}$ & 12,58 & $F$ & $P$ & $\mathrm{P}$ & $\mathrm{P}$ & $\mathrm{P}$ & $\mathrm{P}$ & $P$ & $P$ & $P$ & $P$ & $P$ & $P$ & \begin{tabular}{|l|}
$\mathrm{P}$ \\
\end{tabular} & $P$ & $P$ \\
\hline P.S.P.C. & $\mathrm{I}$ & 12,41 & $\bar{M}$ & & $\mathrm{P}$ & $\mathrm{P}$ & $\begin{array}{ll}P \\
\end{array}$ & $\begin{array}{ll}\mathrm{P} \\
\end{array}$ & $P$ & $P$ & $P$ & $P$ & $P$ & $P$ & $\mathrm{P}$ & $\mathrm{P}$ & \\
\hline E.C.M. & I & 12,00 & $\mathrm{~F}$ & $P$ & $\mathrm{P}$ & $P$ & $\mathrm{P}$ & $\mathrm{P}$ & $\mathrm{P}$ & $P$ & $P$ & $P$ & $P$ & $\mathrm{P}$ & $\mathrm{P}$ & $\mathrm{P}$ & $\bar{P}$ \\
\hline M.Q.B. & I & 12,00 & $M$ & $P$ & $\mathrm{P}$ & $\mathrm{P}$ & $\mathrm{P}$ & $\mathrm{P}$ & $\mathrm{P}$ & $P$ & $P$ & $P$ & $\mathrm{P}$ & $\mathrm{P}$ & $\mathrm{P}$ & $\mathrm{P}$ & $\mathrm{P}$ \\
\hline A.C.D. & I & 12,83 & $\mathrm{~F}$ & $P$ & $\mathrm{P}$ & $\mathrm{P}$ & $\mathrm{P}$ & $\mathrm{P}$ & $\mathrm{P}$ & $\mathrm{P}$ & $\mathrm{P}$ & $P$ & $\mathrm{P}$ & $\mathrm{P}$ & $\mathrm{P}$ & $\mathrm{P}$ & $\mathrm{P}$ \\
\hline R.F.E. & $T$ & 12,00 & $\bar{M}$ & $P$ & $P$ & $\mathrm{P}$ & $P$ & \begin{tabular}{|l|}
$\mathrm{P}$ \\
\end{tabular} & $P$ & $P$ & $P$ & $P$ & $P$ & $P$ & $P$ & $\mathrm{P}$ & $\bar{P}$ \\
\hline S.T.G. & I & 12,58 & $M$ & - & $\mathrm{P}$ & $\mathrm{P}$ & $\mathrm{P}$ & $\mathrm{P}$ & $\mathrm{P}$ & $P$ & $P$ & $P$ & $P$ & \begin{tabular}{l|l} 
\\
\end{tabular} & $\mathrm{P}$ & $\mathrm{P}$ & - \\
\hline M.P.P. & $T$ & 12,58 & $\mathrm{~F}$ & - & $P$ & - & $P$ & $P$ & $P$ & $P$ & $P$ & $P$ & $P$ & $P$ & $\mathrm{P}$ & $P$ & $\bar{P}$ \\
\hline C.L.C. & 1 & 12,33 & $\mathrm{~F}$ & $P$ & $\mathrm{P}$ & $\mathrm{P}$ & $\mathrm{P}$ & $\mathrm{P}$ & $\mathrm{P}$ & $P$ & $P$ & $P$ & $\mathrm{P}$ & $\mathrm{P}$ & $\mathrm{P}$ & $\mathrm{P}$ & $\mathrm{P}$ \\
\hline D.E.H. & $\mathrm{I}$ & 12,66 & $\mathrm{~F}$ & $P$ & $\mathrm{P}$ & $P$ & $\mathrm{P}$ & $\mathrm{P}$ & $\mathrm{P}$ & $P$ & $P$ & $P$ & $\mathrm{P}$ & $P$ & $\mathrm{P}$ & $\mathrm{P}$ & $\mathrm{P}$ \\
\hline M.L.P. & 1 & 12,00 & $\mathrm{~F}$ & $P$ & $\mathrm{P}$ & $\mathrm{P}$ & $\mathrm{P}$ & $\mathrm{P}$ & $\mathrm{P}$ & $\mathrm{P}$ & $P$ & $P$ & $\mathrm{P}$ & $\mathrm{P}$ & $\mathrm{P}$ & $\mathrm{P}$ & $\mathrm{P}$ \\
\hline A.P.M.B. & I & 12,00 & $\mathrm{~F}$ & $P$ & $\mathrm{P}$ & $\mathrm{P}$ & $\mathrm{P}$ & $\mathrm{P}$ & $\mathrm{P}$ & $P$ & $P$ & $P$ & $P$ & $P$ & $\mathrm{P}$ & $\mathrm{P}$ & $\mathrm{P}$ \\
\hline P.S.E. & $T$ & 12,50 & $F$ & $P$ & $P$ & $\mathrm{P}$ & $P$ & - & $P$ & $P$ & $P$ & $P$ & $P$ & $P$ & $P$ & $\mathrm{P}$ & $\bar{P}$ \\
\hline J.R.N. & I & 12,91 & $\bar{M}$ & $P$ & $\mathrm{P}$ & $\mathrm{P}$ & $\mathrm{P}$ & $\mathrm{P}$ & $P$ & $P$ & $P$ & $P$ & $P$ & $P$ & $P$ & $\mathrm{P}$ & $P$ \\
\hline E.L.C.S. & $\mathrm{I}$ & 12,08 & $\bar{M}$ & $P$ & $\begin{array}{l}\mathrm{P} \\
\end{array}$ & $\mathrm{P}$ & $P$ & $P$ & $P$ & $P$ & $P$ & $P$ & $P$ & \begin{tabular}{l|l} 
\\
\end{tabular} & $\mathrm{P}$ & $\mathrm{P}$ & $\bar{P}$ \\
\hline E.A. & 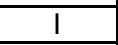 & 12,83 & $\mathrm{M}$ & $\mathrm{P}$ & $\mathrm{P}$ & $\mathrm{P}$ & $\mathrm{P}$ & $\mathrm{P}$ & $\mathrm{P}$ & $\mathrm{P}$ & $\mathrm{P}$ & $\mathrm{P}$ & $P$ & \begin{tabular}{l|l} 
\\
\end{tabular} & $\mathrm{P}$ & $\mathrm{P}$ & $P$ \\
\hline M.S. & $\mathrm{I}$ & 12,25 & $M$ & $P$ & $\mathrm{P}$ & $\mathrm{P}$ & $\mathrm{P}$ & $\mathrm{P}$ & $\mathrm{P}$ & $\mathrm{P}$ & $P$ & $\mathrm{P}$ & $\mathrm{P}$ & $\mathrm{P}$ & $\mathrm{P}$ & $\mathrm{P}$ & $\mathrm{P}$ \\
\hline R.C.L.A. & 1 & 12,33 & $\mathrm{~F}$ & $P$ & $\mathrm{P}$ & $\mathrm{P}$ & $\mathrm{P}$ & $\mathrm{P}$ & $\mathrm{P}$ & $\mathrm{P}$ & $P$ & $\mathrm{P}$ & $\mathrm{P}$ & $\mathrm{P}$ & $\mathrm{P}$ & $\mathrm{P}$ & $\mathrm{P}$ \\
\hline C.S.D. & I & 12,08 & $\mathrm{~F}$ & $P$ & $\mathrm{P}$ & $\mathrm{P}$ & $\mathrm{P}$ & $\mathrm{P}$ & $\mathrm{P}$ & $\mathrm{P}$ & $P$ & $\mathrm{P}$ & $P$ & $P$ & $P$ & $\mathrm{P}$ & $\mathrm{P}$ \\
\hline D.C.G.O. & I & 12,33 & $\mathrm{~F}$ & $P$ & $P$ & $\mathrm{P}$ & $\mathrm{P}$ & $\mathrm{P}$ & $\mathrm{P}$ & $P$ & $P$ & $\mathrm{P}$ & $P$ & \begin{tabular}{l|}
$P$ \\
\end{tabular} & $\mathrm{P}$ & $\mathrm{P}$ & $\bar{P}$ \\
\hline R.V.D. & 1 & 12,16 & $M$ & $\mathrm{P}$ & $\mathrm{P}$ & $\mathrm{P}$ & $\mathrm{P}$ & $\mathrm{P}$ & $\mathrm{P}$ & $\mathrm{P}$ & $\mathrm{P}$ & $\mathrm{P}$ & $P$ & $\mathrm{P}$ & $\mathrm{P}$ & $\mathrm{P}$ & $\mathrm{P}$ \\
\hline I.M.L. & I & 12,58 & $F$ & $P$ & $\mathrm{P}$ & $\mathrm{P}$ & $\mathrm{P}$ & $\mathrm{P}$ & $\mathrm{P}$ & $P$ & $P$ & $\mathrm{P}$ & $P$ & \begin{tabular}{l|} 
\\
\end{tabular} & $\mathrm{P}$ & $\mathrm{P}$ & $P$ \\
\hline A.P.B. & 1 & 12,66 & $F$ & $\mathrm{P}$ & $\mathrm{P}$ & $\mathrm{P}$ & $\mathrm{P}$ & $\mathrm{P}$ & $\mathrm{P}$ & $\mathrm{P}$ & $\mathrm{P}$ & $\mathrm{P}$ & $P$ & $\mathrm{P}$ & $\mathrm{P}$ & $\mathrm{P}$ & $P$ \\
\hline C.C.P. & I & 12,41 & $F$ & $\mathrm{P}$ & $\mathrm{P}$ & $\mathrm{P}$ & $\mathrm{P}$ & $\mathrm{P}$ & $\mathrm{P}$ & $\mathrm{P}$ & $\mathrm{P}$ & $\mathrm{P}$ & $\mathrm{P}$ & $\mathrm{P}$ & $\mathrm{P}$ & $\mathrm{P}$ & $\mathrm{P}$ \\
\hline F.Z. & 1 & 12,66 & $M$ & $P$ & $\mathrm{P}$ & $\mathrm{P}$ & $\mathrm{P}$ & $\mathrm{P}$ & $\mathrm{P}$ & $\mathrm{P}$ & $P$ & $\mathrm{P}$ & $P$ & $\mathrm{P}$ & $\mathrm{P}$ & $\mathrm{P}$ & $\mathrm{P}$ \\
\hline J.C.M.J. & II & 12,00 & $M$ & - & $\mathrm{P}$ & $P$ & $\mathrm{P}$ & - & $\mathrm{P}$ & $P$ & $P$ & $\mathrm{P}$ & $\mathrm{P}$ & $P$ & $\mathrm{P}$ & $\mathrm{P}$ & \\
\hline M.A.P.T. & II & 12,08 & $\mathrm{M}$ & $P$ & $P$ & $\mathrm{P}$ & $P$ & $\mathrm{P}$ & $\mathrm{P}$ & $P$ & $P$ & $P$ & $P$ & $P$ & $\mathrm{P}$ & $\mathrm{P}$ & $\bar{P}$ \\
\hline P.B.J. & II & 12,83 & $M$ & $\mathrm{P}$ & $\mathrm{P}$ & $\mathrm{P}$ & $\mathrm{P}$ & - & $\mathrm{P}$ & $\mathrm{P}$ & $\mathrm{P}$ & $\mathrm{P}$ & - & $\mathrm{P}$ & $\mathrm{P}$ & $\mathrm{P}$ & $\mathrm{P}$ \\
\hline R.G.M. & II & 12,25 & $\bar{M}$ & $P$ & $P$ & $P$ & $P$ & $\mathrm{P}$ & $P$ & $P$ & $P$ & $\mathrm{P}$ & $P$ & $\mathrm{P}$ & $\mathrm{P}$ & $P$ & $\bar{P}$ \\
\hline T.C.C.С. & II & 12,00 & $F$ & $\mathrm{P}$ & $\mathrm{P}$ & $P$ & $\mathrm{P}$ & $\mathrm{P}$ & $\mathrm{P}$ & $P$ & $\mathrm{P}$ & $\mathrm{P}$ & $P$ & $\mathrm{P}$ & $\mathrm{P}$ & $\mathrm{P}$ & $\mathrm{P}$ \\
\hline R.A.S.S. & II & 12,41 & $\mathrm{~F}$ & - & $\mathrm{P}$ & - & - & - & $\mathrm{P}$ & $P$ & $P$ & \begin{tabular}{|l|}
$\mathrm{P}$ \\
\end{tabular} & - & - & - & $\mathrm{P}$ & \\
\hline R.B.R. & II & 12,25 & $\mathrm{~F}$ & - & $\mathrm{P}$ & $P$ & $\mathrm{P}$ & $\mathrm{P}$ & $\mathrm{P}$ & $P$ & $P$ & $\mathrm{P}$ & $P$ & $\mathrm{P}$ & $\mathrm{P}$ & $\mathrm{P}$ & $\mathrm{P}$ \\
\hline F.B.A. & II & 12,41 & $\mathrm{~F}$ & - & $\mathrm{P}$ & $\mathrm{P}$ & $\mathrm{P}$ & $\mathrm{P}$ & $\mathrm{P}$ & $P$ & $P$ & $\mathrm{P}$ & $\mathrm{P}$ & $\mathrm{P}$ & $\mathrm{P}$ & $\mathrm{P}$ & \\
\hline M.F.G. & II & 12,00 & $\mathrm{~F}$ & $P$ & $\mathrm{P}$ & $\mathrm{P}$ & $\mathrm{P}$ & $\mathrm{P}$ & $\mathrm{P}$ & $\mathrm{P}$ & $P$ & $\mathrm{P}$ & $\mathrm{P}$ & $\mathrm{P}$ & $\mathrm{P}$ & $\mathrm{P}$ & $\mathrm{P}$ \\
\hline E.C.L. & II & 12,00 & $\mathrm{~F}$ & $P$ & $P$ & $P$ & $P$ & $\mathrm{P}$ & $P$ & \begin{tabular}{|l|}
$\mathrm{P}$ \\
\end{tabular} & $P$ & \begin{tabular}{|l|}
$\mathrm{P}$ \\
\end{tabular} & $P$ & $\mathrm{P}$ & $P$ & $P$ & $P$ \\
\hline J.A.M. & II & 12,91 & $\bar{M}$ & - & $P$ & $P$ & $P$ & $\mathrm{P}$ & $P$ & $P$ & $P$ & \begin{tabular}{|l|}
$\mathrm{P}$ \\
\end{tabular} & - & - & - & $P$ & - \\
\hline B.M.L. & II & 12,25 & $M$ & - & $\mathrm{P}$ & $P$ & $\mathrm{P}$ & $\mathrm{P}$ & $\mathrm{P}$ & $P$ & $\mathrm{P}$ & $\mathrm{P}$ & $P$ & $\mathrm{P}$ & $\mathrm{P}$ & $\mathrm{P}$ & \\
\hline R.O.B.A. & II & 12,58 & $\mathrm{M}$ & - & $\mathrm{P}$ & $P$ & $\mathrm{P}$ & $\mathrm{P}$ & $\mathrm{P}$ & $P$ & $P$ & \begin{tabular}{ll|}
$P$ \\
\end{tabular} & $P$ & $\mathrm{P}$ & $\mathrm{P}$ & $P$ & \\
\hline C.F.Z.S. & II & 12,08 & $F$ & $P$ & $\begin{array}{l}\mathrm{P} \\
\end{array}$ & $P$ & $\begin{array}{ll}\mathrm{P} \\
\end{array}$ & $\mathrm{P}$ & $P$ & $P$ & $P$ & \begin{tabular}{|l|}
$\mathrm{P}$ \\
\end{tabular} & $P$ & $\mathrm{P}$ & $P$ & $P$ & $\mathrm{P}$ \\
\hline T.S.N.J. & II & 12,66 & $\mathrm{M}$ & $\mathrm{P}$ & $\mathrm{P}$ & $P$ & $\mathrm{P}$ & $\mathrm{P}$ & $\mathrm{P}$ & $P$ & $\mathrm{P}$ & $\mathrm{P}$ & $\mathrm{P}$ & $\mathrm{P}$ & $\mathrm{P}$ & $\mathrm{P}$ & $\mathrm{P}$ \\
\hline E.F.Z. & II & 12,50 & $\mathrm{~F}$ & - & $\mathrm{P}$ & $\mathrm{P}$ & $\mathrm{P}$ & $\mathrm{P}$ & $\mathrm{P}$ & $P$ & $P$ & $\mathrm{P}$ & - & $\mathrm{P}$ & $\mathrm{P}$ & $\mathrm{P}$ & \\
\hline J.A.A.C. & II & 12,83 & $M$ & $P$ & $\mathrm{P}$ & $\mathrm{P}$ & $\mathrm{P}$ & $\mathrm{P}$ & $\mathrm{P}$ & \begin{tabular}{|l|}
$\mathrm{P}$ \\
\end{tabular} & $P$ & $\mathrm{P}$ & $P$ & $\mathrm{P}$ & $\mathrm{P}$ & $\mathrm{P}$ & $\mathrm{P}$ \\
\hline P.B.B.M. & II & 12,91 & $\mathrm{~F}$ & $P$ & $\mathrm{P}$ & $P$ & $\mathrm{P}$ & $\mathrm{P}$ & $\mathrm{P}$ & $\mathrm{P}$ & $P$ & $\mathrm{P}$ & $P$ & $\mathrm{P}$ & $P$ & $\mathrm{P}$ & $\mathrm{P}$ \\
\hline M.H.T. & II & 12,25 & $\mathrm{~F}$ & - & $\mathrm{P}$ & - & $\mathrm{P}$ & $\mathrm{P}$ & $\mathrm{P}$ & $\mathrm{P}$ & $\mathrm{P}$ & $\mathrm{P}$ & $P$ & $\mathrm{P}$ & - & $\mathrm{P}$ & \\
\hline M.G.T. & II & 12,75 & $\mathrm{M}$ & $P$ & $\mathrm{P}$ & $\mathrm{P}$ & $\mathrm{P}$ & $\mathrm{P}$ & $\mathrm{P}$ & $\mathrm{P}$ & $P$ & $\mathrm{P}$ & $\mathrm{P}$ & $\mathrm{P}$ & $\mathrm{P}$ & $\mathrm{P}$ & $\mathrm{P}$ \\
\hline F.B. & II & 12,58 & $\mathrm{~F}$ & $P$ & $\mathrm{P}$ & $\mathrm{P}$ & $\mathrm{P}$ & $\mathrm{P}$ & $\mathrm{P}$ & $\mathrm{P}$ & $P$ & $\mathrm{P}$ & $\mathrm{P}$ & $\mathrm{P}$ & $\mathrm{P}$ & $\mathrm{P}$ & $\mathrm{P}$ \\
\hline A.B.S.M. & II & 12,00 & $F$ & - & $\mathrm{P}$ & - & $\mathrm{P}$ & - & $\mathrm{P}$ & $\mathrm{P}$ & $P$ & $\mathrm{P}$ & - & - & - & $\mathrm{P}$ & \\
\hline R.T.D.G. & II & 12,75 & $M$ & $P$ & $\mathrm{P}$ & $P$ & $\mathrm{P}$ & $\mathrm{P}$ & $\mathrm{P}$ & $\mathrm{P}$ & $P$ & $\mathrm{P}$ & $P$ & $\mathrm{P}$ & $\mathrm{P}$ & $\mathrm{P}$ & $\mathrm{P}$ \\
\hline G.C.T.N. & II & 12,00 & $M$ & - & $\mathrm{P}$ & $P$ & $\mathrm{P}$ & $\mathrm{P}$ & $\mathrm{P}$ & \begin{tabular}{|l|}
$\mathrm{P}$ \\
\end{tabular} & $\mathrm{P}$ & $\mathrm{P}$ & $\mathrm{P}$ & $\mathrm{P}$ & $\mathrm{P}$ & $\mathrm{P}$ & \\
\hline C.B.J. & II & 12,50 & $F$ & $P$ & $P$ & $P$ & $\mathrm{P}$ & $\mathrm{P}$ & $\mathrm{P}$ & $\mathrm{P}$ & $P$ & $P$ & $P$ & $\mathrm{P}$ & $P$ & $\mathrm{P}$ & $\mathrm{P}$ \\
\hline D.A.M. & II & 12,58 & $\mathrm{M}$ & $P$ & $\mathrm{P}$ & $P$ & $\mathrm{P}$ & - & $\mathrm{P}$ & \begin{tabular}{|l|}
$P$ \\
\end{tabular} & $P$ & $\mathrm{P}$ & $P$ & $\mathrm{P}$ & $\mathrm{P}$ & $\mathrm{P}$ & $\mathrm{P}$ \\
\hline L.B. & II & 12,66 & $F$ & $\mathrm{P}$ & $\mathrm{P}$ & $P$ & $\mathrm{P}$ & $\mathrm{P}$ & $\mathrm{P}$ & \begin{tabular}{|l|}
$\mathrm{P}$ \\
\end{tabular} & $\mathrm{P}$ & $\mathrm{P}$ & $P$ & $\mathrm{P}$ & $\mathrm{P}$ & $\mathrm{P}$ & $\mathrm{P}$ \\
\hline G.S.M. & II & 12,58 & $\mathrm{M}$ & $P$ & $\mathrm{P}$ & $P$ & $\mathrm{P}$ & $\mathrm{P}$ & $\mathrm{P}$ & $\mathrm{P}$ & $\mathrm{P}$ & $\mathrm{P}$ & $P$ & $\mathrm{P}$ & $\mathrm{P}$ & $\mathrm{P}$ & $\mathrm{P}$ \\
\hline A.G.M. & II & 12,75 & $\mathrm{M}$ & - & $\mathrm{P}$ & $\mathrm{P}$ & $\mathrm{P}$ & $\mathrm{P}$ & $\mathrm{P}$ & $\mathrm{P}$ & $P$ & $\mathrm{P}$ & $\mathrm{P}$ & $\mathrm{P}$ & $P$ & $\mathrm{P}$ & \\
\hline G.R.P. & II & 12,33 & $\mathrm{~F}$ & $P$ & $\mathrm{P}$ & $P$ & $P$ & $\mathrm{P}$ & $\mathrm{P}$ & \begin{tabular}{|l|}
$\mathrm{P}$ \\
\end{tabular} & $P$ & $\mathrm{P}$ & $P$ & $P$ & $P$ & $\mathrm{P}$ & $\mathrm{P}$ \\
\hline
\end{tabular}


TABELA A-18

\begin{tabular}{|c|c|c|c|c|c|c|c|c|c|c|c|c|c|c|c|c|c|}
\hline Nome & Classe & Idade & Gênero & 37 & 36 & 35 & 34 & 33 & 32 & 31 & 41 & 42 & 43 & 44 & 45 & 46 & 47 \\
\hline A.C.M. & $\mathrm{I}$ & 12,58 & $\mathrm{~F}$ & $\mathrm{P}$ & $\mathrm{P}$ & $\mathrm{P}$ & $\mathrm{P}$ & $\mathrm{P}$ & $\mathrm{P}$ & $\mathrm{P}$ & $\mathrm{P}$ & $\mathrm{P}$ & $\mathrm{P}$ & $\mathrm{P}$ & $\mathrm{P}$ & $\mathrm{P}$ & $P$ \\
\hline P.S.P.C. & $\mathrm{I}$ & 12,41 & $\mathrm{M}$ & $\mathrm{P}$ & $\mathrm{P}$ & $P$ & $P$ & $\mathrm{P}$ & $P$ & $\mathrm{P}$ & $P$ & $P$ & $P$ & $\mathrm{P}$ & $\mathrm{P}$ & $P$ & $P$ \\
\hline E.C.M. & $\mathrm{I}$ & 12,00 & $\mathrm{~F}$ & $\mathrm{P}$ & $\mathrm{P}$ & $P$ & $P$ & $P$ & $P$ & $P$ & $P$ & $P$ & $P$ & $P$ & $\mathrm{P}$ & $P$ & $P$ \\
\hline M.Q.B. & I & 12,00 & $\mathrm{M}$ & $\mathrm{P}$ & $\mathrm{P}$ & $\mathrm{P}$ & $\mathrm{P}$ & $\mathrm{P}$ & $\mathrm{P}$ & $\mathrm{P}$ & $P$ & $\mathrm{P}$ & $\mathrm{P}$ & $\mathrm{P}$ & $\mathrm{P}$ & $\mathrm{P}$ & $\mathrm{P}$ \\
\hline A.C.D. & I & 12,83 & $\mathrm{~F}$ & $\mathrm{P}$ & $\mathrm{P}$ & $\mathrm{P}$ & $\mathrm{P}$ & $\mathrm{P}$ & $\mathrm{P}$ & $\mathrm{P}$ & $\mathrm{P}$ & $\mathrm{P}$ & $\mathrm{P}$ & $\mathrm{P}$ & $\mathrm{P}$ & $\mathrm{P}$ & $P$ \\
\hline R.F.E. & $\mathrm{I}$ & 12,00 & $\bar{M}$ & $\mathrm{P}$ & $\mathrm{P}$ & $\mathrm{P}$ & $\mathrm{P}$ & $\mathrm{P}$ & $P$ & $\mathrm{P}$ & $\mathrm{P}$ & $\mathrm{P}$ & $\mathrm{P}$ & $\mathrm{P}$ & $\mathrm{P}$ & $\mathrm{P}$ & $P$ \\
\hline S.T.G. & I & 12,58 & $\mathrm{M}$ & - & $\mathrm{P}$ & $\mathrm{P}$ & $P$ & $P$ & $P$ & $P$ & $\mathrm{P}$ & $\mathrm{P}$ & $\mathrm{P}$ & $P$ & $P$ & $P$ & - \\
\hline M.P.P. & I & 12,58 & $\mathrm{~F}$ & $\mathrm{P}$ & $\mathrm{P}$ & - & $\mathrm{P}$ & $\mathrm{P}$ & $P$ & $\mathrm{P}$ & $\mathrm{P}$ & $\mathrm{P}$ & $\mathrm{P}$ & $\mathrm{P}$ & - & $\mathrm{P}$ & $P$ \\
\hline C.L.C. & I & 12,33 & $\mathrm{~F}$ & $\mathrm{P}$ & $\mathrm{P}$ & $\mathrm{P}$ & $\mathrm{P}$ & $\mathrm{P}$ & $P$ & $\mathrm{P}$ & $P$ & $\mathrm{P}$ & $\mathrm{P}$ & $\mathrm{P}$ & $\mathrm{P}$ & $\mathrm{P}$ & $P$ \\
\hline D.E.H. & I & 12,66 & $F$ & $\mathrm{P}$ & $\mathrm{P}$ & $\mathrm{P}$ & $\mathrm{P}$ & $\mathrm{P}$ & $\mathrm{P}$ & $\mathrm{P}$ & $\mathrm{P}$ & $\mathrm{P}$ & $\mathrm{P}$ & $\mathrm{P}$ & $\mathrm{P}$ & $\mathrm{P}$ & $P$ \\
\hline M.L.P. & $\mathrm{I}$ & 12,00 & $F$ & $\mathrm{P}$ & $\mathrm{P}$ & $\mathrm{P}$ & $\mathrm{P}$ & $\mathrm{P}$ & $P$ & $\mathrm{P}$ & $P$ & $\mathrm{P}$ & $\mathrm{P}$ & $\mathrm{P}$ & $\mathrm{P}$ & $\mathrm{P}$ & $\mathrm{P}$ \\
\hline A.P.M.B. & I & 12,00 & $\mathrm{~F}$ & $\mathrm{P}$ & $\mathrm{P}$ & $\mathrm{P}$ & $\mathrm{P}$ & $\mathrm{P}$ & $\mathrm{P}$ & $\mathrm{P}$ & $\mathrm{P}$ & $\mathrm{P}$ & $\mathrm{P}$ & $\mathrm{P}$ & $\mathrm{P}$ & $\mathrm{P}$ & $P$ \\
\hline P.S.E. & $\mathrm{I}$ & 12,50 & $\mathrm{~F}$ & $\mathrm{P}$ & $\mathrm{P}$ & - & $\mathrm{P}$ & $P$ & $P$ & $P$ & $P$ & $P$ & $\mathrm{P}$ & $P$ & $\mathrm{P}$ & $P$ & $P$ \\
\hline J.R.N. & $\mathrm{I}$ & 12,91 & $\mathrm{M}$ & $\mathrm{P}$ & $\mathrm{P}$ & $\mathrm{P}$ & $\mathrm{P}$ & $\mathrm{P}$ & $\mathrm{P}$ & $\mathrm{P}$ & $\mathrm{P}$ & $\mathrm{P}$ & $\mathrm{P}$ & $\mathrm{P}$ & $\mathrm{P}$ & $\mathrm{P}$ & $P$ \\
\hline E.L.C.S. & $\mathrm{I}$ & 12,08 & $\bar{M}$ & $\mathrm{P}$ & $\mathrm{P}$ & $\mathrm{P}$ & $\mathrm{P}$ & $\mathrm{P}$ & $\mathrm{P}$ & $\mathrm{P}$ & $\mathrm{P}$ & $\mathrm{P}$ & $\mathrm{P}$ & $\mathrm{P}$ & $\mathrm{P}$ & $\mathrm{P}$ & $\mathrm{P}$ \\
\hline E.A. & I & 12,83 & $\bar{M}$ & $\mathrm{P}$ & $\mathrm{P}$ & $\mathrm{P}$ & $\mathrm{P}$ & $\mathrm{P}$ & $\mathrm{P}$ & $\mathrm{P}$ & $\mathrm{P}$ & $\mathrm{P}$ & $\mathrm{P}$ & $\mathrm{P}$ & $\mathrm{P}$ & $\mathrm{P}$ & $P$ \\
\hline M.S. & $\mathrm{I}$ & 12,25 & $\bar{M}$ & $\mathrm{P}$ & $\mathrm{P}$ & $\mathrm{P}$ & $\mathrm{P}$ & $\mathrm{P}$ & $\mathrm{P}$ & $\mathrm{P}$ & $P$ & $\mathrm{P}$ & $\mathrm{P}$ & $\mathrm{P}$ & $\mathrm{P}$ & $\mathrm{P}$ & $\mathrm{P}$ \\
\hline R.C.L.A. & $\mathrm{I}$ & 12,33 & $\mathrm{~F}$ & $\mathrm{P}$ & $\mathrm{P}$ & $P$ & $\mathrm{P}$ & $P$ & $P$ & $P$ & $\mathrm{P}$ & $\mathrm{P}$ & $\mathrm{P}$ & $P$ & $\mathrm{P}$ & $P$ & $P$ \\
\hline C.S.D. & $\mathrm{I}$ & 12,08 & $\mathrm{~F}$ & $\mathrm{P}$ & $\mathrm{P}$ & $\mathrm{P}$ & $P$ & $\mathrm{P}$ & $\mathrm{P}$ & $\mathrm{P}$ & $P$ & $\mathrm{P}$ & $\mathrm{P}$ & $\mathrm{P}$ & $\mathrm{P}$ & $\mathrm{P}$ & $P$ \\
\hline D.C.G.O. & $\mathrm{I}$ & 12,33 & $\mathrm{~F}$ & $\mathrm{P}$ & $\mathrm{P}$ & $P$ & $\mathrm{P}$ & $\mathrm{P}$ & $\mathrm{P}$ & $\mathrm{P}$ & $\mathrm{P}$ & $\mathrm{P}$ & $\mathrm{P}$ & $\mathrm{P}$ & $\mathrm{P}$ & $\mathrm{P}$ & $P$ \\
\hline R.V.D. & $\mathrm{I}$ & 12,16 & $\bar{M}$ & $\mathrm{P}$ & $\mathrm{P}$ & $\mathrm{P}$ & $\mathrm{P}$ & $\mathrm{P}$ & $P$ & $\mathrm{P}$ & $\mathrm{P}$ & $\mathrm{P}$ & $\mathrm{P}$ & $\mathrm{P}$ & $\mathrm{P}$ & $\mathrm{P}$ & $P$ \\
\hline I.M.L. & $\mathrm{I}$ & 12,58 & $\mathrm{~F}$ & $\mathrm{P}$ & $\mathrm{P}$ & $\mathrm{P}$ & $\mathrm{P}$ & $\mathrm{P}$ & $\mathrm{P}$ & $\mathrm{P}$ & $\mathrm{P}$ & $\mathrm{P}$ & $\mathrm{P}$ & $\mathrm{P}$ & $\mathrm{P}$ & $\mathrm{P}$ & $\mathrm{P}$ \\
\hline A.P.B. & I & 12,66 & $\mathrm{~F}$ & $\mathrm{P}$ & $\mathrm{P}$ & $\mathrm{P}$ & $\mathrm{P}$ & $\mathrm{P}$ & $P$ & $\mathrm{P}$ & $\mathrm{P}$ & $\mathrm{P}$ & $\mathrm{P}$ & $\mathrm{P}$ & $\mathrm{P}$ & $P$ & $\mathrm{P}$ \\
\hline C.C.P. & $\mathrm{T}$ & 12,41 & $\mathrm{~F}$ & $\mathrm{P}$ & $\mathrm{P}$ & $\mathrm{P}$ & $\mathrm{P}$ & $\mathrm{P}$ & $\mathrm{P}$ & $\mathrm{P}$ & $\mathrm{P}$ & $\mathrm{P}$ & $\mathrm{P}$ & $\mathrm{P}$ & $\mathrm{P}$ & $\mathrm{P}$ & $P$ \\
\hline F.Z. & $\mathrm{I}$ & 12,66 & $\bar{M}$ & $\mathrm{P}$ & $\mathrm{P}$ & $\mathrm{P}$ & $\mathrm{P}$ & $\mathrm{P}$ & $\mathrm{P}$ & $\mathrm{P}$ & $\mathrm{P}$ & $\mathrm{P}$ & $\mathrm{P}$ & $\mathrm{P}$ & $\mathrm{P}$ & $\mathrm{P}$ & $P$ \\
\hline J.C.M.J. & II & 12,00 & $M$ & - & $\mathrm{P}$ & - & - & - & $P$ & $\mathrm{P}$ & $\mathrm{P}$ & $\mathrm{P}$ & $\mathrm{P}$ & $\mathrm{P}$ & $\mathrm{P}$ & $\mathrm{P}$ & - \\
\hline M.A.P.T. & II & 12,08 & $\bar{M}$ & $\mathrm{P}$ & $\mathrm{P}$ & $\mathrm{P}$ & $\mathrm{P}$ & $\mathrm{P}$ & $\mathrm{P}$ & $\mathrm{P}$ & $\mathrm{P}$ & $\mathrm{P}$ & $\mathrm{P}$ & $\mathrm{P}$ & $\mathrm{P}$ & $\mathrm{P}$ & $P$ \\
\hline P.B.J. & II & 12,83 & $\bar{M}$ & $\mathrm{P}$ & $\mathrm{P}$ & $\mathrm{P}$ & $\mathrm{P}$ & $\mathrm{P}$ & $\mathrm{P}$ & $\mathrm{P}$ & $\mathrm{P}$ & $\mathrm{P}$ & $\mathrm{P}$ & $\mathrm{P}$ & $\mathrm{P}$ & $\mathrm{P}$ & $\mathrm{P}$ \\
\hline R.G.M. & II & 12,25 & $\bar{M}$ & $\mathrm{P}$ & $\mathrm{P}$ & $P$ & $\mathrm{P}$ & $\mathrm{P}$ & $P$ & $\mathrm{P}$ & $\mathrm{P}$ & $P$ & $\mathrm{P}$ & $\mathrm{P}$ & $\mathrm{P}$ & $\mathrm{P}$ & $P$ \\
\hline T.C.C.C. & II & 12,00 & $F$ & $\mathrm{P}$ & $\mathrm{P}$ & $\mathrm{P}$ & $\mathrm{P}$ & $\mathrm{P}$ & $\mathrm{P}$ & $\mathrm{P}$ & $\mathrm{P}$ & $\mathrm{P}$ & $\mathrm{P}$ & $\mathrm{P}$ & $\mathrm{P}$ & $\mathrm{P}$ & $P$ \\
\hline R.A.S.S. & II & 12,41 & $F$ & - & $\mathrm{P}$ & $\mathrm{P}$ & $\mathrm{P}$ & $\mathrm{P}$ & $P$ & $\mathrm{P}$ & $\mathrm{P}$ & $\mathrm{P}$ & $\mathrm{P}$ & - & $\mathrm{P}$ & $\mathrm{P}$ & - \\
\hline R.B.R. & II & 12,25 & $F$ & - & $\mathrm{P}$ & $\mathrm{P}$ & $\mathrm{P}$ & $\mathrm{P}$ & $P$ & $\mathrm{P}$ & $\mathrm{P}$ & $\mathrm{P}$ & $\mathrm{P}$ & $\mathrm{P}$ & $\mathrm{P}$ & $\mathrm{P}$ & - \\
\hline F.B.A. & II & 12,41 & $\mathrm{~F}$ & $\mathrm{P}$ & $\mathrm{P}$ & $\mathrm{P}$ & $\mathrm{P}$ & $\mathrm{P}$ & $P$ & $\mathrm{P}$ & $P$ & $\mathrm{P}$ & $\mathrm{P}$ & $\mathrm{P}$ & $\mathrm{P}$ & $\mathrm{P}$ & - \\
\hline M.F.G. & II & 12,00 & $F$ & $\mathrm{P}$ & $\mathrm{P}$ & $\mathrm{P}$ & $\mathrm{P}$ & $\mathrm{P}$ & $\mathrm{P}$ & $\mathrm{P}$ & $\mathrm{P}$ & $\mathrm{P}$ & $\mathrm{P}$ & $\mathrm{P}$ & $\mathrm{P}$ & $\mathrm{P}$ & $P$ \\
\hline E.C.L. & II & 12,00 & $\mathrm{~F}$ & $\mathrm{P}$ & $\mathrm{P}$ & $\mathrm{P}$ & $\mathrm{P}$ & $\mathrm{P}$ & $\mathrm{P}$ & $\mathrm{P}$ & $\mathrm{P}$ & $\mathrm{P}$ & $\mathrm{P}$ & $\mathrm{P}$ & $\mathrm{P}$ & $\mathrm{P}$ & $\mathrm{P}$ \\
\hline J.A.M. & II & 12,91 & $\bar{M}$ & $\mathrm{P}$ & $\mathrm{P}$ & $\mathrm{P}$ & $P$ & $\mathrm{P}$ & $P$ & $P$ & $\mathrm{P}$ & $\mathrm{P}$ & $\mathrm{P}$ & $\mathrm{P}$ & $\mathrm{P}$ & $P$ & $P$ \\
\hline B.M.L. & II & 12,25 & $M$ & $\mathrm{P}$ & $\mathrm{P}$ & $\mathrm{P}$ & $P$ & $\mathrm{P}$ & $P$ & $P$ & $\mathrm{P}$ & $\mathrm{P}$ & $P$ & $\mathrm{P}$ & $P$ & $P$ & $P$ \\
\hline R.O.B.A. & II & 12,58 & $M$ & $\mathrm{P}$ & $\mathrm{P}$ & $\mathrm{P}$ & $\mathrm{P}$ & $\mathrm{P}$ & $P$ & $\mathrm{P}$ & $P$ & $P$ & $\mathrm{P}$ & $\mathrm{P}$ & $\mathrm{P}$ & $P$ & $P$ \\
\hline C.F.Z.S. & II & 12,08 & $\mathrm{~F}$ & $P$ & $P$ & $\mathrm{P}$ & $P$ & $\mathrm{P}$ & $P$ & $P$ & $P$ & $\mathrm{P}$ & $P$ & $\mathrm{P}$ & $P$ & $P$ & $P$ \\
\hline T.S.N.J. & II & 12,66 & $\bar{M}$ & - & $P$ & $\mathrm{P}$ & $P$ & $\mathrm{P}$ & $\mathrm{P}$ & $P$ & $\mathrm{P}$ & $\mathrm{P}$ & $P$ & $\mathrm{P}$ & $\mathrm{P}$ & $P$ & - \\
\hline E.F.Z. & II & 12,50 & $\mathrm{~F}$ & $\mathrm{P}$ & $P$ & $\mathrm{P}$ & $P$ & $P$ & $P$ & $P$ & $P$ & $\mathrm{P}$ & $P$ & $P$ & $\mathrm{P}$ & $P$ & - \\
\hline J.A.A.C. & II & 12,83 & $\bar{M}$ & $\mathrm{P}$ & $\mathrm{P}$ & $\mathrm{P}$ & $\mathrm{P}$ & $\mathrm{P}$ & $P$ & $\mathrm{P}$ & $\mathrm{P}$ & $\mathrm{P}$ & $\mathrm{P}$ & $\mathrm{P}$ & $\mathrm{P}$ & $P$ & $P$ \\
\hline P.B.B.M. & II & 12,91 & $F$ & $\mathrm{P}$ & $\mathrm{P}$ & $\mathrm{P}$ & $\mathrm{P}$ & $\mathrm{P}$ & $P$ & $\mathrm{P}$ & $P$ & $P$ & $\mathrm{P}$ & $\mathrm{P}$ & $\mathrm{P}$ & $P$ & $P$ \\
\hline M.H.T. & II & 12,25 & $\mathrm{~F}$ & $\mathrm{P}$ & $\mathrm{P}$ & $\mathrm{P}$ & $\mathrm{P}$ & $\mathrm{P}$ & $\mathrm{P}$ & $\mathrm{P}$ & $\mathrm{P}$ & $\mathrm{P}$ & $\mathrm{P}$ & $\mathrm{P}$ & - & $\mathrm{P}$ & - \\
\hline M.G.T. & II & 12,75 & $M$ & $\mathrm{P}$ & $\mathrm{P}$ & $\mathrm{P}$ & $\mathrm{P}$ & $\mathrm{P}$ & $\mathrm{P}$ & $\mathrm{P}$ & $\mathrm{P}$ & $\mathrm{P}$ & $\mathrm{P}$ & $\mathrm{P}$ & $\mathrm{P}$ & $\mathrm{P}$ & $P$ \\
\hline F.B. & II & 12,58 & $F$ & $\mathrm{P}$ & $\mathrm{P}$ & $P$ & $\mathrm{P}$ & $\mathrm{P}$ & $P$ & $\mathrm{P}$ & $P$ & $P$ & $P$ & $P$ & $\mathrm{P}$ & $\mathrm{P}$ & $P$ \\
\hline A.B.S.M. & II & 12,00 & $\mathrm{~F}$ & $\mathrm{P}$ & $\mathrm{P}$ & - & $\mathrm{P}$ & $\mathrm{P}$ & $\mathrm{P}$ & $\mathrm{P}$ & $\mathrm{P}$ & $\mathrm{P}$ & $\mathrm{P}$ & $\mathrm{P}$ & - & $\mathrm{P}$ & $P$ \\
\hline R.T.D.G. & II & 12,75 & $\mathrm{M}$ & $\mathrm{P}$ & $\mathrm{P}$ & $P$ & $\mathrm{P}$ & $\mathrm{P}$ & $\mathrm{P}$ & $\mathrm{P}$ & $\mathrm{P}$ & $P$ & $\mathrm{P}$ & $\mathrm{P}$ & $\mathrm{P}$ & $\mathrm{P}$ & $\mathrm{P}$ \\
\hline G.C.T.N. & II & 12,00 & $\bar{M}$ & - & $\mathrm{P}$ & $\mathrm{P}$ & $\mathrm{P}$ & $\mathrm{P}$ & $\mathrm{P}$ & $\mathrm{P}$ & $\mathrm{P}$ & $\mathrm{P}$ & $\mathrm{P}$ & $\mathrm{P}$ & $\mathrm{P}$ & $\mathrm{P}$ & - \\
\hline C.B.J. & II & 12,50 & $\mathrm{~F}$ & $\mathrm{P}$ & $\mathrm{P}$ & $\mathrm{P}$ & $\mathrm{P}$ & $\mathrm{P}$ & $\mathrm{P}$ & $\mathrm{P}$ & $P$ & $\mathrm{P}$ & $\mathrm{P}$ & $\mathrm{P}$ & $\mathrm{P}$ & $\mathrm{P}$ & $P$ \\
\hline D.A.M. & II & 12,58 & $\bar{M}$ & $P$ & $P$ & $P$ & $P$ & $P$ & $P$ & $P$ & $P$ & $P$ & $P$ & $P$ & $P$ & $P$ & $P$ \\
\hline L.B. & II & 12,66 & $\mathrm{~F}$ & $P$ & $P$ & $P$ & $P$ & $P$ & $P$ & $P$ & $\mathrm{P}$ & $P$ & $P$ & $P$ & $P$ & $P$ & $P$ \\
\hline G.S.M. & II & 12,58 & $\bar{M}$ & $P$ & $P$ & $P$ & $P$ & $P$ & $P$ & $P$ & $P$ & $P$ & $P$ & $P$ & $\mathrm{P}$ & $P$ & $P$ \\
\hline A.G.M. & II & 12,75 & $M$ & - & $\mathrm{P}$ & $\mathrm{P}$ & $\mathrm{P}$ & $\mathrm{P}$ & $\mathrm{P}$ & $\mathrm{P}$ & $P$ & $\mathrm{P}$ & $\mathrm{P}$ & $\mathrm{P}$ & $\mathrm{P}$ & $\mathrm{P}$ & - \\
\hline G.R.P. & II & 12,33 & $\mathrm{~F}$ & $\mathrm{P}$ & $\mathrm{P}$ & $\mathrm{P}$ & $\mathrm{P}$ & $\mathrm{P}$ & $\mathrm{P}$ & $\mathrm{P}$ & $P$ & $\mathrm{P}$ & $\mathrm{P}$ & $\mathrm{P}$ & $\mathrm{P}$ & $\mathrm{P}$ & $P$ \\
\hline
\end{tabular}


TABELA A-19

\begin{tabular}{|c|c|c|c|c|c|c|c|c|c|c|c|c|c|c|c|c|c|}
\hline Nome & Classe & Idade & Gênero & 17 & 16 & 15 & 14 & 13 & 12 & 11 & 21 & 22 & 23 & 24 & 25 & 26 & 27 \\
\hline R.A.A. & 1 & 13,83 & $M$ & $P$ & $P$ & $\mathrm{P}$ & $\mathrm{P}$ & $\mathrm{P}$ & $\mathrm{P}$ & $P$ & $\mathrm{P}$ & $P$ & $\mathrm{P}$ & $P$ & $\mathrm{P}$ & $\mathrm{P}$ & $P$ \\
\hline D.F.D & $\mathrm{I}$ & 13,16 & $\bar{M}$ & $\mathrm{P}$ & $\mathrm{P}$ & $P$ & $\mathrm{P}$ & $\mathrm{P}$ & $P$ & $\mathrm{P}$ & $P$ & $P$ & $P$ & $\mathrm{P}$ & $\mathrm{P}$ & $\mathrm{P}$ & $P$ \\
\hline A.C.M. & $\mathrm{I}$ & 13,00 & $\mathrm{~F}$ & $\mathrm{P}$ & $\mathrm{P}$ & $\mathrm{P}$ & $\mathrm{P}$ & $\mathrm{P}$ & $\mathrm{P}$ & $\mathrm{P}$ & $\mathrm{P}$ & $\mathrm{P}$ & $\mathrm{P}$ & $\mathrm{P}$ & $\mathrm{P}$ & $\mathrm{P}$ & $\mathrm{P}$ \\
\hline E.C.M. & $\mathrm{I}$ & 13,00 & $\mathrm{~F}$ & $\mathrm{P}$ & $\mathrm{P}$ & $\mathrm{P}$ & $\mathrm{P}$ & $\mathrm{P}$ & $\mathrm{P}$ & $\mathrm{P}$ & $P$ & $\mathrm{P}$ & $\mathrm{P}$ & $\mathrm{P}$ & $\mathrm{P}$ & $\mathrm{P}$ & $\mathrm{P}$ \\
\hline M.Q.B. & I & 13,00 & $M$ & $\mathrm{P}$ & $\mathrm{P}$ & $\mathrm{P}$ & $\mathrm{P}$ & $\mathrm{P}$ & $P$ & $\mathrm{P}$ & $\mathrm{P}$ & $\mathrm{P}$ & $\mathrm{P}$ & $\mathrm{P}$ & $\mathrm{P}$ & $P$ & $\mathrm{P}$ \\
\hline A.C.D. & $\mathrm{I}$ & 13,00 & $\mathrm{~F}$ & $\mathrm{P}$ & $\mathrm{P}$ & $P$ & $P$ & $\mathrm{P}$ & $P$ & $P$ & $\mathrm{P}$ & $P$ & $\mathrm{P}$ & $P$ & $\mathrm{P}$ & $P$ & $P$ \\
\hline F.S. & I & 13,50 & $\mathrm{M}$ & $\mathrm{P}$ & $\mathrm{P}$ & $\mathrm{P}$ & $\mathrm{P}$ & $\mathrm{P}$ & $\mathrm{P}$ & $\mathrm{P}$ & $P$ & $\mathrm{P}$ & - & $\mathrm{P}$ & $\mathrm{P}$ & $\mathrm{P}$ & $\mathrm{P}$ \\
\hline R.F.E. & $\mathrm{I}$ & 13,00 & $\bar{M}$ & $\mathrm{P}$ & $\mathrm{P}$ & $\mathrm{P}$ & $\mathrm{P}$ & $\mathrm{P}$ & $\mathrm{P}$ & $\mathrm{P}$ & $\mathrm{P}$ & $\mathrm{P}$ & $\mathrm{P}$ & $\mathrm{P}$ & $\mathrm{P}$ & $\mathrm{P}$ & $\mathrm{P}$ \\
\hline S.T.G. & $\mathrm{I}$ & 13,00 & $\bar{M}$ & $\mathrm{P}$ & $\mathrm{P}$ & $\mathrm{P}$ & $\mathrm{P}$ & $\mathrm{P}$ & $\mathrm{P}$ & $\mathrm{P}$ & $\mathrm{P}$ & $\mathrm{P}$ & $\mathrm{P}$ & $\mathrm{P}$ & $\mathrm{P}$ & $\mathrm{P}$ & $P$ \\
\hline M.P.P. & $T$ & 13,58 & $\mathrm{~F}$ & $\mathrm{P}$ & $\mathrm{P}$ & $\mathrm{P}$ & $\mathrm{P}$ & $\mathrm{P}$ & $\mathrm{P}$ & $\mathrm{P}$ & $\bar{P}$ & $\mathrm{P}$ & $\mathrm{P}$ & $\mathrm{P}$ & $\mathrm{P}$ & $\mathrm{P}$ & $P$ \\
\hline C.L.C. & $\mathrm{T}$ & 13,25 & $\mathrm{~F}$ & $P$ & $\mathrm{P}$ & $P$ & $P$ & $P$ & $P$ & $P$ & $P$ & $P$ & $P$ & $P$ & $P$ & $P$ & $P$ \\
\hline D.E.H. & 1 & 13,66 & $\mathrm{~F}$ & $\mathrm{P}$ & $\mathrm{P}$ & $\mathrm{P}$ & $\mathrm{P}$ & $\mathrm{P}$ & $\mathrm{P}$ & $\mathrm{P}$ & $P$ & $\mathrm{P}$ & $\mathrm{P}$ & $\mathrm{P}$ & $\mathrm{P}$ & $\mathrm{P}$ & $\mathrm{P}$ \\
\hline M.L.P. & $\mathrm{I}$ & 13,00 & $\mathrm{~F}$ & $\mathrm{P}$ & $P$ & $\mathrm{P}$ & $\mathrm{P}$ & $\mathrm{P}$ & $\mathrm{P}$ & $\mathrm{P}$ & $\mathrm{P}$ & $\mathrm{P}$ & $\mathrm{P}$ & $\mathrm{P}$ & $\mathrm{P}$ & $\mathrm{P}$ & $\mathrm{P}$ \\
\hline A.P.M.B. & 1 & 13,00 & $\mathrm{~F}$ & $\mathrm{P}$ & $\mathrm{P}$ & $\mathrm{P}$ & $\mathrm{P}$ & $\mathrm{P}$ & $\mathrm{P}$ & $\mathrm{P}$ & $P$ & $\mathrm{P}$ & $\mathrm{P}$ & $\mathrm{P}$ & $\mathrm{P}$ & $\mathrm{P}$ & $\mathrm{P}$ \\
\hline P.S.E. & $\mathrm{I}$ & 13,50 & $\mathrm{~F}$ & $\mathrm{P}$ & $\mathrm{P}$ & $\mathrm{P}$ & $\mathrm{P}$ & $\mathrm{P}$ & $\mathrm{P}$ & $\mathrm{P}$ & $\mathrm{P}$ & $\mathrm{P}$ & $\mathrm{P}$ & $\mathrm{P}$ & $\mathrm{P}$ & $\mathrm{P}$ & $\mathrm{P}$ \\
\hline J.R.N. & I & 13,91 & $M$ & $\mathrm{P}$ & $\mathrm{P}$ & $\mathrm{P}$ & $\mathrm{P}$ & $\mathrm{P}$ & $P$ & $P$ & $\mathrm{P}$ & $\mathrm{P}$ & $\mathrm{P}$ & $\mathrm{P}$ & $\mathrm{P}$ & $P$ & $\mathrm{P}$ \\
\hline E.L.C.S. & $\mathrm{I}$ & 13,41 & $\bar{M}$ & $\mathrm{P}$ & $\mathrm{P}$ & $\mathrm{P}$ & $\mathrm{P}$ & $\mathrm{P}$ & $\mathrm{P}$ & $\mathrm{P}$ & $\mathrm{P}$ & $\mathrm{P}$ & $\mathrm{P}$ & $\mathrm{P}$ & $\mathrm{P}$ & $\mathrm{P}$ & $\mathrm{P}$ \\
\hline E.A. & $\mathrm{I}$ & 13,83 & $\bar{M}$ & $\mathrm{P}$ & $P$ & $\mathrm{P}$ & $\mathrm{P}$ & $\mathrm{P}$ & $\mathrm{P}$ & $\mathrm{P}$ & $\mathrm{P}$ & $\mathrm{P}$ & $\mathrm{P}$ & $\mathrm{P}$ & $\mathrm{P}$ & $\mathrm{P}$ & $\mathrm{P}$ \\
\hline M.S. & $\mathrm{I}$ & 13,25 & $M$ & $\mathrm{P}$ & $\mathrm{P}$ & $\mathrm{P}$ & $\mathrm{P}$ & $\mathrm{P}$ & $P$ & $\mathrm{P}$ & $\mathrm{P}$ & $\mathrm{P}$ & $\mathrm{P}$ & $\mathrm{P}$ & $\mathrm{P}$ & $\mathrm{P}$ & $P$ \\
\hline A.L.T.P. & $\mathrm{I}$ & 13,00 & $\mathrm{~F}$ & $\mathrm{P}$ & $\mathrm{P}$ & $\mathrm{P}$ & $\mathrm{P}$ & $\mathrm{P}$ & $\mathrm{P}$ & $\mathrm{P}$ & $\mathrm{P}$ & $\mathrm{P}$ & $\mathrm{P}$ & $\mathrm{P}$ & $\mathrm{P}$ & $\mathrm{P}$ & - \\
\hline R.C.L.A. & 1 & 13,33 & $\mathrm{~F}$ & $\mathrm{P}$ & $\mathrm{P}$ & $\mathrm{P}$ & $\mathrm{P}$ & $\mathrm{P}$ & $\mathrm{P}$ & $\mathrm{P}$ & $\mathrm{P}$ & $\mathrm{P}$ & $\mathrm{P}$ & $\mathrm{P}$ & $\mathrm{P}$ & $\mathrm{P}$ & $\mathrm{P}$ \\
\hline C.S.D. & $\mathrm{I}$ & 13,08 & $\mathrm{~F}$ & $\mathrm{P}$ & $\mathrm{P}$ & $\mathrm{P}$ & $\mathrm{P}$ & $\mathrm{P}$ & $\mathrm{P}$ & $\mathrm{P}$ & $\mathrm{P}$ & $\mathrm{P}$ & $\mathrm{P}$ & $\mathrm{P}$ & $\mathrm{P}$ & $\mathrm{P}$ & $\mathrm{P}$ \\
\hline D.C.G.O. & $\mathrm{I}$ & 13,33 & $\mathrm{~F}$ & $\mathrm{P}$ & $P$ & $\mathrm{P}$ & $\mathrm{P}$ & $\mathrm{P}$ & $\mathrm{P}$ & $\mathrm{P}$ & $\mathrm{P}$ & $\mathrm{P}$ & $\mathrm{P}$ & $\mathrm{P}$ & $\mathrm{P}$ & $\mathrm{P}$ & $P$ \\
\hline R.V.D. & $\mathrm{I}$ & 13,16 & $\bar{M}$ & $\mathrm{P}$ & $\mathrm{P}$ & $\mathrm{P}$ & $\mathrm{P}$ & $\mathrm{P}$ & $\mathrm{P}$ & $\mathrm{P}$ & $\mathrm{P}$ & $\mathrm{P}$ & $\mathrm{P}$ & $\mathrm{P}$ & $P$ & $\mathrm{P}$ & $P$ \\
\hline I.M.L. & $\mathrm{I}$ & 13,58 & $\mathrm{~F}$ & $\mathrm{P}$ & $\mathrm{P}$ & $\mathrm{P}$ & $\mathrm{P}$ & $\mathrm{P}$ & $\mathrm{P}$ & $\mathrm{P}$ & $\mathrm{P}$ & $\mathrm{P}$ & $\mathrm{P}$ & $\mathrm{P}$ & $\mathrm{P}$ & $\mathrm{P}$ & $\mathrm{P}$ \\
\hline A.P.B. & I & 13,66 & $\mathrm{~F}$ & $\mathrm{P}$ & $\mathrm{P}$ & $\mathrm{P}$ & $\mathrm{P}$ & $\mathrm{P}$ & $\mathrm{P}$ & $\mathrm{P}$ & $\mathrm{P}$ & $\mathrm{P}$ & $\mathrm{P}$ & $\mathrm{P}$ & $\mathrm{P}$ & $\mathrm{P}$ & $\mathrm{P}$ \\
\hline C.C.P. & 1 & 13,41 & $\mathrm{~F}$ & $\mathrm{P}$ & $\mathrm{P}$ & $\mathrm{P}$ & $\mathrm{P}$ & $\mathrm{P}$ & $\mathrm{P}$ & $\mathrm{P}$ & $\mathrm{P}$ & $\mathrm{P}$ & $\mathrm{P}$ & $\mathrm{P}$ & $\mathrm{P}$ & $\mathrm{P}$ & $\mathrm{P}$ \\
\hline F.Z. & $\mathrm{I}$ & 13,66 & $\bar{M}$ & $\mathrm{P}$ & $\mathrm{P}$ & $\mathrm{P}$ & $\mathrm{P}$ & $\mathrm{P}$ & $\mathrm{P}$ & $\mathrm{P}$ & $\mathrm{P}$ & $\mathrm{P}$ & $\mathrm{P}$ & $\mathrm{P}$ & $\mathrm{P}$ & $\mathrm{P}$ & $\mathrm{P}$ \\
\hline J.C.M.J. & II & 13,00 & $\bar{M}$ & $\mathrm{P}$ & $\mathrm{P}$ & $\mathrm{P}$ & $\mathrm{P}$ & $\mathrm{P}$ & $\mathrm{P}$ & $\mathrm{P}$ & $\mathrm{P}$ & $\mathrm{P}$ & $\mathrm{P}$ & $\mathrm{P}$ & $\mathrm{P}$ & $\mathrm{P}$ & $P$ \\
\hline M.A.P.T. & II & 13,00 & $M$ & $\mathrm{P}$ & $\mathrm{P}$ & $\mathrm{P}$ & $\mathrm{P}$ & $\mathrm{P}$ & $\mathrm{P}$ & $\mathrm{P}$ & $\mathrm{P}$ & $\mathrm{P}$ & $P$ & $\mathrm{P}$ & $P$ & $P$ & $P$ \\
\hline P.B.J. & II & 13,75 & $M$ & $\mathrm{P}$ & $P$ & $\mathrm{P}$ & $\mathrm{P}$ & - & $\mathrm{P}$ & $\mathrm{P}$ & $\mathrm{P}$ & $\mathrm{P}$ & $\mathrm{P}$ & $\mathrm{P}$ & $\mathrm{P}$ & $\mathrm{P}$ & $\mathrm{P}$ \\
\hline R.G.M. & II & 13,33 & $\bar{M}$ & $\mathrm{P}$ & $\mathrm{P}$ & $P$ & $\mathrm{P}$ & $\mathrm{P}$ & $P$ & $P$ & $\mathrm{P}$ & $P$ & $\mathrm{P}$ & $P$ & $P$ & $P$ & $P$ \\
\hline T.C.C.C. & II & 13,00 & $\mathrm{~F}$ & $\mathrm{P}$ & $\mathrm{P}$ & $\mathrm{P}$ & $\mathrm{P}$ & $\mathrm{P}$ & $\mathrm{P}$ & $\mathrm{P}$ & $P$ & $\mathrm{P}$ & $\mathrm{P}$ & $\mathrm{P}$ & $\mathrm{P}$ & $\mathrm{P}$ & $\mathrm{P}$ \\
\hline M.F.G. & II & 13,00 & $F$ & $\mathrm{P}$ & $\mathrm{P}$ & $\mathrm{P}$ & $\mathrm{P}$ & $\mathrm{P}$ & $\mathrm{P}$ & $\mathrm{P}$ & $\mathrm{P}$ & $\mathrm{P}$ & $\mathrm{P}$ & $\mathrm{P}$ & $\mathrm{P}$ & $\mathrm{P}$ & $\mathrm{P}$ \\
\hline R.P.F. & II & 13,91 & $\bar{M}$ & $\mathrm{P}$ & $\mathrm{P}$ & $\mathrm{P}$ & $\mathrm{P}$ & $\mathrm{P}$ & $P$ & $\mathrm{P}$ & $P$ & $\mathrm{P}$ & $\mathrm{P}$ & $\mathrm{P}$ & $\mathrm{P}$ & $\mathrm{P}$ & $P$ \\
\hline E.C.L. & II & 13,00 & $F$ & $\mathrm{P}$ & $P$ & $\mathrm{P}$ & $\mathrm{P}$ & $\mathrm{P}$ & $P$ & $\mathrm{P}$ & $\mathrm{P}$ & $\mathrm{P}$ & $\mathrm{P}$ & $\mathrm{P}$ & $\mathrm{P}$ & $\mathrm{P}$ & $P$ \\
\hline J.A.M. & II & 13,91 & $M$ & $\mathrm{P}$ & $\mathrm{P}$ & $\mathrm{P}$ & $\mathrm{P}$ & $\mathrm{P}$ & $\mathrm{P}$ & $\mathrm{P}$ & $\mathrm{P}$ & $\mathrm{P}$ & $\mathrm{P}$ & $\mathrm{P}$ & $\mathrm{P}$ & $\mathrm{P}$ & $P$ \\
\hline B.M.L. & II & 13,25 & $\bar{M}$ & $\mathrm{P}$ & $\mathrm{P}$ & $\mathrm{P}$ & $\mathrm{P}$ & $\mathrm{P}$ & $\mathrm{P}$ & $\mathrm{P}$ & $\mathrm{P}$ & $\mathrm{P}$ & $\mathrm{P}$ & $\mathrm{P}$ & $\mathrm{P}$ & $\mathrm{P}$ & $P$ \\
\hline R.O.B.A. & II & 13,00 & $\bar{M}$ & $\mathrm{P}$ & $P$ & $\mathrm{P}$ & $\mathrm{P}$ & $\mathrm{P}$ & $P$ & $\mathrm{P}$ & $P$ & $\mathrm{P}$ & $\mathrm{P}$ & $\mathrm{P}$ & $\mathrm{P}$ & $\mathrm{P}$ & $P$ \\
\hline C.F.Z.S. & II & 13,00 & $\mathrm{~F}$ & $\mathrm{P}$ & $\mathrm{P}$ & $\mathrm{P}$ & $\mathrm{P}$ & $\mathrm{P}$ & $\mathrm{P}$ & $\mathrm{P}$ & $\mathrm{P}$ & $\mathrm{P}$ & $\mathrm{P}$ & $\mathrm{P}$ & $\mathrm{P}$ & $P$ & $P$ \\
\hline J.A.A.C. & II & 13,91 & $\mathrm{M}$ & $\mathrm{P}$ & $P$ & $\mathrm{P}$ & $\mathrm{P}$ & $\mathrm{P}$ & $P$ & $\mathrm{P}$ & $\mathrm{P}$ & $\mathrm{P}$ & $\mathrm{P}$ & $\mathrm{P}$ & $\mathrm{P}$ & $P$ & $\mathrm{P}$ \\
\hline P.B.B.M. & II & 13,83 & $\mathrm{~F}$ & $\mathrm{P}$ & $\mathrm{P}$ & $\mathrm{P}$ & $\mathrm{P}$ & $\mathrm{P}$ & $\mathrm{P}$ & $\mathrm{P}$ & $\mathrm{P}$ & $\mathrm{P}$ & $\mathrm{P}$ & $\mathrm{P}$ & $\mathrm{P}$ & $\mathrm{P}$ & $\mathrm{P}$ \\
\hline M.H.T. & II & 13,33 & $F$ & - & $P$ & $\mathrm{P}$ & $\mathrm{P}$ & $\mathrm{P}$ & $P$ & $\mathrm{P}$ & $P$ & $P$ & $\mathrm{P}$ & $\mathrm{P}$ & $\mathrm{P}$ & $\mathrm{P}$ & - \\
\hline M.G.T. & II & 13,66 & $\mathrm{M}$ & $\mathrm{P}$ & $\mathrm{P}$ & $\mathrm{P}$ & $\mathrm{P}$ & $\mathrm{P}$ & $\mathrm{P}$ & $\mathrm{P}$ & $P$ & $\mathrm{P}$ & $\mathrm{P}$ & $\mathrm{P}$ & $\mathrm{P}$ & $\mathrm{P}$ & $P$ \\
\hline F.B. & II & 13,58 & $F$ & $\mathrm{P}$ & $\mathrm{P}$ & $\mathrm{P}$ & $\mathrm{P}$ & $\mathrm{P}$ & $P$ & $\mathrm{P}$ & $\mathrm{P}$ & $\mathrm{P}$ & $\mathrm{P}$ & $\mathrm{P}$ & $\mathrm{P}$ & $P$ & $\mathrm{P}$ \\
\hline R.T.D.G. & II & 13,91 & $\bar{M}$ & $\mathrm{P}$ & $\mathrm{P}$ & $P$ & $P$ & $\mathrm{P}$ & $P$ & $P$ & $\mathrm{P}$ & $\mathrm{P}$ & $P$ & $P$ & $\mathrm{P}$ & $P$ & $P$ \\
\hline A.B.S.M. & II & 13,00 & $F$ & $\mathrm{P}$ & $\mathrm{P}$ & $\mathrm{P}$ & $\mathrm{P}$ & - & $\mathrm{P}$ & $\mathrm{P}$ & $\mathrm{P}$ & $\mathrm{P}$ & - & $\mathrm{P}$ & $\mathrm{P}$ & $\mathrm{P}$ & $P$ \\
\hline C.B.J. & II & 13,58 & $\mathrm{~F}$ & $\mathrm{P}$ & $\mathrm{P}$ & $\mathrm{P}$ & $\mathrm{P}$ & $\mathrm{P}$ & $\mathrm{P}$ & $\mathrm{P}$ & $\mathrm{P}$ & $\mathrm{P}$ & $\mathrm{P}$ & $\mathrm{P}$ & $\mathrm{P}$ & $\mathrm{P}$ & $\mathrm{P}$ \\
\hline G.C.T.N. & II & 13,00 & $\bar{M}$ & - & $\mathrm{P}$ & $P$ & $P$ & $\mathrm{P}$ & $\mathrm{P}$ & $\mathrm{P}$ & $P$ & $P$ & $P$ & $\mathrm{P}$ & $\mathrm{P}$ & $\mathrm{P}$ & - \\
\hline D.A.M. & II & 13,66 & $\bar{M}$ & $\mathrm{P}$ & $\mathrm{P}$ & $\mathrm{P}$ & $\mathrm{P}$ & $\mathrm{P}$ & $\mathrm{P}$ & $\mathrm{P}$ & $\mathrm{P}$ & $\mathrm{P}$ & $\mathrm{P}$ & $\mathrm{P}$ & $\mathrm{P}$ & $\mathrm{P}$ & $P$ \\
\hline A.L.M. & II & 13,58 & $F$ & $\mathrm{P}$ & $\mathrm{P}$ & $\mathrm{P}$ & $P$ & $\mathrm{P}$ & $\mathrm{P}$ & $P$ & $P$ & $P$ & $P$ & $\mathrm{P}$ & $\mathrm{P}$ & $P$ & $P$ \\
\hline G.S.M. & II & 13,50 & $M$ & $\mathrm{P}$ & $P$ & $\mathrm{P}$ & $\mathrm{P}$ & $\mathrm{P}$ & $\mathrm{P}$ & $\mathrm{P}$ & $\mathrm{P}$ & $\mathrm{P}$ & $\mathrm{P}$ & $\mathrm{P}$ & $\mathrm{P}$ & $\mathrm{P}$ & $\mathrm{P}$ \\
\hline G.R.P. & II & 13,33 & $\mathrm{~F}$ & $\mathrm{P}$ & $\mathrm{P}$ & $P$ & $P$ & $P$ & $\mathrm{P}$ & $\mathrm{P}$ & $\mathrm{P}$ & $P$ & $P$ & $P$ & $P$ & $P$ & $P$ \\
\hline
\end{tabular}


TABELA A-20

\begin{tabular}{|c|c|c|c|c|c|c|c|c|c|c|c|c|c|c|c|c|c|}
\hline Nome & Classe & Idade & Gênero & 37 & 36 & 35 & 34 & 33 & 32 & 31 & 41 & 42 & 43 & 44 & 45 & 46 & 47 \\
\hline R.A.A. & $\mathrm{I}$ & 13,83 & $\bar{M}$ & $\mathrm{P}$ & $\mathrm{P}$ & $\mathrm{P}$ & $\mathrm{P}$ & $\mathrm{P}$ & $P$ & $\mathrm{P}$ & $P$ & $P$ & $\mathrm{P}$ & $\mathrm{P}$ & $\mathrm{P}$ & $P$ & $\mathrm{P}$ \\
\hline D.F.D & $\mathrm{I}$ & 13,16 & $\bar{M}$ & $\mathrm{P}$ & $\mathrm{P}$ & $P$ & $\mathrm{P}$ & $\mathrm{P}$ & $P$ & $\mathrm{P}$ & $P$ & $P$ & $P$ & $\mathrm{P}$ & $\mathrm{P}$ & $\mathrm{P}$ & $\mathrm{P}$ \\
\hline A.C.M. & $\mathrm{I}$ & 13,00 & $\mathrm{~F}$ & $\mathrm{P}$ & $\mathrm{P}$ & $\mathrm{P}$ & $\mathrm{P}$ & $\mathrm{P}$ & $\mathrm{P}$ & $\mathrm{P}$ & $\mathrm{P}$ & $\mathrm{P}$ & $\mathrm{P}$ & $P$ & $\mathrm{P}$ & $\mathrm{P}$ & $\mathrm{P}$ \\
\hline E.C.M. & $\mathrm{I}$ & 13,00 & $\mathrm{~F}$ & $\mathrm{P}$ & $\mathrm{P}$ & $\mathrm{P}$ & $\mathrm{P}$ & $\mathrm{P}$ & $\mathrm{P}$ & $\mathrm{P}$ & $P$ & $\mathrm{P}$ & $\mathrm{P}$ & $\mathrm{P}$ & $\mathrm{P}$ & $\mathrm{P}$ & $\mathrm{P}$ \\
\hline M.Q.B. & I & 13,00 & $M$ & $\mathrm{P}$ & $\mathrm{P}$ & $\mathrm{P}$ & $\mathrm{P}$ & $\mathrm{P}$ & $\mathrm{P}$ & $\mathrm{P}$ & $\mathrm{P}$ & $\mathrm{P}$ & $\mathrm{P}$ & $\mathrm{P}$ & $\mathrm{P}$ & $P$ & $\mathrm{P}$ \\
\hline A.C.D. & $\mathrm{I}$ & 13,00 & $\mathrm{~F}$ & $\mathrm{P}$ & $\mathrm{P}$ & $P$ & $P$ & $P$ & $P$ & $P$ & $\mathrm{P}$ & $P$ & $\mathrm{P}$ & $P$ & $\mathrm{P}$ & $P$ & $\mathrm{P}$ \\
\hline F.S. & I & 13,50 & $\mathrm{M}$ & $\mathrm{P}$ & $\mathrm{P}$ & $\mathrm{P}$ & $\mathrm{P}$ & $\mathrm{P}$ & $\mathrm{P}$ & $\mathrm{P}$ & $P$ & $\mathrm{P}$ & $\mathrm{P}$ & $\mathrm{P}$ & $\mathrm{P}$ & $\mathrm{P}$ & $\mathrm{P}$ \\
\hline R.F.E. & $\mathrm{I}$ & 13,00 & $\bar{M}$ & $\mathrm{P}$ & $\mathrm{P}$ & $\mathrm{P}$ & $\mathrm{P}$ & $\mathrm{P}$ & $\mathrm{P}$ & $\mathrm{P}$ & $\mathrm{P}$ & $\mathrm{P}$ & $\mathrm{P}$ & $P$ & $\mathrm{P}$ & $\mathrm{P}$ & $\mathrm{P}$ \\
\hline S.T.G. & $\mathrm{I}$ & 13,00 & $\bar{M}$ & $\mathrm{P}$ & $\mathrm{P}$ & $\mathrm{P}$ & $\mathrm{P}$ & $\mathrm{P}$ & $\mathrm{P}$ & $\mathrm{P}$ & $\mathrm{P}$ & $\mathrm{P}$ & $\mathrm{P}$ & $P$ & $\mathrm{P}$ & $\mathrm{P}$ & $\mathrm{P}$ \\
\hline M.P.P. & $\mathrm{I}$ & 13,58 & $\mathrm{~F}$ & $\mathrm{P}$ & $\mathrm{P}$ & - & $\mathrm{P}$ & $\mathrm{P}$ & $\mathrm{P}$ & $\mathrm{P}$ & $\mathrm{P}$ & $\mathrm{P}$ & $\mathrm{P}$ & $\mathrm{P}$ & - & $\mathrm{P}$ & $P$ \\
\hline C.L.C. & 1 & 13,25 & $\mathrm{~F}$ & $\mathrm{P}$ & $\mathrm{P}$ & $\mathrm{P}$ & $\mathrm{P}$ & $\mathrm{P}$ & $\mathrm{P}$ & $\mathrm{P}$ & $\mathrm{P}$ & $P$ & $P$ & $P$ & $\mathrm{P}$ & $P$ & $\mathrm{P}$ \\
\hline D.E.H. & 1 & 13,66 & $\mathrm{~F}$ & $\mathrm{P}$ & $\mathrm{P}$ & $\mathrm{P}$ & $\mathrm{P}$ & $\mathrm{P}$ & $\mathrm{P}$ & $\mathrm{P}$ & $P$ & $\mathrm{P}$ & $\mathrm{P}$ & $\mathrm{P}$ & $\mathrm{P}$ & $\mathrm{P}$ & $P$ \\
\hline M.L.P. & $\mathrm{I}$ & 13,00 & $\mathrm{~F}$ & $\mathrm{P}$ & $P$ & $\mathrm{P}$ & $\mathrm{P}$ & $\mathrm{P}$ & $\mathrm{P}$ & $\mathrm{P}$ & $\mathrm{P}$ & $\mathrm{P}$ & $\mathrm{P}$ & $P$ & $\mathrm{P}$ & $\mathrm{P}$ & $P$ \\
\hline A.P.M.B. & 1 & 13,00 & $\mathrm{~F}$ & $\mathrm{P}$ & $\mathrm{P}$ & $\mathrm{P}$ & $\mathrm{P}$ & $\mathrm{P}$ & $\mathrm{P}$ & $\mathrm{P}$ & $P$ & $\mathrm{P}$ & $\mathrm{P}$ & $\mathrm{P}$ & $\mathrm{P}$ & $\mathrm{P}$ & $P$ \\
\hline P.S.E. & $\mathrm{I}$ & 13,50 & $\mathrm{~F}$ & $\mathrm{P}$ & $\mathrm{P}$ & $\mathrm{P}$ & $\mathrm{P}$ & $\mathrm{P}$ & $\mathrm{P}$ & $\mathrm{P}$ & $\mathrm{P}$ & $\mathrm{P}$ & $\mathrm{P}$ & $\mathrm{P}$ & $\mathrm{P}$ & $\mathrm{P}$ & $P$ \\
\hline J.R.N. & I & 13,91 & $M$ & $\mathrm{P}$ & $\mathrm{P}$ & $\mathrm{P}$ & $\mathrm{P}$ & $\mathrm{P}$ & $\mathrm{P}$ & $P$ & $\mathrm{P}$ & $\mathrm{P}$ & $\mathrm{P}$ & $\mathrm{P}$ & $\mathrm{P}$ & $P$ & $\mathrm{P}$ \\
\hline E.L.C.S. & $\mathrm{I}$ & 13,41 & $\bar{M}$ & $\mathrm{P}$ & $\mathrm{P}$ & $\mathrm{P}$ & $\mathrm{P}$ & $\mathrm{P}$ & $\mathrm{P}$ & $\mathrm{P}$ & $\mathrm{P}$ & $\mathrm{P}$ & $\mathrm{P}$ & $\mathrm{P}$ & $\mathrm{P}$ & $\mathrm{P}$ & $\mathrm{P}$ \\
\hline E.A. & $\mathrm{I}$ & 13,83 & $\bar{M}$ & $\mathrm{P}$ & $P$ & $\mathrm{P}$ & $\mathrm{P}$ & $\mathrm{P}$ & $\mathrm{P}$ & $\mathrm{P}$ & $\mathrm{P}$ & $\mathrm{P}$ & $\mathrm{P}$ & $\mathrm{P}$ & $\mathrm{P}$ & $\mathrm{P}$ & $P$ \\
\hline M.S. & $\mathrm{I}$ & 13,25 & $M$ & $\mathrm{P}$ & $\mathrm{P}$ & $\mathrm{P}$ & $\mathrm{P}$ & $\mathrm{P}$ & $\mathrm{P}$ & $\mathrm{P}$ & $\mathrm{P}$ & $\mathrm{P}$ & $\mathrm{P}$ & $\mathrm{P}$ & $\mathrm{P}$ & $\mathrm{P}$ & $\mathrm{P}$ \\
\hline A.L.T.P. & $\mathrm{I}$ & 13,00 & $\mathrm{~F}$ & $\mathrm{P}$ & $\mathrm{P}$ & $\mathrm{P}$ & $\mathrm{P}$ & $\mathrm{P}$ & $\mathrm{P}$ & $\mathrm{P}$ & $\mathrm{P}$ & $\mathrm{P}$ & $\mathrm{P}$ & $\mathrm{P}$ & $\mathrm{P}$ & $\mathrm{P}$ & $\mathrm{P}$ \\
\hline R.C.L.A. & $\mathrm{I}$ & 13,33 & $\mathrm{~F}$ & $\mathrm{P}$ & $\mathrm{P}$ & $\mathrm{P}$ & $\mathrm{P}$ & $\mathrm{P}$ & $\mathrm{P}$ & $\mathrm{P}$ & $\mathrm{P}$ & $\mathrm{P}$ & $\mathrm{P}$ & $P$ & $\mathrm{P}$ & $\mathrm{P}$ & $\mathrm{P}$ \\
\hline C.S.D. & $\mathrm{I}$ & 13,08 & $\mathrm{~F}$ & $\mathrm{P}$ & $\mathrm{P}$ & $\mathrm{P}$ & $\mathrm{P}$ & $\mathrm{P}$ & $\mathrm{P}$ & $\mathrm{P}$ & $\mathrm{P}$ & $\mathrm{P}$ & $\mathrm{P}$ & $P$ & $\mathrm{P}$ & $\mathrm{P}$ & $P$ \\
\hline D.C.G.O. & $\mathrm{I}$ & 13,33 & $\mathrm{~F}$ & $\mathrm{P}$ & $P$ & $\mathrm{P}$ & $\mathrm{P}$ & $\mathrm{P}$ & $\mathrm{P}$ & $\mathrm{P}$ & $\mathrm{P}$ & $\mathrm{P}$ & $\mathrm{P}$ & $P$ & $\mathrm{P}$ & $\mathrm{P}$ & $P$ \\
\hline R.V.D. & $\mathrm{I}$ & 13,16 & $\bar{M}$ & $\mathrm{P}$ & $\mathrm{P}$ & $\mathrm{P}$ & $\mathrm{P}$ & $\mathrm{P}$ & $\mathrm{P}$ & $\mathrm{P}$ & $\mathrm{P}$ & $\mathrm{P}$ & $\mathrm{P}$ & $\mathrm{P}$ & $\mathrm{P}$ & $\mathrm{P}$ & $\mathrm{P}$ \\
\hline I.M.L. & $\mathrm{I}$ & 13,58 & $\mathrm{~F}$ & $\mathrm{P}$ & $\mathrm{P}$ & $\mathrm{P}$ & $\mathrm{P}$ & $\mathrm{P}$ & $\mathrm{P}$ & $\mathrm{P}$ & $\mathrm{P}$ & $\mathrm{P}$ & $\mathrm{P}$ & $\mathrm{P}$ & $\mathrm{P}$ & $\mathrm{P}$ & $P$ \\
\hline A.P.B. & I & 13,66 & $\mathrm{~F}$ & $\mathrm{P}$ & $\mathrm{P}$ & $\mathrm{P}$ & $\mathrm{P}$ & $\mathrm{P}$ & $\mathrm{P}$ & $\mathrm{P}$ & $\mathrm{P}$ & $\mathrm{P}$ & $\mathrm{P}$ & $\mathrm{P}$ & $\mathrm{P}$ & $\mathrm{P}$ & $\mathrm{P}$ \\
\hline C.C.P. & 1 & 13,41 & $\mathrm{~F}$ & $\mathrm{P}$ & $\mathrm{P}$ & $\mathrm{P}$ & $\mathrm{P}$ & $\mathrm{P}$ & $\mathrm{P}$ & $\mathrm{P}$ & $\mathrm{P}$ & $\mathrm{P}$ & $\mathrm{P}$ & $\mathrm{P}$ & $\mathrm{P}$ & $\mathrm{P}$ & $P$ \\
\hline F.Z. & $\mathrm{I}$ & 13,66 & $\bar{M}$ & $\mathrm{P}$ & $\mathrm{P}$ & $\mathrm{P}$ & $\mathrm{P}$ & $\mathrm{P}$ & $\mathrm{P}$ & $\mathrm{P}$ & $\mathrm{P}$ & $\mathrm{P}$ & $\mathrm{P}$ & $P$ & $\mathrm{P}$ & $\mathrm{P}$ & $P$ \\
\hline J.C.M.J. & II & 13,00 & $\bar{M}$ & $\mathrm{P}$ & $\mathrm{P}$ & $\mathrm{P}$ & $\mathrm{P}$ & $\mathrm{P}$ & $\mathrm{P}$ & $\mathrm{P}$ & $\mathrm{P}$ & $\mathrm{P}$ & $\mathrm{P}$ & $P$ & $\mathrm{P}$ & $\mathrm{P}$ & $\mathrm{P}$ \\
\hline M.A.P.T. & II & 13,00 & $M$ & $\mathrm{P}$ & $\mathrm{P}$ & $\mathrm{P}$ & $\mathrm{P}$ & $\mathrm{P}$ & $\mathrm{P}$ & $\mathrm{P}$ & $\mathrm{P}$ & $\mathrm{P}$ & $P$ & $P$ & $P$ & $P$ & $\mathrm{P}$ \\
\hline P.B.J. & II & 13,75 & $M$ & $\mathrm{P}$ & $P$ & $\mathrm{P}$ & $\mathrm{P}$ & $\mathrm{P}$ & $\mathrm{P}$ & $\mathrm{P}$ & $\mathrm{P}$ & $\mathrm{P}$ & $\mathrm{P}$ & $P$ & $\mathrm{P}$ & $\mathrm{P}$ & $P$ \\
\hline R.G.M. & II & 13,33 & $\bar{M}$ & $\mathrm{P}$ & $\mathrm{P}$ & $P$ & $\mathrm{P}$ & $P$ & $P$ & $P$ & $\mathrm{P}$ & $P$ & $\mathrm{P}$ & $P$ & $\mathrm{P}$ & $P$ & $\mathrm{P}$ \\
\hline T.C.C.C. & II & 13,00 & $\mathrm{~F}$ & $\mathrm{P}$ & $\mathrm{P}$ & $\mathrm{P}$ & $\mathrm{P}$ & $\mathrm{P}$ & $\mathrm{P}$ & $\mathrm{P}$ & $P$ & $\mathrm{P}$ & $\mathrm{P}$ & $P$ & $\mathrm{P}$ & $\mathrm{P}$ & $\mathrm{P}$ \\
\hline M.F.G. & II & 13,00 & $F$ & $\mathrm{P}$ & $\mathrm{P}$ & $\mathrm{P}$ & $\mathrm{P}$ & $\mathrm{P}$ & $\mathrm{P}$ & $\mathrm{P}$ & $\mathrm{P}$ & $\mathrm{P}$ & $\mathrm{P}$ & $P$ & $\mathrm{P}$ & $\mathrm{P}$ & $\mathrm{P}$ \\
\hline R.P.F. & II & 13,91 & $\bar{M}$ & $\mathrm{P}$ & $\mathrm{P}$ & $\mathrm{P}$ & $\mathrm{P}$ & $\mathrm{P}$ & $\mathrm{P}$ & $\mathrm{P}$ & $P$ & $\mathrm{P}$ & $\mathrm{P}$ & $\mathrm{P}$ & $\mathrm{P}$ & $\mathrm{P}$ & $\mathrm{P}$ \\
\hline E.C.L. & II & 13,00 & $F$ & $\mathrm{P}$ & $P$ & $\mathrm{P}$ & $\mathrm{P}$ & $\mathrm{P}$ & $\mathrm{P}$ & $\mathrm{P}$ & $\mathrm{P}$ & $\mathrm{P}$ & $\mathrm{P}$ & $\mathrm{P}$ & $\mathrm{P}$ & $\mathrm{P}$ & $\mathrm{P}$ \\
\hline J.A.M. & II & 13,91 & $M$ & $\mathrm{P}$ & $\mathrm{P}$ & $\mathrm{P}$ & $\mathrm{P}$ & $\mathrm{P}$ & $\mathrm{P}$ & $\mathrm{P}$ & $\mathrm{P}$ & $\mathrm{P}$ & $\mathrm{P}$ & $\mathrm{P}$ & $\mathrm{P}$ & $\mathrm{P}$ & $\mathrm{P}$ \\
\hline B.M.L. & II & 13,25 & $\bar{M}$ & $\mathrm{P}$ & $\mathrm{P}$ & $\mathrm{P}$ & $\mathrm{P}$ & $\mathrm{P}$ & $\mathrm{P}$ & $\mathrm{P}$ & $\mathrm{P}$ & $\mathrm{P}$ & $\mathrm{P}$ & $\mathrm{P}$ & $\mathrm{P}$ & $\mathrm{P}$ & $\mathrm{P}$ \\
\hline R.O.B.A. & II & 13,00 & $\bar{M}$ & $\mathrm{P}$ & $P$ & $\mathrm{P}$ & $\mathrm{P}$ & $\mathrm{P}$ & $\mathrm{P}$ & $\mathrm{P}$ & $P$ & $\mathrm{P}$ & $\mathrm{P}$ & $\mathrm{P}$ & $\mathrm{P}$ & $\mathrm{P}$ & $P$ \\
\hline C.F.Z.S. & II & 13,00 & $\mathrm{~F}$ & $\mathrm{P}$ & $\mathrm{P}$ & $\mathrm{P}$ & $\mathrm{P}$ & $\mathrm{P}$ & $\mathrm{P}$ & $\mathrm{P}$ & $\mathrm{P}$ & $\mathrm{P}$ & $\mathrm{P}$ & $P$ & $\mathrm{P}$ & $P$ & $\mathrm{P}$ \\
\hline J.A.A.C. & II & 13,91 & $\mathrm{M}$ & $\mathrm{P}$ & $P$ & $\mathrm{P}$ & $\mathrm{P}$ & $\mathrm{P}$ & $\mathrm{P}$ & $\mathrm{P}$ & $\mathrm{P}$ & $\mathrm{P}$ & $\mathrm{P}$ & $\mathrm{P}$ & $\mathrm{P}$ & $P$ & $\mathrm{P}$ \\
\hline P.B.B.M. & II & 13,83 & $\mathrm{~F}$ & $\mathrm{P}$ & $\mathrm{P}$ & $\mathrm{P}$ & $\mathrm{P}$ & $\mathrm{P}$ & $\mathrm{P}$ & $\mathrm{P}$ & $\mathrm{P}$ & $\mathrm{P}$ & $\mathrm{P}$ & $\mathrm{P}$ & $\mathrm{P}$ & $\mathrm{P}$ & $\mathrm{P}$ \\
\hline M.H.T. & II & 13,33 & $F$ & $\mathrm{P}$ & $P$ & $\mathrm{P}$ & $\mathrm{P}$ & $\mathrm{P}$ & $\mathrm{P}$ & $\mathrm{P}$ & $P$ & $P$ & $\mathrm{P}$ & $P$ & $\mathrm{P}$ & $\mathrm{P}$ & $P$ \\
\hline M.G.T. & II & 13,66 & $\mathrm{M}$ & $\mathrm{P}$ & $\mathrm{P}$ & $\mathrm{P}$ & $\mathrm{P}$ & $\mathrm{P}$ & $\mathrm{P}$ & $\mathrm{P}$ & $P$ & $\mathrm{P}$ & $\mathrm{P}$ & $\mathrm{P}$ & $\mathrm{P}$ & $\mathrm{P}$ & $P$ \\
\hline F.B. & II & 13,58 & $F$ & $\mathrm{P}$ & $\mathrm{P}$ & $\mathrm{P}$ & $\mathrm{P}$ & $\mathrm{P}$ & $\mathrm{P}$ & $\mathrm{P}$ & $\mathrm{P}$ & $\mathrm{P}$ & $\mathrm{P}$ & $\mathrm{P}$ & $\mathrm{P}$ & $P$ & $\mathrm{P}$ \\
\hline R.T.D.G. & II & 13,91 & $\bar{M}$ & $\mathrm{P}$ & $\mathrm{P}$ & $P$ & $P$ & $P$ & $P$ & $P$ & $\mathrm{P}$ & $\mathrm{P}$ & $P$ & $\mathrm{P}$ & $\mathrm{P}$ & $P$ & $\mathrm{P}$ \\
\hline A.B.S.M. & II & 13,00 & $\mathrm{~F}$ & $\mathrm{P}$ & $\mathrm{P}$ & $\mathrm{P}$ & $\mathrm{P}$ & $\mathrm{P}$ & $\mathrm{P}$ & $\mathrm{P}$ & $P$ & $\mathrm{P}$ & $\mathrm{P}$ & $\mathrm{P}$ & $\mathrm{P}$ & $\mathrm{P}$ & $P$ \\
\hline C.B.J. & II & 13,58 & $\mathrm{~F}$ & $\mathrm{P}$ & $\mathrm{P}$ & $\mathrm{P}$ & $\mathrm{P}$ & $\mathrm{P}$ & $\mathrm{P}$ & $\mathrm{P}$ & $\mathrm{P}$ & $\mathrm{P}$ & $\mathrm{P}$ & $\mathrm{P}$ & $\mathrm{P}$ & $\mathrm{P}$ & $\mathrm{P}$ \\
\hline G.C.T.N. & II & 13,00 & $\bar{M}$ & $\mathrm{P}$ & $\mathrm{P}$ & $P$ & $P$ & $\mathrm{P}$ & $\mathrm{P}$ & $\mathrm{P}$ & $P$ & $P$ & $P$ & $\mathrm{P}$ & $\mathrm{P}$ & $\mathrm{P}$ & $P$ \\
\hline D.A.M. & II & 13,66 & $\bar{M}$ & $\mathrm{P}$ & $\mathrm{P}$ & $\mathrm{P}$ & $\mathrm{P}$ & $\mathrm{P}$ & $\mathrm{P}$ & $\mathrm{P}$ & $\mathrm{P}$ & $\mathrm{P}$ & $\mathrm{P}$ & $\mathrm{P}$ & $\mathrm{P}$ & $\mathrm{P}$ & $\mathrm{P}$ \\
\hline A.L.M. & II & 13,58 & $F$ & $\mathrm{P}$ & $\mathrm{P}$ & $\mathrm{P}$ & $\mathrm{P}$ & $\mathrm{P}$ & $\mathrm{P}$ & $\mathrm{P}$ & $P$ & $\mathrm{P}$ & $\mathrm{P}$ & $\mathrm{P}$ & $\mathrm{P}$ & $\mathrm{P}$ & $P$ \\
\hline G.S.M. & II & 13,50 & $M$ & $\mathrm{P}$ & $P$ & $\mathrm{P}$ & $\mathrm{P}$ & $\mathrm{P}$ & $\mathrm{P}$ & $\mathrm{P}$ & $P$ & $\mathrm{P}$ & $\mathrm{P}$ & $P$ & $\mathrm{P}$ & $\mathrm{P}$ & $P$ \\
\hline G.R.P. & II & 13,33 & $\mathrm{~F}$ & $\mathrm{P}$ & $\mathrm{P}$ & $\mathrm{P}$ & $\mathrm{P}$ & $\mathrm{P}$ & $\mathrm{P}$ & $\mathrm{P}$ & $\mathrm{P}$ & $\mathrm{P}$ & $\mathrm{P}$ & $\mathrm{P}$ & $\mathrm{P}$ & $\mathrm{P}$ & $\mathrm{P}$ \\
\hline
\end{tabular}




\section{Universidade de São Paulo Faculdade de Odontologia de Bauru}

A1. Dr. Octávio Pinheiro Brisolla, 9-75 - Bauru-SP - CEP 17012-901 - C.P. 73

PABX (0XX14)235-8000 - FAX (0XX14)223-4679

Comite de Élica en Pesquisa

OS. $0^{\circ} \mathrm{CEP} / 062002 \mathrm{FOB}$

Bauru, 13 de julho de 2002

Senhor Professor,

Temos o prazer de informar-The que após analise por este Comité de Etica em Pesquisa em Seres Humanos, seu pedido de alteração do titulo do projeto de pesquisa intitulado 'Estudo panorâmico retrospectivo transversal da seqüëncia do erupção dentária, comparando os gêneros masculino e feminino, em crianças dos 5 aos 13 anos de idade, brasileiras, leucodermas, de origem mediterrânea, da regiảo de Bauru", de autoria do C.D. Rodrigo Hermont Cançado, sob a sua orientaçāo, para 'Estudo comparativo da sequêência de erupçāo dos dentes permanentes e da calcificação dos segundos molares nas más oclusōes do Classe I a Classe II do Angle", foi aprovado considerando que sua melodologia nảo sofrou modificaçes.

Sendo o que nos apresenta para o momento, despedimo-nos,

Atenciosamente,

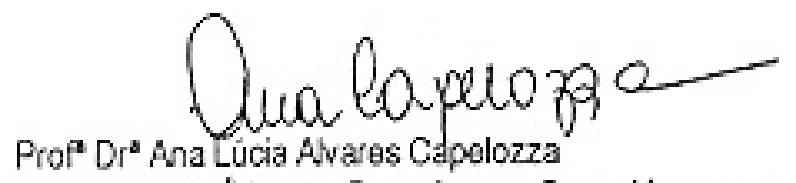

Ccordenadora do Comité de Etica em Pesquisa em Seres Humanos 